Paulo Thiago Fracasso

\title{
Redução de Gastos com Energia Elétrica em Sistemas de Distribuição de Água Utilizando Processos Decisórios de Markov
}

Tese apresentada à Escola Politécnica da Universidade de São Paulo para obtenção do Título de Doutor em Ciências. 
Paulo Thiago Fracasso

\section{Redução de Gastos com Energia Elétrica em Sistemas de Distribuição de Água Utilizando Processos Decisórios de Markov}

Tese apresentada à Escola Politécnica da Universidade de São Paulo para obtenção do Título de Doutor em Ciências.

Programa:

Engenharia Elétrica

Área de concentração:

Engenharia de Computação

Orientador:

Prof $^{a}$. Dr ${ }^{a}$. Anna Helena Reali Costa 
Este exemplar foi revisado e alterado em relação à versão original, sob responsabilidade única do autor e com a anuência de sua orientadora.

São Paulo, 06 de junho de 2014

Paulo Thiago Fracasso

Anna Helena Reali Costa

Ficha Catalográfica

Fracasso, Paulo Thiago

Redução de Gastos com Energia Elétrica em Sistemas de Distribuição de Água Utilizando Processos Decisórios de Markov - Edição Revisada. Paulo Thiago Fracasso. São Paulo, 2014.

$132 \mathrm{p}$.

Tese (Doutorado) — Escola Politécnica da Universidade de São Paulo. Departamento de Engenharia de Computação e Sistemas Digitais.

1. Energia Elétrica (Gastos; Redução) 2. Método MDP I. Universidade de São Paulo. Escola Politécnica. Departamento de Engenharia de Computação e Sistemas Digitais II. Título 


\section{Dedicatória}

Ao Henrique e à Adriana. 


\section{Agradecimentos}

Agradeço primeiramente a Deus, que possibilitou subir mais um degrau na caminhada da vida, e a meus pais, João e Adelia, por proverem as bases da formação da pessoa que sou hoje. Agradeço também à professora Anna Helena Reali Costa, não só pela orientação, mas principalmente pela motivação e entusiasmo contagiantes. Não poderia deixar de mencionar o professor Frank Barnes que contribuiu muito para a elaboração deste trabalho, sempre com sugestões práticas e de vanguarda. Ao Instituto de Pesquisas Tecnológicas - IPT e ao Conselho Nacional de Desenvolvimento Científico e Tecnológico CNPq por financiarem meu estágio na Universidade do Colorado, período que foi o mais produtivo desta pesquisa. Finalmente, um agradecimento especial à minha amada esposa, Adriana, pela compreensão, companheirismo e amor que tem me proporcionado em mais esta jornada. 
"A percepção do desconhecido é a mais fascinante das experiências. O homem que não tem os olhos abertos para o misterioso passará pela vida sem ver nada."

Albert Einstein 


\section{Resumo}

Os sistemas de distribuição de água são parte fundamental de qualquer cidade e seus custos, principalmente com energia elétrica, constituem gastos significativos às companhias de saneamento. A operação ótima, em termos energético, pode proporcionar, além da otimização das despesas, reduções significativas de perda de água, prevenir intervenções corretivas na rede e aumentar a robustez do sistema de distribuição. Assim, esta tese apresenta a modelagem do problema de redução de gastos com energia elétrica em sistemas de distribuição de água utilizando Processos Decisórios de Markov cuja função de transição de estado está associada a incertezas decorrentes do modelo hidráulico, da curva de demanda, do truncamento do algoritmo de cálculo e da discretização das variáveis de estado. São apresentados três experimentos para verificar a modelagem proposta: a) com um sistema de distribuição simplificado e modelo hidráulico explícito; b) comparativo entre três diferentes técnicas utilizando simulador hidráulico; e c) comparativo entre um sistema real, com controle baseado em nível, e o mesmo sistema simulado, porém, utilizando controlador proposto. Os resultados dos experimentos demonstram que este sistema de controle é eficaz na redução das despesas com energia elétrica e aumento na robustez dos sistemas de distribuição de água. Além disso, também são respeitadas as restrições operacionais destes sistemas, garantindo a integridade das tubulações e eliminando a possibilidade de interrupções no fornecimento de água. 


\section{Abstract}

Water distribution systems are the fundamental part of any city and their costs, mainly with energy, constitute a significant expenditure for water utility companies. The optimal operation, in energetic terms, can provide, in addition to optimization of expenditure, significant savings in water losses, prevent wear and tear and increase the distribution system soundness. Thus, this thesis presents the modeling of the problem of reducing energy expenses in water distribution systems using Markov Decision Processes whose state transition function is associated with uncertainty arising out of hydraulic model, demand curve, truncation in the calculation algorithm and the state variables discretization. Three experiments are presented to verify the proposed modeling: a) with a streamlined distribution system and explicit hydraulic model; b) comparing three different techniques using hydraulic simulator; and c) comparison between a real system, based on level control, and the same simulated system, however, using the proposed controller. The experiment results demonstrate that this technique is effective to reduces electricity expenses and to increases the reliability of the system. Moreover, it respects system operational restrictions, to ensure minimizing the risk of pipe rupture and to avoid water outages. 


\section{Lista de Figuras}

1.1 Projeção do consumo de energia elétrica no Brasil. . . . . . . . . . . . . . 3

1.2 Sistema de distribuição de água com controle a) reativo e b) deliberativo. . 6

1.3 Sistema de controle deliberativo utilizando um simulador hidráulico. . . . . 7

1.4 Sistema de controle deliberativo utilizando um simulador hidráulico associado a uma incerteza na transição de estado. . . . . . . . . . . . . . 8

3.1 Modelo simplificado de um sistema de distribuição de água (adaptado de Queensland Environmental Protection Agency (2002)). . . . . . . . . . . 22

3.2 Representação esquemática de um sistema de distribuição de água. . . . . 25

3.3 Demanda típica de água nos segmentos comercial, residencial e industrial (adaptado de Haestad et al. (2003)) . . . . . . . . . . . . . . . 26

3.4 Exemplo de padrão horário da demanda nas quatro estações do ano calculados a partir de dados históricos.. . . . . . . . . . . . . . 28

3.5 Curva característica de uma bomba (adaptado de Sirový et al. (2010)). . . 31

3.6 Curva do sistema e ponto de operação (adaptado de PROCEL (2005)). . 31

6.1 Sistema de distribuição simplificado e modelo hidráulico explícito. . . . . . 58

6.2 Demanda de água dos experimentos com sistema de distribuição simplificado e modelo hidráulico explícito. . . . . . . . . . . . . 58

6.3 Curva do sistema e das bombas. . . . . . . . . . . . . . 59

6.4 Potência elétrica das bombas. . . . . . . . . . . . . . 60

6.5 Política do Controlador 1 calculada com incerteza apenas da discretização da variável de estado $H-u(\mathcal{X})=\frac{\Delta h}{\sqrt{12}} \ldots \ldots \ldots \ldots$. . . . . . 64

6.6 Política do Controlador 2 calculada com incertezas da discretização da variável de estado $H-u(\mathcal{X})=\frac{\Delta h}{\sqrt{12}}$ e da demanda de água $-u(D)=25 \ldots \quad$. 64 
6.7 Política do Controlador 2 calculada com incertezas da discretização da variável de estado $H-u(\mathcal{X})=\frac{\Delta h}{\sqrt{12}}$ e da demanda de água $-u(D)=30 \ldots$.

6.8 Política do Controlador 2 calculada com incertezas da discretização da variável de estado $H-u(\mathcal{X})=\frac{\Delta h}{\sqrt{12}}$ e da demanda de água $-u(D)=35 .$.

6.9 Política do Controlador 2 calculada com incertezas da discretização da variável de estado $H-u(\mathcal{X})=\frac{\Delta h}{\sqrt{12}}$ e da demanda de água $-u(D)=40 .$.

6.10 Política do Controlador 2 calculada com incertezas da discretização da variável de estado $H-u(\mathcal{X})=\frac{\Delta h}{\sqrt{12}}$ e da demanda de água $-u(D)=45 .$.

6.11 Política do Controlador 2 calculada com incertezas da discretização da variável de estado $H-u(\mathcal{X})=\frac{\Delta h}{\sqrt{12}}$ e da demanda de água $-u(D)=50 \ldots \quad 67$

6.12 Área de abastecimento do sistema de distribuição de Monroe - MI. . . . . 70

6.13 Rede de distribuição de Monroe - MI. . . . . . . . . . . . . . . . . . . . 71

6.14 Curva característica das bombas do sistema de distribuição de água da cidade de Monroe - MI.

6.15 Curva de rendimento das bombas do sistema de distribuição de água da cidade de Monroe - MI.

6.16 Demanda de água nos meses de verão na cidade de Monroe - MI. . . . . . 73

6.17 Pressão no nó $J_{6}$, onde $60 \leq P\left(J_{6}\right) \leq 75 \ldots \ldots \ldots$. . . . . . 82

6.18 Pressão no nó $J_{27}$, onde $45 \leq P\left(J_{27}\right) \leq 65$. . . . . . . . . . . . 82

6.19 Pressão no nó $J_{131}$, onde $40 \leq P\left(J_{131}\right) \leq 60$. . . . . . . . . . . 83

6.20 Pressão no nó $J_{514}$, onde $60 \leq P\left(J_{514}\right) \leq 80 \ldots \ldots \ldots$. . . . . . . 83

6.21 Nível de água do tanque de armazenamento $T_{2} \ldots \ldots \ldots$. . . . . 84

6.22 Nível de água do tanque de armazenamento $T_{3} \ldots \ldots$. . . . . . . . 84

6.23 Nível de água do tanque de armazenamento $T_{5} \ldots \ldots \ldots \ldots$

6.24 Volume de água armazenado conjuntamente pelos tanques $T_{2}, T_{3}$ e $T_{5} \ldots \quad$. 85

6.25 Rede de distribuição de água do sistema real. . . . . . . . . . . . . . . 92

6.26 Variação da cota da lâmina de água dos reservatórios $R_{7000}$ e $R_{7008}$. . . . 92

6.27 Curva de desempenho e rendimento das bombas $U_{5007}$ e $U_{5009} \ldots \ldots$. . . . 93 
6.28 Demanda de água do sistema real, referente ao mês de junho de 2012. . . 94

6.29 Política do sistema de controle com modelagem por MDP quando as bombas são acionadas diretamete. . . . . . . . . . . . . . . . . . 99

6.30 Política do sistema de controle com modelagem por MDP quando as bombas são acionadas por inversores de frequência. . . . . . . . . . . . . . . 100

A.1 Distribuições de probabilidade fontes de incerteza do tipo B. . . . . . . . 116 


\section{Lista de Tabelas}

2.1 Sumário das abordagens de otimização em redes de distribuição de água. 13

3.1 Coeficientes de vazão típicos (IDELCHIK, 2005) . . . . . . . . . . . . . 30

6.1 Resultados dos experimentos com sistema de distribuição simplificado e modelo hidráulico explícito. . . . . . . . . . . . . . . . . . 68

6.2 Características dos tanques do sistema de distribuição de Monroe - MI. . . 73

6.3 Características dos tanques do sistema de distribuição de Monroe - MI. . . 74

6.4 Parâmetro do módulo Darwin Scheduler do software WaterGEMS. . . . . . 75

6.5 Parâmetro do algoritmo PEPSO . . . . . . . . . . . . 76

6.6 Parâmetro das variáveis de estado. . . . . . . . . . . . . . 77

6.7 Energia elétrica consumida (Unidade: $k W h) \ldots \ldots \ldots$. . . . . . 80

6.8 Tempo de execução dos algoritmos. . . . . . . . . . . . . . . . 81

6.9 Acionamento das bombas realizado pelo WaterGEMS. . . . . . . . . . . 86

6.10 Acionamento das bombas realizado pelo PEPSO. . . . . . . . . . 87

6.11 Acionamento das bombas realizado pelo MDP. . . . . . . . . . 88

6.12 Gastos com energia elétrica do mês de junho de 2012 da rede de distribuição do sistema real. . . . . . . . . . . . . . . . . . . . 98

6.13 Gastos com energia elétrica da rede de distribuição do sistema real utilizando controlador MDP com acionamento direto das bombas. . . . . . . 100

6.14 Gastos com energia elétrica da rede de distribuição do sistema real utilizando controlador MDP com acionamento das bombas por inversor de frequência. . . . . . . . . . . . . . . . . . . 100

6.15 Potencial de redução dos gastos com energia elétrica da rede de distribuição do sistema real utilizando controlador MDP com acionamento direto das bombas (Direto) e por inversor de frequência (VFD) . . . . . . . . . . 101 
A.1 Valor da distribuição t-Student com número de graus de liberdade igual a $\nu$ e intervalo de confiança igual a $p \ldots \ldots$. . . . . . . . . . . . . . . . .

B.1 Valores das pressões no nó $J_{6}$, onde $60 \leq P\left(J_{6}\right) \leq 75$ (Unidade: $P S I$ ). . . 121

B.2 Valores das pressões no nó $J_{27}$, onde $45 \leq P\left(J_{27}\right) \leq 65$ (Unidade: $P S I$ ). . . 122

B.3 Valores das pressões no nó $J_{131}$, onde $40 \leq P\left(J_{131}\right) \leq 60$ (Unidade: PSI). . 123

B.4 Valores das pressões no nó $J_{514}$, onde $60 \leq P\left(J_{514}\right) \leq 80$ (Unidade: $P S I$ ). . 124

B.5 Valores do nível do tanque de armazenamento $T_{2}$, onde $0,5 \leq H\left(T_{2}\right) \leq$ 31,25 (Unidade: $f t$ ). . . . . . . . . . . . . . . . 125

B.6 Valores do nível do tanque de armazenamento $T_{3}$, onde $0,5 \leq H\left(T_{3}\right) \leq 28,0$ (Unidade: ft) . . . . . . . . . . . . . . . . 126

B.7 Valores do nível do tanque de armazenamento $T_{5}$, onde $1,0 \leq H\left(T_{5}\right) \leq$ 33,25 (Unidade: $f t$ ). . . . . . . . . . . . . . . . . . . 127

B.8 Volume de água armazenado conjuntamente pelos tanques $T_{2}, T_{3}$ e $T_{5}$ (Unidade: $\left.\times 10^{3} \mathrm{gal}\right) \ldots \ldots \ldots \ldots \ldots \ldots . \ldots \ldots \ldots$

C.1 Dados das tubulações da rede de distribuição do sistema real. . . . . . . . 129

C.2 Dados dos nós da rede de distribuição do sistema real. . . . . . . . . . . . . 132 


\section{Lista de Abreviaturas e Siglas}

$\begin{array}{ll}\text { ABESCO } & \text { Associação Brasileira das Empresas de Serviços de Conservação } \\ \text { ANEEL } & \text { Ae Energia } \\ \text { BEP } & \text { Best Efficiency Point } \\ \text { CNPq } & \text { Conselho Nacional de Desenvolvimento Científico e Tecnológico } \\ \text { EEA } & \text { Estação Elevatória de Água } \\ \text { EEE } & \text { Estação Elevatória de Esgoto } \\ \text { EPA } & \text { Environmental Protection Agency } \\ \text { EPE } & \text { Empresa de Pesquisa Energética } \\ \text { ETA } & \text { Estação de Tratamento de Água } \\ \text { ETE } & \text { Estação de Tratamento de Esgoto } \\ \text { EWD } & \text { Energy and Water Department } \\ \text { IEA } & \text { International Energy Agency } \\ \text { IPT } & \text { Instituto de Pesquisas Tecnológicas } \\ \text { ISO } & \text { International Organization for Standardization } \\ \text { IWA } & \text { International Water Association } \\ \text { MDP } & \text { Markov Decision Processes } \\ \text { MME } & \text { Ministério de Minas e Energia } \\ \text { PEPSO } & \text { Pollutant Emission Pump Station Optimization } \\ \text { PNE } & \text { Plano Nacional de Energia } \\ \text { PNEf } & \text { Plano Nacional de Eficiência Energética } \\ \text { PROCEL } & \text { Programa Nacional de Conservação de Energia Elétrica } \\ \text { PRV } & \text { Pressure Reducing Valve } \\ \text { REN21 } & \text { Renewable Energy Policy Network for the 21st Century } \\ \text { SEE } & \text { Secretaria de Energia Elétrica } \\ \text { SNIS } & \text { Sistema Nacional de Informações sobre Saneamento } \\ \text { SNSA } & \text { Secronal de Saneamento Ambiental } \\ \text { WSU } & \text { Eevelopment Programme } \\ \text { ENitity }\end{array}$




\section{Lista de Símbolos}

\begin{tabular}{|c|c|}
\hline Símbolo & Definição \\
\hline$a$ & Ação \\
\hline$s$ & Estado \\
\hline$r$ & Recompensa \\
\hline$\widehat{s}$ & Estimativa do estado $s$ \\
\hline$\widehat{r}$ & Estimativa da recompensa $r$ \\
\hline$S$ & Conjunto de estados \\
\hline$A$ & Conjunto de ações \\
\hline$U(s)$ & Incerteza associada ao estado $s$ \\
\hline$Q$ & Vazão \\
\hline$P$ & Pressão \\
\hline $\mathcal{M}$ & Representação topológica de um sistema de distribuição de água \\
\hline$N$ & Conjunto de nós \\
\hline$n$ & Elemento do conjunto de nós \\
\hline$E$ & Conjunto de arestas \\
\hline$e$ & Elemento do conjunto de arestas \\
\hline$f_{M}$ & Mapeamento entre os elementos dos conjuntos de nós e arestas \\
\hline$R$ & Conjunto de reservatórios \\
\hline$r$ & Elemento do conjunto de reservatórios \\
\hline$N_{R}$ & Número total de reservatórios no sistema de distribuição \\
\hline$T$ & Conjunto de tanques de armazenamento \\
\hline$t$ & Elemento do conjunto de tanques de armazenamento \\
\hline$N_{T}$ & Número total de tanques no sistema de distribuição \\
\hline$J$ & Conjunto de junções \\
\hline$j$ & Elemento do conjunto de junções \\
\hline$N_{J}$ & Número total de junções no sistema de distribuição \\
\hline$U$ & Conjunto de bombas \\
\hline$u$ & Elemento do conjunto de bombas \\
\hline$N_{U}$ & Número total de bombas no sistema de distribuição \\
\hline
\end{tabular}




\begin{tabular}{|c|c|}
\hline Símbolo & Definição \\
\hline$V$ & Conjunto de válvulas \\
\hline$v$ & Elemento do conjunto de válvulas \\
\hline$N_{V}$ & Número total de válvulas no sistema de distribuição \\
\hline$L$ & Conjunto de tubulações \\
\hline$l$ & Elemento do conjunto de tubulações \\
\hline$N_{T}$ & Número total de tubulações no sistema de distribuição \\
\hline$Z(r)$ & Cota de elevação da lâmina de água do reservatório $r$ \\
\hline$Z(t)$ & Cota de elevação da base do tanque de armazenamento $t$ \\
\hline$Z(j)$ & Cota de elevação da junção $j$ \\
\hline$H_{\min }(t)$ & Nível mínimo do tanque de armazenamento $t$ \\
\hline$H_{\max }(t)$ & Nível máximo do tanque de armazenamento $t$ \\
\hline$f_{V}(t,\{V o l, H\})$ & Curva de volume em função da altura do tanque $t$ \\
\hline Vol & Volume do tanque de armazenamento \\
\hline$H$ & Nível do tanque de armazenamento \\
\hline$D B(j)$ & Demanda base da junção $j$ \\
\hline$K(u)$ & Condição de operação da bomba $u$ \\
\hline$f_{C}(u,\{P, Q\})$ & Curva característica da bomba $u$ \\
\hline$f_{R}(u,\{\eta, Q\})$ & Curva de rendimento da bomba $u$ \\
\hline$K(v)$ & Condição de operação da válvula $v$ \\
\hline$C_{V}(v)$ & Coeficiente de vazão da válvula $v$ \\
\hline$D(l)$ & Diâmetro da tubulação $l$ \\
\hline$W(l)$ & Comprimento da tubulação $l$ \\
\hline$R a(l)$ & Rugosidade da tubulação $l$ \\
\hline$d s$ & Conjunto das estações do ano \\
\hline$d h$ & Conjunto das horas do dia \\
\hline$f_{D}(d s, d h)$ & Padrão horário da demanda de uma estação \\
\hline$f_{S}(d s)$ & Multiplicador da estação \\
\hline$\Delta t$ & Passo de tempo \\
\hline$T_{\min }$ & Instante de tempo inicial \\
\hline$T_{\max }$ & Instante de tempo final \\
\hline$P_{O P}$ & Preço da energia no horário de ponta \\
\hline$P_{F P}$ & Preço da energia no horário fora-de-ponta \\
\hline$P_{D M}$ & Preço da demanda \\
\hline
\end{tabular}




\begin{tabular}{|c|c|}
\hline Símbolo & Definição \\
\hline$\rho$ & Massa específica \\
\hline$\mu$ & Viscosidade dinâmica \\
\hline$\nu$ & Viscosidade cinemática \\
\hline$\varepsilon$ & Erro de truncamento do simulador hidráulico \\
\hline$N_{D y}$ & Número de dados históricos no período de 12 meses \\
\hline$D y_{i}$ & Início do período de 12 meses \\
\hline$D y_{f}$ & Término do período de 12 meses \\
\hline$\Delta d$ & Passo de tempo dos dados históricos \\
\hline$N_{D s}$ & Número de dados históricos de uma estação do ano \\
\hline$D s_{i}$ & Início do período de uma estação do ano \\
\hline$D s_{f}$ & Término do período de uma estação do ano \\
\hline$\Delta P$ & Perda de carga \\
\hline$g$ & Aceleração da gravidade local \\
\hline$f$ & Fator de atrito \\
\hline$v(l)$ & Velocidade médio do fluido na tubulação $l$ \\
\hline$R e$ & Número de Reynolds \\
\hline $\mathcal{S}$ & Conjunto finito de estados \\
\hline$\sigma$ & Estado pertencente ao conjunto $\mathcal{S}$ \\
\hline$\sigma^{\prime}$ & Próximo estado pertencente ao conjunto $\mathcal{S}$ \\
\hline$s_{d}$ & Estado na época de decisão $d$ \\
\hline$N_{S}$ & Número total de estados \\
\hline $\mathcal{X}$ & Variável de estado \\
\hline$N_{\mathcal{X}}$ & Número total de variáveis de estado \\
\hline $\mathcal{A}$ & Conjunto finito de ações \\
\hline $\mathcal{A}_{\sigma}$ & Sub-conjunto das ações permitidas no estado $\sigma$ \\
\hline$\alpha$ & Ação pertencente ao conjunto $\mathcal{A}$ \\
\hline$a_{d}$ & Ação na época de decisão $d$ \\
\hline $\mathcal{D}$ & Sequência finita de épocas de decisão \\
\hline$d$ & Época de decisão \\
\hline$D_{\max }$ & Horizonte de tempo \\
\hline $\mathcal{T}$ & Função de transição de estados \\
\hline $\mathcal{R}$ & Função de recompensa \\
\hline$r_{d}$ & Recompensa obtida na época decisão $d$ \\
\hline
\end{tabular}




\begin{tabular}{|c|c|}
\hline Símbolo & Definição \\
\hline$f_{T}(\sigma, \alpha, d)$ & $\begin{array}{l}\text { Função de transição de estado calculada no estado } \sigma \text {, devido à ação } \alpha \\
\text { na época de decisão } d\end{array}$ \\
\hline$u(\mathcal{M})$ & Incerteza do modelo hidráulico \\
\hline$\frac{\partial f_{T}}{\partial \mathcal{M}}$ & Coeficiente de sensibilidade do modelo hidráulico \\
\hline$e_{\mathcal{M}}$ & Erro relativo de uma determinada medição do modelo hidráulico $\mathcal{M}$ \\
\hline$\overline{e_{\mathcal{M}}}$ & Erro relativo médio de um conjunto de medições do modelo hidráulico \\
\hline$\sigma\left(e_{\mathcal{M}}\right)$ & Desvio padrão de um conjunto de medições do modelo hidráulico $\mathcal{M}$ \\
\hline$N_{M}$ & Número de medições realizadas no modelo hidráulico $\mathcal{M}$ \\
\hline $\mathcal{X}_{R}$ & Valor medido no sistema real \\
\hline $\mathcal{X}_{S}$ & Valor calculado pelo simulador hidráulico \\
\hline$u(D)$ & Incerteza da demanda de água \\
\hline$\frac{\partial f_{T}}{\partial D}$ & Coeficiente de sensibilidade da demanda de água \\
\hline$\sigma(D)$ & Desvio padrão da demanda de água \\
\hline$u(T)$ & Incerteza do truncamento do algoritmo de cálculo \\
\hline$\frac{\partial f_{T}}{\partial T}$ & Coeficiente de sensibilidade do truncamento do algoritmo de cálculo \\
\hline$u(\mathcal{X})$ & Incerteza da discretização da variável de estado \\
\hline$\frac{\partial f_{T}}{\partial \mathcal{X}}$ & Coeficiente de sensibilidade da discretização da variável de estado \\
\hline$\Delta x$ & Coeficiente de discretização da variável de estado $\mathcal{X}$ \\
\hline $\mathcal{X}_{\min }$ & Menor valor da variável de estado $\mathcal{X}$ \\
\hline $\mathcal{X}_{\max }$ & Maior valor da variável de estado $\mathcal{X}$ \\
\hline$C_{C}$ & Custo do consumo de energia elétrica \\
\hline$C_{D}$ & Custo da demanda de energia elétrica \\
\hline$P w$ & Potência elétrica \\
\hline$B C$ & Ciclo de tarifação \\
\hline$F P$ & Período fora-de-ponta \\
\hline$O P$ & Período de ponta \\
\hline$\pi$ & Política de uma MDP \\
\hline $\mathcal{V}$ & Função valor de um MDP \\
\hline $\mathcal{Q}$ & Função valor da ação de um MDP \\
\hline$\gamma$ & Fator de desconto de um MDP \\
\hline
\end{tabular}




\section{Sumário}

1 Introdução 1

1.1 Motivação . . . . . . . . . . . . . . . . . . 2

1.2 Eficiência energética no saneamento . . . . . . . . . . . . . . 3

1.3 Processo de controle nos sistemas de distribuição de água . . . . . . . . . . 6

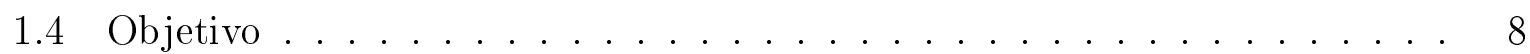

1.5 Organização do Documento . . . . . . . . . . . . . . 9

2 Panorama das Técnicas de Otimização para Sistemas de Distribuição de $\begin{array}{ll}\text { Água } & 11\end{array}$

2.1 Introdução . . . . . . . . . . . . . . . . . . . . . 11

2.2 Modelo experimental . . . . . . . . . . . . . . . . . . . 12

2.3 Modelo hidráulico . . . . . . . . . . . . . . . . . . . . . . 16

2.4 Algoritmo de otimização . . . . . . . . . . . . . . . . . . . 16

2.5 Objetivo da otimização . . . . . . . . . . . . . . . . . 18

2.6 Representação das Ações . . . . . . . . . . . . . . . . . . . . 19

2.7 Discussões Finais . . . . . . . . . . . . . . . . . . . 19

3 Sistemas de Distribuição de Água $\quad 22$

3.1 Introdução . . . . . . . . . . . . . . . . . . . . . . 22

3.2 Modelo Hidráulico . . . . . . . . . . . . . . . . . . . . . 24

3.3 Parametrização da Simulação . . . . . . . . . . . . . 26

3.4 Equacionamento Matemático . . . . . . . . . . . . 28

3.5 Discussões Finais . . . . . . . . . . . . . . . . . . 32 
4.1 Introdução . . . . . . . . . . . . . . . . . . . . 33

4.2 Formalização do MDP . . . . . . . . . . . . . . . . 34

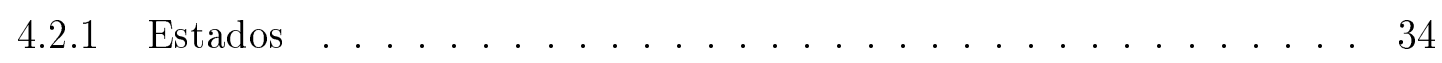

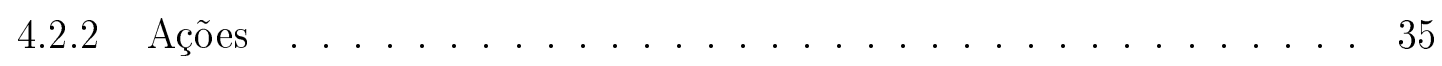

4.2 .3 Épocas de Decisão . . . . . . . . . . . . . . 35

4.2.4 Função de Transição de Estado . . . . . . . . . . . . . . . 35

4.2 .5 Função de Recompensa . . . . . . . . . . . . . . . . 36

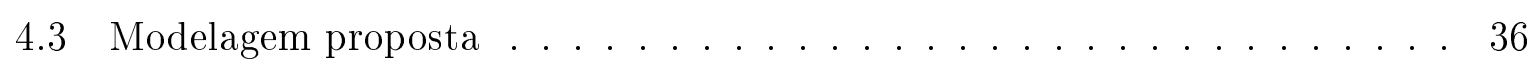

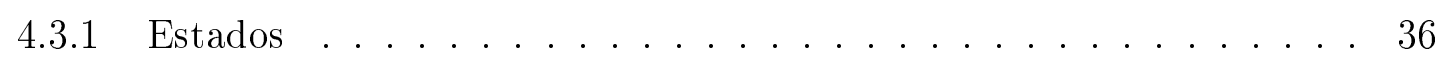

4.3 .2 Ações . . . . . . . . . . . . . . . . 37

4.3 .3 Épocas de Decisão . . . . . . . . . . . . . . . 38

4.3 .4 Função de Transição . . . . . . . . . . . . . . . . . . 38

4.3.5 Função de Recompensa . . . . . . . . . . . . . . . . . 43

4.4 Discussões Finais . . . . . . . . . . . . . . . . . 44

5 Solução de Sistemas de Distribuição de Água Modelados por MDP 46

5.1 Fundamentação ............................ 46

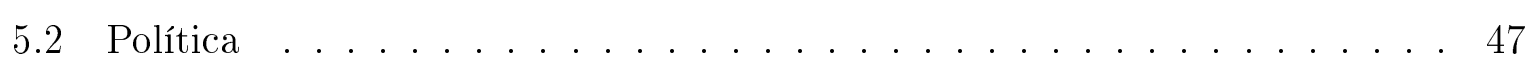

5.3 Função valor . . . . . . . . . . . . . . . . . 47

5.4 Princípio de Otimalidade de Bellman . . . . . . . . . . . . . 48

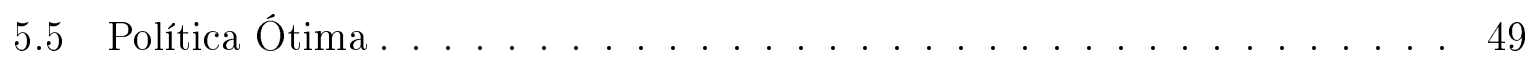

5.6 Resolução de um MDP com horizonte de tempo infinito . . . . . . . . . . 50

5.6 .1 Policy Iteration . . . . . . . . . . . . . . . . . . 50

5.6 .2 Value Iteration . . . . . . . . . . . . . . 52

5.7 Resolução de um MDP com horizonte de tempo finito . . . . . . . . . . 53

5.8 Discussões Finais . . . . . . . . . . . . . . . . . . 55 
6.1 Experimentos com Sistema de Distribuição Simplificado e Modelo Hidráulico Explícito . . . . . . . . . . . . . . . . 57

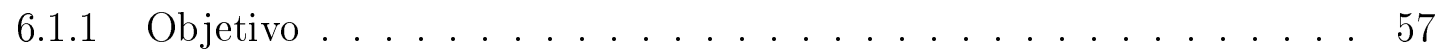

6.1.2 Detalhamento do Experimento . . . . . . . . . . . 57

6.1 .3 Modelo MDP ....................... 60

6.1.4 Resultados ...................... 63

6.1.5 Análise dos Resultados . . . . . . . . . . . . . . . 67

6.2 Experimentos Comparativos . . . . . . . . . . . . . . . 69

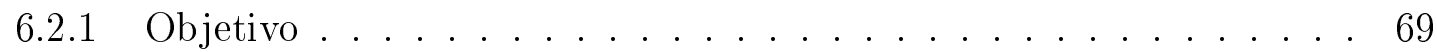

6.2.2 Detalhamento do Experimento . . . . . . . . . . . 70

6.2 .3 WaterGEMS ........................ 74

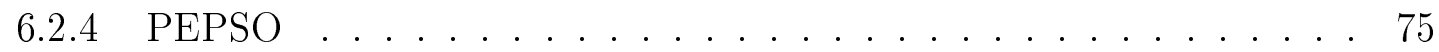

6.2 .5 Modelo MDP . . . . . . . . . . . . . . 76

6.2.6 Resultados . . . . . . . . . . . . . . . 79

6.2.7 Análise dos Resultados . . . . . . . . . . . . . . . . 89

6.3 Experimentos com Sistema Real . . . . . . . . . . . . . . . . . 90

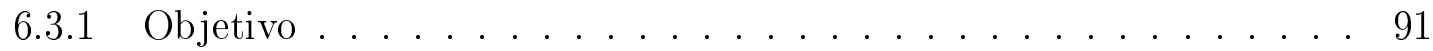

6.3.2 Detalhamento do Experimento . . . . . . . . . . . . . 91

6.3.3 Controlador Atual . . . . . . . . . . . . . . . . . . . 94

6.3.4 Modelo MDP . . . . . . . . . . . . . . 95

6.3 .5 Resultados . . . . . . . . . . . . . . . . 98

6.3.6 Análise dos Resultados . . . . . . . . . . . . . . . 100

$\begin{array}{lll}7 & \text { Conclusão } & 103\end{array}$

7.1 Discussão sobre os Resultados dos Experimentos . . . . . . . . . . . . 103

7.2 Contribuições . . . . . . . . . . . . . . . . . . 104 
7.3 Trabalhos Futuros . . . . . . . . . . . . . . . 105

$\begin{array}{ll}\text { Referências } & 107\end{array}$

Apêndice A - Avaliação da Incerteza $\quad 112$

A.1 Introdução . . . . . . . . . . . . . . . . . . . . 112

A.2 Incerteza-padrão . . . . . . . . . . . . . . . . . . 113

A.2.1 Avaliação do Tipo A . . . . . . . . . . . . . . . . . . 114

A.2.2 Avaliação do Tipo B . . . . . . . . . . . . . . . . . . 115

A.3 Combinando as fontes de incerteza . . . . . . . . . . . 116

A.3.1 Coeficiente de sensibilidade . . . . . . . . . . . 116

A.3.2 Incerteza-padrão combinada . . . . . . . . . . . . . . . 117

A.4 Abrangência da estimativa de incerteza . . . . . . . . . . . . . 117

A.4.1 Graus de liberdade efetivos . . . . . . . . . . . . 118

A.4.2 Fator de abrangência . . . . . . . . . . . . . 118

A.4.3 Incerteza expandida . . . . . . . . . . . . . . . 119

Apêndice B - Resultados dos Experimentos Comparativos $\quad 121$

Apêndice C - Informações dos Experimentos com Sistema Real 129 


\section{Introdução}

É inquestionável que, para continuar a crescer e se desenvolver no ritmo atual, a humanidade deve planejar seu desenvolvimento pautado em preocupações crescentes com o binômio meio-ambiente e energia (GILPIN, 1995).

Uma das formas de conciliar crescimento econômico com respeito ao meio-ambiente é por meio da utilização de uma matriz energética mais limpa. Neste cenário, o Brasil ocupa posição privilegiada em relação ao resto do mundo, uma vez que as fontes de energia renováveis (hidroelétrica, biomassa, eólica e biocombustíveis) no ano de 2012 correspondiam a 42,4\% do total da matriz energética (EPE, 2013), enquanto que no mundo este valor era de apenas 13,2\% (IEA, 2013). Quando se observa apenas a energia elétrica, os números são ainda mais favoráveis, com participação de $84,5 \%$ de fontes renováveis no país (EPE, 2013) contra 19,4\% no mundo (REN21, 2011), referente ao ano de 2010.

A partir do século XX a energia elétrica se tornou um dos pilares de sustentação da sociedade moderna e ganha cada vez mais importância em decorrência do crescimento populacional, do aumento da demanda por bens e suprimento, e da mudança do perfil de sua utilização pela sociedade, cada vez mais dependente da energia elétrica. Outro fato relevante relacionado ao crescimento econômico é que, ao mesmo tempo em que traz qualidade de vida à população, também é o indutor à busca incessante de novas fontes de matéria-prima e de mais energia.

Este ciclo vicioso entre desenvolvimento e energia pode ser minimizado por meio de ações que elevem o rendimento nos processos que utilizam energia, ou seja, aumentando o resultado do trabalho realizado com a mesma quantidade de energia, também conhecido como eficiência energética. Desta forma, há economia de recursos com investimento em novas fontes produtoras de energia e diminuição do custo da transformação de energia em trabalho ou de matéria-prima em produto. 


\subsection{Motivação}

O potencial global de reduções do consumo energético é grande. De acordo com o World Energy Assessment este número é de $30 \%$ para os países desenvolvidos e de até $50 \%$ em países em desenvolvimento (UNDP, 2004). Dentro deste panorama, a energia elétrica é o grupo energético mais propício para as reduções, principalmente por ter participação relevante na matriz energética global e cujas soluções de melhoria da eficiência muitas vezes não necessitam de grandes investimentos ou estas possuem período de retorno atraente (PROCEL, 2006).

De acordo com a Associação Brasileira das Empresas de Serviços de Conservação de Energia - ABESCO, o Brasil desperdiça em ineficiência no setor elétrico cerca de 4.600 MW médios, volume que seria suficiente para abastecer $40 \%$ do consumo residencial de todo o país (ABESCO, 2005).

Agrava-se este fato o crescimento pujante do consumo de energia elétrica no país. Em 2012 o consumo foi de 505,7 TWh, com crescimento de 7,7\% em relação ao ano anterior, porém, a produção aumentou apenas 6,3\%, conforme dados do Boletim de Monitoramento do Sistema Elétrico (SEE, 2013). Os principais entraves para que o crescimento da oferta acompanhe o crescimento da demanda estão associados aos seguintes problemas:

- Diminuição do potencial hidroelétrico, estimado em 65\% (EPE, 2011), e o aumento gradual dos custos associados a sua exploração e transmissão;

- Dificuldades na obtenção de licenças ambientais para a instalação de novas unidades geradoras;

- Rejeição às centrais nucleares após o acidente radioativo na usina de Fukushima, Japão (KING, 2011);

- Problemas ambientais de centrais termoelétricas, principalmente com relação à emissão de gases do efeito estufa;

- Não consolidação de fontes energéticas alternativas, como eólica, biomassa, solar, geotérmica ou maremotriz; e

- Gastos em pesquisa e desenvolvimento de novas fontes energéticas são mínimos e os incentivos não conseguem encorajar novos investimentos no setor.

A partir das constatações de que o Brasil possui um elevado potencial de reduções e de que o crescimento da oferta de energia não acompanha o crescimento da demanda, o 
Ministério de Minas e Energia - MME iniciou, no ano de 2009, um estudo para redução do consumo de energia elétrica por meio de ações de eficiência energética, conhecido como Plano Nacional de Eficiência Energética - PNEf (MME, 2010).

O PNEf foi elaborado com a premissa de redução de $10 \%$ do consumo de energia elétrica no país no período entre 2010 e 2030, tendo como base os valores estabelecidos pelo Plano Nacional de Energia - PNE 2030 (EPE, 2006). Desta forma, o PNEf projeta que em 2030 o consumo de energia elétrica no país seja de 923,2 TWh, contra 1025,6 TWh projetados pelo PNE 2030, conforme Figura 1.1.

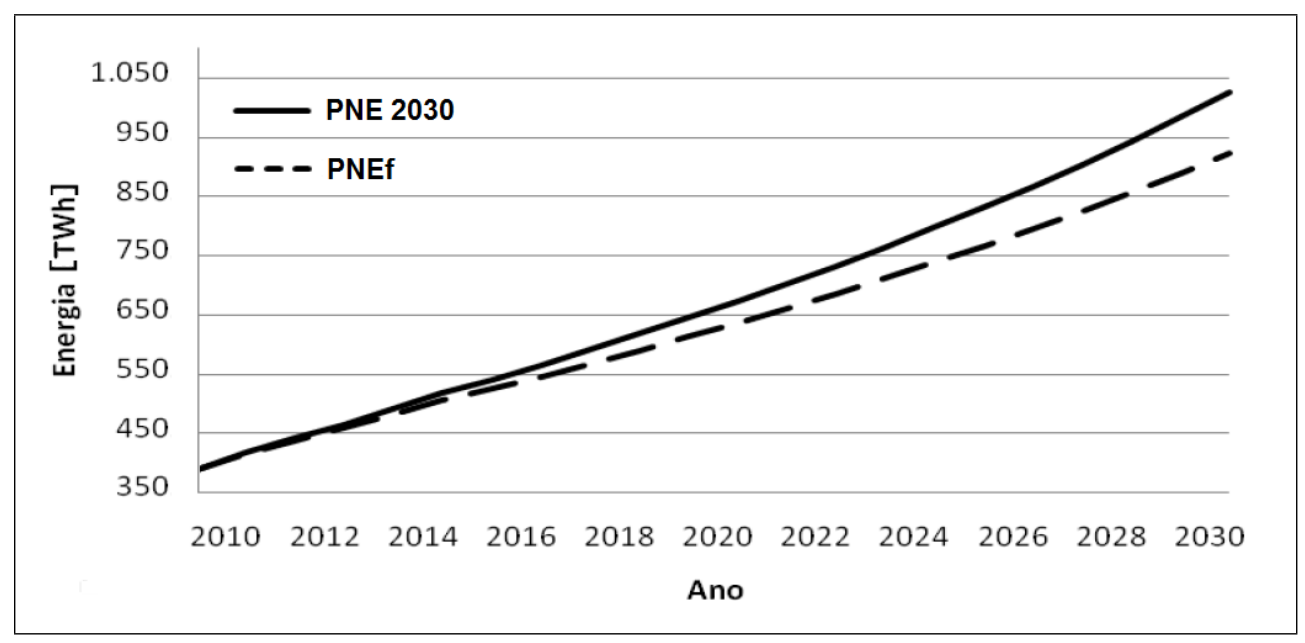

Figura 1.1: Projeção do consumo de energia elétrica no Brasil.

Também no PNEf são apresentados os potenciais estimados de recuperação de energia em diversos setores. Dentre estes, o setor com maior potencial percentual de recuperação é o de saneamento. Segundo dados da Secretaria Nacional de Saneamento Ambiental SNSA, órgão ligado ao Ministério das Cidades, as empresas de saneamento também são massivas consumidoras de energia elétrica. No ano de 2007 foram consumidos 10,41 TWh, cerca de $2,6 \%$ do consumo total do país, o que totalizou o montante de $\mathrm{R} \$ 2,58$ bilhões e que constituiu a segunda maior despesa para as companhias (SNSA, 2009).

\subsection{Eficiência energética no saneamento}

Nas empresas de saneamento a energia é utilizada principalmente para o tratamento e transporte da água em diferentes estágios, começando com os sistemas de captação de água dos mananciais, ao longo dos processos de tratamento nas Estações de Tratamento de Água (ETA), nas Estações Elevatórias de Água (EEA), na reservação em tanques, na distribuição aos consumidores, na coleta do esgoto nas Estações Elevatórias de Esgoto 
(EEE) e finalmente, nas Estações de Tratamento de Esgoto (ETE).

Neste complexo sistema, composto por centenas de quilômetros de tubulações e por dezenas de estações de bombeamento, a energia elétrica é perdida por diversas razões, dentre as principais podem citar:

- Projetos de estações de bombeamento e de redes de distribuição não otimizados em relação ao uso eficiente da energia;

- Tubulações com grande acúmulo de incrustações em seu interior, o que ocasiona o aumento gradual das perdas de carga associadas;

- Presença de inúmeros pontos de vazamento causados principalmente pela falta de manutenção e por pressões excessivas no sistema de bombeamento;

- Ineficiência do conjunto motobomba devido a equipamentos obsoletos e falta de manutenção dos mesmos;

- Restrições à passagem do fluxo nas redes de distribuição em tubulações que já não atendem mais as demandas de projeto;

- Regulagem de vazão por meio de válvulas, que causam grandes perdas de energia e exigem superdimensionamento do sistema elétrico das bombas;

- Utilização de bombas de grande capacidade ao invés de bombas menores operando de forma distribuída e em paralelo; e

- Inexistência de estratégias eficientes de operação do transporte da água nos diferentes subsistemas que compõem esta cadeia.

Segundo o PNEf, o potencial técnico de recuperação de energia elétrica no setor de saneamento brasileiro é de 45,19\% do consumo atual do setor, sem considerar o aproveitamento de potenciais hidráulicos disponíveis (MME, 2010). As principais medidas apontadas pelo PNEf para que seja alcançado este patamar de reduções são:

- Utilização de motores e bombas mais eficientes;

- Redução de perdas de água por vazamento até o limite de perdas inevitáveis (lavagem de filtros ou manutenção na rede);

- Redução da pressão de bombeamento por meio da modulação da pressão e da vazão nas redes de distribuição; e 
- Melhoria nos processos de controle do sistema de distribuição.

A troca de motores convencionais por outros de alto rendimento ou a troca de bombas por outras mais eficientes sempre figuram no plano de ação das companhias de saneamento para redução do consumo energético, porém, somente são efetivamente concretizadas após a realização de um estudo econômico/financeiro criterioso para determinação da taxa de retorno do investimento, e que em muitos casos acaba inviabilizando que aconteçam.

Atualmente grande parte dos esforços das companhias de saneamento está relacionada à redução das perdas de água por vazamento, também conhecidas como Índice de Perdas Físicas (IWA, 2000), principalmente na troca de tubulações antigas e em ações sistemáticas das equipes de campo com objetivo de eliminar o furto de água. As perdas são agravadas quando as mesmas ocorrem próximas aos consumidores finais, dado o elevado índice de energia agregado à água até aquele ponto da cadeia. Dados do Energy and Water Department do Banco Mundial estimam perdas de cerca de $12 \%$ nos países desenvolvidos, de $21 \%$ nos países em desenvolvimento (EWD, 2006) e no Brasil, o Sistema Nacional de Informações sobre Saneamento - SNIS estima este índice em cerca de 28\% (SNSA, 2009).

A redução da pressão nas redes de distribuição pode ser realizada por meio das seguintes ações: utilização de inversores de frequência nas bombas, utilização de válvulas redutoras de pressão (Pressure Reducing Valve - PRV) ou aumento do diâmetro de adutoras. A utilização de inversores de frequência faz com que as bombas funcionem em condições de operação mais adequadas e com consumo elétrico reduzido, entretanto, necessitam de investimentos para a compra e instalação destes equipamentos. Já a utilização de válvulas faz com que haja grandes perdas de energia e exigem superdimensionamento do sistema elétrico das bombas. Finalmente, o aumento do diâmetro das tubulações permite que se diminua a pressão em pontos críticos da rede, todavia, também necessitam de grandes cifras em investimento.

Em uma análise superficial, aparentemente não há correlação entre as ações para redução de vazamento e redução da pressão de bombeamento visando a mitigação das perdas energéticas no setor de saneamento, porém, os vazamentos de água são causados principalmente pelo excesso de pressão nas redes de distribuição (SKWORCOW et al., 2009), fruto de operações incorretas, ineficientes e não automatizadas.

Dentre todas estas ações, a melhoria no processo de controle do sistema de distribuição de água possibilitaria alcançar os maiores percentuais de reduções do consumo energético, estimados entre 10 e 20\% (LEIBY; BURKE, 2011). Adicionalmente, estas melhorias não necessitam de grandes cifras em investimentos, principalmente não exige troca de tubu- 
lações ou compra de equipamentos. Finalmente, outro ganho indireto desta ação seria o aumento da robustez do sistema com relação a interrupções do fornecimento de água no sistema, dado que a água é um bem vital à manutenção da vida.

\subsection{Processo de controle nos sistemas de distribuição de água}

Os processos de controle nos sistemas de distribuição de água são as operações realizadas pelas empresas de saneamento para que a água, proveniente da ETA, chegue até os consumidores finais. Fundamentalmente, o processo de controle atua em bombas e válvulas de forma a garantir o fornecimento ininterrupto, ou seja, com vazões e pressões adequadas em todos os pontos da rede de distribuição.

A partir das arquiteturas de controle utilizadas na robótica móvel (MURPHY, 2000) é possível traçar um paralelo com as arquiteturas típicas dos sistemas de distribuição de água, conforme Figura 1.2, onde $s$ representa os estados do sistema, i.e. tudo aquilo que deseja controlar, a representa as ações, i.e. tudo aquilo que se pode manipular, e $r$ a recompensa (ou custo) devido à realização de uma determinada ação.

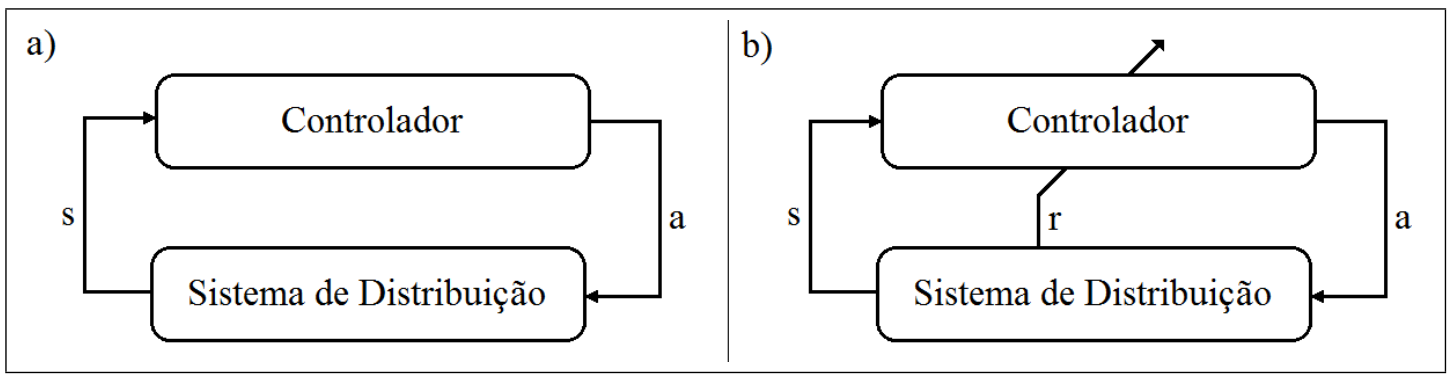

Figura 1.2: Sistema de distribuição de água com controle a) reativo e b) deliberativo.

No sistema de controle reativo, conforme Figura 1.2.a, as ações são função apenas dos estados, ou seja, independentes das recompensas alcançadas. Esta arquitetura é indicada quando se deseja controlar o sistema sem o modelo formal da rede de distribuição. São exemplos desta arquitetura o controlador baseado em nível, no qual as bombas são ativadas/desligadas quando o nível de um tanque de armazenamento de água está abaixo/acima de um determinado valor, ou o controlador por tempo, no qual as bombas são ativadas/desligadas em horários pré-determinados do dia.

Já nos sistemas de controle deliberativos, conforme Figura 1.2.b, as ações também são função dos estados, entretanto, planejadas a priori com objetivo de maximizar as 
recompensas obtidas em um horizonte de tempo determinado. O controle deliberativo é apropriado quando o sistema de distribuição é complexo, com muitas variáveis e dinâmico. Figuram como exemplo desta arquitetura técnicas como algoritmos genéticos, colônia de formigas, programação linear ou dinâmica, etc.

Infelizmente o ajuste das ações pelo controlador deliberativo utilizando o próprio sistema de distribuição real, como descrito pela Figura 1.2.b, não é factível e está associado a muitos riscos, dada a elevada possibilidade de instabilidade no sistema de distribuição, interrupção no fornecimento de água, quebra de equipamentos, ou até mesmo, ruptura de tubulações devido a sobre-pressões. Assim, para que sejam calculadas as ações que maximizem as recompensas utilizando técnicas de controle deliberativas, primeiramente são utilizados softwares de simulação hidráulica, com o objetivo de simular as características de um sistema real, conforme descrito na Figura 1.3. Após testadas e validadas, estas ações podem então ser aplicadas aos sistemas de distribuição real.

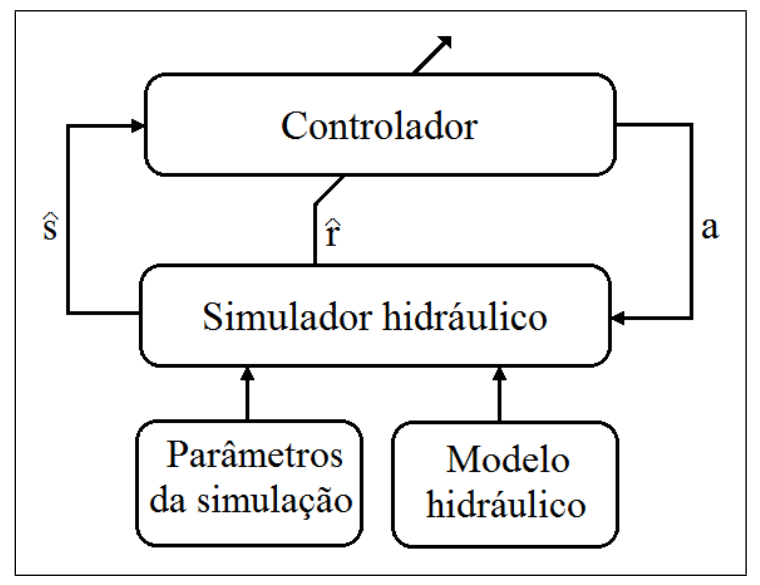

Figura 1.3: Sistema de controle deliberativo utilizando um simulador hidráulico.

Os simuladores hidráulicos fornecem, a partir da ação - $a$, uma estimativa do próximo estado do sistema $-\widehat{s}$ e do valor da recompensa $-\widehat{r}$ utilizando, para tanto, um modelo hidráulico do sistema de distribuição, além da parametrização da simulação (mais detalhes são apresentados no Capítulo 3). Além disso, a maioria dos simuladores hidráulicos disponível no mercado utilizam modelos determinísticos de transição de estado, nos quais a partir de um estado $s \in S$ e uma ação $a \in A$ o sistema evolui com $100 \%$ de chance para o próximo estado $s^{\prime} \in S$, resultando em: $S \times A \rightarrow S$.

Entretanto, quando é utilizado um simulador hidráulico, por mais fiel e detalhada que seja a descrição do modelo da rede de distribuição, sempre haverá uma diferença com relação aos dados do sistema real. Esta diferença pode ser interpretada como uma incerteza na determinação de estado pelo simulador hidráulico. Assim, quando o próximo 
estado $s^{\prime}$ é incerto o modelo de transição de estado é dito probabilístico: $S \times A \times S \rightarrow[0,1]$.

Dentre as arquiteturas de controle deliberativas, uma que modela a transição de estados de forma probabilística são os Processos Decisórios de Markov - MDP (mais detalhes são apresentados no Capítulo 4). Desta forma, a utilização de um simulador hidráulico, associado a um módulo para estimar a incerteza ${ }^{1}$ do próximo estado - $U(s)$ permite que as probabilidades de transição sejam contabilizadas para determinar o conjunto de ações que produzem a maior soma esperada das recompensas, resultando no sistema de controle descrito pela Figura 1.4.

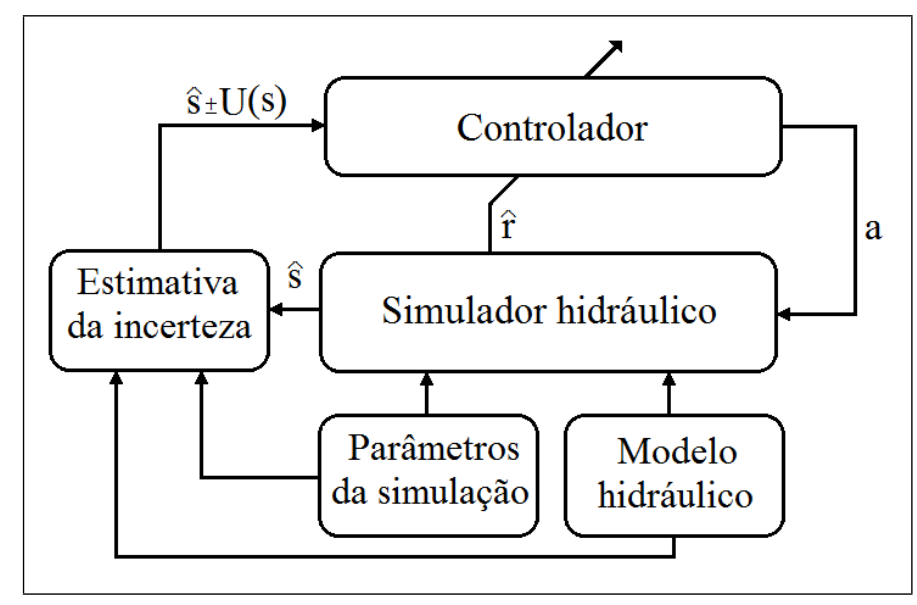

Figura 1.4: Sistema de controle deliberativo utilizando um simulador hidráulico associado a uma incerteza na transição de estado.

\subsection{Objetivo}

O objetivo desta tese é apresentar e avaliar um novo sistema de controle para realizar a operação autônoma das ações em sistemas de distribuição de água, com a premissa de redução dos gastos com energia elétrica e modeladas como um Processo Decisório de Markov, utilizando um simulador hidráulico associado ao cálculo da incerteza do próximo estado para produzir transições de estado probabilísticas.

O desenvolvimento de um novo sistema de controle em sistemas de distribuição de água é justificado por meio dos seguintes argumentos:

- Promove o aumento da eficiência das bombas, fazendo com que se maximize a relação entre a energia utilizada e a vazão de água fornecida ao sistema;

\footnotetext{
${ }^{1}$ Detalhes são apresentados no Apêndice A.
} 
- Propicia a redução do consumo energético e dos gastos com energia elétrica pelas companhias de saneamento;

- Facilita a operação de sistemas de distribuição de água complexos;

- Reduz a possibilidade de interrupções no fornecimento de água devido a imperícias na operação do sistema de distribuição;

- Diminui os custos com manutenção do conjunto moto-bomba, fazendo com que estes trabalhem em condições de operação mais favoráveis;

- Evita que a rede de distribuição opere em pressões elevadas, minimizando o risco de ruptura das mesmas;

- Minimiza a utilização de válvulas de controle para regulagem de pressão ou vazão, evitando que haja perda de energia cinética por restrição de passagem; e

- Oferece embasamento ao conjunto de regras de controle existentes e propõe melhorias quando necessário.

Assim, a principal contribuição desta tese é a modelagem de sistemas de distribuição de água utilizando Processos Decisórios de Markov com função de transição de estado calculada em simulador hidráulico na presença de incertezas.

Adicionalmente esta tese também contribui com:

- Um novo sistema de controle para redução de gastos com energia elétrica em redes de distribuição de água; e

- Experimentos com modelo hidráulico e parametrização detalhados para realização de análises comparativas futuras com outros sistemas de controle.

\subsection{Organização do Documento}

Este trabalho está organizado da seguinte forma:

- Capítulo 2 - Panorama das Técnicas de Otimização para Sistemas de Distribuição de Água. Neste capítulo é apresentado uma análise das técnicas utilizadas para otimização de sistemas de distribuição de água. 
- Capítulo 3 - Sistemas de Distribuição de Água. Este capítulo descreve os sistemas de distribuição de água, além de apresentar a modelagem dos parâmetros fluídicos.

- Capítulo 4 - Modelagem por MDP de Sistemas de Distribuição de Água. Neste capítulo é apresentada a formalização matemática dos Processos Decisórios de Markov e a contribuição principal desta tese, a modelagem utilizando MDP do problema de minimização dos gastos com energia elétrica nos sistemas de distribuição de água.

- Capítulo 5 - Solução de Sistemas de Distribuição de Água Modelados por MDP. Este capítulo descreve as soluções clássicas dos problemas modelados por MDP com horizonte infinito, além do algoritmo para solução do problema de minimização dos gastos com energia elétrica em sistemas de distribuição de água, modelado por MDP com horizonte finito.

- Capítulo 6 - Experimentos. Este capítulo apresenta os resultados de três experimentos realizados: o primeiro, com um sistema de distribuição simplificado e modelo hidráulico explícito; o segundo, que é o comprativo entre três diferentes técnicas de redução do consumo energético; e o último, o comparativo entre um sistema real e o sistema de controle proposto.

- Capítulo 7 - Conclusão. Este capítulo apresenta as conclusões deste trabalho e suas contribuição. Além disso, também são apresentadas as propostas de continuidade deste trabalho.

- Apêndice A. Neste apêndice é apresentada a técnica para estimação da incerteza de uma variável, baseada na combinação de variâncias das fontes de erro.

- Apêndice B. Apresenta os resultados dos experimento comparativo entre três diferentes técnicas de redução do consumo energético.

- Apêndice C. Finalmente, este apêndice apresenta as informações complementares do modelo hidráulico do experimento com sistema real. 


\section{Panorama das Técnicas de Otimização para Sistemas de Distribuição de Água}

Neste capítulo é apresentado um panorama das técnicas utilizadas para otimização de sistemas de distribuição de água. As informações aqui apresentadas cobrem os anos de 2005 a 2011 e são complementares aos trabalhos de Goldman et al. (1999) e López-Ibáñez (2009), que cobrem os anos de 1975 a 2004.

\subsection{Introdução}

O uso de algoritmos de otimização visando a melhora das redes de distribuição de água, principalmente em relação ao consumo energético, não é um assunto novo. O primeiro artigo a tratar do assunto data do ano de 1970 (EPP; FOWLER, 1970), quando foi utilizado um modelo macroscópico de uma rede de distribuição associado a um algoritmo de controle baseado em programação dinâmica.

De lá para cá muita coisa mudou, principalmente com relação aos modelos hidráulicos utilizados. Hoje em dia, redes de distribuição complexas podem ser simuladas utilizando softwares que descrevem fielmente suas características, por exemplo, o EPANET (EPA, 2000) e o WaterGEMS (BENTLEY, 2009). Também, houve muitos avanços nos algoritmos de otimização utilizados, principalmente relacionados ao aumento da capacidade de processamento dos computadores atuais.

Em Goldman et al. (1999) é apresentada a evolução dos algoritmos de otimização compreendida entre os anos de 1975 a 1995. Já em López-Ibáñez (2009) é apresentada uma revisão das abordagens entre os anos 1995 a 2004.

Ampliando as informações contidas nestes dois trabalhos importantes, é apresentado o estado da arte dos algoritmos de otimização em redes de distribuição de água, compre- 
endido no período de 2005 a 2011, conforme apresenta a Tabela 2.1.

As informações foram sumarizadas em função do modelo experimental da rede de distribuição de água, representada pelo número de tanques (coluna 2) e de bombas (coluna 3), pelo modelo hidráulico (coluna 4), pelo tipo do algoritmo de otimização utilizado (coluna 5), pela função objetivo do algoritmo de otimização (coluna 6) e pela representação do acionamento das bombas (coluna 7). A seguir, cada um destes itens é discutido detalhadamente.

\subsection{Modelo experimental}

Os modelos experimentais são a forma de testar, em condições controladas e reprodutíveis, os algoritmos de otimização em uma determinada rede de distribuição. Os dois principais componentes dos modelos experimentais são os tanques e as bombas, mas também fazem parte as tubulações, as singularidades (curvas, derivações, reduções, etc.) e as válvulas.

Os tanques de armazenamento são elementos importante em um sistema de distribuição de água dado que: garantem a equalização das pressões de rede, suprem a deficiência na distribuição de água quando nos períodos de pico da demanda e também possibilitam uma reserva de água para que as bombas operem somente em períodos de tarifa energética mais favorável.

Já as bombas são os elementos que fazem com que a água circule pela rede de distribuição. Estas podem ser acionadas diretamente (índice D da coluna 3) ou por meio de inversores de frequência (índice F da coluna 3), quando é possível ajustar a velocidade de rotação da bomba.

Um elemento importante dos sistemas de distribuição de água e que não está presente nas diversas abordagens de otimização de consumo energético aqui apresentadas são as válvulas. Elas são divididas em duas grandes categorias: bloqueio e controle. As válvulas de bloqueio servem para determinar o caminho que a água deverá percorrer, ou para isolar determinados pontos da rede. Já as válvulas de controle possibilitam a modulação da curva de perda de carga do sistema, fazendo com que as bombas operem em pontos diferentes de sua curva característica. 
Tabela 2.1: Sumário das abordagens de otimização em redes de distribuição de água.

\begin{tabular}{|c|c|c|c|c|c|c|c|}
\hline Referência & Tanques & Bombas & $\begin{array}{c}\text { Modelo } \\
\text { hidráulico }\end{array}$ & $\begin{array}{l}\text { Algoritmo de } \\
\text { otimização }\end{array}$ & $\begin{array}{l}\text { Objetivo da } \\
\text { otimização }\end{array}$ & $\begin{array}{l}\text { Representação } \\
\text { das ações }\end{array}$ & Comentários \\
\hline $\begin{array}{l}\text { López-Ibáñez, Pra- } \\
\text { sad e Paechter (2005) }\end{array}$ & 2 & $3(\mathrm{D})$ & $\begin{array}{l}\text { Simulador } \\
\text { hidrúlico } \\
\text { (EPANET) }\end{array}$ & $\begin{array}{l}\text { Algoritmo } \\
\text { evolutivo }\end{array}$ & $\begin{array}{c}\text { Despesas com } \\
\text { energia elétrica } \\
\text { e chaveamento } \\
\text { das bombas }\end{array}$ & Explícito & $\begin{array}{l}\text { Otimizador multi-objetivos que utiliza } \\
\text { o princípio de Pareto. O fator de de- } \\
\text { manda e o nível dos tanques fazem } \\
\text { parte das restrições do problema. }\end{array}$ \\
\hline Firmino et al. (2006) & 1 & $8(\mathrm{D})$ & $\begin{array}{l}\text { Modelo } \\
\text { explícito }\end{array}$ & $\begin{array}{l}\text { Programação } \\
\text { linear-mista }\end{array}$ & $\begin{array}{l}\text { Despesas com } \\
\text { energia elétrica }\end{array}$ & Explícito & $\begin{array}{l}\text { Realiza primeiramente a otimização li- } \\
\text { near contínua para obter o volume } \\
\text { ótimo e a partir desta informação é re- } \\
\text { alizada a otimização linear inteira vi- } \\
\text { sando reduzir o número de acionamen- } \\
\text { tos das bombas de forma a preservar } \\
\text { sua vida útil. }\end{array}$ \\
\hline $\begin{array}{l}\text { Maturana et al. } \\
(2006)\end{array}$ & 2 & $2(\mathrm{D})$ & $\begin{array}{l}\text { Modelo } \\
\text { explícito }\end{array}$ & $\begin{array}{l}\text { Baseado em } \\
\text { agentes }\end{array}$ & $\begin{array}{l}\text { Despesas com } \\
\text { energia elétrica }\end{array}$ & Implícito & $\begin{array}{l}\text { Sistema de controle em tempo real ba- } \\
\text { seado em agentes. Os agentes das } \\
\text { bombas cuidam do seu acionamento e } \\
\text { de seu consumo energético, já os agen- } \\
\text { tes dos tanques cuidam para que não } \\
\text { haja extravasamento ou falta de água. }\end{array}$ \\
\hline Wang e Brdys (2006) & 1 & $4(\mathrm{D})$ & $\begin{array}{l}\text { Simulador } \\
\text { hidrúlico } \\
\text { (EPANET) }\end{array}$ & $\begin{array}{l}\text { Programação } \\
\text { linear-mista } \\
\text { (CPLEX) }\end{array}$ & $\begin{array}{l}\text { Despesas com } \\
\text { energia elétrica, } \\
\text { pressão da rede } \\
\text { e vazamento }\end{array}$ & Explícito & $\begin{array}{l}\text { Sistema de controle que chaveia, de } \\
\text { forma suave, entre três funções de oti- } \\
\text { mização. Modelagem do vazamento é } \\
\text { função da pressão da rede. }\end{array}$ \\
\hline $\begin{array}{l}\text { Ulanicki, Kahler e } \\
\text { See (2007) }\end{array}$ & 7 & $4(\mathrm{D})+1(\mathrm{~F})$ & $\begin{array}{l}\text { Simulador } \\
\text { hidráulico } \\
\text { (Ginas) }\end{array}$ & $\begin{array}{l}\text { Programação } \\
\text { dinâmica }\end{array}$ & $\begin{array}{c}\text { Despesas com } \\
\text { energia elétrica } \\
\text { e do tratamento } \\
\text { da água, e } \\
\text { penalidades }\end{array}$ & Explícito & $\begin{array}{l}\text { As variáveis inteiras de acionamento } \\
\text { das bombas são transformadas em } \\
\text { contínuas relaxadas e a solução do pro- } \\
\text { blema é obtida por meio de um contro- } \\
\text { lador dinâmico ótimo. As penalidades } \\
\text { estão associadas aos níveis dos tanques } \\
\text { de armazenamento. }\end{array}$ \\
\hline
\end{tabular}


Tabela 2.1: Sumário das abordagens de otimização em redes de distribuição de água (continuação).

\begin{tabular}{|c|c|c|c|c|c|c|c|}
\hline Referência & Tanques & Bombas & $\begin{array}{c}\text { Modelo } \\
\text { hidráulico }\end{array}$ & $\begin{array}{l}\text { Algoritmo de } \\
\text { otimização }\end{array}$ & $\begin{array}{l}\text { Objetivo da } \\
\text { otimização }\end{array}$ & $\begin{array}{l}\text { Representação } \\
\text { das ações }\end{array}$ & Comentários \\
\hline $\begin{array}{l}\text { López-Ibáñez, Pra- } \\
\text { sad e Paechter (2008) }\end{array}$ & $\begin{array}{l}2 \\
6\end{array}$ & $\begin{array}{l}3(\mathrm{D}) \\
7(\mathrm{D})\end{array}$ & $\begin{array}{l}\text { Simulador } \\
\text { hidrúlico } \\
\text { (EPANET) }\end{array}$ & $\begin{array}{l}\text { Colônia de } \\
\text { formigas }\end{array}$ & $\begin{array}{l}\text { Despesas com } \\
\text { energia elétrica }\end{array}$ & Implícito & $\begin{array}{l}\text { A política de controle determina o } \\
\text { número máximo de acionamentos das } \\
\text { bombas e o tempo em que estas per- } \\
\text { manecerão ligadas. }\end{array}$ \\
\hline López-Ibáñez (2009) & $\begin{array}{l}2 \\
6\end{array}$ & $\begin{array}{l}3(\mathrm{D}) \\
7(\mathrm{D})\end{array}$ & $\begin{array}{l}\text { Simulador } \\
\text { hidrúlico } \\
\text { (EPANET) }\end{array}$ & $\begin{array}{l}\text { Algoritmos } \\
\text { genéticos }\end{array}$ & $\begin{array}{l}\text { Despesas com } \\
\text { energia elétrica }\end{array}$ & $\begin{array}{l}\text { Explícito e } \\
\text { implícito }\end{array}$ & $\begin{array}{l}\text { Análise comparativa de variantes de } \\
\text { algoritmos genéticos aplicados à oti- } \\
\text { mização do problema de redes de dis- } \\
\text { tribuição de água em diferentes cená- } \\
\text { rios e condições. }\end{array}$ \\
\hline $\begin{array}{l}\text { Pasha } \\
(2009)\end{array}$ & 1 & $4(\mathrm{D})$ & $\begin{array}{l}\text { Simulador } \\
\text { hidrúlico } \\
\text { (EPANET) }\end{array}$ & $\begin{array}{l}\text { Programação } \\
\text { linear }\end{array}$ & $\begin{array}{l}\text { Despesas com } \\
\text { energia elétrica }\end{array}$ & Explícito & $\begin{array}{l}\text { Realiza a linearização do modelo hi- } \\
\text { draúlico para possibilitar sua utiliza- } \\
\text { ção em abordagens de minimização do } \\
\text { consumo energético em tempo real. }\end{array}$ \\
\hline $\begin{array}{l}\text { Skworcow et al. } \\
(2009)\end{array}$ & 4 & $2(\mathrm{D})+6(\mathrm{~F})$ & $\begin{array}{l}\text { Simulador } \\
\text { hidráulico } \\
\text { (Finese) }\end{array}$ & $\begin{array}{l}\text { Programação } \\
\text { não-linear }\end{array}$ & $\begin{array}{c}\text { Despesas com } \\
\text { energia elétrica } \\
\text { e do tratamento } \\
\text { da água }\end{array}$ & Explícito & $\begin{array}{l}\text { Modelo hidráulico que leva em conta } \\
\text { os vazamentos em função da pressão } \\
\text { na rede de distribuição. Realiza dis- } \\
\text { cretização dos acionamentos contínuos } \\
\text { (bombas com inversores de frequência) } \\
\text { utilizando programação não-linear. }\end{array}$ \\
\hline $\begin{array}{l}\text { Wang, Chang e Chen } \\
(2009)\end{array}$ & 1 & $4(\mathrm{D})$ & $\begin{array}{l}\text { Balanço } \\
\text { de massa }\end{array}$ & $\begin{array}{l}\text { Algoritmo } \\
\text { genético }\end{array}$ & $\begin{array}{l}\text { Despesas com } \\
\text { energia elétrica } \\
\text { e esgotamento } \\
\text { dos recursos } \\
\text { hídricos }\end{array}$ & Explícito & $\begin{array}{l}\text { Realiza o acionamento das bombas em } \\
\text { intervalos de tempo quase-contínuo } \\
\text { utilizando algoritmo genético. }\end{array}$ \\
\hline $\begin{array}{l}\text { Bene, Selek e Hös } \\
(2010)\end{array}$ & 3 & $2(\mathrm{D})$ & $\begin{array}{l}\text { Balanço } \\
\text { de massa }\end{array}$ & $\begin{array}{l}\text { Algoritmo } \\
\text { genético }\end{array}$ & $\begin{array}{l}\text { Despesas com } \\
\text { energia elétrica }\end{array}$ & Explícito & $\begin{array}{l}\text { Técnica que agrupa soluções com fun- } \\
\text { ção custo similares (busca neutra) vi- } \\
\text { sando obter soluções factível e com } \\
\text { menor custo. }\end{array}$ \\
\hline \multicolumn{8}{|c|}{ continua... } \\
\hline
\end{tabular}


Tabela 2.1: Sumário das abordagens de otimização em redes de distribuição de água (continuação).

\begin{tabular}{|c|c|c|c|c|c|c|c|}
\hline Referência & Tanques & Bombas & $\begin{array}{c}\text { Modelo } \\
\text { hidráulico }\end{array}$ & $\begin{array}{l}\text { Algoritmo de } \\
\text { otimização }\end{array}$ & $\begin{array}{l}\text { Objetivo da } \\
\text { otimização }\end{array}$ & $\begin{array}{l}\text { Representação } \\
\text { das ações }\end{array}$ & Comentários \\
\hline $\begin{array}{l}\text { Costa, Castro e Ra- } \\
\text { mos (2010) }\end{array}$ & 2 & $8(\mathrm{D})$ & $\begin{array}{l}\text { Simulador } \\
\text { hidrúlico } \\
\text { (EPANET) }\end{array}$ & $\begin{array}{l}\text { Algoritmo } \\
\text { genético }\end{array}$ & $\begin{array}{l}\text { Despesas com } \\
\text { energia elétrica }\end{array}$ & Explícito & $\begin{array}{l}\text { Abordagem que incorpora pré- } \\
\text { avaliação das soluções factíveis para } \\
\text { posterior processamento e determina- } \\
\text { ção da solução. }\end{array}$ \\
\hline Dötsch et al. (2010) & $\begin{array}{l}2 \\
2 \\
2\end{array}$ & $\begin{array}{l}3(\mathrm{D}) \\
2(\mathrm{D}) \\
5(\mathrm{D})\end{array}$ & $\begin{array}{l}\text { Simulador } \\
\text { hidrúlico } \\
\text { (EPANET) }\end{array}$ & $\begin{array}{l}\text { Baseado em } \\
\text { agentes }\end{array}$ & $\begin{array}{l}\text { Despesas com } \\
\text { energia elétrica }\end{array}$ & Implícito & $\begin{array}{l}\text { Técnica de otimização baseada em } \\
\text { agentes cuja estratégia de coordenação } \\
\text { é chamada de defesa indireta. }\end{array}$ \\
\hline $\begin{array}{l}\text { Fang, Gao e Yuan } \\
(2010)\end{array}$ & 30 & $3(\mathrm{D})+3(\mathrm{~F})$ & $\begin{array}{l}\text { Simulador } \\
\text { hidrúlico } \\
\text { (EPANET) }\end{array}$ & $\begin{array}{l}\text { Algoritmo } \\
\text { genético }\end{array}$ & $\begin{array}{c}\text { Despesas com } \\
\text { energia elétrica } \\
\text { e do tratamento } \\
\text { da água }\end{array}$ & Explícito & $\begin{array}{l}\text { Modelagem mista de operação das } \\
\text { bombas, além de utilizar o custo de } \\
\text { tratamento da água de duas ETAs di- } \\
\text { ferentes. }\end{array}$ \\
\hline Shihu et al. (2010) & $\begin{array}{c}\text { Não } \\
\text { informado }\end{array}$ & $\begin{array}{c}\text { Não } \\
\text { informado }\end{array}$ & $\begin{array}{l}\text { Simulador } \\
\text { hidrúlico } \\
\text { (EPANET) }\end{array}$ & $\begin{array}{l}\text { simulated } \\
\text { annealing }\end{array}$ & $\begin{array}{l}\text { Despesas com } \\
\text { energia elétrica } \\
\text { e tratamento da } \\
\text { água }\end{array}$ & Explícito & $\begin{array}{l}\text { Apresenta o comparativo do algoritmo } \\
\text { de otimização na operação do sistema } \\
\text { de bombeamento em um modelo com- } \\
\text { pleto, e outro simplificado, de uma } \\
\text { rede de distribuição de água. }\end{array}$ \\
\hline $\begin{array}{lll}\text { Yang } & \text { e } & \text { Børsting } \\
(2010) & & \end{array}$ & 1 & $3(\mathrm{D})$ & $\begin{array}{l}\text { Modelo } \\
\text { explícito }\end{array}$ & $\begin{array}{l}\text { Programação } \\
\text { não-linear }\end{array}$ & $\begin{array}{l}\text { Consumo da } \\
\text { energia elétrica }\end{array}$ & Implícito & $\begin{array}{l}\text { Otimização por meio de equaciona- } \\
\text { mento explícito do modelo hidráulico } \\
\text { do sistema. Visa obter o ponto de ope- } \\
\text { ração ótimo das bombas. }\end{array}$ \\
\hline $\begin{array}{l}\text { Savic, Bicik e Morley } \\
\text { (2011) }\end{array}$ & 1 & $4(\mathrm{D})$ & $\begin{array}{l}\text { Simulador } \\
\text { hidrúlico } \\
\text { (EPANET) }\end{array}$ & $\begin{array}{l}\text { Algoritmo } \\
\text { genético }\end{array}$ & $\begin{array}{l}\text { Despesas com } \\
\text { energia elétrica } \\
\text { e chaveamento } \\
\text { das bombas }\end{array}$ & Explícito & $\begin{array}{l}\text { Algoritmo multi-objetivo que mini- } \\
\text { miza o número de acionamentos da } \\
\text { bomba e o despesas com energia elé- } \\
\text { trica. }\end{array}$ \\
\hline $\begin{array}{l}\text { Zhuan, Zhang e Guo } \\
\text { (2011) }\end{array}$ & 3 & $4(\mathrm{D})$ & $\begin{array}{l}\text { Balanço } \\
\text { de massa }\end{array}$ & $\begin{array}{l}\text { Programação } \\
\text { dinâmica }\end{array}$ & $\begin{array}{c}\text { Custo e } \\
\text { consumo de } \\
\text { energia elétrica }\end{array}$ & Implícito & $\begin{array}{l}\text { Comparativo de duas técnicas de oti- } \\
\text { mização. O acionamento das bombas } \\
\text { é realizado pelo nível do tanque, na } \\
\text { programação dinâmica e pelo horário } \\
\text { na programação linear. }\end{array}$ \\
\hline
\end{tabular}




\subsection{Modelo hidráulico}

Para determinar o custo de uma política de controle para acionamento de bombas e válvulas em uma rede de distribuição de água ou para avaliar as restrições operacionais associadas a esta rede, é necessário algum modelo matemático deste sistema. Alguns representantes dos modelos hidráulicos incluem: balanço de massa, modelo explícito e simulação hidráulica.

O modelo por balanço de massa simplifica um sistema baseado em tanques pelas seguintes hipóteses: a) O volume de água escoado no sistema, num intervalo de tempo definido, é igual à demanda de consumo mais a variação do nível dos tanques; b) As bombas são utilizadas somente para enviar água aos tanques e estes por sua vez, utilizados para suprir a demanda da rede; e c) As restrições de pressão e de vazão da rede são ignoradas.

Já o modelo explícito é definido como um conjunto de equações não lineares que representam uma determinada rede de distribuição em uma faixa de demanda específica. Esta abordagem resulta em modelos mais precisos comparados com os de balanço de massa e com a vantagem de não exigirem grande poder de processamento. Por outro lado, este tipo de modelagem é muito sensível aos dados utilizados, onde qualquer pequena modificação do sistema já não garante mais a aderência ao modelo.

Finalmente, os simuladores hidráulicos solucionam as equações hidráulicas (conservação de massa e de energia) para modelar a dinâmica não linear de um sistema complexo de distribuição de água. A qualidade dos modelos gerados é função da quantidade da informação introduzida no sistema e de sua posterior calibração com dados em condições reais. Atualmente a maioria das publicações utiliza este tipo de modelo, principalmente com o software EPANET (EPA, 2000), uma vez que é gratuito, de fácil utilização e com equacionamento preciso da fluido-dinâmica da rede.

\subsection{Algoritmo de otimização}

Os algoritmos de otimização são o cerne da operação eficiente de sistemas de distribuição de água. Programação dinâmica, programação linear e programação não linear são técnicas que figuram entre as mais utilizadas desde os primórdios da otimização. Mais recentemente, técnicas de busca heurística, como algoritmos genéticos, arrefecimento simulado (simulated annealing) e colônia de formigas, além de abordagens baseadas em 
agentes, também são utilizadas para a solução deste tipo de problema. A seguir é apresentado um breve descritivo das técnicas que figuram na Tabela 2.1.

A programação dinâmica é uma forma implícita de controle, na qual em sistemas de distribuição de água o nível do tanque é utilizado como variável de controle. A melhor solução para o problema é obtida por meio da avaliação de todas as transições de estado entre os intervalos de tempo adjacentes. Desta forma, um problema complexo que envolve vários sub problemas pode ser reduzido a uma série de problemas envolvendo uma única variável. Porém, a complexidade do problema aumenta exponencialmente com o número de variáveis de controle.

Já a programação linear é utilizada para resolver problemas de otimização nos quais a função objetivo e todas as restrições são funções lineares de variáveis de decisão não negativas. Nesta técnica, as variáveis utilizadas podem ser inteiras, contínuas ou mistas. Por outro lado, a programação não linear, como o próprio nome diz, é utilizada em problemas onde a função objetivo ou as restrições do problema de otimização são não lineares. Problemas não lineares também podem ser resolvidos via programação linear, porém, a função objetivo e espaço de soluções são aproximados por funções lineares dentro de um intervalo limitado.

Os algoritmos genéticos, uma subclasse dos algoritmos evolutivos, são baseados no princípio de sobrevivência dos mais aptos, conforme teoria da evolução das espécies de Darwin. Os algoritmos genéticos são compostos pelo tripé reprodução (recombinação), mutação e seleção. A cada nova geração, soluções contendo os estados dos elementos (bombas e válvulas) são avaliadas e, posteriormente, classificadas em função de uma função objetivo (consumo ou despesas com energia elétrica). A tendência deste processo é que, com o decorrer das gerações as piores soluções desapareçam, e em contrapartida, sejam obtidas soluções mais bem ajustadas às restrições do problema e com a função objetivo mais próxima do valor ótimo. Destacam-se nesta abordagem soluções com variáveis discretas e binárias.

Atualmente, os algoritmos genéticos são a técnica de otimização mais utilizada e difundida para resolução do problema de otimização de sistemas de distribuição de água. As novas abordagens possuem apenas pequenas variações da proposição original e focam principalmente na questão de busca da solução e na inclusão de penalidades para estados que não obedecem a alguma restrição.

Outro algoritmo de otimização que possui inspiração biológica é o de colônia de formigas. Esta técnica está baseada na constatação de que as formigas são capazes de encontrar 
um caminho ótimo, entre o formigueiro e uma fonte de alimento, utilizando uma comunicação indireta com uma substância química chamada feromônio. Computacionalmente esta técnica constrói estocasticamente rotas em um grafo, onde caminhos que melhoram a função objetivo tendem a ter maior probabilidade de serem escolhidos em relação aos demais. Além disso, os valores de feromônio (probabilidade de seleção de um determinado caminho) são diminuídos a cada iteração, uma operação conhecida como evaporação. Este processo diminui os valores de feromônio associado a componentes da solução que raramente aparecem ou que não tenham sido reforçados recentemente, por isso, a busca é direcionada para as regiões mais promissoras do espaço de estados.

Finalmente, outra técnica encontrada na literatura que trata do problema de otimização em redes de distribuição de água é a baseada em agentes. Os agentes são algoritmos capazes de raciocinar de forma autônoma e que reagem às mudanças neles induzidas, tanto pelo ambiente como por outros agentes. A arquitetura do agente é organizada de acordo com as seguintes características:

- Autonomia - Cada agente toma suas próprias decisões e é responsável pela execução destas para a obtenção de um objetivo;

- Cooperação - Agentes combinam suas capacidades e regras de interação em grupos colaborativos (clusters) para se adaptarem e responderem a eventos e objetivos mútuos;

- Comunicação - Agentes compartilham uma linguagem em comum e são capazes de comunicar entre si; e

- Pró atividade - Agentes periodicamente, ou de forma assíncrona, propõem estratégias para melhorar o desempenho do sistema ou para impedir a inclusão de estados prejudiciais.

\subsection{Objetivo da otimização}

Nos artigos apresentados na Tabela 2.1 a despesa com energia elétrica é unanimidade como objetivo da otimização, porém, algumas abordagens realizam a otimização multiobjetivos. Dentre os outros objetivos que são apresentados estão: minimização do número de acionamento das bombas, visando prolongar sua vida útil e reduzir a necessidade de manutenções corretivas; minimização da pressão de rede, de forma a evitar possíveis danos à rede de distribuição; redução dos vazamentos, que é modelado em função da pressão de 
rede; minimização do custo do tratamento da água, onde pode ser utilizada água de fontes diferentes e com custos diferentes; e minimização do esgotamento dos recursos hídricos, evitando que bombas submersas trabalhem de forma contínua e que esgotem a água dos lençóis freáticos.

Um fato importante observado é que apenas um dos artigos levou em conta o consumo energético como objetivo da otimização, todos os outros priorizaram a questão econômica. Este fato está relacionado aos gastos com energia elétrica serem a segunda maior despesa das companhias de saneamento, desta forma, as mesmas priorizam a questão econômica.

\subsection{Representação das Ações}

Outro aspecto relevante dos algoritmos de otimização, conforme Goldman et al. (1999) e López-Ibáñez (2009), é a representação das ações. Esta é dividida em duas categorias: explícita e implícita. A representação explícita especifica o estado da bomba (ligada ou desligada) ou válvula (aberta ou fechada). Este tipo de abordagem faz com que o controle fique restrito à demanda de água utilizada pelo algoritmo de otimização. Qualquer pequena variação do modelo do sistema pode fazer com que a solução não seja mais a ótima ou que alguma restrição do problema seja infringidá. Já a representação implícita define a operação das bombas e válvulas em termos da propriedade de outros elementos da rede de distribuição, como por exemplo, o nível de tanque, a pressão num determinado ponto da rede de distribuição, o horário, ou ambos. Assim, a representação implícita traduz as restrições do problema na forma de ações que podem ser executadas.

\subsection{Discussões Finais}

A partir das características dos trabalhos realizados até o momento sobre otimização de sistemas de distribuição de água, compilados na Tabela 2.1, são apresentadas as justificativas das escolhas contidas nesta tese.

Dentro do modelo experimental, verifica-se que a quase totalidade das técnicas tenta reproduzir, mesmo que macroscopicamente, um sistema de distribuição real e em todos há a presença de pelo menos uma bomba e de um tanque de armazenamento. Assim, também pretende-se desenvolver modelos experimentais que simulem características de sistemas de distribuição reais, com a presença de tanques de armazenamento, bombas (tanto aquelas acionadas diretamente, como aquelas acionadas por meio de inversores de 
frequência) e válvulas.

Com relação ao modelo hidráulico, grande parte das técnicas utiliza simuladores hidráulicos e a maioria delas utiliza o software EPANET. A utilização de simuladores hidráulicos é justificada devido à possibilidade de simulações com grande fidelidade, em diferentes cenários, em condições dinâmicas, principalmente com relação à demanda de água, além de ser de fácil utilização e amplamente difundido entre as companhias de saneamento. Assim, neste trabalho também será utilizado o simulador hidráulico EPANET.

O cerne das técnicas de otimização está relacionada ao algoritmo utilizado. As abordagens clássicas, como programação linear (PASHA; LANSEY, 2009), programação não linear (SKWORCOW et al., 2009; YANG; BøRSTING, 2010), programação mista (FIRMINO et al., 2006; WANG; BRDYS, 2006) ou programação dinâmica (ULANICKI; KAHLER; SEE, 2007; ZHUAN; ZHANG; GUO, 2011) não são recomendadas para redes de distribuição complexas, com muitas variáveis e restrições (HAIMES, 1977).

Já as técnicas com metaheurísticas, nas quais a informação do ambiente é incompleta e os recursos computacionais são limitados, por exemplo, colônia de formigas (LÓPEZIBÁÑEZ; PRASAD; PAECHTER, 2008), simulated annealing (SHIHU et al., 2010), e, em especial, algoritmos genéticos (LÓPEZ-IBÁÑEZ, 2009; WANG; CHANG; CHEN, 2009; BENE; SELEK; HÖS, 2010; COSTA; CASTRO; RAMOS, 2010; FANG; GAO; YUAN, 2010; SAVIC; BICIK; MORLEY, 2011) são a tendência do momento, entretanto, são de difícil e empírica parametrização, além de não garantirem encontrar o máximo global. No caso das técnicas baseadas em agente (MATURANA et al., 2006; DÖTSCH et al., 2010) são necessários tempos de treinamento proibitivos e que não garantem a robustez do sistema, bem como, soluções ótimas.

Neste cenário, modelos para tomada de decisões sequenciais, como os Processos Decisórios de Markov - MDP, podem lidar com estes problemas e também promover as seguintes vantagens em relação às outras técnicas (WHITE, 1993): convergência - garante a convergência em um número finito de iterações; planejamento - gera políticas de controle para a tomada de decisões sequenciais; e máximo global - garantia de obter a máxima soma das recompensas. Desta forma, esta tese adota a modelagem do problema por MDP e programação dinâmica para solucioná-lo.

Como observado na Tabela 2.1, quase a totalidade das técnicas utiliza como objetivo da otimização as despesas com energia elétricas nas redes de distribuição de água. Este fato é explicado devido a energia elétrica ser a segunda maior despesa das companhias de saneamento, atrás somente das despesas com mão de obra. Assim, esta tese também 
utilizou como objetivo da otimização as despesas com energia elétrica.

Finalmente sobre a representação das ações, nesta tese utilizou-se a formulação implícita, dado que a política de um MDP mapeia o conjunto de estados no conjunto de ações, fazendo com que as respostas sejam mais robustas, dado que estão condicionadas às variáveis de estado.

Desta forma, nesta tese utilizou-se o modelo experimental emulando as características de um sistema de distribuição real, com modelo hidráulico empregando o simulador EPANET, com problema de minimização de gastos com energia elétrica modelado por MDP e solucionado por programação dinâmica, e com representação implícita das ações. 


\section{Sistemas de Distribuição de Água}

Este capítulo apresenta a anatomia dos sistemas de distribuição de água, para os quais são descritos os seus principais componentes e suas características. Além disso, também são apresentadas a sua representação topológica, o modelo hidráulico, a parametrização da simulação e o equacionamento de sistemas fluídicos.

\subsection{Introdução}

Os sistemas de distribuição de água, em uma visão macroscópica, podem ser considerados como os responsáveis pelo transporte de água, desde os reservatórios de captação de água bruta até os consumidores finais, conforme apresenta o modelo da Figura 3.1.

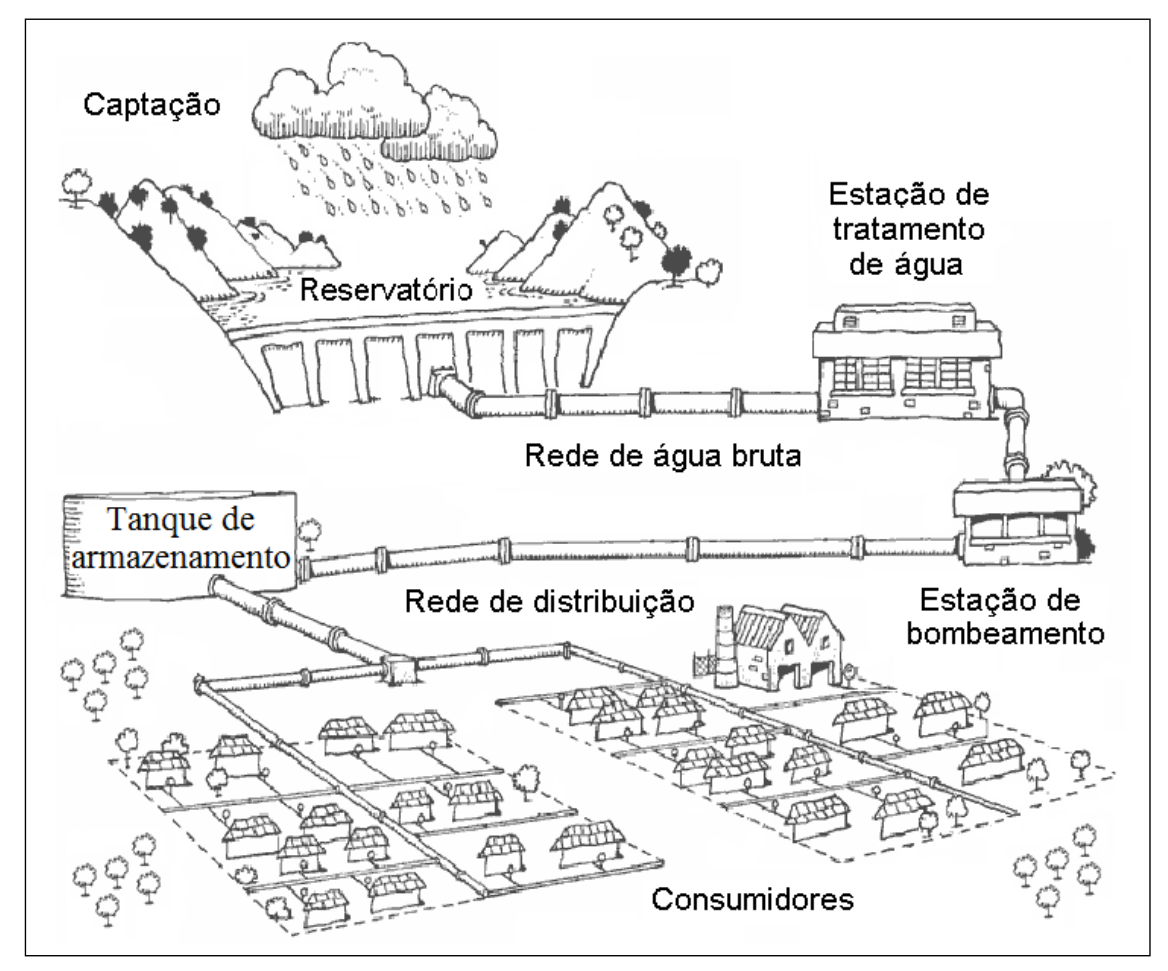

Figura 3.1: Modelo simplificado de um sistema de distribuição de água (adaptado de Queensland Environmental Protection Agency (2002)). 
Neste modelo a água é obtida por meio de chuva, degelo ou captação de rios e armazenada em um reservatório para que o fornecimento seja mantido ininterrupto durante todo o ano. A partir do reservatório, a água bruta é destinada para uma estação de tratamento para que seja purificada e se torne própria para o consumo. A água potável é então transferida, por meio de uma estação de bombeamento, para um tanque de armazenamento e por fim disponibilizada aos consumidores finais. Já sob a ótica operacional, um sistema de distribuição de água é função de duas variáveis fortemente correlacionadas: vazão - $Q$ e pressão $-P$.

A vazão é determinada pela utilização de água pelos consumidores conectados à rede de distribuição, também conhecido como demanda de água. Já a pressão, vista como a energia agregada ao fluido (IDELCHIK, 2005), possibilita que sejam vencidas as perdas inerentes do sistema de distribuição, seja por perdas de energia cinética (atrito do fluido com as paredes da tubulação) ou por perdas de energia potencial (alteração da cota de elevação de um ponto a outro). Desta forma, se a pressão num determinado ponto do sistema de distribuição não for suficiente para vencer estas perdas, não haverá vazão para suprir a demanda correspondente.

Uma forma simples de se obter pressão suficiente numa determinada localidade é por meio da gravidade, isto é, possuindo suprimentos de água elevados em relação aos locais que se deseja abastecer com uma determinada vazão. Elementos hidráulicos que possuem esta capacidade são os tanques de armazenamento.

Nos sistemas de distribuição de água, os tanques de armazenamento, vistos como fontes de água com altura variável e capacidade limitada de suprimento, são utilizados para manter a pressão de rede constante. Desta forma, há adutoras que alimentam estes tanques e que posteriormente distribuem para os consumidores de uma determinada área. Nos sistemas nos quais há tanques de armazenamento, a água pode ser acumulada em horários nos quais o custo da energia elétrica é mais baixo para posteriormente ser distribuída por gravidade. Já nos horários com custo de energia elétrica mais elevado, tenta-se minimizar a utilização da energia elétrica, trabalhando-se com o previsional de demanda e nível do reservatório para evitar a falta de água.

Por outro lado, os reservatórios, vistos como fontes de água com cota de elevação fixa e capacidade ilimitada, na maioria das vezes estão em cotas inferiores aos pontos de demanda de água no sistema de distribuição, dado que são oriundos de rios, lagos ou represas, o que impossibilita a sua utilização para vencer as perdas de energia potencial na rede, além de não possuirem água tratada e sim bruta. Desta forma, entram em cena 
as estações de bombeamento.

As estações de bombeamento, compostas por uma ou mais bombas, injetam energia cinética no fluido e possibilitam tanto a elevação da água de locais com cotas mais baixas para outros com cotas mais elevadas, visando o armazenamento em tanques, como também possibilitam o aumento da pressão de rede no sistema de distribuição.

A seguir, complementar aos diagramas das Figuras 1.3 e 1.4, é apresentado o modelo hidráulico, a parametrização da simulação, além do equacionamento matemático utilizado nos simuladores hidráulicos.

\subsection{Modelo Hidráulico}

Segundo Haestad et al. (2003), o modelo hidráulico - $\mathcal{M}$ de um sistema de distribuição de água pode ser feito por meio de um grafo:

$$
\mathcal{M}=\left(N, E, f_{M}\right)
$$

onde $N$ é um conjunto de nós, $E$ é um conjunto de arestas e $f_{M}$ é o mapeamento entre os elementos dos conjuntos de nós e arestas, tal que $f_{M}: N \times N \mapsto E$.

Os elementos hidráulicos de um sistema de distribuição de água que compõem o conjunto de nós são: os reservatórios, que fornecem água bruta à estação de tratamento; os tanques de armazenamento, que mantêm a rede com pressão equalizada e proporcionam fornecimento complementar às bombas durante os horários de pico de consumo; e as junções, que interligam tubulações, bombas ou válvulas, e onde a demanda de água dos consumidores é inserida na rede de distribuição. Sendo assim, a representação do conjunto de nós é definida como:

$$
N=\{R, T, J\}
$$

onde $R=\left\{r_{i} \mid 1 \leq i \leq N_{R}\right\}$ é o conjunto dos reservatórios, $T=\left\{t_{i} \mid 1 \leq i \leq N_{T}\right\}$ é o conjunto dos tanques de armazenamento e $J=\left\{j_{i} \mid 1 \leq i \leq N_{J}\right\}$ é o conjunto das junções.

Por sua vez, os elementos hidráulicos do conjunto das arestas são: as tubulações, que transportam a água entre dois pontos; as bombas, que bombeiam a água na rede de distribuição; e as válvulas, que permitem bloquear o fluxo de água, além de modular o binômio pressão/vazão nos casos de válvulas de controle. Desta forma, a representação do conjunto das arestas é:

$$
E=\{U, V, L\}
$$


onde $U=\left\{u_{i} \mid 1 \leq i \leq N_{U}\right\}$ é o conjunto das bombas, $V=\left\{v_{i} \mid 1 \leq i \leq N_{V}\right\}$ é o conjunto das válvulas e $L=\left\{l_{i} \mid 1 \leq i \leq N_{L}\right\}$ é o conjunto das tubulações.

Um exemplo simplificado de um sistema de distribuição de água é apresentado na Figura 3.2. Este sistema é composto por um reservatório $\left(r_{1}\right)$, dois tanques de armazenamento $\left(t_{1}\right.$ e $\left.t_{2}\right)$, sete junções $\left(j_{1}, \ldots, j_{7}\right)$, duas bombas $\left(u_{1}\right.$ e $\left.u_{2}\right)$, uma válvula de bloqueio $\left(v_{1}\right)$ e sete tubos $\left(l_{1}, \ldots, l_{7}\right)$. Portanto, o modelo hidráulico desta figura será descrito por $\mathcal{M}_{\text {exemplo }}=\left(N, E, f_{M}\right)$, onde $N=\left\{r_{1}, t_{1}, t_{2}, j_{1}, \ldots, j_{7}\right\}, E=\left\{u_{1}, u_{2}, v_{1}, l_{1}, \ldots, l_{7}\right\} \mathrm{e}$ $f_{M}=\left\{\left(r_{1}, j_{1}, l_{1}\right),\left(j_{1}, j_{2}, u_{1}\right),\left(j_{2}, t_{1}, l_{2}\right),\left(t_{1}, j_{3}, l_{3}\right),\left(j_{1}, j_{4}, u_{2}\right),\left(j_{4}, j_{5}, l_{4}\right),\left(j_{5}, j_{6}, l_{5}\right),\left(j_{3}, j_{6}, v_{1}\right)\right.$, $\left.,\left(j_{6}, t_{2}, l_{6}\right),\left(t_{2}, j_{7}, l_{7}\right)\right\}$.

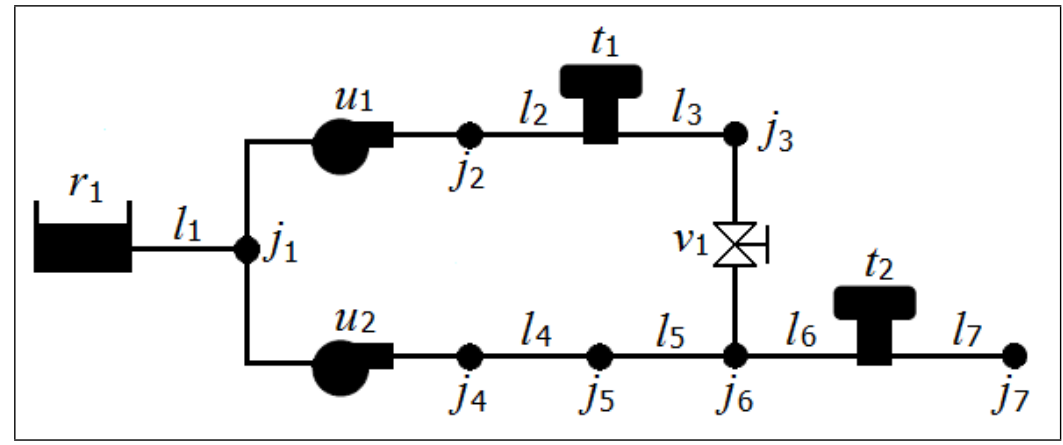

Figura 3.2: Representação esquemática de um sistema de distribuição de água.

Finalmente, para a completa caracterização do modelo hidráulico de um sistema de distribuição de água, as propriedades específicas de todos os elementos que compõem os conjuntos de nós e de arestas devem ser descritas. A seguir são apresentadas estas propriedades:

- Reservatório $\left(r_{i} \in R\right)$ : cota de elevação da lâmina de água - $Z\left(r_{i}\right)$;

- Tanque de armazenamento $\left(t_{i} \in T\right)$ : cota de elevação da base do tanque $-Z\left(t_{i}\right)$, nível mínimo $-H_{\min }\left(t_{i}\right)$, nível máximo $-H_{\max }\left(t_{i}\right)$ e curva de volume $-f_{V}\left(t_{i},\{V o l, H\}\right)$;

- Junção $\left(j_{i} \in J\right)$ : cota de elevação - $Z\left(j_{i}\right)$ e demanda base - $D B\left(j_{i}\right)$;

- Bomba $\left(u_{i} \in U\right)$ : condição de operação - $K\left(u_{i}\right)$, curva característica - $f_{C}\left(u_{i},\{P, Q\}\right)$ e curva de rendimento $-f_{R}\left(u_{i},\{\eta, Q\}\right)$;

- Válvula $\left(v_{i} \in V\right)$ : condição de operação $-K\left(v_{i}\right)$ e coeficiente de vazão $-C_{V}\left(v_{i}\right)$; e

- Tubulação $\left(l_{i} \in L\right)$ : diâmetro - $D\left(l_{i}\right)$, comprimento - $W\left(l_{i}\right)$ e rugosidade $-R a\left(l_{i}\right)$. 


\subsection{Parametrização da Simulação}

Adicionalmente ao modelo hidráulico, os simuladores também necessitam que algumas características sejam parametrizadas para a simulação do sistema de distribuição, são elas:

- Demanda de água: padrão horário da demanda de uma estação - $f_{D}(d s, d h)$ e multiplicador da estação $-f_{S}(d s)$, onde $d s=\{$ primavera, verão, outono, inverno $\}$ e $d h=\{0,1,2, \ldots, 21,22,23\}$

- Características temporais do problema: passo de tempo - $\Delta t$ (tipicamente $1 \mathrm{~h}$ ), instante de tempo inicial $-T_{\min }$ e instante de tempo final $-T_{\max }$;

- Custo da energia elétrica ${ }^{1}$ : preço da energia no horário de ponta $-P_{O P}$, preço da energia no horário fora-de-ponta $-P_{F P}$ e preço da demanda - $P_{D M}$;

- Características da água na temperatura de operação: massa específica - $\rho$, viscosidade dinâmica $-\mu$ e viscosidade cinemática $-\nu$; e

- Algoritmo de cálculo: erro de truncamento do simulador hidráulico - $\varepsilon$.

A seguir, a demanda de água, o item mais importante para a parametrização da simulação de um sistema de distribuição, é apresentada em detalhes.

\section{Demanda de Água}

A demanda de água apresenta valores variáveis durante o dia e diferentes padrões de consumo, dependendo do segmento que a utiliza, conforme Figura 3.3.
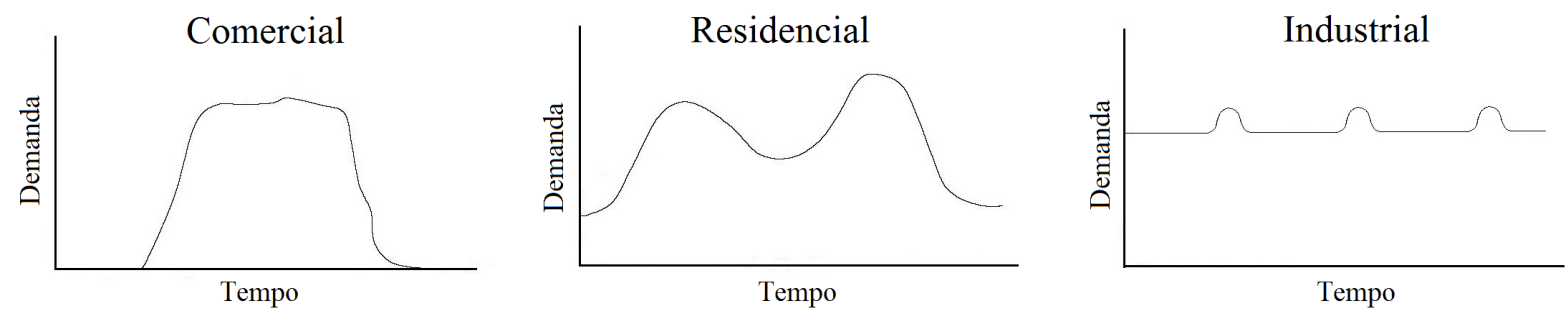

Figura 3.3: Demanda típica de água nos segmentos comercial, residencial e industrial (adaptado de Haestad et al. (2003)).

O segmento comercial apresenta consumo apenas nos horários comerciais, tipicamente entre 08:00 e 17:00; o segmento residencial apresenta dois picos de consumo, um no início

\footnotetext{
${ }^{1}$ Considerando a modalidade tarifária verde, conforme Resolução ANEEL 456 de 29/11/2000.
} 
da manhã e outro no início da noite; além disso, durante as madrugadas há um pequeno consumo relacionado ao enchimento de caixas de águas e à utilização de banheiros; e o segmento industrial possui consumo praticamente constante durante o dia, tendo apenas pequenos picos durante as trocas de turno.

O valor da demanda base de um determinado nó $j_{i}$, visto como a média anual da vazão neste nó, é calculado a partir de dados históricos da vazão durante o período ininterrupto de 12 meses (HAESTAD et al., 2003), resultando em:

$$
D B\left(j_{i}\right)=\frac{1}{N_{D y}} \sum_{d=D y_{i}}^{D y_{f}} Q\left(d, j_{i}\right)
$$

onde $Q\left(d, j_{i}\right)$ é a vazão de água no instante de tempo $d$ no nó $j_{i}, D y_{i}$ e $D y_{f}$ são os instantes de início e fim do período de 12 meses, respectivamente, $N_{D y}=\frac{D y_{f}-D y_{i}}{\Delta d}$ é o número de dados históricos no período de um ano e $\Delta d$ é o passo de tempo.

O multiplicador da estação, visto como um ponderador da vazão média anual de toda a rede de distribuição, é calculado a partir da seguinte equação:

$$
f_{S}(d s)=\frac{1}{N_{J}} \sum_{i=1}^{N_{J}} \frac{1}{D B\left(j_{i}\right)}\left(\frac{1}{N_{D s}} \sum_{d=D s_{i}}^{D s_{f}} Q\left(d \equiv d s \quad \bmod N_{D s}, j_{i}\right)\right)
$$

onde $D s_{i}$ e $D s_{f}$ são as datas de início e fim da estação, respectivamente, $N_{D s}=\frac{D s_{f}-D s_{i}}{\Delta d}$ é o número de dados no período da estação e $N_{J}$ é o número de nós da rede.

Já o padrão horário da demanda de uma estação, ou simplesmente curva da demanda, é calculado para cada uma das 24 horas do dia segundo a seguinte equação:

$$
f_{D}(d h)=\frac{1}{N_{J} \cdot N_{D s}} \sum_{i=1}^{N_{J}} \sum_{d=D h_{i}}^{D h_{f}} Q\left(d \equiv d h \quad \bmod N_{D h}, j_{i}\right) .
$$

onde $D h_{i}$ e $D h_{f}$ são os horários de início e fim do dia e $N_{D h}=24$.

Assim, quando é observado o comportamento do consumo de água em um sistema de distribuição de água a Equação 3.6 produz quatro curvas, uma para cada estação do ano, durante o período de 24 horas, conforme pode ser observado no exemplo da Figura 3.4.

Finalmente, a demanda de água num determinado nó $j_{i}$ é função da estação do ano $d s$ e do horário $d h$ e calculada por meio da seguinte equação:

$$
D\left(j_{i}, d s, d h\right)=D B\left(j_{i}\right) \cdot f_{S}(d s) \cdot f_{D}(d h)
$$




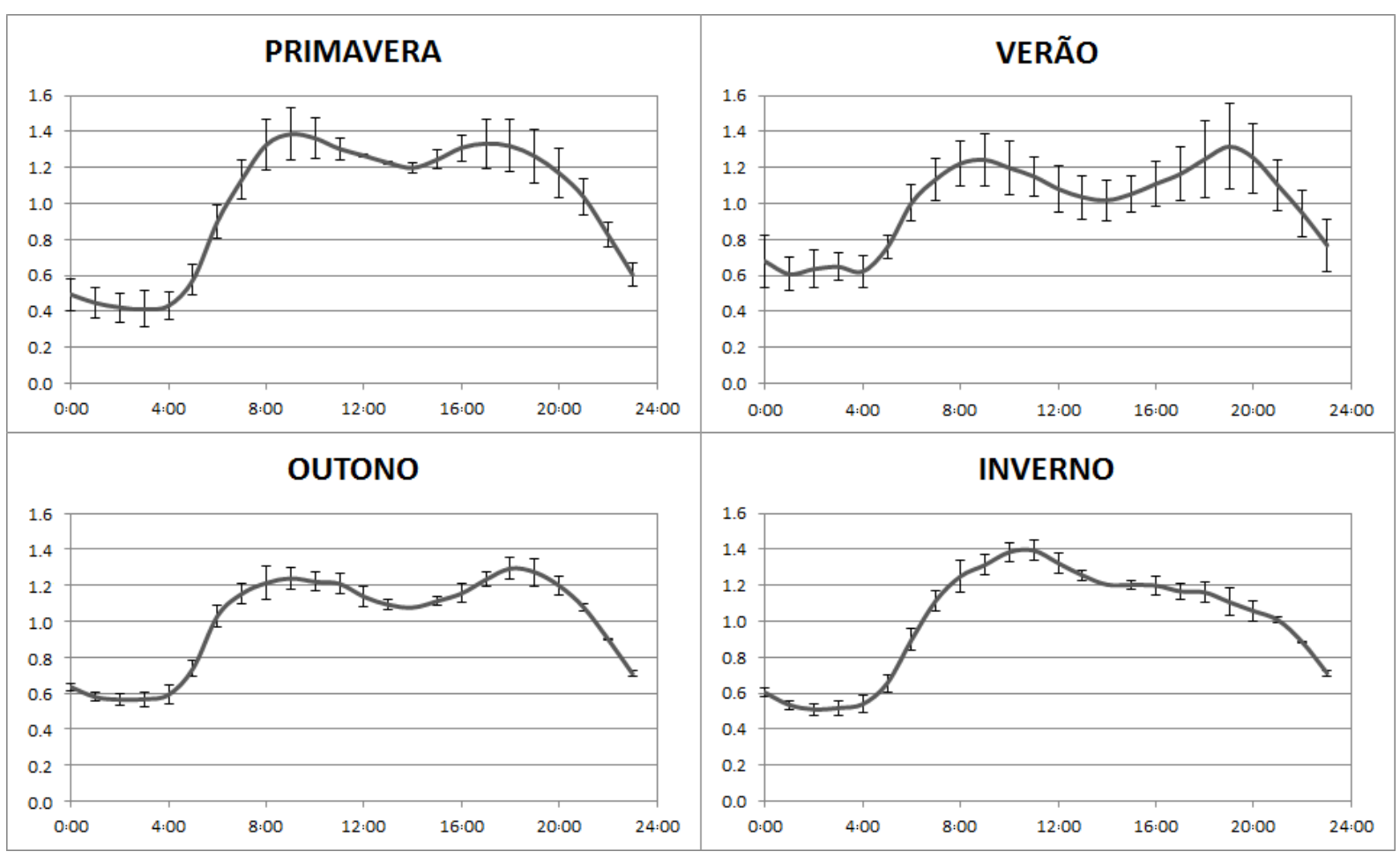

Figura 3.4: Exemplo de padrão horário da demanda nas quatro estações do ano calculados a partir de dados históricos..

A próxima seção apresenta o equacionamento de sistemas fluídicos que possibilitam a determinação do ponto de operação de pressão e vazão a partir das características dos elementos hidráulicos que compõem o sistema de distribuição de água.

\subsection{Equacionamento Matemático}

Em sistemas fluídicos, o equacionamento da perda de carga $\Delta P$ nos permite descrever a redução do valor da pressão de um escoamento entre dois nós distintos de uma rede. Ela pode ser interpretada como as quantidades perdidas de energia cinética, por fricção das moléculas nas paredes de uma tubulação, e/ou de energia potencial, devido à alteração na elevação entre dois pontos (IDELCHIK, 2005).

O valor da perda de carga em uma tubulação $l$ de seção uniforme, a partir do nó $j_{A}$ até o nó $j_{B}$, é calculado por meio da equação de Bernoulli:

$$
\Delta P(l)=P\left(j_{B}\right)-P\left(j_{A}\right)=-\rho \cdot g \cdot\left(Z\left(j_{B}\right)-Z\left(j_{A}\right)+\frac{f \cdot W(l) \cdot v(l)^{2}}{2 \cdot D(l) \cdot g}\right),
$$

onde $P\left(j_{A}\right)$ e $P\left(j_{B}\right)$ são as pressões absolutas (pressão manométrica acrescida da pressão atmosférica) nos nós $j_{A}$ e $j_{B}, Z\left(j_{A}\right)$ e $Z\left(j_{B}\right)$ são as cotas dos nós $j_{A}$ e $j_{B}, \rho$ é a massa 
específica do fluido, $g$ é a aceleração da gravidade local, $f$ é o fator de atrito, $W(l)$ é o comprimento do tubo $l, v(l)$ é a velocidade média do escoamento e $D(l)$ é o diâmetro do tubo $l$.

O número de Reynolds é um adimensional que permite avaliar a relação entre as forças de inércia e de viscosidade, e calculado pela seguinte equação:

$$
R e=\frac{\rho \cdot v(l) \cdot D(l)}{\mu}=\frac{v(l) \cdot D(l)}{\nu},
$$

onde $\mu$ e $\nu$ são as viscosidades dinâmica e cinemática do fluido, respectivamente.

No caso de escoamentos laminares, quando o número de Reynolds é inferior a 3500 , o fator de atrito será:

$$
f=\frac{64}{R e} .
$$

No caso de escoamentos turbulentos, quando o número de Reynolds é superior a 3500 , temos que o fator de atrito será:

$$
\frac{1}{\sqrt{f}}=-2 \cdot \log \left(\frac{R a(l) / D(l)}{3,7}+\frac{2,51}{R e \cdot \sqrt{f}}\right)
$$

onde $R a(l)$ é a rugosidade do tubo $l$ e $R e$ é o número de Reynolds do escoamento.

Já a perda de carga de uma válvula $v$ é calculada da seguinte forma:

$$
\Delta P(v)=P\left(j_{B}\right)-P\left(j_{A}\right)=\left(\frac{Q(v)}{C_{V}(v)}\right)^{2} \cdot \rho,
$$

onde $Q(v)$ é a vazão e $C_{V}(v)$ é o coeficiente de vazão da válvula $v$.

No caso de outras singularidades, como por exemplo expansões, reduções, curvas ou conexões em T, é utilizada a mesma equação anterior, somente adequando o valor do coeficiente de vazão. A Tabela 3.1 apresenta os valores típicos do coeficiente de vazão, determinados experimentalmente, para as singularidades mais comuns.

Nas bombas, pressão e vazão também são correlacionadas e representadas por meio de uma curva, também conhecida como curva característica da bomba - $f_{C}$, conforme mostrado na Figura 3.5. Nesta figura, além da relação entre pressão e vazão quando a bomba opera em plena capacidade (curva na cor vermelha com legenda 100\% rpm), também são apresentadas as curvas para diferentes velocidades de rotação do motor (demais curvas na cor vermelha).

Evidentemente que a energia elétrica utilizada para movimentar o motor acoplado a uma bomba não será totalmente transferida ao fluido, seja pelas perdas mecânicas 
Tabela 3.1: Coeficientes de vazão típicos (IDELCHIK, 2005).

\begin{tabular}{cc}
\hline Singularidade & Coeficiente de vazão \\
\hline Válvula gaveta (aberta) & 0,39 \\
Válvula gaveta (50\%) & 4,8 \\
Expansão cônica (50\%) & 0,08 \\
Redução cônica (50\%) & 0,07 \\
Curva 90 (raio longo) & $0,16-0,18$ \\
Curva 90 (raio curto) & $0,35-0,40$ \\
Conexão em T (linear) & $0,30-0,40$ \\
Conexão em T (inclinado) & $0,75-1,80$ \\
\hline
\end{tabular}

(acoplamento entre motor e bomba) ou pelas perdas elétricas (dissipadas na forma de energia térmica do motor). Desta forma a Figura 3.5 também apresenta a curva de rendimento da bomba - $f_{R}$ em função do seu ponto de operação (curvas na cor preta). O ponto onde o rendimento é máximo é conhecido como BEP (best efficiency point) e os valores típicos estão na faixa entre 60 a $85 \%$ de eficiência (HAESTAD et al., 2003).

Já a curva do sistema, que descreve a relação de dependência entre pressão e vazão em um determinado sistema fluídico, será o somatório das perdas de cargas isoladas em todas as tubulações e singularidades do sistema.

A Figura 3.6 apresenta dois exemplos de curva do sistema para condições hipotéticas: com uma válvula totalmente aberta (curva na cor vermelha) e com válvula parcialmente fechada (curva na cor azul). A diferença entre estas duas curvas está na introdução de mais perda de carga pelo fechamento parcial da válvula, até o limite para o qual não haveria mais vazão e a perda de carga máxima.

Por fim, o ponto de operação de um sistema fluídico, determinação inequívoca da pressão e da vazão num determinado instante, pode ser obtido graficamente por meio do cruzamento entre as curvas do sistema e da bomba (GARCIA, 2005), por exemplo representado pelos pontos A e B da Figura 3.6.

Já em modelos complexos, como é o caso de sistemas de distribuição de água, o ponto de operação é obtido computacionalmente por meio de softwares de simulação hidráulica. Nestes softwares os valores da pressão e da vazão são determinados iterativamente, em um processo de busca por meio de minimização do erro (EPA, 2000). Desta forma, neste trabalho a determinação dos pontos de operação nas diversas situações simuladas serão realizadas por meio de um software de simulação hidráulica. 


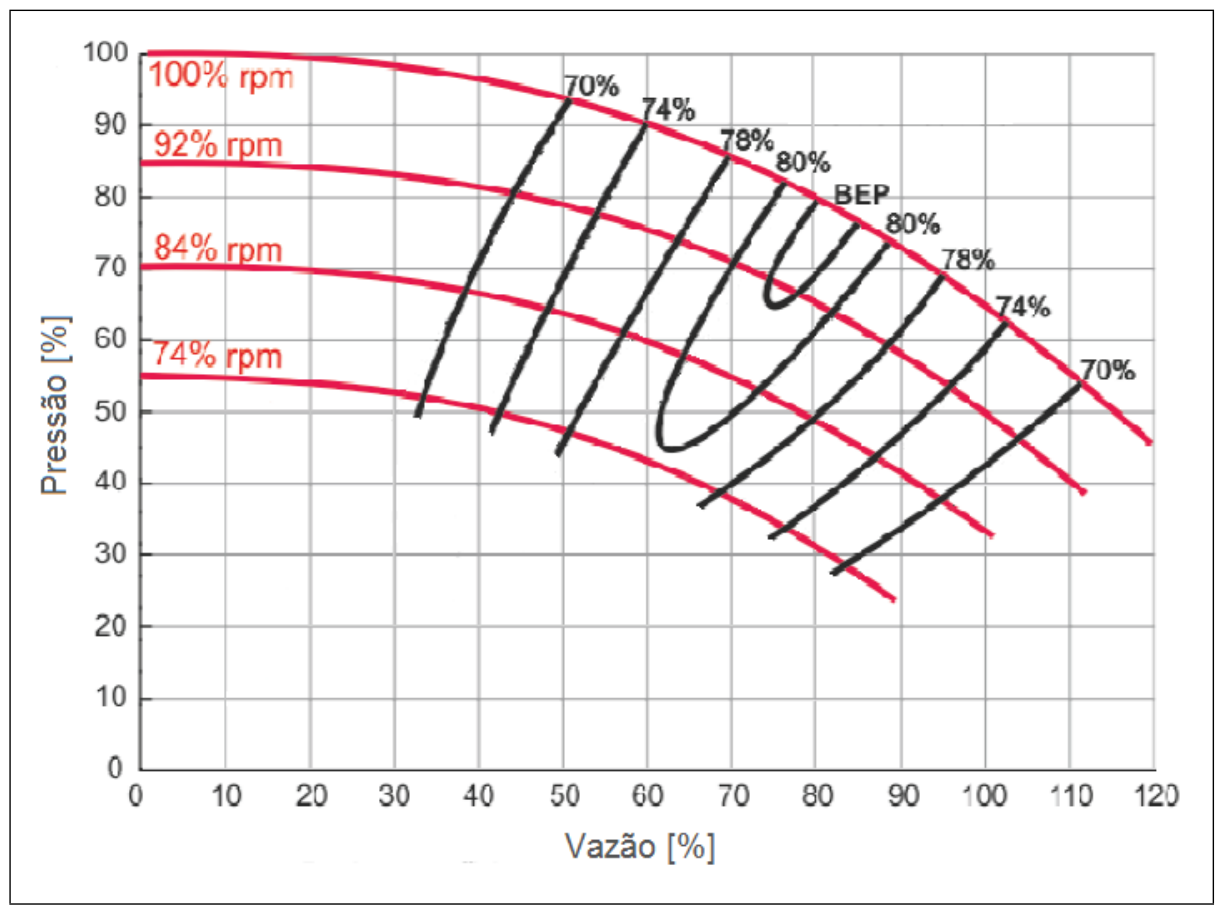

Figura 3.5: Curva característica de uma bomba (adaptado de Sirový et al. (2010)).

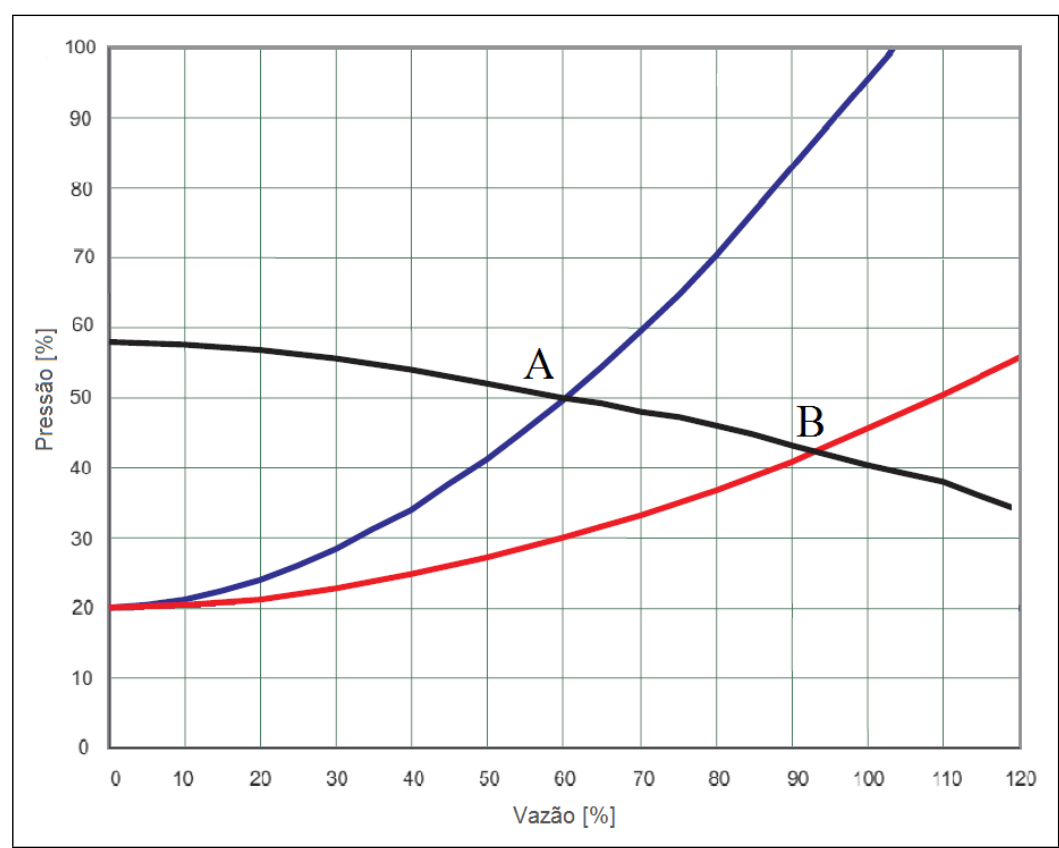

Figura 3.6: Curva do sistema e ponto de operação (adaptado de PROCEL (2005)). 


\subsection{Discussões Finais}

Este capítulo apresentou o modelo hidráulico de um sistema de distribuição de água, a parametrização da simulação e o equacionamento matemático utilizado nos simuladores hidráulicos. Estes conceitos são complementares às informações contidas na seção Processo de controle nos sistemas de distribuição de água do Capítulo 1, mais especificamente os diagramas contidos nas Figuras 1.3 e 1.4.

A utilização de simuladores hidráulicos, aplicados para emular os sistemas de distribuição real, implica na descrição do modelo hidráulico do sistema, além da parametrização da simulação. Assim, o simulador hidráulico possui as seguintes características:

- Entradas: ações oriunda do controlador - a, aquilo que, ao ser variado, proporciona uma mudança de estado;

- Saídas: estimativa do próximo estado do sistema - $\widehat{s}$, podendo ser a pressão em um determinado nó $n \in N$ e/ou a vazão em uma determinada aresta $e \in E$ do modelo hidráulico $\mathcal{M}$, e a estimativa do valor da recompensa - $\widehat{r}$, sendo o gasto com energia no período compreendido entre $T_{\min }$ e $T_{\text {max }}$; e

- Requisitos: modelo hidráulico - $\mathcal{M}$ e parametrização da simulação.

No próximo capítulo, Modelagem por MDP de Sistemas de Distribuição de Água, é apresentada a modelagem do problema de minimização de gastos com energia elétrica em sistemas de distribuição de água por MDP, na qual a transição de estado calculada, pelo simulador hidráulico, está associada a uma incerteza. 


\section{Modelagem por MDP de Sistemas de Distribuição de Água}

Este capítulo apresenta os Processos Decisórios de Markov por meio da sua formalização matemática, limitado a conjuntos finitos de estados e ações, horizonte de tempo finito e políticas determinísticas. Ademais, este capítulo também descreve a modelagem proposta por esta tese do problema de minimização dos gastos com energia elétrica nos sistemas de distribuição de água por meio dos Processos Decisórios de Markov.

\subsection{Introdução}

Os Processos Decisórios de Markov, também conhecidos como MDP (Markov Decision Processes), são uma poderosa ferramenta matemática para modelagem de problemas de tomada de decisão nos quais os resultados são incertos (PUTERMAN, 1994). Atualmente são utilizados para resolver uma enorme variedade de problemas de otimização e nos mais diversos campos, como economia, biologia e robótica.

Ele funciona por meio de um processo sequencial de escolha de ações em épocas de decisão que alteram o estado da próxima época de decisão por meio de uma distribuição de probabilidade, além de incorrer recompensas ou punições para um controlador, quem executa as ações (HOWARD, 1960). Assim, o objetivo do controlador é identificar, para cada estado, a ação que maximiza o valor esperado das recompensas.

Desta forma, a escolha da modelagem por MDP do problema de minimização de gastos com energia elétrica em sistemas de distribuição de água está fundamentada em três importantes características e que não são apresentadas pelas técnicas de otimização descritas no Capítulo 2: 1) garante a convergência em um número finito de iterações; 2) gera políticas de controle para a tomada de decisões sequenciais; e 3) garante a maximização da soma esperada das recompensas. 


\subsection{Formalização do MDP}

Formalmente um MDP com horizonte de tempo finito, ou simplesmente MDP finito, pode ser definido pela tupla $\langle\mathcal{S}, \mathcal{A}, \mathcal{D}, \mathcal{T}, \mathcal{R}\rangle$ onde $\mathcal{S}$ é um conjunto finito de estados, $\mathcal{A}$ é um conjunto finito de ações, $\mathcal{D}$ é uma sequência finita de épocas de decisão, $\mathcal{T}$ é uma função de transição de estado e $\mathcal{R}$ é uma função de recompensa.

A seguir cada um dos componentes desta tupla, bem como os outros elementos necessários para a modelagem e resolução de um problema modelado por um MDP, são apresentados.

\subsubsection{Estados}

Os estados são a caracterização única de tudo que é importante para o controlador na modelagem do problema e tomada de decisões (SUTTON; BARTO, 1998). Os estados podem ser definidos por meio da representação atômica, resultando em:

$$
\mathcal{S}=\left\{\sigma_{1}, \sigma_{2}, \ldots, \sigma_{N_{S}}\right\}
$$

onde $|\mathcal{S}|=N_{S}$ é o número total de estados do problema.

Apesar de funcional, a representação atômica possui dois inconvenientes: i) o conjunto de estados de um determinado problema que se deseja modelar pode ser extremamente complexo e enumerá-los é impraticável; ii) a descrição atômica não traz informações estruturadas, impossibilitando tomar proveito das relações de independência entre as variáveis de estado para se otimizar o tempo de resolução do problema.

Para evitar tais problemas os estados também podem ser descritos por meio da representação fatorada, onde os estados são compostos pelo conjunto $\mathcal{X}$ de variáveis de estado, aquelas que melhor descrevem o problema a ser modelado:

$$
\mathcal{X}=\left\{\mathcal{X}_{1}, \mathcal{X}_{2}, \ldots, \mathcal{X}_{N_{\mathcal{X}}}\right\}
$$

onde $N_{\mathcal{X}}$ é o número de variáveis de estados que descrevem o problema.

Assim, na representação fatorada o conjunto finito de estados é definido pelo produto Cartesiano das $N_{V}$ variáveis de estados e que resulta em:

$$
\mathcal{S}=\operatorname{dom}\left(\mathcal{X}_{1}\right) \times \operatorname{dom}\left(\mathcal{X}_{2}\right) \times \cdots \times \operatorname{dom}\left(\mathcal{X}_{N_{V}}\right),
$$

sendo $\operatorname{dom}(\mathcal{X})$ igual ao domínio da variável $\mathcal{X}$. 


\subsubsection{Ações}

As ações permitem ao controlador mudar de um estado $\sigma$ na época de decisão $d$ para um estado $\sigma^{\prime}$ na época de decisão $d+1$, onde $\sigma$ e $\sigma^{\prime} \in \mathcal{S}$. O conjunto de ações $\mathcal{A}$ é definido como a união de todas as possíveis ações em cada estado:

$$
\mathcal{A}=\bigcup_{\sigma \in S} \mathcal{A}_{\sigma}
$$

onde $\mathcal{A}_{\sigma}$ é um sub-conjunto de ações permitidas no estado $\sigma$.

\subsection{3 Épocas de Decisão}

As épocas de decisão são os instantes onde as ações são tomadas. Em problemas com horizonte de tempo finito, o conjunto $\mathcal{D}$ é definido como a sequência finita de números naturais:

$$
\mathcal{D}=\left\{1,2,3, \ldots, D_{\max }\right\}
$$

onde $|\mathcal{D}|=D_{\max }$ é o horizonte de tempo, i.e., onde um MDP finito termina.

\subsubsection{Função de Transição de Estado}

Quando a ação $\alpha$ é executada no estado $\sigma$ e na época de decisão $d$ o estado do sistema evolui para o novo estado $\sigma^{\prime}$ na época de decisão $d+1$ baseado em uma função distribuição de probabilidade discreta $\mathcal{T}$ sobre todos os possíveis estados pertencentes ao conjunto $\mathcal{S}$ e definido como:

$$
\mathcal{T}\left(\sigma, \alpha, \sigma^{\prime}, d\right)=P\left(s_{d+1}=\sigma^{\prime} \mid s_{d}=\sigma, a_{d}=\alpha\right)
$$

onde $\mathcal{T}: \mathcal{S} \times \mathcal{A} \times \mathcal{S} \times \mathcal{D} \mapsto[0,1]$ e $P$ é uma função de distribuição de probabilidade discreta.

Para que a função de transição de estado $\mathcal{T}$ seja considerada uma distribuição de probabilidade válida, ela deve possuir as seguintes propriedades:

$$
\begin{gathered}
\mathcal{T}\left(\sigma, \alpha, \sigma^{\prime}, d\right) \geq 0, \text { para todo } \sigma^{\prime} \in \mathcal{S} \text { e } \\
\sum_{\sigma^{\prime} \in \mathcal{S}} \mathcal{T}\left(\sigma, \alpha, \sigma^{\prime}, d\right)=1 .
\end{gathered}
$$




\subsubsection{Função de Recompensa}

A função de recompensa $\mathcal{R}$ especifica o valor recebido pelo controlador por executar a ação $\alpha$, no estado $\sigma$ e na época de decisão $d$. Esta função é definida como:

$$
\mathcal{R}(\sigma, \alpha, d)=\left\{r_{d} \in \mathbb{R} \mid s_{d}=\sigma, a_{d}=\alpha\right\}
$$

onde $\mathcal{R}: \mathcal{S} \times \mathcal{A} \times \mathcal{D} \mapsto \mathbb{R}$ é computada na época de decisão $d$.

Assim, o objetivo de um MDP é maximizar o valor das recompensas esperadas pelo controlador.

\subsection{Modelagem proposta}

Um sistema de distribuição de água com foco na minimização de gastos com energia elétrica em um horizonte de tempo finito pode ser modelado como um MDP por meio da tupla $\langle\mathcal{S}, \mathcal{A}, \mathcal{D}, \mathcal{T}, \mathcal{R}\rangle$ onde $\mathcal{S}$ é um conjunto finito de estados, $\mathcal{A}$ é um conjunto finito de ações, $\mathcal{D}$ é uma sequência finita de épocas de decisão, $\mathcal{T}$ é uma função de transição de estado e $\mathcal{R}$ é uma função de recompensa. A seguir, cada um dos elementos desta tupla será discutido isoladamente.

\subsubsection{Estados}

A teoria de controle define que os estados podem ser vistos como as variáveis que determinam completamente o comportamento do sistema em qualquer instante (OGATA, 2002). Desta forma, em sistemas de distribuição de água representados por meio do grafo $\mathcal{M}$ a pressão ${ }^{1}$ em um determinado nó $n \in N$ e a vazão em uma determinada aresta $e \in E$ podem ser consideradas como as variáveis de estado do problema modelado, desde que estas sejam medidas e que também seja possível controlar.

Como estas variáveis de estado são descritas no espaço contínuo, a representação fatorada é muito mais adequada que a representação atômica (MAUSAM; KOLOBOV, 2012). Na literatura são descritas diversas abordagens para realizar a discretização de espaços contínuos (FENG; HANSEN, 2002; SANNER et al., 2011; MUNOS; MOORE, 1998), porém, a escolha de uma determinada técnica deve ser pautada pelo compromisso entre a quantidade de memória disponível e a exatidão da solução (SUTTON; BARTO, 1998). Nesta

\footnotetext{
${ }^{1} \mathrm{O}$ termo pressão aqui descrito refere-se à pressão absoluta que é a soma da pressão atmosférica na cota de elevação e da pressão manométrica do nó.
} 
tese será utilizada a discretização uniforme devido à facilidade no cálculo da incerteza associada, que é descrita por meio de uma distribuição de probabilidade uniforme.

Há, entretanto, uma ressalva com relação aos nós de $\mathcal{M}$ referentes aos reservatórios: neste elemento hidráulico é possível medir a sua pressão, porém, é impossível controlá-la dado que a cota de elevação da lâmina de água é governada pelo regime hidrológico local.

Assim, o conjunto de estados $\mathcal{S}$ pode ser descrito por meio da representação fatorada, onde cada estado é composto pelas variáveis de estado que descrevem o problema, resultando na seguinte representação:

$$
\mathcal{S}=\operatorname{dom}\left(P\left(n_{1}\right)\right) \times \cdots \times \operatorname{dom}\left(P\left(n_{S_{N}}\right)\right) \times \operatorname{dom}\left(Q\left(e_{1}\right)\right) \times \cdots \times \operatorname{dom}\left(Q\left(e_{S_{E}}\right)\right),
$$

onde $P\left(n_{1}\right), \ldots, P\left(n_{S_{N}}\right)$ são as pressões dos $S_{N}$ nós, $Q\left(e_{1}\right), \ldots, Q\left(e_{S_{E}}\right)$ são as vazões das $S_{E}$ arestas, definidas como as variáveis controladas, $n_{1}, \ldots, n_{S_{N}} \in N$ e $e_{1}, \ldots, e_{S_{E}} \in E$.

\subsubsection{Ações}

Analogamente aos estados, a teoria de controle define que as ações são consideradas como as variáveis manipuladas, aquelas nas quais o valor ou a condição é variada de modo que afete o valor das variáveis controladas (OGATA, 2002). Desta forma, em sistemas de distribuição de água os dois únicos elementos hidráulicos que atendem a esta premissa são as bombas e as válvulas.

Por exemplo, se no sistema da Figura 3.2 deseja-se que haja um incremento da variável de estado $P\left(t_{2}\right)$, nível de água ${ }^{2}$ no tanque de armazenamento $t_{2}$, pode-se optar por ativar a bomba $u_{2}$ e fechar a válvula $v_{1}$, i.e., $K\left(u_{2}\right)=1$ e $K\left(v_{1}\right)=0$ respectivamente, ou mesmo, ativar a bomba $u_{1}$ e abrir a válvula $v_{1}$, i.e., $K\left(u_{1}\right)=1$ e $K\left(v_{1}\right)=1$ respectivamente.

O conjunto de ações $\mathcal{A}$ também é descrito por meio da representação fatorada, onde cada ação é composta pelo conjunto das variáveis manipuladas. Desta forma, o conjunto de ações será definido como:

$$
\mathcal{A}=\operatorname{dom}\left(K\left(u_{1}\right)\right) \times \cdots \times \operatorname{dom}\left(K\left(u_{N_{U}}\right)\right) \times \operatorname{dom}\left(K\left(v_{1}\right)\right) \times \cdots \times \operatorname{dom}\left(K\left(v_{N_{V}}\right)\right),
$$

onde $K\left(u_{1}\right), \ldots, K\left(u_{N_{U}}\right)$ são as condições de operação de todas as $N_{U}$ bombas, $K\left(v_{1}\right), \ldots, K\left(v_{N_{V}}\right)$ são as condições de operação de todas as $N_{V}$ válvulas, $u_{1}, \ldots, u_{N_{U}} \in U$ e $v_{1}, \ldots, v_{N_{V}} \in V$.

No caso de bombas acionadas diretamente ou de válvulas de bloqueio, a condição

\footnotetext{
${ }^{2} \mathrm{O}$ nível de água é visto como a pressão atmosférica na cota de elevação mais a pressão da coluna de líquido no tanque de armazenamento.
} 
de operação pertencerá ao conjunto binário $K\left(u_{i}\right)$ ou $K\left(v_{i}\right) \in\{0,1\}$, onde 0 representa bomba desligada ou válvula fechada e 1 representa bomba ligada ou válvula aberta. No caso de bombas acionadas por meio de inversores de frequência ou de válvulas de controle, estas estarão no domínio contínuo $K\left(u_{i}\right)$ ou $K\left(v_{i}\right) \in[0,1]$ e deverão ser discretizas para que o conjunto de ações seja finito.

\subsection{3 Épocas de Decisão}

As épocas de decisão são definidas em função das características temporais do problema. Desta forma, o conjunto $\mathcal{D}$ será a sequência finita:

$$
\mathcal{D}=\left\{1, \Delta t, 2 \cdot \Delta t \ldots, \frac{T_{\max }-T_{\min }}{\Delta t}\right\},
$$

onde $\Delta t$ é o passo de tempo, $T_{\min }$ é o instante de tempo inicial e $T_{\max }$ é o instante de tempo final. Neste caso, o conjunto $\mathcal{D}$ são timestamps ${ }^{3}$ compreendidas no intervalo entre $T_{\min }$ e $T_{\max }$.

\subsubsection{Função de Transição}

A função de transição de estado $\mathcal{T}$ em um sistema de distribuição de água não pode ser explicitamente definida devido às relações de dependência entre as variáveis controladas e manipuladas, além da complexidade do modelo hidráulico do sistema de distribuição de água. Assim, o valor do próximo estado é obtido por meio de um software de simulação hidráulica e calculado por meio da seguinte função:

$$
\sigma^{\prime}=f_{T}(\sigma, \alpha, d)
$$

onde $f_{T}$ é a função que calcula o próximo estado $\sigma^{\prime}$ por meio do software de simulação hidráulica, $\sigma$ é o estado atual, $\alpha$ é a ação executada no estado e $d$ é a época de decisão.

Nesta tese foi utilizado o software de simulação hidráulica EPANET, desenvolvido pela Agência de Proteção Ambiental Norte-Americana (United States Envorinmental Protection Agency - EPA). Esta escolha se deu porque o EPANET é o software de simulação hidráulica mais usado no mundo, com código de programação aberto e, além de simulações hidráulicas, também possibilita a simulação do comportamento da qualidade da água em sistemas de distribuição(EPA, 2000).

\footnotetext{
${ }^{3}$ Sequência de caracteres que informam a data e a hora de um determinado evento no tempo. Por exemplo, dd/mm/aaaa hh:mm:ss
} 
Para a realização dos cálculos da função $f_{T}$, além de $\sigma, \alpha$ e $d$, o software de simulação EPANET também deve possuir o modelo hidráulico do sistema e a parametrização da simulação, conforme definido no Capítulo 3.

Devido a imprecisões do modelo hidráulico, do desconhecimento da demanda futura de água, do truncamento do algoritmo de cálculo do software de simulação hidráulica e da discretização das variáveis de estado, a função de transição de estados $\mathcal{T}$ resulta em uma função probabilística e associada a uma incerteza. Desta forma, a função de transição de estados pode ser descrita por meio de uma distribuição normal $\mathcal{N}$, com média igual ao valor do próximo estado $\sigma^{\prime}$ e com desvio padrão igual ao valor da incerteza da transição de estado $u\left(f_{T}\right)$ :

$$
\mathcal{T} \sim \mathcal{N}\left(\sigma^{\prime}, u\left(f_{T}\right)\right)
$$

A estimativa de incerteza da transição de estado para sistemas de distribuição de água é calculada conforme o descrito no Apêndice A, por meio do método da combinação de variâncias das fontes de incerteza, onde notadamente aquelas com maior contribuição são:

- Modelo hidráulico - $u(\mathcal{M})$ : inerente à reprodução de um sistema real por meio de um modelo computacional;

- Previsão da demanda - $u(D)$ : devido ao desconhecimento do valor futuro da demanda de água;

- Truncamento - $u(T)$ : fruto do truncamento do algoritmo iterativo de cálculo do software de simulação hidráulica; e

- Discretização - $u(\mathcal{X})$ : devido às variáveis de estado serem transformadas do espaço contínuo para o espaço discreto.

Assim, a estimativa de incerteza da transição de estado é calculada por meio da seguinte equação:

$$
u\left(f_{T}\right)=\sqrt{\left(\frac{\partial f_{T}}{\partial \mathcal{M}} \cdot u(\mathcal{M})\right)^{2}+\left(\frac{\partial f_{T}}{\partial D} \cdot u(D)\right)^{2}+\left(\frac{\partial f_{T}}{\partial T} \cdot u(T)\right)^{2}+\left(\frac{\partial f_{T}}{\partial \mathcal{X}} \cdot u(\mathcal{X})\right)^{2}},
$$

onde $\frac{\partial f_{T}}{\partial \mathcal{M}}, \frac{\partial f_{T}}{\partial D}, \frac{\partial f_{T}}{\partial T}$ e $\frac{\partial f_{T}}{\partial \mathcal{X}}$ são os coeficientes de sensibilidade do modelo hidráulico, da previsão da demanda, do truncamento e da discretização das variáveis de estado, respectivamente, calculados no estado $\sigma$, a partir da ação $\alpha$ e no instante $d$; já $u(\mathcal{M}), u(D)$, $u(T)$ e $u(\mathcal{X})$ são as incertezas padrão do modelo hidráulico, da previsão da demanda e do truncamento, respectivamente. 
A seguir cada uma das fontes de incerteza elencadas são descritas, cobrindo a determinação da incerteza padrão e do coeficiente de sensibilidade.

\section{a. Modelo Hidráulico}

Para avaliar a aderência do modelo hidráulico $\mathcal{M}$ com relação ao sistema de distribuição real são realizados testes de medição em campo, nas quais os dados obtidos pelo simulador hidráulico são comparados com os dados medidos no sistema real.

A partir destes dados é calculado o erro relativo de uma determinada medição $i$ resultando em:

$$
e_{\mathcal{M}}(i)=\frac{\mathcal{X}_{R}(i)-\mathcal{X}_{S}(i)}{\mathcal{X}_{R}(i)}
$$

onde $\mathcal{X}_{R}(i)$ é o valor medido no sistema real e $\mathcal{X}_{S}(i)$ é o valor calculado pelo simulador hidráulico, ambos para a mesma variável de estado, mesma unidade e mesmo instante de tempo.

Após a determinação do erro relativo, os dados se tornam adimensionais, fazendo com que os mesmos possam ser combinados entre si, independentemente da variável de estado. Assim, os cálculos do valor médio ${ }^{4} \overline{e_{\mathcal{M}}}$ e do desvio padrão $\sigma\left(e_{\mathcal{M}}\right)$ relativos ao modelo hidráulico, obtidos a partir de $N_{M}$ medições, são:

$$
\begin{gathered}
\overline{e_{\mathcal{M}}}=\frac{1}{N_{M}} \sum_{i=1}^{N_{M}} e_{\mathcal{M}}(i), \\
\sigma\left(e_{\mathcal{M}}\right)=\sqrt{\frac{1}{N_{M}-1} \sum_{i=1}^{N_{M}}\left(e_{\mathcal{M}}(i)-\overline{e_{\mathcal{M}}}\right)^{2}}
\end{gathered}
$$

Finalmente, a incerteza padrão do erro do modelo hidráulico será o desvio padrão da média (ISO, 2008), calculada como:

$$
u(\mathcal{M})=\frac{\sigma\left(e_{\mathcal{M}}\right)}{\sqrt{N_{M}}}
$$

Segundo Takahashi et al. (2010), para que a avaliação de aderência do modelo hidráulico seja considerada consistente com o sistema real, as seguintes recomendações devem ser seguidas para se determinar o número de medições: as medições devem cobrir diferentes variáveis de estado, ou seja, quantidades equivalentes de pressão e de vazão; os pontos selecionados devem cobrir as especificidades da rede de distribuição de água, evitando-se a concentração numa determinada região geográfica; e as medições devem ser feitas em

\footnotetext{
${ }^{4}$ Em Hydraulic Research (1983) são definidos os intervalos que o erro relativo médio pode ter para que o modelo hidráulico seja considerado aceitável.
} 
diferentes instantes de tempo e que possam representar a dinâmica da rede em diferentes condições de operação.

Com relação ao coeficiente de sensibilidade, este pode ser considerado unitário, pois a incerteza do modelo hidráulico possui correlação direta na determinação do próximo estado $\sigma^{\prime}$ e as variáveis medidas são potenciais estados do sistema. Desta forma, o coeficiente de sensibilidade do erro do modelo hidráulico será:

$$
\frac{\partial f_{T}}{\partial \mathcal{M}}=1
$$

\section{b. Previsão da Demanda}

Como a previsão da demanda de água é calculada a partir de dados históricos, os mesmos são fortemente influenciados pela temperatura ambiente, regime hidrológico e fatores econômicos (CARRAGHER; STEWART; BEAL, 2012). Assim, a variabilidade dos dados históricos, obtidos a partir do desvio padrão da média, fornecem um indicativo da incerteza associada à previsão da demanda futura.

Assim, os valores do desvio padrão $\sigma(D)$ e incerteza padrão $u(D)$ do erro da previsão da demanda são calculados por meio das seguintes equações:

$$
\begin{gathered}
\sigma(D)=\sqrt{\frac{1}{N_{J} \cdot N_{D s}-1} \sum_{i=1}^{N_{J}} \sum_{d=D s_{i}}^{D s_{f}}\left[Q\left(d \equiv d h \quad \bmod N_{D h}, j_{i}\right)-f_{D}(d h)\right]^{2}}, \mathrm{e} \\
u(D)=\frac{\sigma(D)}{\sqrt{N_{J} \cdot N_{D s}}},
\end{gathered}
$$

onde dh é uma das 24 horas do dia, $D s_{i}$ e $D s_{f}$ são as datas de início e fim da estação do ano, respectivamente, $N_{D h}=24, N_{D s}=\frac{D s_{f}-D s_{i}}{\Delta d}$ é o número de dados no período da estação, $j_{i}$ é um nó qualquer da rede e $N_{J}$ é o número total de nós do modelo hidráulico.

Na Figura 3.4 é possível observar a amplitude típica da incerteza da demanda nas quatro estações do ano (barras verticais em torno do valor médio), nas quais a variabilidade dos meses de outono e de inverno é menor que nos meses de primavera e de verão.

Para que os valores da incerteza calculada sejam considerados válidos Haestad et al. (2003) recomendam que os dados históricos devam ser de períodos superiores a 5 anos ininterruptos, cobrindo especificidades climáticas e sociais do consumo de água

Finalmente o coeficiente de sensibilidade desta fonte de erro será obtido por meio da derivada parcial calculada numericamente em torno do estado atual $\sigma$, da ação $\alpha$ e da 
previsão de demanda $D$, conforme equação abaixo:

$$
\frac{\partial T}{\partial D} \approx \frac{\left.f_{T}(\sigma, \alpha, d)\right|_{D+\epsilon}-\left.f_{T}(\sigma, \alpha, d)\right|_{D}}{\epsilon},
$$

tal que $\epsilon \ll 1$ e onde $\left.f_{T}(\sigma, \alpha, d)\right|_{D+\epsilon}$ e $\left.f_{T}(\sigma, \alpha, d)\right|_{D}$ são calculadas por meio do software de simulação hidráulica.

\section{c. Truncamento}

Devido aos sistemas de distribuição de água serem governados por equações nãolineares, os softwares de simulação hidráulica utilizam algoritmos iterativos para o cálculo de uma determinada solução.

No caso do EPANET o seu algoritmo iterativo converge quando a soma de todas as mudanças de vazão divididas pela soma das vazões em todas as arestas é menor que o erro de truncamento definido a priori pelo usuário (EPA, 2000), conforme abaixo:

$$
\frac{\sum_{i=1}^{N_{E}}\left(Q\left(e_{i}\right)_{n}-Q\left(e_{i}\right)_{n-1}\right)}{\sum_{i=1}^{N_{E}} Q\left(e_{i}\right)_{n}}<\varepsilon,
$$

onde $\varepsilon$ é o erro de truncamento do software de simulação hidráulica, $e_{i} \in E, n$ é a iteração atual e $n-1$ é a iteração anterior do algoritmo iterativo.

Desta forma, a incerteza padrão devido ao erro de truncamento do software de simulação hidráulica $u(T)$ será o próprio valor do erro de truncamento:

$$
u(T)=\varepsilon
$$

Finalmente, o coeficiente de sensibilidade, como no caso do erro de previsão da demanda, também será calculado a partir da derivada parcial numérica, porém, neste caso será utilizada a variação em torno do valor do erro do truncamento, conforme equação abaixo:

$$
\frac{\partial f_{T}}{\partial T} \approx \frac{\left.f_{T}(\sigma, \alpha, d)\right|_{\varepsilon+\epsilon}-\left.f_{T}(\sigma, \alpha, d)\right|_{\varepsilon}}{\epsilon},
$$

tal que $\epsilon \ll \varepsilon$ e onde $\left.f_{T}(\sigma, \alpha, d)\right|_{\varepsilon+\epsilon}$ e $\left.f_{T}(\sigma, \alpha, d)\right|_{\varepsilon}$ são calculadas por meio do software de simulação hidráulica.

\section{d. Discretização}

Devido as variáveis de estado, que compõem a representação fatorada dos estados, serem descritas no espaço contínuo as mesmas devem ser discretizadas para sua representação no espaço discreto. Como nesta tese será utilizada a discretização uniforme, tem-se que a variável de estado $\mathcal{X}$, descrita no intervalo contínuo $\left[\mathcal{X}^{\text {min }}, \mathcal{X}^{\text {max }}\right]$, será descrita pelo 
seguinte conjunto:

$$
\mathcal{X}=\left\{\mathcal{X}_{\min }+\Delta x\left(i-\frac{1}{2}\right) \mid i=1,2, \ldots, \frac{\mathcal{X}_{\max }-\mathcal{X}_{\min }}{\Delta x}\right\},
$$

onde $\Delta x$ é a constante de discretização da variável de estado $\mathcal{X}$ de forma a se dividir o intervalo $\left[\mathcal{X}_{\max }, \mathcal{X}_{\min }\right]$ em um número inteiro.

Desta forma, a discretização uniforme é descrita por meio de uma distribuição de probabilidade uniforme ${ }^{5}$ e sua incerteza padrão será:

$$
u(\mathcal{X})=\frac{\Delta x}{\sqrt{12}}
$$

onde $u(\mathcal{X})$ é a incerteza padrão da discretização da variável de estado $\mathcal{X}$ e $\Delta x$ é a constante de discretização da variável de estado $\mathcal{X}$.

Finalmente, o coeficiente de sensibilidade da discretização será calculado pela derivada parcial numérica, utilizando a variação em torno da variável de estado $\mathcal{X}$, resultando em:

$$
\frac{\partial f_{T}}{\partial \mathcal{X}} \approx \frac{\left.f_{T}(\sigma, \alpha, d)\right|_{\mathcal{X}+\epsilon}-\left.f_{T}(\sigma, \alpha, d)\right|_{\mathcal{X}}}{\epsilon}
$$

tal que $\epsilon \ll 1$ e onde $\left.f_{T}(\sigma, \alpha, d)\right|_{\mathcal{X}+\epsilon}$ e $\left.f_{T}(\sigma, \alpha, d)\right|_{\mathcal{X}}$ são calculadas por meio do software de simulação hidráulica.

\subsubsection{Função de Recompensa}

O valor $r_{d}$ atribuído à função de recompensa $\mathcal{R}$, conforme descrito na Equação 4.9, é considerado nesta modelagem como os gastos com energia elétrica durante um ciclo de tarifação, normalmente 30 dias. Os gastos com energia elétrica para empresas de saneamento são compostos pelo custo do consumo de energia $C_{C}$ e pelo custo da demanda de potência $C_{D}$ e descrito pela ANEEL (2005) na forma da seguinte equação:

$$
r_{d}=-\left(C_{C}+C_{D}\right)
$$

onde o sinal negativo decorre da modelagem, que no caso geral, prevê a maximização das recompensas e neste caso particular, será a minimização dos custos.

O custo do consumo de energia é definido como a energia utilizada (kWh) ao longo do ciclo de tarifação multiplicado pelo preço da energia $(\mathrm{R} \$ / \mathrm{kWh})$. Como o consumo de energia não é constante durante um dia, as concessionárias de energia elétrica praticam

\footnotetext{
${ }^{5}$ Conforme descrito no Apêndice A
} 
preços diferenciados e divididos em dois períodos: ponta e fora-de-ponta. O período de ponta reflete os momentos de maior consumo de eletricidade e com os maiores valores. Por outro lado, o período fora-de-ponta é quando a demanda por eletricidade é baixa e com preço menor. Assim, o custo do consumo de energia é definido como:

$$
C_{C}=\sum^{B C}\left(\sum^{O P} P w(t) \cdot \Delta t \cdot P_{O P}+\sum^{F P} P w(t) \cdot \Delta t \cdot P_{F P}\right)
$$

onde $B C$ é o ciclo de tarifação, $O P$ e $F P$ são os períodos de ponta e fora-de-ponta, respectivamente, $P_{O P}$ e $P_{F P}$ são os preços de energia nos períodos de ponta e fora-deponta, respectivamente, e $P w(t)$ é a potência elétrica medida no instante $t$.

O custo da demanda é definido como a máxima potência elétrica $(\mathrm{kW})$ medida durante o ciclo de tarifação multiplicada pelo preço da demanda $(\mathrm{R} \$ / \mathrm{kW})$. Este custo reflete o custo fixo das concessionárias de energia elétrica em fornecer um determinado nível de disponibilidade de energia para os consumidores e é definido como:

$$
C_{D}=\max _{B C}[P w(t)] \cdot P_{D M}
$$

onde $P_{D M}$ é o preço da demanda. Entretanto, para que o problema respeite a Propriedade de Markov $^{6}$ o custo da demanda é modelado da seguinte forma:

$$
C_{D}=P w(t) \cdot P_{D M}
$$

Desta forma, respeitando-se a Propriedade de Markov é garantida que a política resultante será ótima.

\subsection{Discussões Finais}

Este capítulo apresentou a formalização matemática dos Processos Decisórios de Markov e a modelagem proposta do problema de minimização dos gastos com energia elétrica nos sistemas de distribuição de água.

Fazendo referência aos diagramas contidos nas Figuras 1.3 e 1.4, este capítulo descreveu o bloco controlador. Este bloco fornece as ações (as condições de operação de bombas e válvulas) para o simulador hidráulico a partir do estado (pressão em um determinado nó e/ou vazão em uma determinada aresta) e do valor da recompensa (gastos com energia elétrica), além da função de transição a ser calculada a partir das incertezas associadas

\footnotetext{
${ }^{6}$ Onde os estados futuros dependem apenas do estado atual (MAUSAM; KOLOBOV, 2012).
} 
ao modelo hidráulico, à previsão da demanda, ao truncamento do algoritmo de cálculo e à discretização das variáveis de estado.

Assim, a contribuição desta tese está no cálculo da incerteza da função de transição de estado, utilizado para descrever o conhecimento incompleto e a aleatoriedade dos sistemas de distribuição de água, assim como, a modelagem por MDP do problema de minimização de gastos com energia elétrica em sistema de distribuição de água.

Devido a existência de incertezas na determinação dos próximos estados, uma forma de realizar a modelagem poderia ser realizada utilizando os Processos Decisórios de Markov Parcialmente Observáveis - POMDP. Neste tipo de modelagem os próximos estados não são observados diretamente, mas estimados a partir de uma distribuição de probabilidade do conjunto de possíveis estados, com base na probabilidade das observações. Infelizmente, o alto custo computacional para sua solução limita-o para problemas simples e com poucas variáveis (BRAZIUNAS, 2003). Consequentemente, nesta tese optou-se pela modelagem do problema por meio da combinação das variâncias de parte das fontes de incerteza existentes, com objetivo de aproximar as imperfeições nas observações dos estados, da modelagem por POMDP, para estados completamente observáveis na presença de incertezas.

No próximo capítulo, Solução de Sistemas de Distribuição de Água Modelados por MDP, são apresentadas duas possíveis soluções para problemas modelados por MDP, além de um algoritmo para solução da modelagem do problema utilizada neste tese. 


\section{Solução de Sistemas de Distribuição de Água Modelados por MDP}

Este capítulo apresenta os conceitos relacionados à solução de problemas modelados por MDP, como política, princípio de otimalidade de Bellman e função valor. Também são apresentados os dois principais algoritmos de Programação Dinâmica para a solução de problemas com horizonte de tempo infinito, policy iteration e value iteration, e também o algoritmo backup order, utilizado para a solução de problemas com horizonte de tempo finito. Este último será aplicado para a solução do problema de redução de gastos com energia elétrica em sistemas de distribuição de água, apresentado no capítulo anterior.

\subsection{Fundamentação}

Como visto no Capítulo 4, os processos decisórios de Markov são modelos de problemas de decisão sequenciais que são caracterizado pela tupla $\langle\mathcal{S}, \mathcal{A}, \mathcal{D}, \mathcal{T}, \mathcal{R}\rangle$ e cuja solução é obtida por algoritmos de programação dinâmica, quando existe um modelo completo do MDP, ou por aprendizado por reforço, quando o modelo do MDP é construído por meio de um processo iterativo entre o controlador e o ambiente (WIERING; OTTERLO, 2012).

Adicionalmente, os problemas modelados por MDP podem ser classificados com horizonte de tempo finito ou infinito. Nos problemas com horizonte de tempo finito, onde $d \in\left[1, D_{\max }\right]$, a execução finaliza quando a época de decisão atinge o horizonte de tempo $D_{\max }$. Já no caso de horizonte de tempo infinito, onde $d \in[1, \infty]$, a execução é finalizada quando se encontra um estado objetivo, para problemas episódicos, ou quando a política se estabiliza, para problemas não-episódicos (WIERING; OTTERLO, 2012).

Desta forma, esta tese será focada na utilização de algoritmos de programação dinâmica para solução do MDP com horizonte de tempo finito, uma vez que o modelo do problema de minimização de gastos com energia elétrica em sistema de distribuição de 
água possui modelo completamente definido pela tupla $\langle\mathcal{S}, \mathcal{A}, \mathcal{D}, \mathcal{T}, \mathcal{R}\rangle$ e a redução de gastos com energia elétrica está limitada a um período de tempo pré determinado.

\subsection{Política}

Uma política $\pi$ em problemas modelados por um MDP com horizonte de tempo finito é definida como o mapeamento dos conjuntos de estados $\mathcal{S}$ e de épocas de decisão $\mathcal{D}$ em um conjunto de ações $\mathcal{A}$. Se a política $\pi$ mapeia cada estado em uma única ação, a política é dita determinística, tal que $\pi: \mathcal{S} \times \mathcal{D} \mapsto A$. Já quando a política $\pi$ está associada a uma probabilidade para uma determinação ação, tal que $\pi: \mathcal{S} \times A \times \mathcal{D} \mapsto[0,1]$, esta é dita uma política estocástica. Neste trabalho serão consideras apenas políticas determinísticas dado que em sistemas de distribuição de água as ações em cada estado devem ser únicas e não inequívocas.

Uma política determinística opera da seguinte maneira: um estado inicial $s_{0}$ é fornecido ao controlador; uma política $\pi$ sugere a ação $a_{0}$ no estado $s_{0}$, tal que $\pi\left(s_{0}, d_{0}\right)=a_{0}$; a ação $a_{0}$ é executada e uma recompensa $r_{0}$ é recebida pelo controlador; baseada na função de transição de estado $T$ é determinado o próximo estado $s_{1}$ com probabilidade $\mathcal{T}\left(s_{0}, a_{0}, s_{1}, d_{0}\right)$. Este processo é repetido produzindo-se a seguinte sequência:

$$
s_{0} \rightarrow \pi\left(s_{0}, d_{0}\right) \rightarrow a_{0} \rightarrow r_{0} \rightarrow s_{1} \rightarrow \pi\left(s_{1}, d_{1}\right) \rightarrow a_{1} \rightarrow r_{1} \ldots
$$

\subsection{Função valor}

De forma geral, a função valor pode ser vista como o elo de ligação entre um critério de otimalidade e uma política, uma vez que espera-se que a resolução de um problema modelado como um MDP maximize o valor esperado da soma das recompensas (SUTTON; BARTO, 1998).

A função valor $\mathcal{V}^{\pi}(\sigma, d)$ em problema de horizonte de tempo finito é definida como uma estimativa do valor esperado das recompensas futuras que serão atribuídas ao controlador a partir de um determinado estado e expressa como:

$$
\mathcal{V}^{\pi}(\sigma, d)=E_{\pi}\left\{R_{d} \mid s_{d}=\sigma\right\}
$$

onde $\mathcal{V}^{\pi}: \mathcal{S} \times \mathcal{D} \mapsto \mathbb{R}, E_{\pi}$ representa o valor esperado de recompensa no estado $\sigma$ e na época de decisão $d$, expresso em uma função de recompensas acumulada $R_{d}$, caso o 
controlador siga uma política $\pi$. Já a função de recompensas acumulada é definida como:

$$
R_{d}=\sum_{i=d}^{D_{\max }} \gamma^{i-1} \cdot r_{d}
$$

onde $\gamma$ é um escalar chamado de fator de desconto, com $0 \leq \gamma \leq 1$, e que é utilizado para ponderar valores de recompensa presentes e futuros.

No caso de problemas modelados como um MDP finito, o fator de desconto não possui efeito prático, dessa forma, utiliza-se $\gamma=1$. Já no caso de problemas modelados como um MDP infinito, quando $\gamma=0$, o controlador é considerado míope pois só computa decisões com consequências imediatas. Por outro lado, quando $\gamma=1$, todas as recompensas são igualmente importantes para a obtenção da solução num horizonte de tempo infinito.

Também neste cenário é comum a utilização da função valor de ação expressa como: $\mathcal{Q}^{\pi}: \mathcal{S} \times \mathcal{A} \times \mathcal{D} \mapsto \mathbb{R}$. Esta função possui a mesma definição da função valor $\mathcal{V}^{\pi}$, porém, o valor esperado das recompensas leva em conta a ação $\alpha$ na época de decisão $d$, caso o controlador siga a política $\pi$. A função valor de ação é definida como:

$$
\mathcal{Q}^{\pi}(\sigma, \alpha, d)=E_{\pi}\left\{R_{d} \mid s_{d}=\sigma, a_{d}=\alpha\right\}
$$

Assim, a relação entre a função valor $\mathcal{V}^{\pi}(\sigma, d)$ e a função valor da ação $\mathcal{Q}^{\pi}(\sigma, \alpha, d)$ quando o controlador está sujeito à política $\pi(\sigma, d)$ é:

$$
\mathcal{V}^{\pi}(\sigma, d)=\mathcal{Q}^{\pi}(\sigma, \pi(\sigma, d), d)
$$

\subsection{Princípio de Otimalidade de Bellman}

Para que a solução de um problema modelado como um MDP seja ótima, com relação ao valor acumulado das recompensas, esta deve seguir o princípio de otimalidade de Bellman (1957), que diz: "Uma política ótima possui a propriedade de que qualquer que seja o estado ou a ação iniciais, a decisão resultante deve constituir uma política ótima no que se refere ao estado resultante da primeira decisão.".

Basicamente o princípio de otimalidade de Bellman diz que uma política para ser ótima deve satisfazer uma relação de recursividade, que reflete na sua dependência com o estado inicial e a ação inicial. Esta relação é obtida por meio da expansão da equação 
da função valor:

$$
\begin{aligned}
\mathcal{V}^{\pi}(\sigma, d) & =E_{\pi}\left\{R_{d} \mid s_{d}=\sigma\right\} \\
& =E_{\pi}\left\{r_{d}+\gamma \cdot r_{d+1}+\gamma^{2} \cdot r_{d+2}+\ldots \mid s_{d}=\sigma\right\} \\
& =E_{\pi}\left\{r_{d}+\gamma \cdot \mathcal{V}^{\pi}\left(s_{d+1}=\sigma^{\prime}\right) \mid s_{d}=\sigma\right\} \\
& =\mathcal{R}(\sigma, \alpha, d)+\gamma \sum_{\sigma^{\prime} \in \mathcal{S}} \mathcal{T}\left(\sigma, \alpha, \sigma^{\prime}, d\right) \cdot \mathcal{V}^{\pi}\left(\sigma^{\prime}, d+1\right)
\end{aligned}
$$

A equação 5.5 mostra que o valor esperado da função valor de um determinado estado é definido em termos de recompensas imediatas e valores dos próximos estados, ponderados pela função de transição de estados.

\subsection{Política Ótima}

Para que o MDP obtenha uma política ótima $\pi^{*}$, deve-se maximizar o valor acumulado das recompensas, o que significa maximizar a função valor da equação 5.5 para todos os estados $s \in \mathcal{S}$. Desta forma, esta afirmação é representada pela seguinte equação:

$$
\mathcal{V}^{*}(\sigma, d)=\max _{\alpha \in \mathcal{A}}\left[\mathcal{R}(\sigma, \alpha, d)+\gamma \sum_{\sigma^{\prime} \in \mathcal{S}} \mathcal{T}\left(\sigma, \alpha, \sigma^{\prime}, d\right) \cdot \mathcal{V}^{*}\left(\sigma^{\prime}, d+1\right)\right],
$$

que é conhecida como equação de otimalidade de Bellman. A partir dela é possível obter uma política ótima que maximiza o valor acumulado das recompensas por meio da seguinte equação.

$$
\pi^{*}(\sigma, d)=\arg \max _{\alpha \in \mathcal{A}}\left[\mathcal{R}(\sigma, \alpha, d)+\gamma \sum_{\sigma^{\prime} \in \mathcal{S}} \mathcal{T}\left(\sigma, \alpha, \sigma^{\prime}, d\right) \cdot \mathcal{V}^{*}\left(\sigma^{\prime}, d+1\right)\right] .
$$

A equação de otimalidade de Bellman também pode ser re-escrita em termos da função valor da ação, conforme abaixo:

$$
\mathcal{Q}^{*}(\sigma, \alpha, d)=\mathcal{R}(\sigma, \alpha, d)+\gamma \sum_{\sigma^{\prime} \in \mathcal{S}} \mathcal{T}\left(\sigma, \alpha, \sigma^{\prime}, d\right) \cdot \max _{\alpha^{\prime} \in \mathcal{A}}\left[\mathcal{Q}^{*}\left(\sigma^{\prime}, \alpha^{\prime}, d+1\right)\right]
$$

Devido à relação $\mathcal{V}^{*}(\sigma, d)=\max _{\alpha \in \mathcal{A}}\left[\mathcal{Q}^{*}(\sigma, \alpha, d)\right]$ a equação 5.8 pode ser re-escrita em termos da função valor ótima para o estado $\sigma^{\prime} \in \mathcal{S}$, resultando em:

$$
\mathcal{Q}^{*}(\sigma, \alpha, d)=\mathcal{R}(\sigma, \alpha, d)+\gamma \sum_{\sigma^{\prime} \in \mathcal{S}} \mathcal{T}\left(\sigma, \alpha, \sigma^{\prime}, d\right) \cdot \mathcal{V}^{*}\left(\sigma^{\prime}, d+1\right)
$$


Analogamente à equação 5.7, a política ótima também pode ser obtida somente pela maximização das ações que resultem em maiores valores da função valor de ação, conforme abaixo:

$$
\pi^{*}(\sigma, d)=\arg \max _{\alpha \in \mathcal{A}}\left[\mathcal{Q}^{*}(\sigma, \alpha, d)\right]
$$

Em suma, a melhor ação será aquela que produz os maiores valores esperados com base nos próximos estados que resultam desta ação.

\subsection{Resolução de um MDP com horizonte de tempo infinito}

No caso de problemas modelados por MDP com horizonte de tempo infinito, a época de decisão pode ser omitida, dado que as funções de transição de estado e de recompensas são estacionárias e não dependem da época de decisão (MAUSAM; KOLOBOV, 2012), fazendo com que a função valor ótima $\mathcal{V}^{*}$ e a política ótima $\pi^{*}$ possam ser re-escritas da seguinte forma:

$$
\begin{gathered}
\mathcal{V}^{*}(\sigma)=\max _{\alpha \in \mathcal{A}}\left[\mathcal{R}(\sigma, \alpha)+\gamma \sum_{\sigma^{\prime} \in \mathcal{S}} \mathcal{T}\left(\sigma, \alpha, \sigma^{\prime}\right) \cdot \mathcal{V}^{*}\left(\sigma^{\prime}\right)\right], \\
\pi^{*}(\sigma)=\arg \max _{\alpha \in \mathcal{A}}\left[\mathcal{R}(\sigma, \alpha)+\gamma \sum_{\sigma^{\prime} \in \mathcal{S}} \mathcal{T}\left(\sigma, \alpha, \sigma^{\prime}\right) \cdot \mathcal{V}^{*}\left(\sigma^{\prime}\right)\right] .
\end{gathered}
$$

A seguir são apresentados os dois principais algoritmos de programação dinâmica para a solução de problemas modelados por MDP com horizonte de tempo infinito: policy interaction e value interaction.

\subsubsection{Policy Iteration}

O algoritmo policy iteration (HOWARD, 1960) é um método para resolução de um MDP por meio de um processo iterativo de avaliação e atualização de uma política até que esta se estabilize.

Este algoritmo é dividido em três fases, conforme Algoritmo 1: inicialização, onde são atribuídos valores arbitrários para a função valor $\mathcal{V}(\sigma)$ e para a política $\pi(\sigma)$; avaliação da política, onde é calculada a função valor $\mathcal{V}(\sigma)$ para todos os estados $\sigma \in \mathcal{S}$ a partir das ações da política $\pi(\sigma)$; e melhoria da política, onde é verificado se as ações da política $\pi(\sigma)$ maximizam os valores da função valor $\mathcal{V}(\sigma)$ e, em caso negativo, a política $\pi(\sigma)$ é atualizada utilizando as ações que a maximizem. 


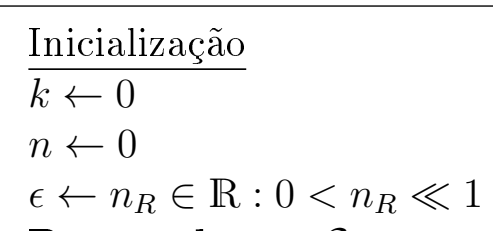

\section{Para cada $\sigma \in \mathcal{S}$ executar:}

$\mathcal{V}_{k}(\sigma) \leftarrow n_{V} \in \mathbb{R}$

$\pi_{n}(\sigma) \leftarrow \alpha \in \mathcal{A}(\sigma)$

\section{Fim}

\section{Repetir}

Avaliação da política

\section{Repetir}

$k \leftarrow k+1$

Para cada $\sigma \in \mathcal{S}$ executar:

$$
\begin{aligned}
& \mathcal{V}_{k}(\sigma) \leftarrow \mathcal{R}\left(\sigma, \pi_{n}(\sigma)\right)+\gamma \sum_{\sigma^{\prime} \in S} \mathcal{T}\left(\sigma, \pi_{n}(\sigma), \sigma^{\prime}\right) \cdot \mathcal{V}_{k-1}\left(\sigma^{\prime}\right) \\
& \Delta(\sigma) \leftarrow\left|\mathcal{V}_{k}(\sigma)-\mathcal{V}_{k-1}(\sigma)\right|
\end{aligned}
$$

Fim

Até que $\max _{\sigma \in \mathcal{S}} \Delta(\sigma)<\epsilon$

$\underline{\text { Melhoria da política }}$

$n \leftarrow n+1$

Para cada $\sigma \in \mathcal{S}$ executar:

$\mid \pi_{n}(\sigma) \leftarrow \arg \max _{\alpha \in A}\left[\mathcal{R}(\sigma, \alpha)+\gamma \sum_{\sigma^{\prime} \in S} \mathcal{T}\left(\sigma, \alpha, \sigma^{\prime}\right) \cdot \mathcal{V}_{k}\left(\sigma^{\prime}\right)\right]$

Fim

Até que $\pi_{n}==\pi_{n-1}$

$\frac{\text { Saída da política ótima }}{\pi^{*}=\pi_{n}}$

\section{Retornar $\pi^{*}$}

Algoritmo 1: Policy iteration para solução de problemas modelados por MDP com horizonte de tempo infinito.

As duas últimas fases do algoritmo, avaliação e melhoria, são repetidas até que não haja mais mudanças nas ações da política $\pi_{n}$, resultando na política ótima $\pi^{*}$. Assim, o algoritmo policy iteration gera uma sequência alternada entre políticas e funções valores até que seja encontrada uma política ótima, conforme pode ser observado na sequência abaixo:

$$
\pi_{0} \stackrel{A}{\rightarrow} \mathcal{V}^{\pi_{0}} \stackrel{M}{\rightarrow} \pi_{1} \stackrel{A}{\rightarrow} \mathcal{V}^{\pi_{1}} \stackrel{M}{\rightarrow} \pi_{2} \stackrel{A}{\rightarrow} \mathcal{V}^{\pi_{2}} \stackrel{M}{\rightarrow} \pi_{3} \stackrel{A}{\rightarrow} \mathcal{V}^{\pi_{3}} \rightarrow \cdots \rightarrow \pi^{*} \stackrel{A}{\rightarrow} \mathcal{V}^{*}
$$

onde $\pi_{n}$ é a política na $n$-ésima iteração, $\mathcal{V}^{\pi_{n}}$ é a função valor calculada em todos os estados a partir da política $\pi_{n}$ na $n$-ésima iteração, $\pi^{*}$ é a política ótima, $\mathcal{V}^{*}$ é a função valor ótima, $\stackrel{A}{\rightarrow}$ representa o processo de avaliação da política e $\stackrel{M}{\rightarrow}$ representa o processo de melhoria da política. 
Para um MDP com espaço de estados finito o algoritmo policy iteration converge após um número finito de iterações, porém, de forma ineficiente. A ineficiência está relacionada ao fato de este algoritmo calcular a função valor $\mathcal{V}(\sigma)$ para todos os estados $\sigma \in \mathcal{S}$, o que envolve múltiplas varreduras do espaço de estado a cada iteração, e que se repete sempre que há mudanças nas ações da política intermediária $\pi_{i}(\sigma)$. Sua utilização tornase proibitiva quando o espaço de estados é suficientemente grande, apesar de o algoritmo convergir após algumas iterações.

\subsubsection{Value Iteration}

O algoritmo value iteration (BELLMAN, 1957) também é um método baseado em aproximações sucessivas para resolução de um MDP, porém, diferentemente do algoritmo policy iteration, este não apresenta a característica de múltiplas varreduras do espaço de estado a cada iteração. Ao invés disso, ele combina uma versão truncada da etapa de avaliação do algoritmo policy iteration, onde é realizado um único cálculo da função valor em cada estado $\sigma \in \mathcal{S}$, além de uma etapa de determinação da política ótima, quando a função valor $\mathcal{V}(\sigma)$ está estabilizada em todo estado $\sigma \in \mathcal{S}$.

O algoritmo value iteration também é dividido em três fases, conforme apresenta o Algoritmo 2: inicialização, onde são atribuídos valores arbitrários para a função valor $\mathcal{V}(\sigma)$ para todo $\sigma \in \mathcal{S}$; determinação da função valor, onde é calculada a função valor $\mathcal{V}(\sigma)$ para todos os estados $\sigma \in \mathcal{S}$ a partir da maximização do valor para as possíveis ações $\alpha \in \mathcal{A}_{\sigma}$ naquele estado; e determinação da política ótima, onde a política ótima $\pi^{*}(\sigma)$ é determinada a partir das ações que levaram à maximização da função valor $\mathcal{V}(\sigma)$.

O algoritmo value iteration gera uma sequência de funções valor até que se encontre o seu valor ótimo e posteriormente encontrada uma política ótima, conforme pode ser observado na sequência abaixo:

$$
\mathcal{V}_{0} \rightarrow \mathcal{V}_{1} \rightarrow \mathcal{V}_{2} \rightarrow \mathcal{V}_{3} \rightarrow \mathcal{V}_{4} \rightarrow \mathcal{V}_{5} \rightarrow \mathcal{V}_{6} \rightarrow \cdots \rightarrow \mathcal{V}^{*} \rightarrow \pi^{*}
$$

onde $\mathcal{V}_{n}$ é a função valor de todos os estados $\sigma \in \mathcal{S}$ calculadas na $n$-ésima iteração, $\mathcal{V}^{*}$ é a função valor ótima e $\pi^{*}$ é a política ótima resultante do algoritmo. 


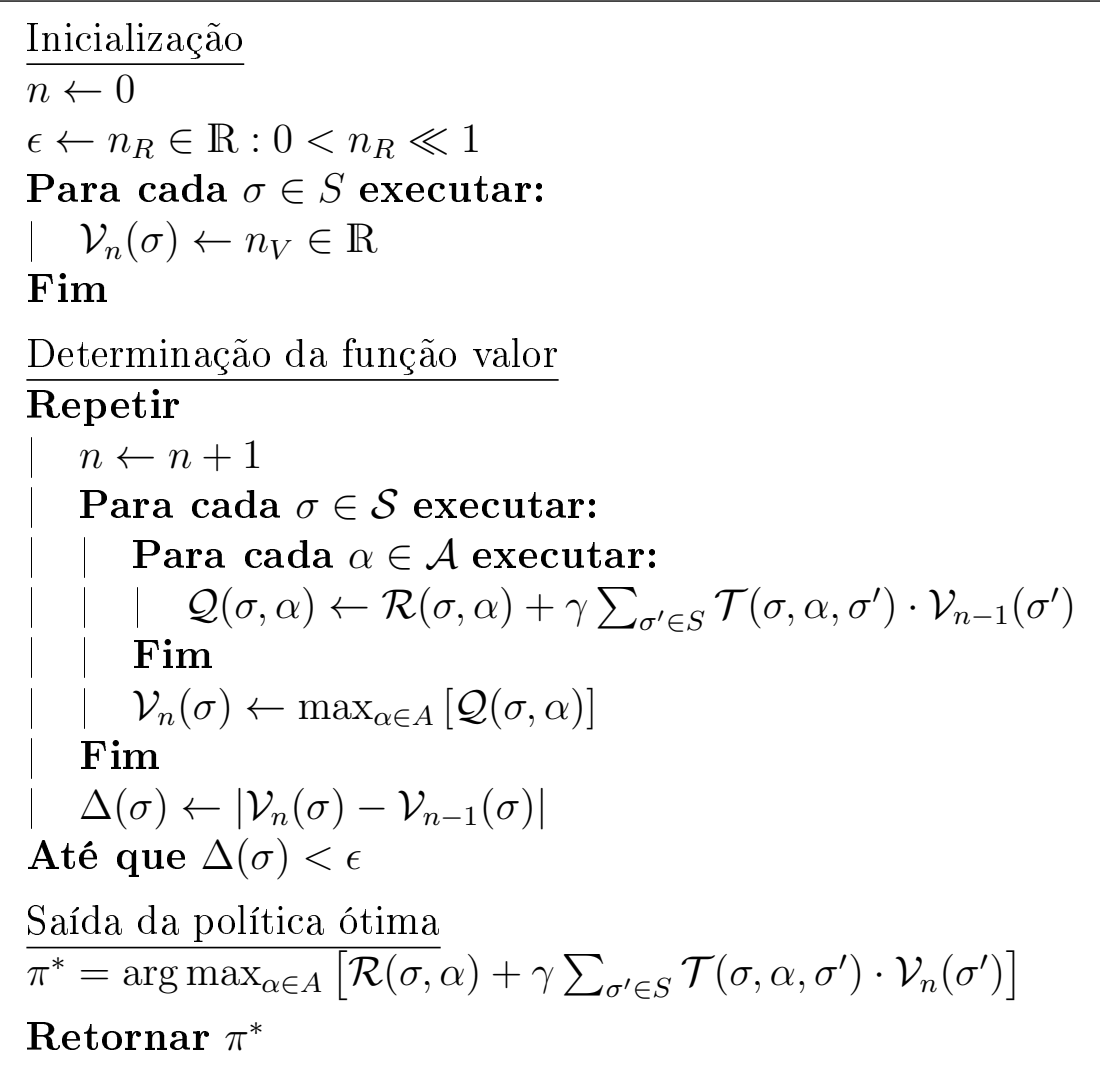

Algoritmo 2: Value iteration para solução de problemas modelados por MDP com horizonte de tempo infinito.

\subsection{Resolução de um MDP com horizonte de tempo finito}

A modelagem do problema de redução dos gastos com energia elétrica em sistemas de distribuição de água é realizada por meio de um MDP com horizonte de tempo finito, conforme descrito no Capítulo 4. Este tipo de modelagem simplifica a resolução do problema (MAUSAM; KOLOBOV, 2012), fazendo com que a solução possa ser encontrada utilizando uma versão modificada do algoritmo value iteration, conhecida como algoritmo backup order (BERTSEKAS, 2007).

O algoritmo backup order torna-se poderoso para a solução deste tipo de problema devido à característica de o MDP com horizonte de tempo finito ser visto como um grafo acíclico, onde o controlador percorre apenas uma única vez cada estado aumentado (estado mais época de decisão). Desta forma, a obtenção da solução ótima é garantida (não apenas $\epsilon$-consistente), além de redução do tempo de convergência da solução, dado que é realizado apenas um único cálculo da função valor e da política em cada estado aumentado. 
Com relação à execução deste algoritmo, se inicia a determinação da função valor e política dos estados com época de decisão igual ao horizonte de tempo do problema $-D_{\max }$. Depois, a época de decisão é decrementada e as funções valores e políticas são calculadas a partir daquelas calculadas na época de decisão anterior. Este processo é repetido até que a época de decisão seja igual a zero, obtendo assim as ações que maximizam as funções valores e que resultam na política ótima descrita pelo Algoritmo 3.

$$
\begin{aligned}
& \frac{\text { Inicialização }}{D_{\max } \leftarrow \frac{T_{\max }-T_{\min }}{\Delta t}} \\
& d \leftarrow D_{\max } \\
& \gamma \leftarrow 1
\end{aligned}
$$

Para cada $\sigma \in S$ executar:

$$
\mathcal{V}(\sigma, d) \leftarrow 0
$$

\section{Fim}

Determinação da função valor e política ótima

\section{Repetir}

$d \leftarrow d-1$

Para cada $\sigma \in \mathcal{S}$ executar:

\section{Para cada $\alpha \in \mathcal{A}$ executar:}

$$
\mid \mathcal{Q}(\sigma, \alpha, d) \leftarrow \mathcal{R}(\sigma, \alpha, d)+\gamma \sum_{\sigma^{\prime}} \mathcal{T}\left(\sigma, \alpha, \sigma^{\prime}, d\right) \cdot \mathcal{V}\left(\sigma^{\prime}, d+1\right)
$$

\section{Fim}

$$
\begin{aligned}
& \mathcal{V}(\sigma, d) \leftarrow \max _{\alpha} \mathcal{Q}(\sigma, \alpha, d) \\
& \pi^{*}(\sigma, d) \leftarrow \arg \max _{\alpha} \mathcal{Q}(\sigma, \alpha, d)
\end{aligned}
$$

\section{Fim}

Até que $d==0$

Saída da política ótima

\section{Retornar $\pi^{*}$}

Algoritmo 3: Backup order para solução de problemas modelados por MDP com horizonte de tempo finito.

Assim o algoritmo back order encontra as políticas ótimas em todos os estados de uma determinada época de decisão, iniciando a partir do horizonte de decisão até o instante inicial, resultando na seguinte sequência:

$$
\left.\left.\left.\left.\pi^{*}\right|_{d=D_{\max }} \rightarrow \pi^{*}\right|_{d=D_{\max }-1} \rightarrow \cdots \rightarrow \pi^{*}\right|_{d=1} \rightarrow \pi^{*}\right|_{d=0}
$$

onde $\left.\pi^{*}\right|_{d=n}$ é a política ótima do conjunto de estados $\mathcal{S}$ calculadas na $n$-ésima época de decisão. 


\subsection{Discussões Finais}

Este capítulo apresentou a solução de problemas modelados por MDP com horizonte de tempo infinito utilizando os dois algoritmos clássicos de programação dinâmica, policy iteration e value iteration. Ademais, também foi apresentada a solução para problemas modelados por MDP com horizonte de tempo finito utilizando o algoritmo backup order.

Para que a modelagem do problema forneça soluções factíveis é necessário garantir a existência de uma Política Própria ${ }^{1}$. Desta forma, são atribuídos valores de recompensa elevados, porém finitos, às transições que levem a estados indeterminados (MAUSAM; KOLOBOV, 2012). Com esta conduta, as ações que conduzem a estes estados acabam sendo altamente indesejáveis, evitando estados indeterminados e garantindo a existência de Políticas Próprias.

No próximo capítulo, Experimentos, o algoritmo backup order será utilizado para a solução de três diferentes problemas de redução de gastos com energia elétrica em sistemas de distribuição de água, uma vez que todos estes são modelados por MDP com horizonte de tempo finito.

\footnotetext{
${ }^{1}$ Política que garante a conclusão do problema.
} 


\section{$6 \quad$ Experimentos}

Esta tese propõe a modelagem de sistemas de distribuição de água utilizando Processos Decisórios de Markov com função de transição de estado calculada em simulador hidráulico na presença de incertezas decorrentes do modelo hidráulico, da curva de demanda, do truncamento do algoritmo de cálculo e da discretização das variáveis de estado.

Desta forma, para verificar a eficácia da modelagem proposta foram realizados três tipos de experimentos: a) com um sistema de distribuição simplificado e modelo hidráulico explícito, onde o modelo hidráulico da rede de distribuição de água é descrito por meio de equações matemáticas, i.e., de forma explícita; b) comparativo entre três diferentes técnicas utilizando simulador hidráulico, onde o modelo do sistema de distribuição e a parametrização dos experimentos foi igual para ambas as técnicas; e c) comparativo entre um sistema real com controle baseado em nível e o mesmo sistema simulado, porém, utilizando controlador MDP, cujo objetivo é identificar os potenciais ganhos no caso de implementação do controlador proposto.

Com relação às incertezas associadas à transição de estados, o primeiro experimento utilizou apenas efeitos da incerteza da discretização das variáveis de estado e da demanda de água, o segundo experimento utiliza incertezas devidas ao truncamento do algoritmo de cálculo e à discretização das variáveis de estado, e no terceiro, foi utilizado o modelo completo para cálculo da incerteza na transição de estado.

A seguir estes experimentos são explorados em detalhes, onde são descritos: o objetivo do experimento, o detalhamento dos dados e informações utilizadas nas simulações, a descrição do modelo MDP do experimento, os resultados obtidos e a análise críticas dos mesmos. 


\subsection{Experimentos com Sistema de Distribuição Simpli- ficado e Modelo Hidráulico Explícito}

Os experimentos com um sistema de distribuição simplificado e modelo hidráulico explícito, ou seja, onde o modelo hidráulico da rede de distribuição de água é descrito por meio de equações matemáticas, servem para verificar os efeitos de diferentes níveis de incerteza aplicados à curva de demanda de água no controlador de um sistema de distribuição simplificado, composto por: uma fonte de água, três bombas, um tanque de armazenamento e um ponto de consumo de água.

Como o modelo hidráulico é explícito não há a presença de incerteza devido à modelagem do sistema hidráulico ou incerteza devida ao algoritmo de cálculo do simulador hidráulico; porém, há presença dos efeitos da incerteza da discretização das variáveis de estado e da demanda de água. Entretanto, as análises deste experimento são concentradas apenas nos efeitos da variabilidade da incerteza da demanda.

\subsubsection{Objetivo}

O objetivo destes experimentos é analisar os efeitos da incerteza da curva de demanda de água em dois tipos de controlador: 1) sistema de distribuição simplificado modelado por MDP e com incerteza apenas da discretização das variáveis de estado; e 2) sistema de distribuição simplificado modelado por MDP, porém, com incertezas da discretização das variáveis de estado e da curva de demanda.

\subsubsection{Detalhamento do Experimento}

Os experimentos com sistema de distribuição simplificado e modelo hidráulico explícito foram realizados a partir de um sistema composto de uma fonte ilimitada de água tratada, três bombas idênticas ligadas em paralelo, um tanque de armazenamento e um ponto de consumo que simula a demanda de água de um determinado grupo de consumidores, conforme apresenta a Figura 6.1.

O problema consiste na redução dos gastos com energia elétrica durante o período de 24 horas, onde o tanque de armazenamento é cilíndrico, com área de 89, $7 \mathrm{~m}^{2}$ e com nível variando entre $0 m$ e $7 m$, as bombas possuem acionamento direto (ligado ou desligado) e o preço da energia elétrica (tarifa do uso do sistema de distribuição - TUSD mais a tarifa de energia - TE) é de $R \$ 0,24 / k W h$, uniforme durante as 24 horas do dia. 


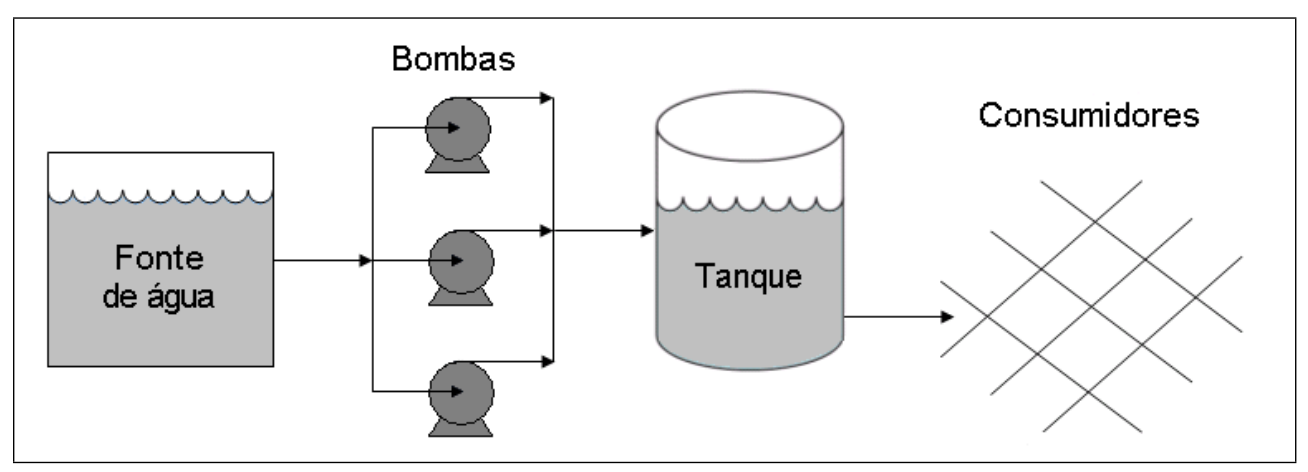

Figura 6.1: Sistema de distribuição simplificado e modelo hidráulico explícito.

A curva de demanda diária de água é descrita pela Figura 6.2, na qual a curva contínua representa o valor médio da demanda e as curvas tracejadas representam a incerteza expandida associada ao valor médio da demanda. Por exemplo, se a incerteza expandida da demanda possui valor igual a $50 \mathrm{~m}^{3} / \mathrm{h}$ durante todo o dia, às 12:00 a demanda média de água é de aproximadamente $200 \mathrm{~m}^{3} / \mathrm{h}$, podendo variar entre $150 \mathrm{~m}^{3} / \mathrm{h}$ e $250 \mathrm{~m}^{3} / \mathrm{h}$ com nível de confiança de 95,45\%, i.e., com fator de abrangência igual a 2.

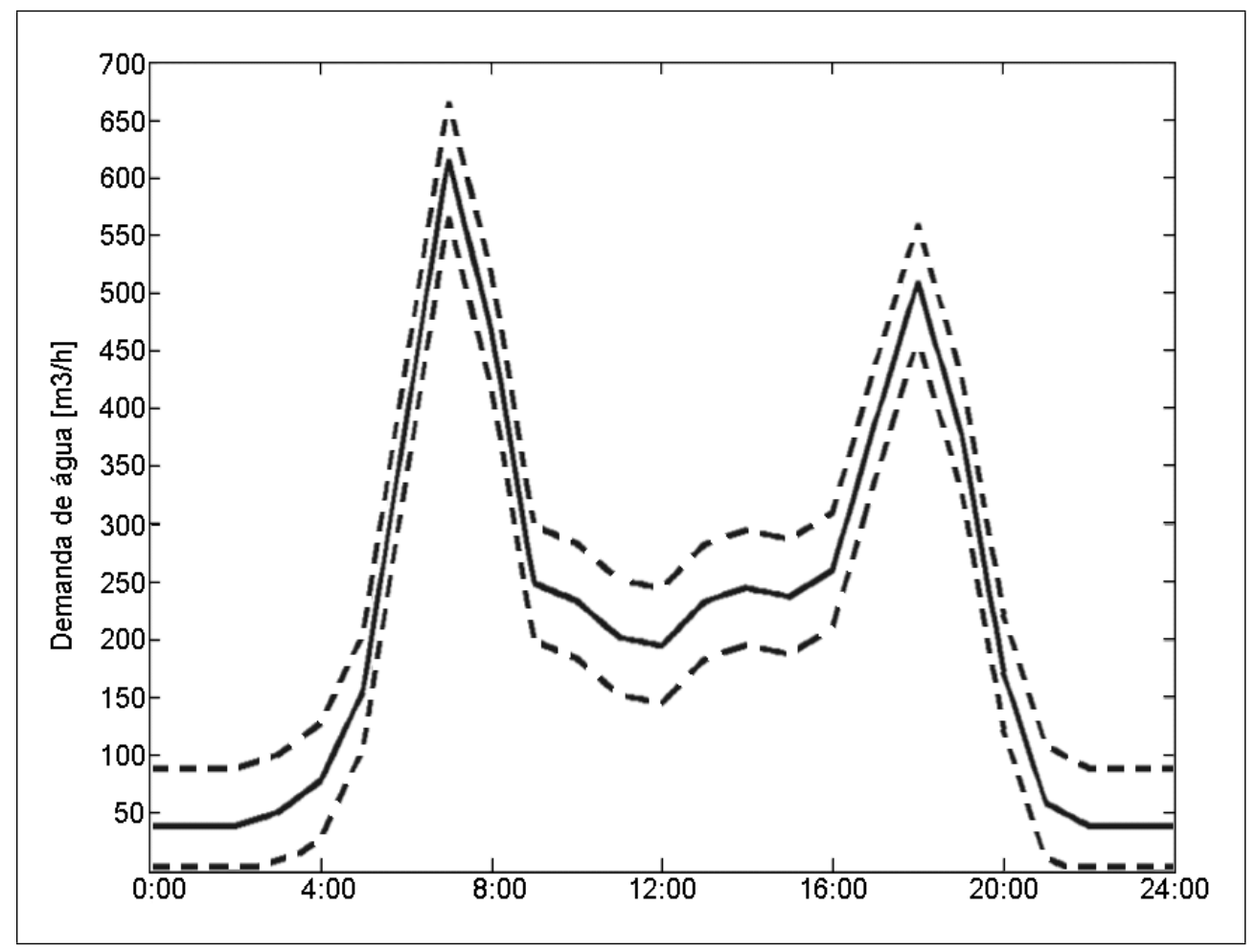

Figura 6.2: Demanda de água dos experimentos com sistema de distribuição simplificado e modelo hidráulico explícito.

Já o comportamento fluídico deste sistema é descrito pela equação 6.1 e representado 
pelas curvas de cor cinza da Figura 6.3.

$$
P=4,627 \cdot 10^{-4} \cdot Q^{2}+3,255 \cdot 10^{-3} \cdot Q+9,777 \cdot H
$$

onde $P$ é a pressão manométrica do sistema, em $k P a, Q$ é a vazão de água do sistema, em $m^{3} / h$, e $H$ é a altura de água no tanque de armazenamento, em $m$.

Por outro lado, o comportamento fluídico das bombas é descrito pela equação 6.2 e representado pelas curvas de cor preta da Figura 6.3.

$$
\begin{array}{ll}
P=0, & \text { se } N_{A}=0 \\
P=89,7-1,376 \cdot 10^{-9} \cdot\left(\frac{Q}{N_{A}}\right)^{4,59}, & \text { se } N_{A}>0
\end{array}
$$

onde $P$ e $Q$ também são a pressão manométrica e a vazão de água no sistema, respectivamente, e $N_{A}$ é o número de bombas que estão ligadas num determinado instante.

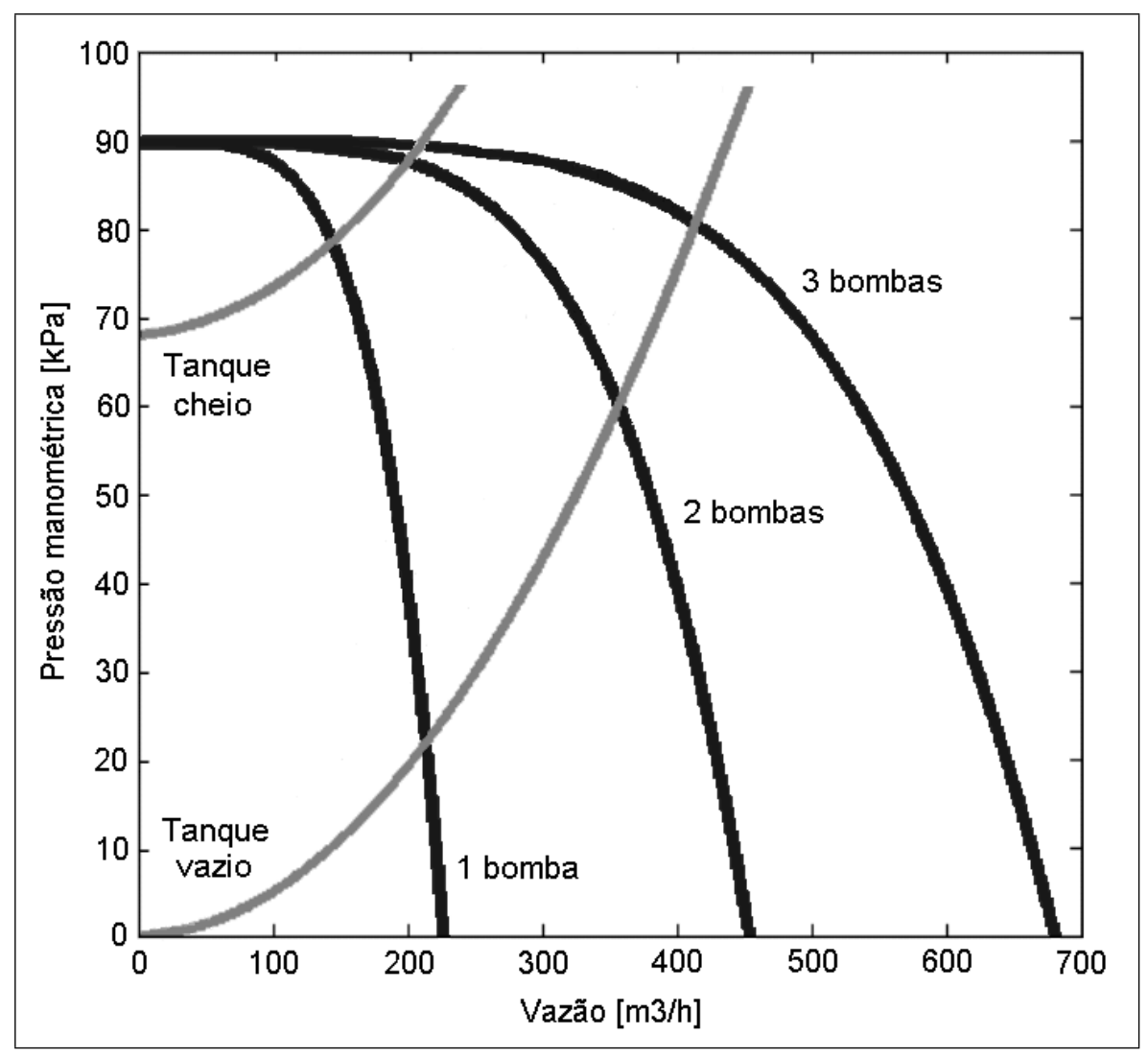

Figura 6.3: Curva do sistema e das bombas.

Finalmente, a potência elétrica das bombas é descrita pela equação 6.3 e representada pelas curvas da Figura 6.4. 


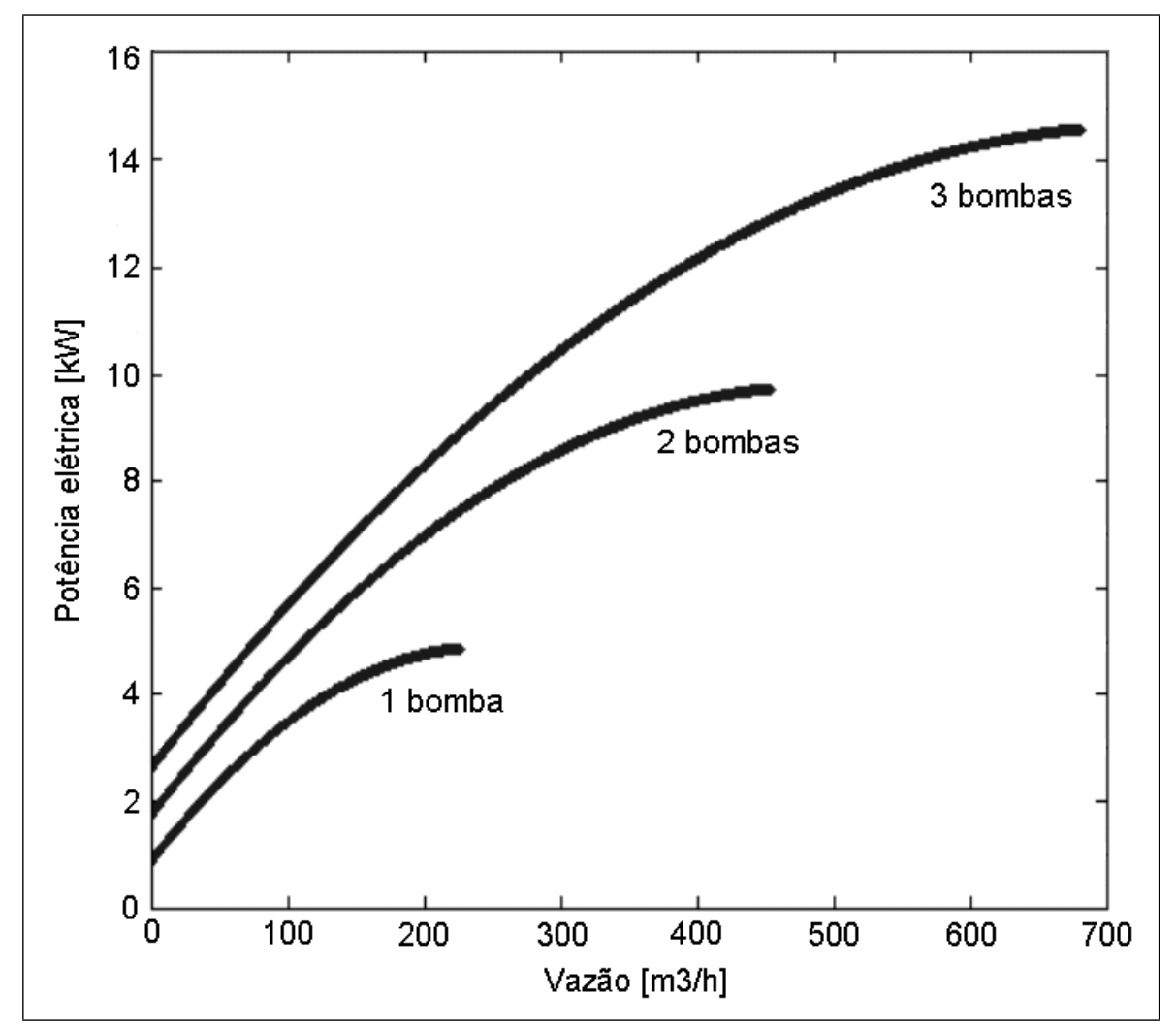

Figura 6.4: Potência elétrica das bombas.

$$
\begin{array}{ll}
P w=0, & \text { se } N_{A}=0 \\
P w=N_{A} \cdot\left(-6,69 \cdot 10^{-5} \cdot\left(\frac{Q}{N_{A}}\right)^{2}+3,28 \cdot 10^{-2} \cdot\left(\frac{Q}{N_{A}}\right)+0,87\right), & \text { se } N_{A}>0
\end{array}
$$

onde $P w$ é a potência elétrica das bombas, em $k W, Q$ é a vazão de recalque, em $m^{3} / h$, e $N_{A}$ é o número de bombas que estão ligadas num determinado instante.

\subsubsection{Modelo MDP}

Apresentadas as características do modelo hidráulico deste sistema de distribuição simplificado, faz-se necessário determinar os parâmetros que serão utilizados para descrever a tupla $\langle\mathcal{S}, \mathcal{A}, \mathcal{D}, \mathcal{T}, \mathcal{R}\rangle$ dos Processos Decisórios de Markov.

Neste experimento será adotada como variável de estado o nível de água no tanque de armazenamento, resultando em: $\mathcal{S}=(H)$. Por sua vez, o conjunto $H$ é discretizado 
uniformemente, resultando em:

$$
H=\left\{H_{\text {min }}+\Delta h\left(i-\frac{1}{2}\right) \mid i=1,2, \ldots, \frac{H_{\max }-H_{\min }}{\Delta h}\right\}
$$

onde $\Delta h$ é a constante de discretização do nível de água no tanque de armazenamento, expressa em $m$. Sendo $H^{\min }$ e $H^{\max }$ igual a $0 m$ e $7 m$, respectivamente, e $\Delta h$ definido como $0,25 m$ temos que o conjunto discreto de estados será:

$$
\mathcal{S}=\{0.125,0.375,0.625, \ldots, 6.375,6.625,6.875\}
$$

onde devido a existência de apenas uma variável de estado utilizou-se a descrição enumerada ao invés da descrição fatorada.

O conjunto discreto de ações que pode ser executada pelo controlador em qualquer estado do conjunto $\mathcal{S}$ é descrito pelo número de bombas que estão ligadas num determinado instante:

$$
\mathcal{A}=\{0,1,2,3\}
$$

Como na descrição do conjunto de estado, também utilizou-se a descrição enumerada das ações ao invés da descrição fatorada.

O conjunto de épocas de decisão é definido no intervalo de tempo de 24 horas, iniciando às 0:00 e finalizando às 24:00. Por ser um intervalo contínuo o mesmo é discretizado uniformemente pelo passo de tempo $\Delta t=0: 15$, ou seja, a cada 15 minutos, resultando em:

$$
\begin{aligned}
\mathcal{D} & =\left\{T_{\min }, T_{\min }+\Delta t, \ldots, T_{\max }\right\} \\
& =\{0: 00,0: 15,0: 30, \ldots, 23: 30,23: 45,24: 00\},
\end{aligned}
$$

onde $T_{\min }$ é o instante de tempo inicial e $T_{\max }$ é o horizonte de tempo do problema.

A função de transição de estados é descrita pela equação abaixo e considerada probabilística devido à incerteza da curva de demanda de água:

$$
h(d+1)=h(d)+\left[Q\left(h(d), N_{A}\right)-\mathcal{N}(D(d), u(D))\right] \cdot \frac{\Delta t}{A R E A}
$$

onde $h($.$) é o nível de água no tanque de armazenamento numa determinada época de$ decisão, $Q(h(d), A)$ é a vazão de água do sistema e que é função do nível de água no tanque de armazenamento na época de decisão $d$ e do número de bombas que estão ligadas, $D(d)$ e $u(D)$ são a demanda de água e a incerteza padrão respectivamente, $A R E A$ é a área da base do tanque de armazenamento e $\Delta t$ é o passo de tempo. 
A incerteza da demanda de água é descrita por uma distribuição de probabilidade normal, com média igual ao valor da demanda de água $D(d)$, obtido a partir da Figura 6.2, e com desvio padrão igual a incerteza padrão associada à curva. Assim, a incerteza padrão da demanda será:

$$
u(D)=\frac{U(D)}{k},
$$

onde $u(D)$ e $U(D)$ são a incerteza padrão e a incerteza expandida da demanda de água, respectivamente, e $k$ é o fator de abrangência da incerteza.

Já a incerteza associada à discretização da variável de estado $H$, nível de água no tanque de armazenamento, é descrita por uma distribuição de probabilidade uniforme no intervalo $[h(d+1)-\Delta h, h(d+1)+\Delta h]$ e possui valor igual a:

$$
u(\mathcal{X})=\frac{\Delta h}{\sqrt{12}}
$$

onde $u(\mathcal{X})$ é a incerteza padrão da discretização da variável de estado $H$ e $\Delta h$ é a constante de discretização da variável de estado $H$.

Assim, a incerteza da transição de estado na presença da incertezas devido à demanda de água e à discretização da variável de estado $H$ será:

$$
u\left(f_{T}\right)=\sqrt{\left(\frac{\partial f_{T}}{\partial D} \cdot u(D)\right)^{2}+\left(\frac{\partial f_{T}}{\partial \mathcal{X}} \cdot u(\mathcal{X})\right)^{2}}
$$

onde $\frac{\partial f_{T}}{\partial D}$ e $\frac{\partial f_{T}}{\partial \mathcal{X}}$ são os coeficientes de sensibilidade da demanda de água e da discretização da variável de estado $H$, respectivamente.

Já no caso de incerteza apenas devida à discretização da variável de estado, a incerteza da transição de estado resume-se à:

$$
u\left(f_{T}\right)=\frac{\partial f_{T}}{\partial \mathcal{X}} \cdot u(\mathcal{X})
$$

Finalmente, a função de recompensas $\mathcal{R}$ é o gasto com energia elétrica durante o período de 24 horas e definida como:

$$
\mathcal{R}=-\sum_{d=T_{\min }}^{T_{\max }} \frac{P w(d) \cdot P_{E N}}{\Delta t}
$$

onde $P w(d)$ é a potência elétrica das bombas na época de decisão $d$ obtida da equação $6.3, P_{E N}$ é o preço da energia elétrica, igual a $R \$ 0,24 / k W h$, e $\Delta t$ é o passo de tempo.

A seguir são apresentados os resultados dos experimentos realizados com o sistema de 
distribuição simplificado e modelo hidráulico explícito.

\subsubsection{Resultados}

Os experimentos com sistema de distribuição simplificado e modelo hidráulico explícito foram realizados em uma série de 1000 repetições, com objetivo de analisar uma média representativa desta série de simulações.

Nestes experimentos foram realizadas simulações com dois tipos de controladores: Controlador 1 - problema modelado por MDP e com incerteza apenas da discretização das variáveis de estado; e Controlador 2 - problema modelado por MDP, porém, com incertezas da discretização da variável de estado e da curva de demanda. Cada um dos controladores foi testado com diferentes níveis de incerteza na curva de demanda, a saber: $u(D)=\{0,25,30,35,40,45,50\}$.

Os resultados dos experimentos são apresentados na forma gráfica por meio da política de controle fornecida pelo algoritmo, cujo eixo das ordenadas é a variável de estado $H$, nível de água no tanque de armazenamento, e o eixo das abscissas é o intervalo de tempo do problema, as 24 horas do dia.

Sendo assim, a Figura 6.5 apresenta a política do controlador calculada com incerteza apenas da discretização da variável de estado $H$. Já as Figuras 6.6, 6.7, 6.8, 6.9, 6.10 e 6.11 apresentam as políticas do controlador calculadas com incertezas da discretização da variável de estado $H$ e da demanda de água para valores de 25, 30, 35, 40, 45 e $50 \mathrm{~m}^{3} / \mathrm{h}$, respectivamente. Nestas figuras a cor branca representa todas as bombas desligadas, a cor cinza clara apenas uma bomba ligada, a cor cinza médio duas bombas ligadas, a cor cinza escuro três bombas ligadas e a cor preta representa a região proibida, onde independetemente da ação do controlador, não será possível suprir a demanda de água na rede de distribuição.

Por exemplo, na política descrita pela Figura 6.5 se às 2:00 o nível de água do tanque for de $6 \mathrm{~m}$, a ação do controlador será desligar todas as bombas. Já se no mesmo horário o nível do tanque for de $2 m$ o controlador deve ligar apenas uma bomba. Porém, se às 6:00 o nível de água no tanque for inferior a $3 m$, independentemente da ação, não será possível suprir a demanda de água na rede de distribuição naquele momento ou num momento subsequente.

A partir destas políticas foram realizados 1000 experimentos cujo estado inicial do problema foi o instante 00:00 e com tanque de armazenamento completamento vazio, i.e, 


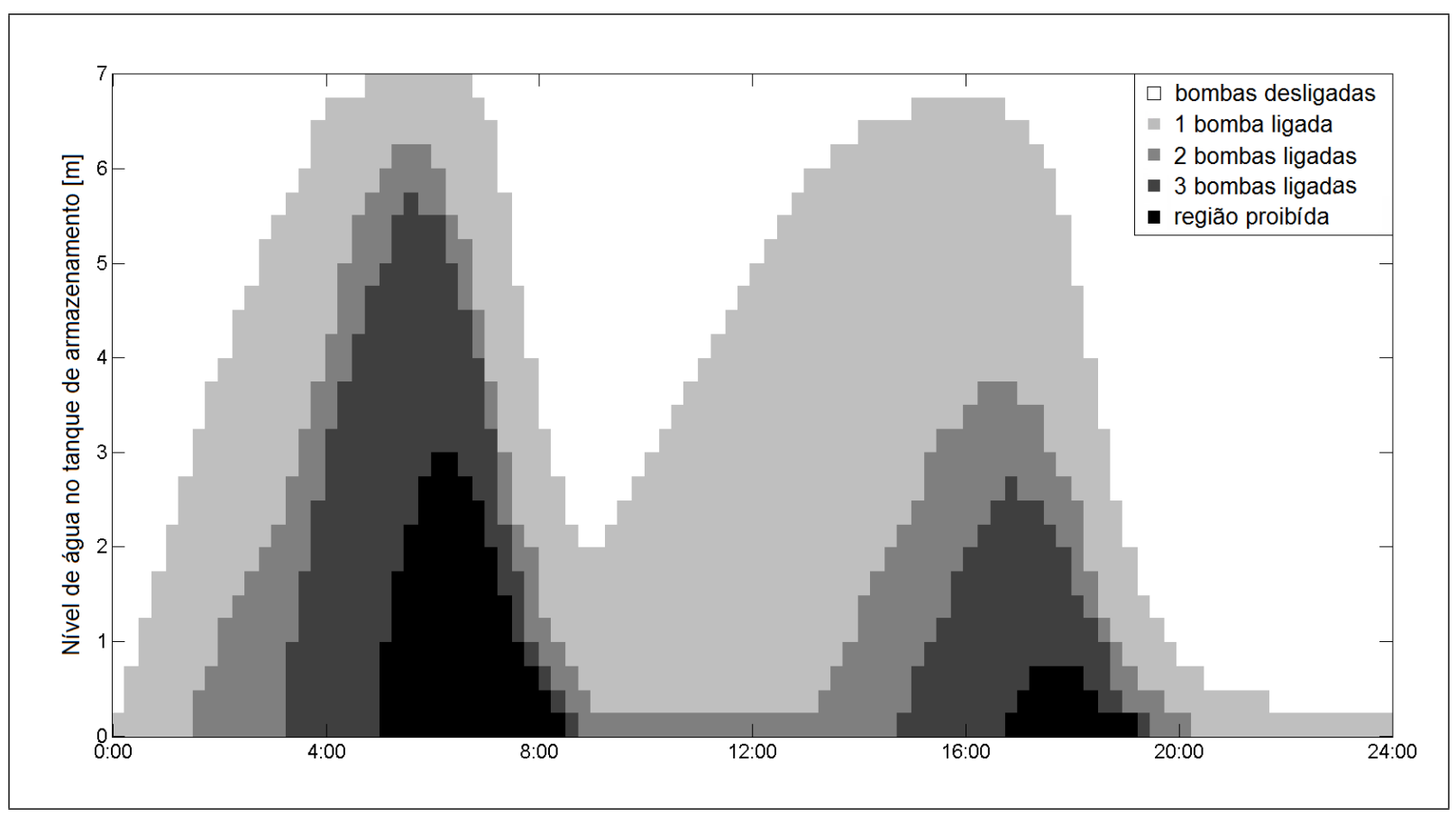

Figura 6.5: Política do Controlador 1 calculada com incerteza apenas da discretização da variável de estado $H-u(\mathcal{X})=\frac{\Delta h}{\sqrt{12}}$.

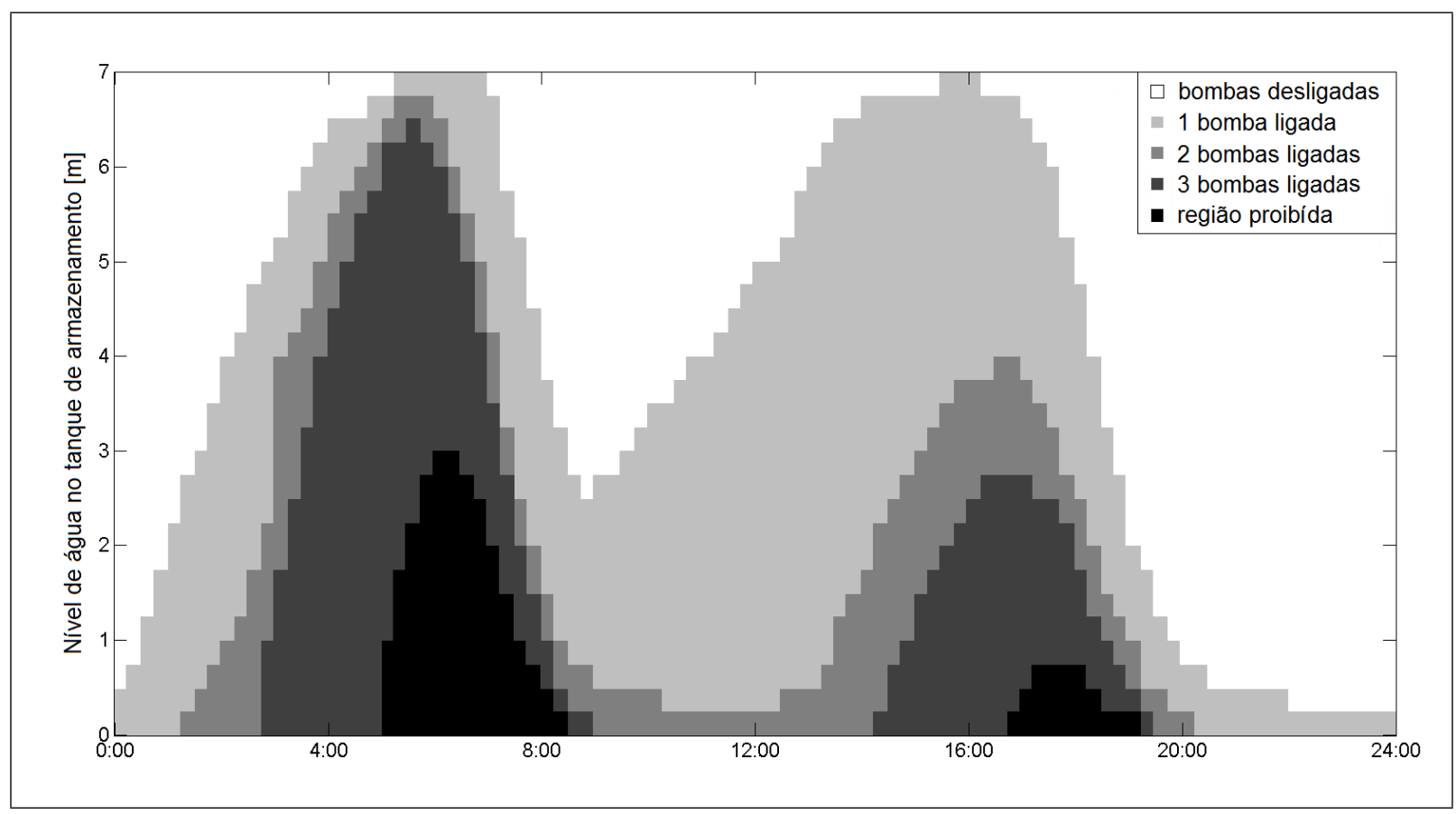

Figura 6.6: Política do Controlador 2 calculada com incertezas da discretização da variável de estado $H-u(\mathcal{X})=\frac{\Delta h}{\sqrt{12}}$ e da demanda de água $-u(D)=25$. 


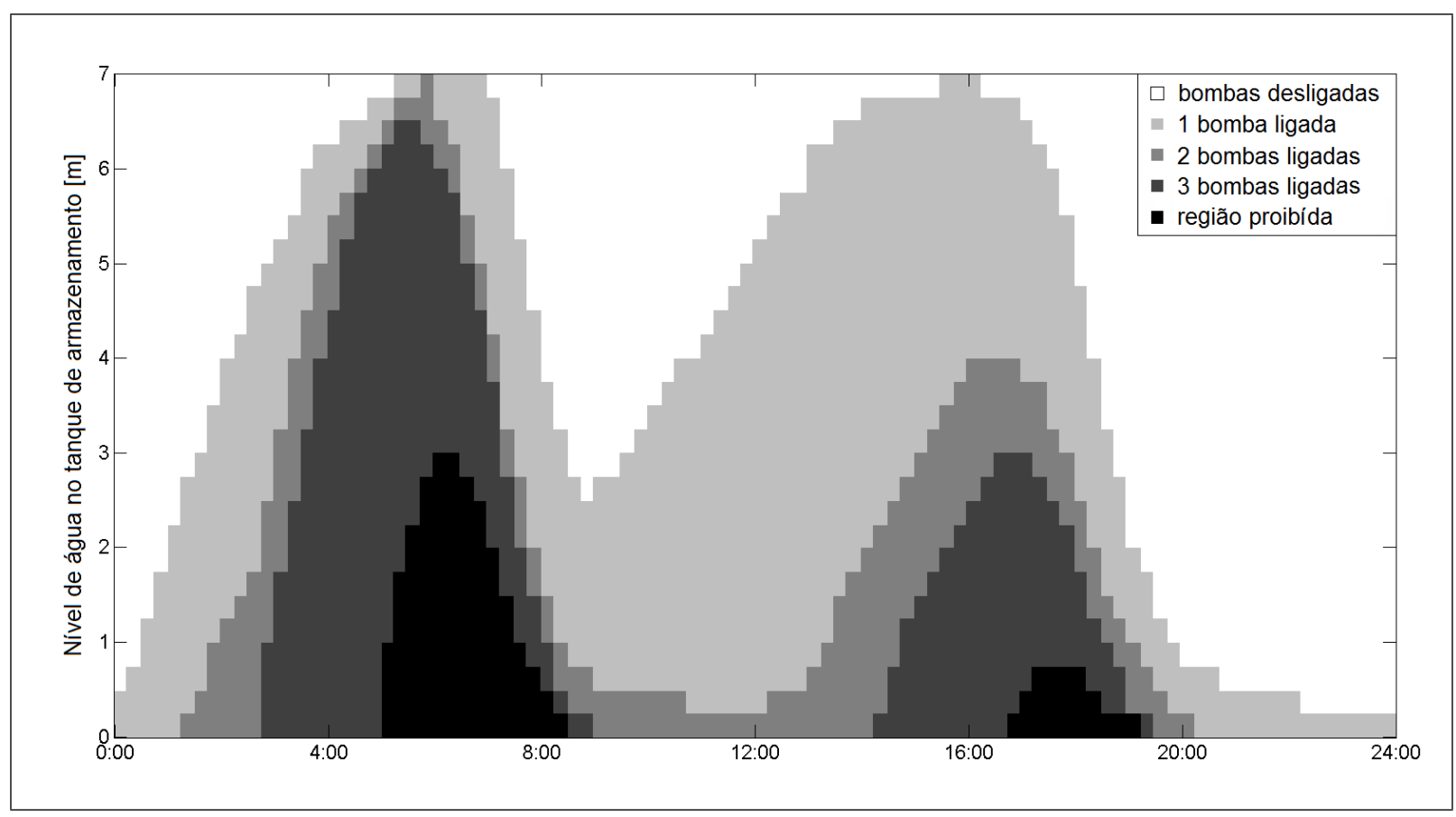

Figura 6.7: Política do Controlador 2 calculada com incertezas da discretização da variável de estado $H-u(\mathcal{X})=\frac{\Delta h}{\sqrt{12}}$ e da demanda de água $-u(D)=30$.

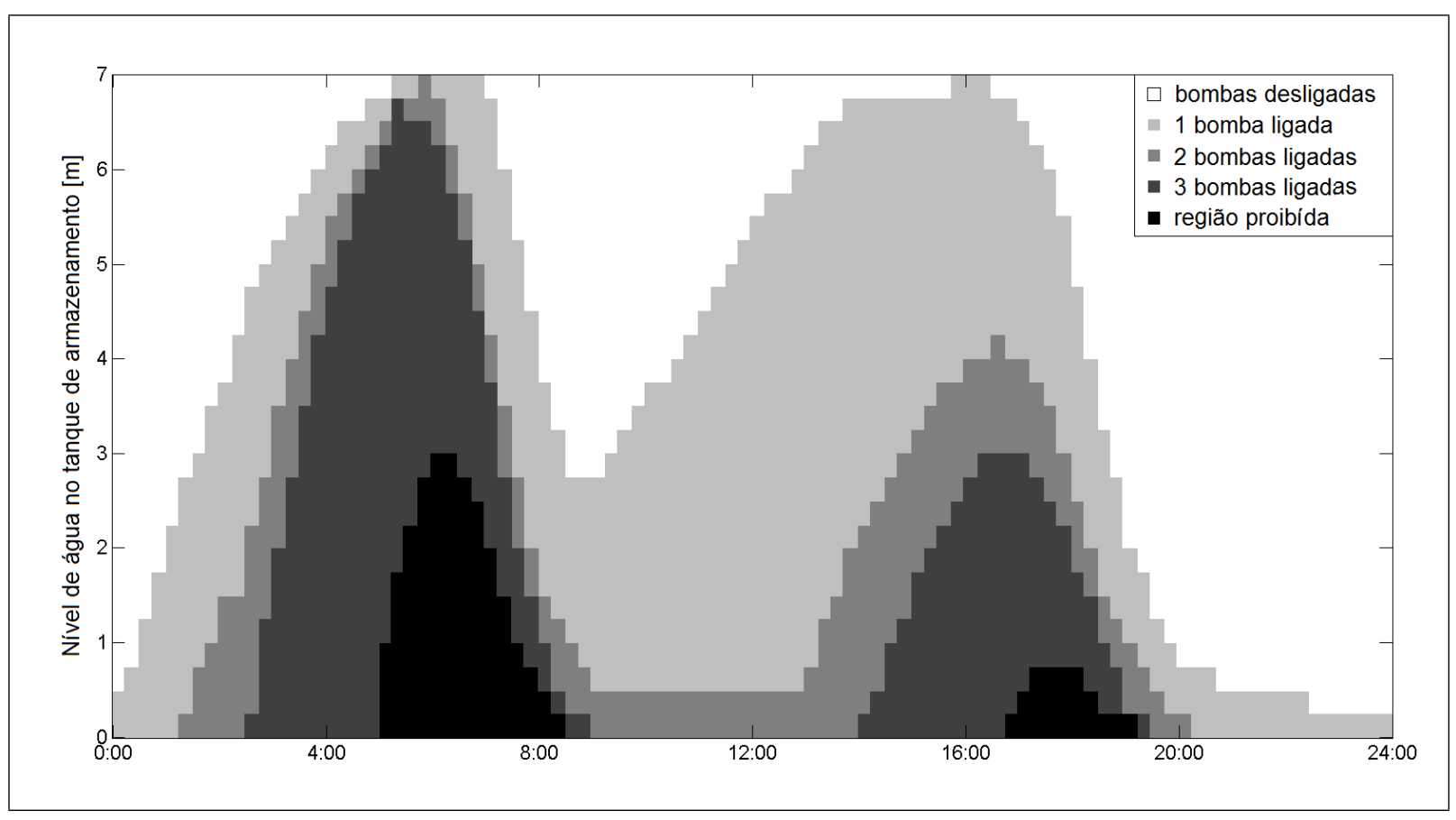

Figura 6.8: Política do Controlador 2 calculada com incertezas da discretização da variável de estado $H-u(\mathcal{X})=\frac{\Delta h}{\sqrt{12}}$ e da demanda de água $-u(D)=35$. 


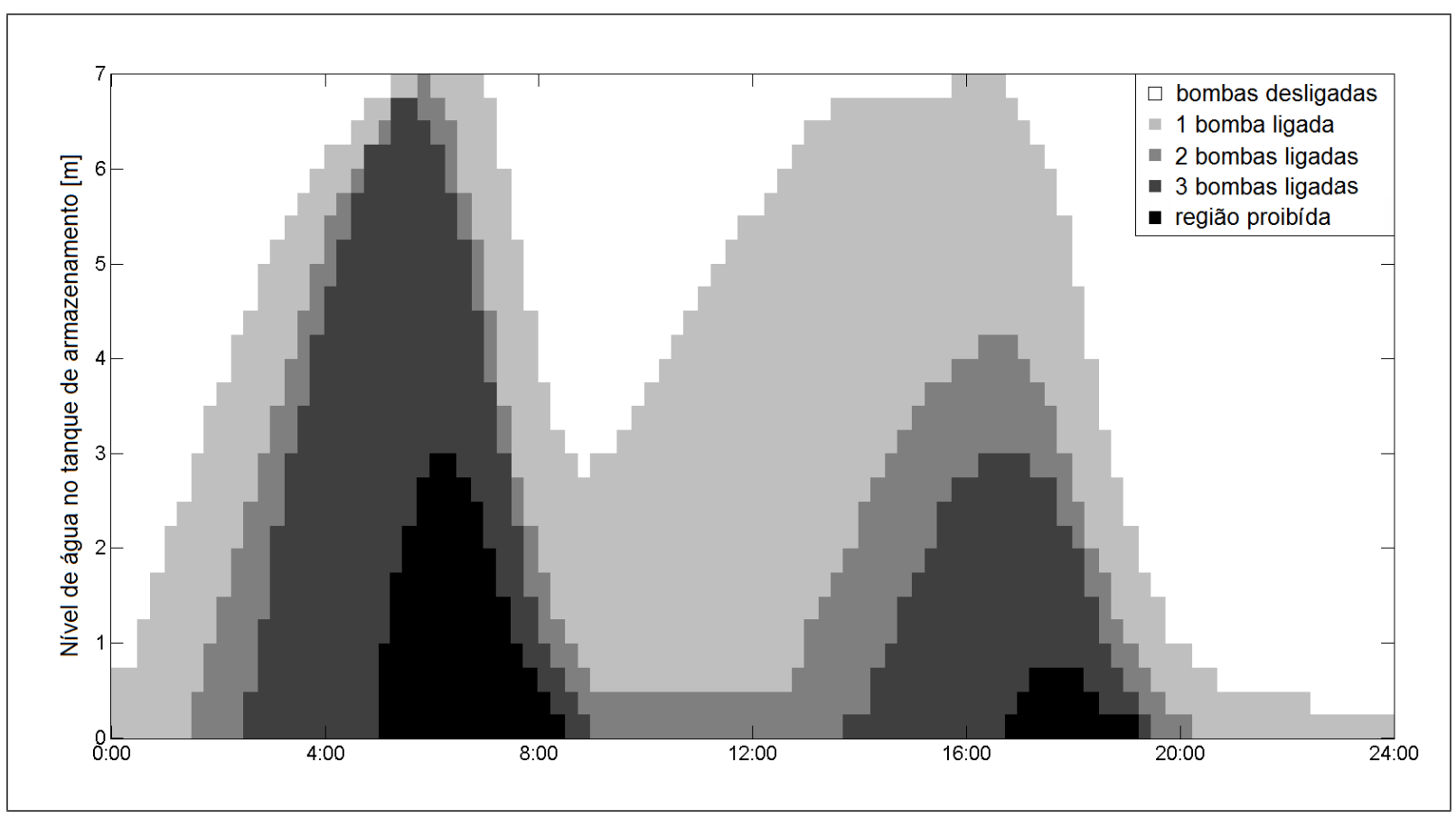

Figura 6.9: Política do Controlador 2 calculada com incertezas da discretização da variável de estado $H-u(\mathcal{X})=\frac{\Delta h}{\sqrt{12}}$ e da demanda de água $-u(D)=40$.

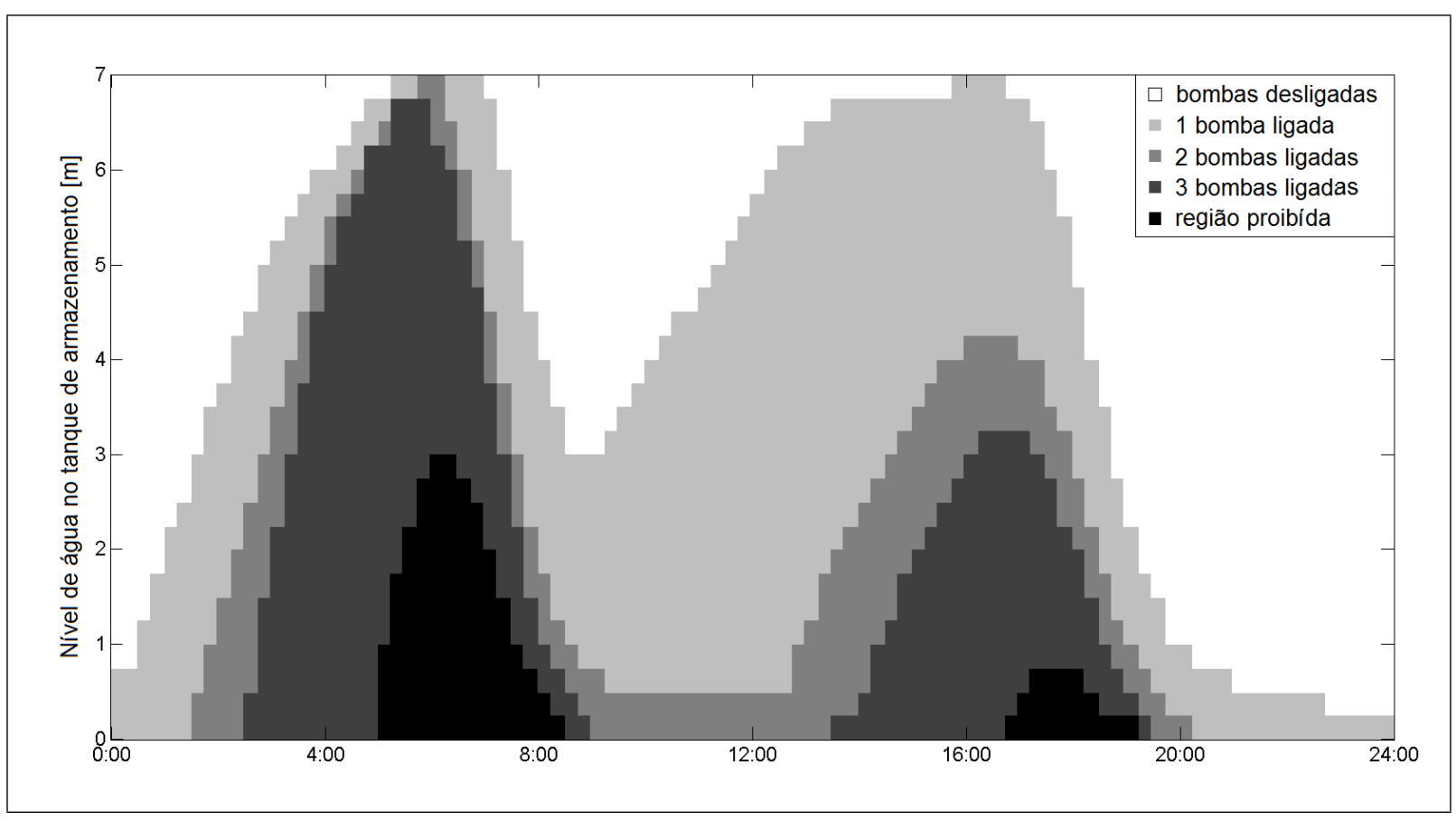

Figura 6.10: Política do Controlador 2 calculada com incertezas da discretização da variável de estado $H-u(\mathcal{X})=\frac{\Delta h}{\sqrt{12}}$ e da demanda de água $-u(D)=45$. 


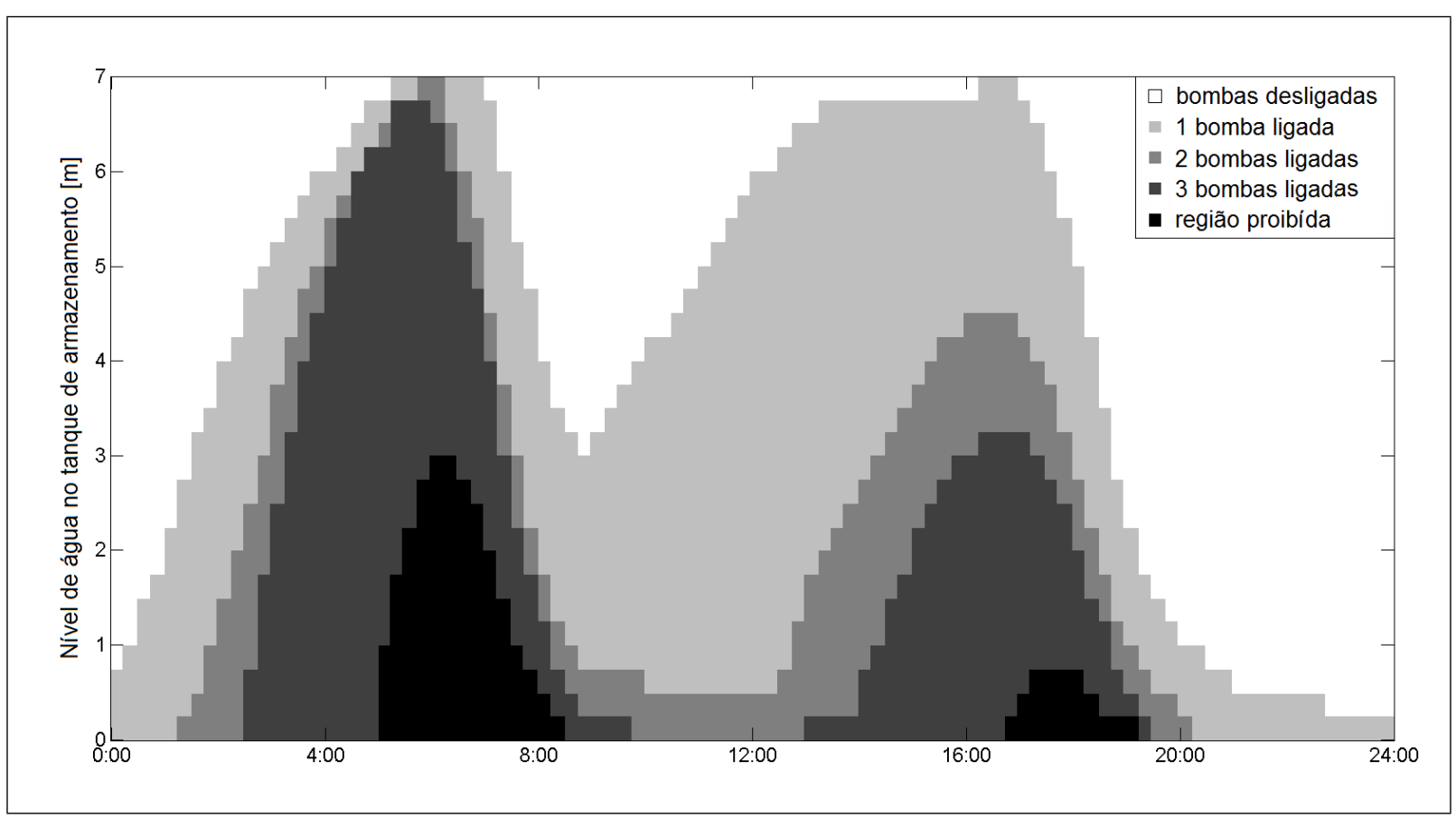

Figura 6.11: Política do Controlador 2 calculada com incertezas da discretização da variável de estado $H-u(\mathcal{X})=\frac{\Delta h}{\sqrt{12}}$ e da demanda de água $-u(D)=50$.

$h=0 \mathrm{~m}$. Os valores da demandas foram associados a ruído branco cujo desvio padrão é igual a incerteza padrão pertencente ao conjunto $u(D)=\{0,25,30,35,40,45,50\}$.

O Controlador 1 foi submetido aos diferentes níveis de incerteza associados à demanda de água, embora não tenha sido projetado para levar em conta este efeito. Já o Controlador 2 foi submetido somente à incerteza que foi projetado. Em ambos os controladores deseja-se analisar os efeitos da incerteza da curva de demanda de água, tanto em relação à robustez do sistema, como em relação aos gastos com energia elétrica.

Os resultados das simulações são compilados na Tabela 6.1, a qual está dividida em percentual de sucesso, quando o controlador consegue suprir a demanda de água durante todo dia, e em gastos com energia elétrica, que é calculada como a média dos gastos com energia consumida pelas bombas nas simulações que obtiveram sucesso.

\subsubsection{Análise dos Resultados}

A partir dos resultados gráficos da política é possível verificar que estes são condizentes com o formato da curva de demanda de água, onde há dois picos de consumo durante o dia, início da manhã e início da noite. Além disso, estes picos de consumo produzem regiões proibidas, onde não é possível suprir a demanda de água caso o controlador atinja 
Tabela 6.1: Resultados dos experimentos com sistema de distribuição simplificado e modelo hidráulico explícito.

\begin{tabular}{|c|c|c|c|c|c|}
\hline \multicolumn{2}{|c|}{ Incerteza } & \multicolumn{2}{|c|}{ Percentual de sucesso [\%] } & \multicolumn{2}{|c|}{ Gastos com energia elétrica $[\mathrm{R} \$ /$ dia $]$} \\
\hline$u(\mathcal{X})$ & $u(D)$ & Controlador 1 & Controlador 2 & Controlador 1 & Controlador 2 \\
\hline \multirow{7}{*}{$\frac{\Delta h}{\sqrt{12}}$} & 0 & 100,0 & 100,0 & 139,9 & 139,9 \\
\hline & 25 & 97,4 & 99,2 & 140,5 & 142,6 \\
\hline & 30 & 94,2 & 98,8 & 140,7 & 143,4 \\
\hline & 35 & 87,6 & 97,2 & 141,0 & 144,4 \\
\hline & 40 & 82,0 & 94,1 & 141,2 & 146,1 \\
\hline & 45 & 72,7 & 94,3 & 141,5 & 146,9 \\
\hline & 50 & 62,6 & 91,3 & 141,8 & 148,2 \\
\hline
\end{tabular}

algum destes estados e que devem ser evitados a todo custo.

Quando se analisa as políticas para diferentes incertezas na demanda de água fica evidente que quanto maior a incerteza menor será o número de estados cuja ação ótima será nenhuma bomba ligada, em contrapartida, maior será o numero de estados cuja ação ótima será acionar todas as 3 bombas. Este tipo de política faz com que seja criada uma margem maior da região proibida. Independentemente das ações, a região proibida permanece inalterada para ambos os controladores e independente da incerteza da demanda de água.

Referente aos dados contidos na Tabela 6.1, observa-se que o Controlador 2 é mais robusto que o Controlador 1. Este fato reflete o objetivo de sua concepção, que é atuar em sistemas de distribuição na presença de incerteza na demanda de água. Porém, a robustez provoca um aumento nos gastos com energia elétrica, fato que está relacionado ao número maior de bombas que devem ser acionadas para evitar as regiões proibidas.

Os dados do percentual de sucesso não são de $100 \%$ para os Controladores do tipo 2 por dois motivos: a incerteza padrão da demanda de água reflete dados calculados como desvios padrão e que valores superiores ao valor da demanda média mais o desvio padrão são plausíveis, ou seja, pode haver valores de demanda muito superiores àquele para os quais o controlador foi projetado; e nos casos de incertezas mais elevadas, podem ocorrer situações que extrapolam a capacidade de suprimento do sistema de distribuição, mesmo com nível máximo no tanque de armazenamento e todas as bombas operando simultaneamente.

Assim, este experimento demonstra que, caso o sistema de controle seja projetado sem que seja levada em conta a variabilidade da demanda, o controlador não será robusto 
suficiente para que seja aplicado a condições reais.

Independentemente dos gastos com energia elétrica, a premissa de fornecimento contínuo de água sempre deve ser priorizada. Técnicas de otimização que não levam em conta as incertezas inerentes ao processo estão desprezando uma informação importante para a robustez do sistema de controle e consequentemente, estão fadadas ao fracasso.

\subsection{Experimentos Comparativos}

Esta seção apresenta os experimentos realizados para comparar três diferentes técnicas de otimização aplicadas ao mesmo sistema de distribuição de água.

Conforme apresentado no Capítulo 2 - Panorama das Técnicas de Otimização para Sistemas de Distribuição de Água, existem diferentes técnicas de otimização para sistemas de distribuição de água, onde, sem sombra de dúvida, os algoritmos genéticos são a técnica de otimização mais difundida. De forma a verificar se os algoritmos genéticos representam a técnica mais adequada para utilização nos trabalhos realizados para a redução de gastos com energia elétrica nas empresas de saneamento na região dos Grandes Lagos, a Wayne State University - WSU coordenou um programa de comparação de técnicas de otimização para sistemas de distribuição de água.

Neste programa estavam presentes três técnicas de otimização: PEPSO (Pollutant Emission Pump Station Optimization), desenvolvida pela própria WSU e baseada em algoritmos genéticos; WaterGEMS, software da empresa Bentley Systems e baseado também em algoritmos genéticos; e o controlador descrito por esta tese, modelagem do problema por MDP com transição de estado probabilística, calculada como uma incerteza devida ao truncamento do algoritmo de cálculo e à discretização das variáveis de estado.

Essas técnicas foram testadas utilizando o mesmo modelo hidráulico e a mesma parametrização dos experimentos de forma a realizar uma análise comparativa nas mesmas bases. Não foram incluídas incertezas devidas ao modelo hidráulico e à demanda de água nos experimentos, pois os outros sistemas comparados não tinham condição de incluí-las.

\subsubsection{Objetivo}

Comparar nossa proposta com duas outras técnicas de otimização aplicadas ao mesmo sistema de distribuição de água, com foco na minimização do consumo energético. 


\subsubsection{Detalhamento do Experimento}

Para realizar os experimentos foi escolhida a cidade de Monroe - MI para fornecer os dados do modelo hidráulico do seu sistema de distribuição. A cidade de Monroe, localizada a cerca de 25 milhas $^{1}$ de cidade de Detroit - MI, possui 40000 habitantes. Além da cidade de Monroe, o mesmo sistema de distribuição também atente a cidade de Petersburg, os distritos de Monroe Charter e Raisinville, as vilas de Dundee e Maybee, além de porções dos distritos de La Salle, Exeter, London e Ida. A área de atendimento deste sistema de distribuição é apresentada pela Figura 6.12, onde as áreas em verde são as atendidas completamente, as em amarelo, parcialmente, e as em laranja, por meio de venda no atacado.

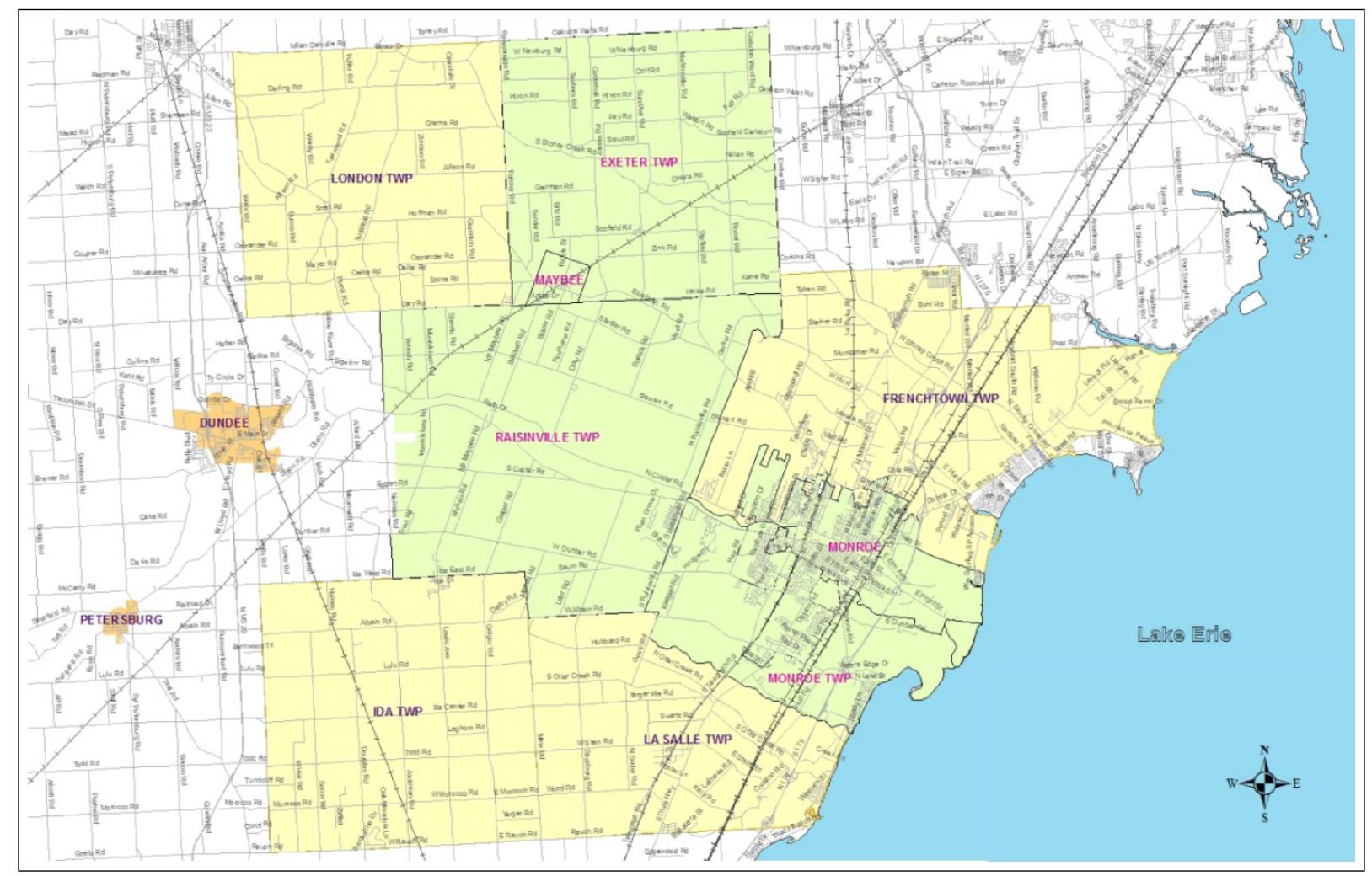

Figura 6.12: Área de abastecimento do sistema de distribuição de Monroe - MI.

O sistema de distribuição de água de Monroe - MI é descrito pela Figura 6.13 e é composto de uma estacão de tratamento de água (ponto na cor cinza), 13 bombas (pontos na cor verde) divididas em duas estações de bombeamento, High Service Pump Station e Booster Station, 3 tanques de armazenamento (pontos na cor azul), 4 pontos de monitoramento de pressão (pontos na cor vermelha) e 285 milhas de tubulação, com

\footnotetext{
${ }^{1}$ Conversão: $1 \mathrm{mi}=1,609 \mathrm{~km}$
} 
diâmetros variando de 2 a 42 polegadas $^{2}$.

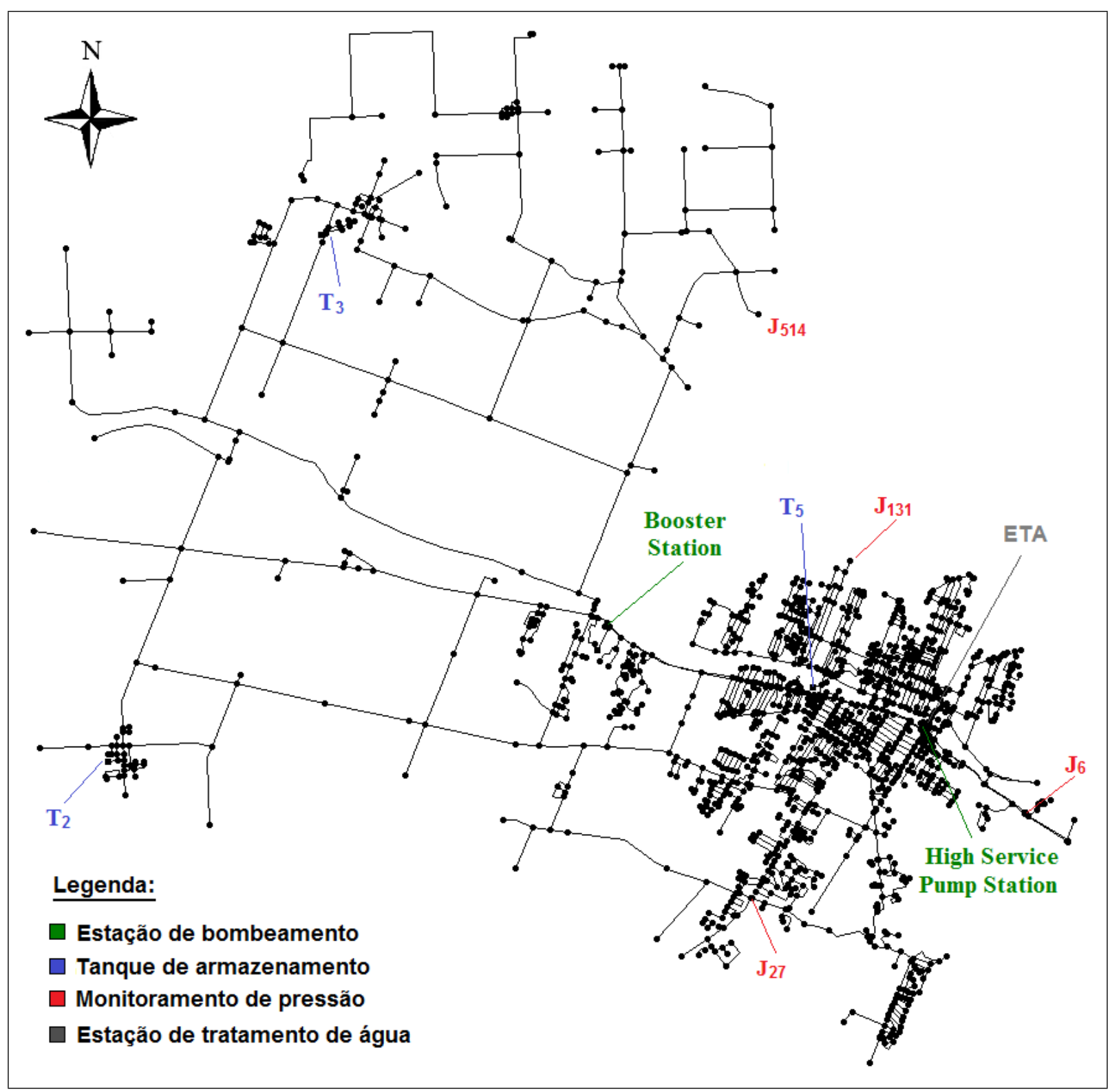

Figura 6.13: Rede de distribuição de Monroe - MI.

As 13 bombas estão da seguinte forma nas estações de bombeamento: High Service Pump Station é composta pelas bombas $E_{2}, E_{3}, E_{4}, E_{5}, E_{6}, E_{7}, W_{8}, W_{9}, W_{10}, W_{11}$ e $W_{12}$, e possuem acionamento direto; e Booster Station é composta pelas bombas PMP e $P M P_{544}$, e são acionadas por inversores de frequência, variando entre $65 \%$ a $100 \%$. As curvas características e de rendimento destas 13 bombas são apresentados pelas Figuras 6.14 e 6.15 , respectivamente.

Os três tanques de armazenamento, $T_{2}, T_{3}$ e $T_{5}$, mantêm a pressão da rede de distri- 


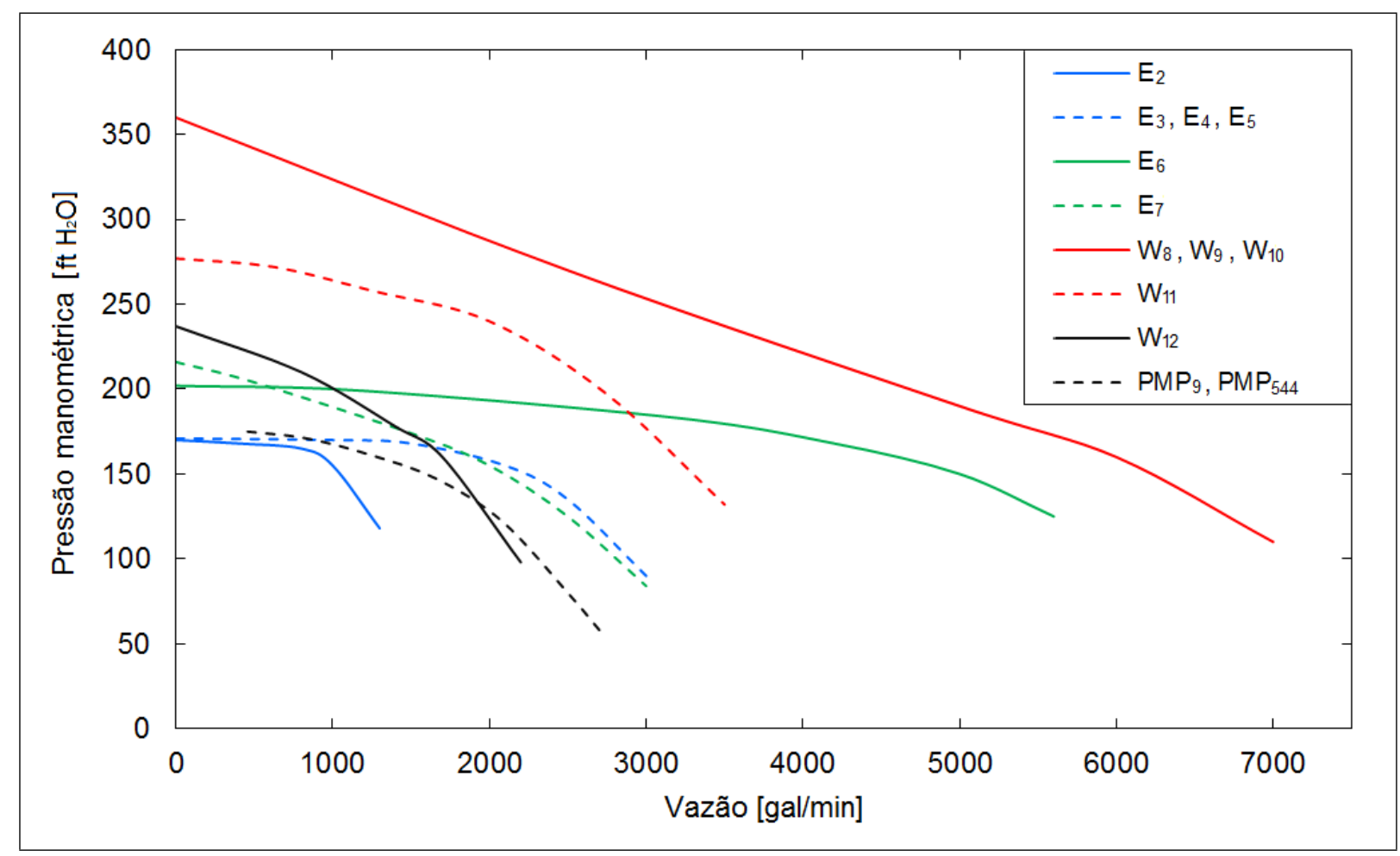

Figura 6.14: Curva característica das bombas do sistema de distribuição de água da cidade de Monroe - MI.

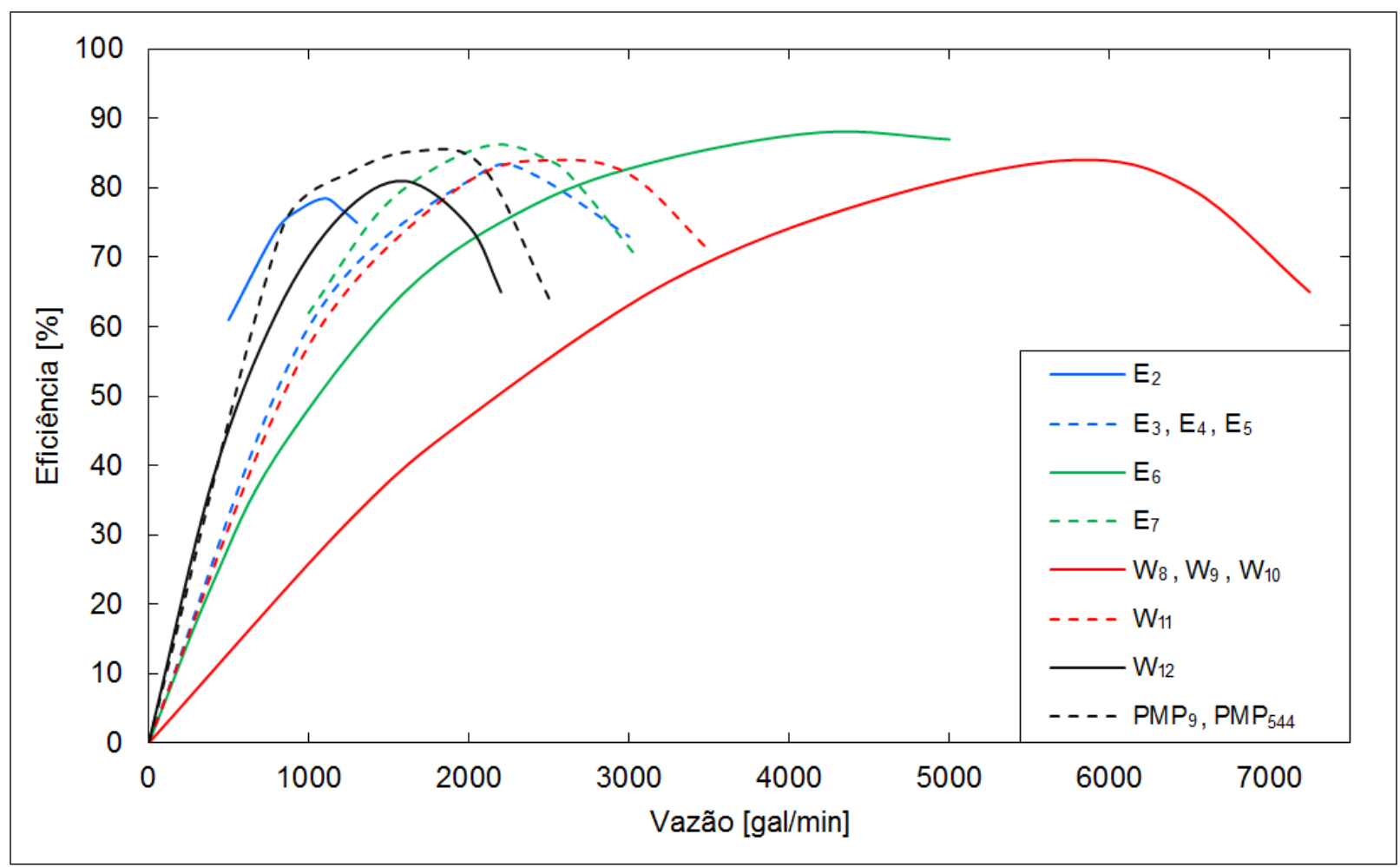

Figura 6.15: Curva de rendimento das bombas do sistema de distribuição de água da cidade de Monroe - MI. 
buição equalizada e ajudam no suprimento de água, juntamente com as bombas, durante os períodos de pico na demanda. Estes três tanques, em conjunto, possuem capacidade de armazenamento de um milhão de galões ${ }^{3}$, cerca de $10 \%$ da demanda diária de água nos meses de verão e possuem características construtivas descritas pela Tabela 6.2.

Tabela 6.2: Características dos tanques do sistema de distribuição de Monroe - MI.

\begin{tabular}{l|ccc}
\hline Característica & $\boldsymbol{T}_{\mathbf{5}}$ & $\boldsymbol{T}_{\mathbf{2}}$ & $\boldsymbol{T}_{\mathbf{3}}$ \\
\hline Nível mínimo [ft $\left.{ }^{4}\right]$ & 1,00 & 0,50 & 0,50 \\
Nível máximo [ft] & 33,25 & 31,25 & 28,00 \\
Elevação [ft] & 712,35 & 740,75 & 772,00 \\
Capacidade [x10 ${ }^{3}$ gal] & 542,32 & 254,87 & 252,53 \\
\hline
\end{tabular}

Os consumidores estão conectados ao sistema de distribuição em mais de 1500 nós e apresentam consumo de água nos meses de verão ${ }^{5}$ descrito pela curva contínua da Figura 6.16. Nesta curva o consumo médio diário é de 9,635 MGD ${ }^{6}$ (linha tracejada da Figura 6.16), com consumo máximo de 11,608 MGD às 09:00 e consumo mínimo de 6,350 MGD às 03:00.

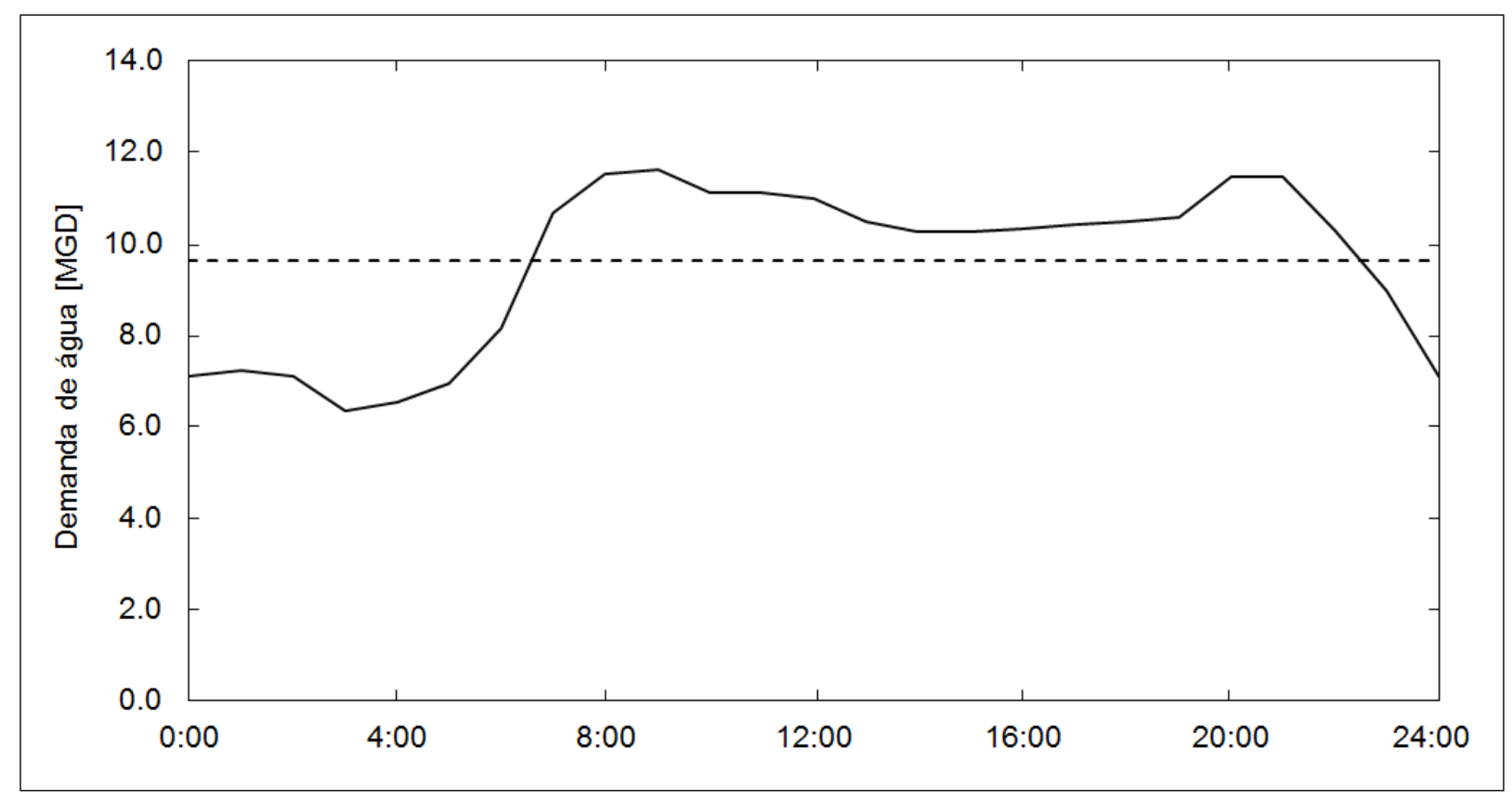

Figura 6.16: Demanda de água nos meses de verão na cidade de Monroe - MI.

Os quatro pontos de monitoramento de pressão na rede de distribuição, nós $J_{6}, J_{27}$, $J_{131}$ e $J_{514}$, servem para verificar se os valores de pressão estão dentro da faixa estabele-

\footnotetext{
${ }^{3}$ Conversão: $1 \mathrm{gal}=3,785 \mathrm{dm}^{3}$

${ }^{5}$ As curvas foram calculadas a partir de dados históricos dos meses de verão do ano de 2010.

${ }^{6}$ Conversão: $1 M G D=41,667 \mathrm{~m}^{3} / \mathrm{h}$
} 
cida pelos operadores visando evitar ruptura nas tubulações da rede ou desabastecimento devido a falta de pressão. Os limites de pressão estabelecidos são descritos pela Tabela 6.3 .

Tabela 6.3: Características dos tanques do sistema de distribuição de Monroe - MI.

\begin{tabular}{l|cc}
\hline Nó & $\begin{array}{c}\text { Pressão mín. } \\
{\left[\text { [PSI }^{7} \text { ] }\right.}\end{array}$ & $\begin{array}{c}\text { Pressão máx. } \\
\text { [PSI] }\end{array}$ \\
\hline$J_{6}$ & 60 & 75 \\
$J_{27}$ & 45 & 65 \\
$J_{131}$ & 40 & 60 \\
$J_{514}$ & 60 & 80 \\
\hline
\end{tabular}

A seguir são apresentadas as características de cada um dos algoritmos utilizados neste experimento comparativo.

\subsubsection{WaterGEMS}

O software WaterGEMS, da empresa Bentley Systems, é um pacote de ferramentas para modelagem de sistemas de distribuição de água. Adicionalmente ao simulador hidráulico poderoso, também possibilita análises do desempenho hidráulico do sistema de distribuição e do consumo energético das bombas, além do desenvolvimento de políticas de controle para operação das estações de bombeamento (BENTLEY, 2009). Neste software também se pode estabelecer restrições operacionais na rede de distribuição como limites nas pressões dos nós, nas velocidade da água nos tubos e nos níveis dos tanques de armazenamento.

O módulo Darwin Scheduler é o algoritmo responsável pela otimização da operação das bombas e possibilita a otimização, tanto dos gastos com energia elétrica, como também pelo consumo energético das bombas, foco desta análise comparativa. Este módulo é baseado na técnica de algoritmos genéticos, cuja função objetivo é definida como:

$$
F_{\text {obj }}=\text { Power }_{\text {WaterGEMS }}+\text { Penalty }_{W a t e r G E M S}
$$

onde Power $_{W a t e r G E M S}$ é o somatório do consumo energético das 13 bombas e Penalty ${ }_{W a t e r G E M S}$ é definido como:

$$
\text { Penalty }_{\text {WaterGEMS }}=\sum_{i=1}^{N_{M}} P V(i) \cdot P F \cdot 10^{5}
$$

onde $P V$ é o valor absoluta da violação, $P F$ é o fator da penalidade, valor no intervalo $[0,5 ; 2,0]$ e $N_{M}$ é o número de variáveis que são monitoradas; neste experimento foram monitoradas as 4 pressões dos nós na cor vermelha da Figura 6.13. 
Finalmente, a Tabela 6.4 apresenta os parâmetros do módulo Darwin Scheduler utilizados neste experimento comparativo.

Tabela 6.4: Parâmetro do módulo Darwin Scheduler do software WaterGEMS.

\begin{tabular}{l|c}
\hline Parâmetro & Valor \\
\hline Número máximo de gerações & 1000 \\
Máximo de gerações não melhoradas & 200 \\
Número máximo de eras & 10 \\
Número máximo de iterações & $10^{5}$ \\
Tamanho da população & 100 \\
Tamanho da população elite & 10 \\
Número de pontos de recombinação & 4 \\
Probabilidade de recombinação & $95 \%$ \\
Probabilidade de mutação & $1,5 \%$ \\
Probabilidade de creeping mutation & $0.1 \%$ \\
Probabilidade de creeping down & $65 \%$ \\
Probabilidade de corte & $1 \%$ \\
Probabilidade de divisão & $90 \%$ \\
Probabilidade de elite mate & $0,5 \%$ \\
Probabilidade de tournament winner & $95 \%$ \\
\hline
\end{tabular}

\subsubsection{PEPSO}

O programa PEPSO (Pollutant Emission Pump Station Optimization), desenvolvido pela Wayne State University, é parte de um projeto para redução do consumo energético e de emissões de gás decorrentes da produção de energia elétrica pelas empresas de saneamento na região dos Grandes Lagos, dado que estas são consumidoras massivas de energia.

O objetivo do PEPSO é a otimização da operação das bombas, de forma que estas trabalhem próximas ao seu ponto de melhor eficiência, como também, deslocar o consumo de energia para períodos do dia onde a produção é realizada por fontes menos poluidoras. Os dados de emissão são obtidos de forma indireta, utilizando o valor do preço de fechamento da energia no mercado livre no dia anterior e, desta forma, estima-se a fonte produtora e determina-se as emissões associadas. Apesar desta interessante funcionalidade, neste experimento comparativo foi considerada uma única fonte produtora e com preço de energia unitário. 
O PEPSO, como o WaterGEMS, possui um algoritmo de otimização também baseado em algoritmos genéticos, porém, a sua função objetivo é calculada da seguinte forma:

$$
F_{o b j}=k_{p w r} \cdot\left(\text { Power }_{P E P S O}\right)^{\exp _{p w r}}+k_{p n t} \cdot\left(\text { Penalty }_{P E P S O}\right)^{\exp _{p n t}}
$$

onde Power ${ }_{P E P S O}$ é o somatório do consumo energético das 13 bombas, Penalty $y_{P E P S O}$ é o somatório das penalidades, $k_{p w r}=1$ e $k_{p n t}=5$ são multiplicadores do consumo energético e das penalidades, $e x_{p w r}=1.2$ e $e x_{p n t}=1.5$ são expoentes do consumo energético e das penalidades. A função de penalidade é definida como:

$$
\text { Penalty }_{P E P S O}=\sum_{i=1}^{N_{m}} P V(i)
$$

onde $P V$ é o valor absoluto da violação e $N_{M}=4$ é o número de variáveis que são monitoradas.

Finalmente, a Tabela 6.5 apresenta os parâmetros utilizados pelo algoritmo de otimização do PEPSO.

Tabela 6.5: Parâmetro do algoritmo PEPSO.

\begin{tabular}{l|c}
\hline Parâmetro & Valor \\
\hline Número máximo de gerações & 1000 \\
Máximo de gerações não melhoradas & 200 \\
Tamanho da população & 100 \\
Tamanho da população elite & 10 \\
Número de pontos de recombinação & 2 \\
Probabilidade de mutação do organismo & aleatório \\
Probabilidade de mutação do cromossomo & aleatório \\
Probabilidade de mutação do gene & aleatório \\
\hline
\end{tabular}

\subsubsection{Modelo MDP}

A modelagem por MDP, como do experimento anterior, é descrito pela tupla $\langle\mathcal{S}, \mathcal{A}, \mathcal{D}, \mathcal{T}, \mathcal{R}\rangle$, onde $\mathcal{S}$ é um conjunto finito de estados, $\mathcal{A}$ é um conjunto finito de ações, $\mathcal{D}$ é uma sequência finita de épocas de decisão, $\mathcal{T}$ é uma função de transição de estado e $\mathcal{R}$ é uma função de recompensa.

Utilizando a representação fatorada o conjunto finito dos estados é composto pelas seguintes variáveis de estado: nível de água nos três tanques de armazenamento, $H\left(T_{2}\right)$, 
$H\left(T_{3}\right)$ e $H\left(T_{5}\right)$; e pressão nos quatro nós monitorados, $P\left(J_{6}\right), P\left(J_{27}\right), P\left(J_{131}\right)$ e $P\left(J_{514}\right)$. Assim, o conjunto de estados é:

$$
S=\left(H\left(T_{2}\right), H\left(T_{3}\right), H\left(T_{5}\right), P\left(J_{6}\right), P\left(J_{27}\right), P\left(J_{131}\right), P\left(J_{514}\right)\right)
$$

Cada uma dessas sete variáveis de estado é discretizada uniformemente no intervalo $\left[\mathcal{X}_{\text {max }}, \mathcal{X}_{\text {min }}\right]$, resultando em:

$$
\mathcal{X}=\left\{\mathcal{X}_{\text {min }}+\Delta x\left(i-\frac{1}{2}\right) \mid i=1,2, \ldots, \frac{\mathcal{X}_{\max }-\mathcal{X}_{\min }}{\Delta x}\right\},
$$

onde $\Delta x$ é a constante de discretização da variável de estado $\mathcal{X}$. A Tabela 6.6 descreve os intervalos de cada uma das variáveis de estado, bem como sua respectiva constante de discretização:

Tabela 6.6: Parâmetro das variáveis de estado.

\begin{tabular}{l|ccc}
\hline Variável de estado & $\boldsymbol{\mathcal { X }}_{\boldsymbol{m i n}}$ & $\boldsymbol{\mathcal { X }}_{\boldsymbol{m a x}}$ & $\boldsymbol{\Delta} \boldsymbol{x}$ \\
\hline$H\left(T_{2}\right)$ & 0,50 & 31,25 & 5,125 \\
$H\left(T_{3}\right)$ & 0,50 & 28,00 & 4,583 \\
$H\left(T_{5}\right)$ & 1,00 & 33,25 & 5,375 \\
$P\left(J_{6}\right)$ & 60,0 & 75,0 & 2,50 \\
$P\left(J_{27}\right)$ & 45,0 & 65,0 & 3,33 \\
$P\left(J_{131}\right)$ & 40,0 & 60,0 & 3,33 \\
$P\left(J_{514}\right)$ & 60,0 & 80,0 & 3,33 \\
\hline
\end{tabular}

O conjunto finito de ações é descrito pelas ações que podem ser executadas por cada uma das 13 bombas, resultando em:

$$
\mathcal{A}=\left(K\left(E_{2}\right), \ldots, K\left(E_{7}\right), K\left(W_{8}\right), \ldots, K\left(W_{12}\right), K\left(P M P_{9}\right), K\left(P M P_{544}\right)\right)
$$

onde as bombas acionadas diretamente são descritas pelo conjunto binário, com 0 para bomba desligada e 1 para bomba ligada, resultando em: $K\left(E_{2}\right)=K\left(E_{3}\right)=K\left(E_{4}\right)=$ $K\left(E_{5}\right)=K\left(E_{6}\right)=K\left(E_{7}\right)=K\left(W_{8}\right)=K\left(W_{9}\right)=K\left(W_{10}\right)=K\left(W_{11}\right)=K\left(W_{12}\right)=\{0,1\}$. Já as bombas acionadas por inversores de frequência são descritas da seguinte forma: $K\left(P M P_{9}\right)=K\left(P M P_{544}\right)=\{0.0,0.65,0.7,0.85,1.0\}$.

Como no experimento anterior, o conjunto de épocas de decisão foi definido no intervalo de tempo de 24 horas, iniciando às 0:00 e finalizando às 24:00. Por ser um intervalo contínuo o mesmo é discretizado uniformemente pelo passo de tempo $\Delta t=1: 00^{8}$, ou seja,

\footnotetext{
${ }^{8} \mathrm{O}$ passo de tempo foi definido de comum acordo entre os três participantes da análise comparativa.
} 
a cada 1 hora, resultando em:

$$
\begin{aligned}
\mathcal{D} & =\left\{T_{\min }, T_{\min }+\Delta t, \ldots, T_{\max }\right\} \\
& =\{0: 00,1: 00,2: 00, \ldots, 22: 00,23: 00,24: 00\},
\end{aligned}
$$

onde $T_{\min }$ é o instante de tempo inicial e $T_{\max }$ é o horizonte de tempo do problema.

Por se tratar de um problema complexo, a transição de estado é realizada pelo software de simulação hidráulica EPANET. Assim, o valor do próximo estado é descrito por meio da seguinte função:

$$
\sigma^{\prime}=f_{T}(\sigma, \alpha, d)
$$

onde $f_{T}$ é a função que calcula o próximo estado $\sigma^{\prime}$ por meio do software de simulação hidráulica, $\sigma$ é o estado atual, $\alpha$ é a ação executada no estado e $d$ é a época de decisão.

Conforme descrito no Capítulo 4, a função de transição de estado está associada a uma incerteza e que neste experimento será devida a duas fontes: truncamento, fruto do truncamento do algoritmo iterativo de cálculo do software de simulação hidráulica; e discretização, devido às variáveis de estado serem transformadas do espaço contínuo para o espaço discreto.

As incertezas decorrentes do modelo hidráulico e da demanda de água não foram incluídas pois os outros sistemas comparados não tinham condição de incluí-las. Apesar deste fato, estas duas fontes de incerteza não terão impacto na análise, uma vez que ambas são de fundamental importância quando as análises comparativas são feitas em sistemas reais e neste caso foram realizadas apenas simulações. Desta forma, a incerteza da função de transição de estado foi:

$$
u\left(f_{T}\right)_{\mathcal{X}_{i}}=\sqrt{\left(\frac{\partial f_{T}}{\partial T} \cdot u(T)\right)^{2}+\left(\frac{\partial f_{T}}{\partial \mathcal{X}_{i}} \cdot u\left(\mathcal{X}_{i}\right)\right)^{2}},
$$

onde $u\left(f_{T}\right)_{\mathcal{X}_{i}}$ é a incerteza padrão da função de transição da variável de estado $\mathcal{X}_{i}, u(T)$ e $u\left(\mathcal{X}_{i}\right)$ são as incertezas padrão do truncamento do algoritmo de cálculo e da discretização da $i$-ésima variável de estado, respectivamente. Já $\frac{\partial f_{T}}{\partial T}$ e $\frac{\partial f_{T}}{\partial \mathcal{X}_{i}}$ são os coeficientes de sensibilidade do truncamento do algoritmo de cálculo e da discretização da $i$-ésima variável de estado, respectivamente.

Com relação ao truncamento do algoritmo de cálculo, a sua incerteza padrão é o próprio valor do erro de truncamento, ou seja, $u(T)=\varepsilon$. Neste experimento foi utilizado o valor de 0,001. Já o seu coeficiente de sensibilidade foi calculado por meio da derivada 
parcial numérica, resultando em:

$$
\frac{\partial f_{T}}{\partial T} \approx \frac{\left.f_{T}(\sigma, \alpha, d)\right|_{\varepsilon+\epsilon}-\left.f_{T}(\sigma, \alpha, d)\right|_{\varepsilon}}{\epsilon},
$$

tal que $\epsilon \ll \varepsilon$ e onde $\left.f_{T}(\sigma, \alpha, d)\right|_{\varepsilon+\epsilon}$ e $\left.f_{T}(\sigma, \alpha, d)\right|_{\varepsilon}$ são calculadas por meio do software de simulação hidráulica EPANET.

Já com relação às sete variáveis de estado do problema, a sua incerteza foi o coeficiente de discretização dividido por raiz de 12 , ou seja, $u\left(\mathcal{X}_{i}\right)=\frac{\Delta x_{i}}{\sqrt{12}}$. Por outro lado, o coeficiente de sensibilidade também foi calculado por meio da derivada parcial numérica:

$$
\frac{\partial f_{T}}{\partial \mathcal{X}_{i}} \approx \frac{\left.f_{T}(\sigma, \alpha, d)\right|_{\mathcal{X}_{i}+\epsilon}-\left.f_{T}(\sigma, \alpha, d)\right|_{\mathcal{X}_{i}}}{\epsilon}
$$

tal que $\epsilon \ll 1$ e onde $\left.f_{T}(\sigma, \alpha, d)\right|_{\mathcal{X}_{i}+\epsilon}$ e $\left.f_{T}(\sigma, \alpha, d)\right|_{\mathcal{X}_{i}}$ também são calculadas por meio do software de simulação hidráulica EPANET.

Finalmente, a função de recompensas $\mathcal{R}$ foi definida como o consumo energético das bombas durante o período de 24 horas, resultando em:

$$
\mathcal{R}=-\sum_{d=T_{\min }}^{T_{\max }} \sum_{u=1}^{13} P w(u, d),
$$

onde $P w(u, d)$ é a potência elétrica da bomba $u$ na época de decisão $d$ e calculada por meio do software de simulação hidráulica EPANET.

A seguir são apresentados os resultados dos experimentos comparativos envolvendo as três técnicas de otimização apresentadas nesta tese.

\subsubsection{Resultados}

Os experimentos foram realizados em série única (sem repetições) pelos três participantes da análise comparativa utilizando o mesmo modelo hidráulico do sistema de distribuição e a mesma parametrização do experimento. No caso das parametrizações específicas de cada um dos algoritmos de otimização, as mesmas estão descritas nas seções anteriores deste capítulo.

O objetivo estabelecido da otimização é a redução dos gastos com energia elétrica do sistema de distribuição de água da cidade de Monroe - MI, respeitando-se as restrições de pressão impostas e de fornecimento contínuo de água durante todo o período.

Sendo assim, a Tabela 6.7 apresenta o consumo energético horário de cada uma das 
três técnicas, onde cada linha da tabela representa o consumo dos 60 minutos da hora correspondente. Além dos dados horários também são apresentados, nas últimas linhas da tabela, o consumo energético diário, obtido por meio da soma dos consumos horários, e a demanda de energia, que é a máxima potência do sistema no período do experimento.

Tabela 6.7: Energia elétrica consumida (Unidade: $k W h$ ).

\begin{tabular}{|c|c|c|c|}
\hline Tempo & WaterGEMS & PEPSO & MDP \\
\hline 00:00 & 139,00 & 297,30 & 68,80 \\
\hline 01:00 & 260,80 & 170,20 & 69,35 \\
\hline 02:00 & 153,40 & 284,90 & 222,44 \\
\hline 03:00 & 80,40 & 221,30 & 195,77 \\
\hline 04:00 & 160,00 & 82,40 & 69,69 \\
\hline 05:00 & 176,00 & 89,10 & 220,31 \\
\hline 06:00 & 260,40 & 127,50 & 258,40 \\
\hline 07:00 & 167,60 & 190,70 & 291,07 \\
\hline 08:00 & 453,20 & 246,90 & 249,55 \\
\hline 09:00 & 253,60 & 267,30 & 264,97 \\
\hline 10:00 & 208,50 & 231,10 & 371,75 \\
\hline $11: 00$ & 406,80 & 319,50 & 249,71 \\
\hline $12: 00$ & 269,90 & 430,30 & 264,89 \\
\hline $13: 00$ & 393,40 & 178,30 & 292,97 \\
\hline 14:00 & 228,70 & 236,90 & 287,10 \\
\hline $15: 00$ & 271,00 & 184,30 & 294,82 \\
\hline $16: 00$ & 390,30 & 495,10 & 293,49 \\
\hline $17: 00$ & 260,00 & 263,10 & 218,07 \\
\hline $18: 00$ & 269,70 & 197,00 & 293,42 \\
\hline 19:00 & 272,00 & 187,40 & 292,34 \\
\hline 20:00 & 341,70 & 490,70 & 303,18 \\
\hline 21:00 & 229,80 & 624,00 & 332,14 \\
\hline $22: 00$ & 360,50 & 14,20 & 245,27 \\
\hline $23: 00$ & 308,70 & 132,40 & 257,76 \\
\hline Total $(k W h)$ & 6315,40 & 5961,90 & 5907,27 \\
\hline Demanda $(k W)$ & 453,20 & 624,00 & 371,75 \\
\hline
\end{tabular}

A energia consumida descrita pela Tabela 6.7 é decorrência da soma de energia consumida por cada uma das 13 bombas. Desta forma, por meio das Tabelas 6.9, 6.10 e 6.11 é possível verificar o acionamento de cada uma das bombas para os três algoritmos 
analisados e que gerou o consumo energético especificado na Tabela 6.7. As células dessas tabelas que não estão preenchidas representam a bomba desligada, já o valor 1 representa a bomba ligada e, no caso das bombas da Booster Station, $P M P_{9}$ e $P M P_{544}$, os valores representam o percentual de acionamento da bomba realizado pelo inversor de frequência.

As Figuras 6.17, 6.18, 6.19 e 6.20 apresentam as curvas das variáveis de estado relacionadas às pressões nos nós $J_{6}, J_{27}, J_{131}$ e $J_{514}$, respectivamente. Nestas figuras, as curvas na cor azul representam o comportamento do WaterGEMS, as curvas na cor vermelha, o comportamento do PEPSO e as curvas na cor roxa, o comportamento do MDP. As Tabelas B.1, B.2, B.3 e B.4 do Anexo B apresentam os valores obtidos nas simulações.

Já as curvas 6.21, 6.22 e 6.23 apresentam as curvas das variáveis de estado relacionadas aos níveis de água nos tanques de armazenamento $T_{2}, T_{3}$ e $T_{5}$, respectivamente. Nestas figuras a representação de curvas segue o mesmo padrão, azul para o WaterGEMS, vermelho para o PEPSO e roxa para o MDP. As Tabelas B.5, B.6 e B.7 do Anexo B apresentam os valores obtidos nas simulações.

A curva 6.24 mostra o volume de água armazenado conjuntamente pelos tanques $T_{2}, T_{3}$ e $T_{5}$ durante o período de execução, onde a representão de cores segue o mesmo padrão das figuras anteriores. A Tabela B.8 do Anexo B apresenta os valores obtidos nas simulações.

Finalmente, a Tabela 6.8 apresenta os tempos de execução do experimento para cada uma das três técnicas analisadas.

Tabela 6.8: Tempo de execução dos algoritmos.

\begin{tabular}{c|c}
\hline Técnica & Tempo de execução \\
\hline WaterGEMS & $79200 \mathrm{~s}$ \\
PEPSO & $28030 \mathrm{~s}$ \\
MDP & $46671 \mathrm{~s}$ \\
\hline
\end{tabular}




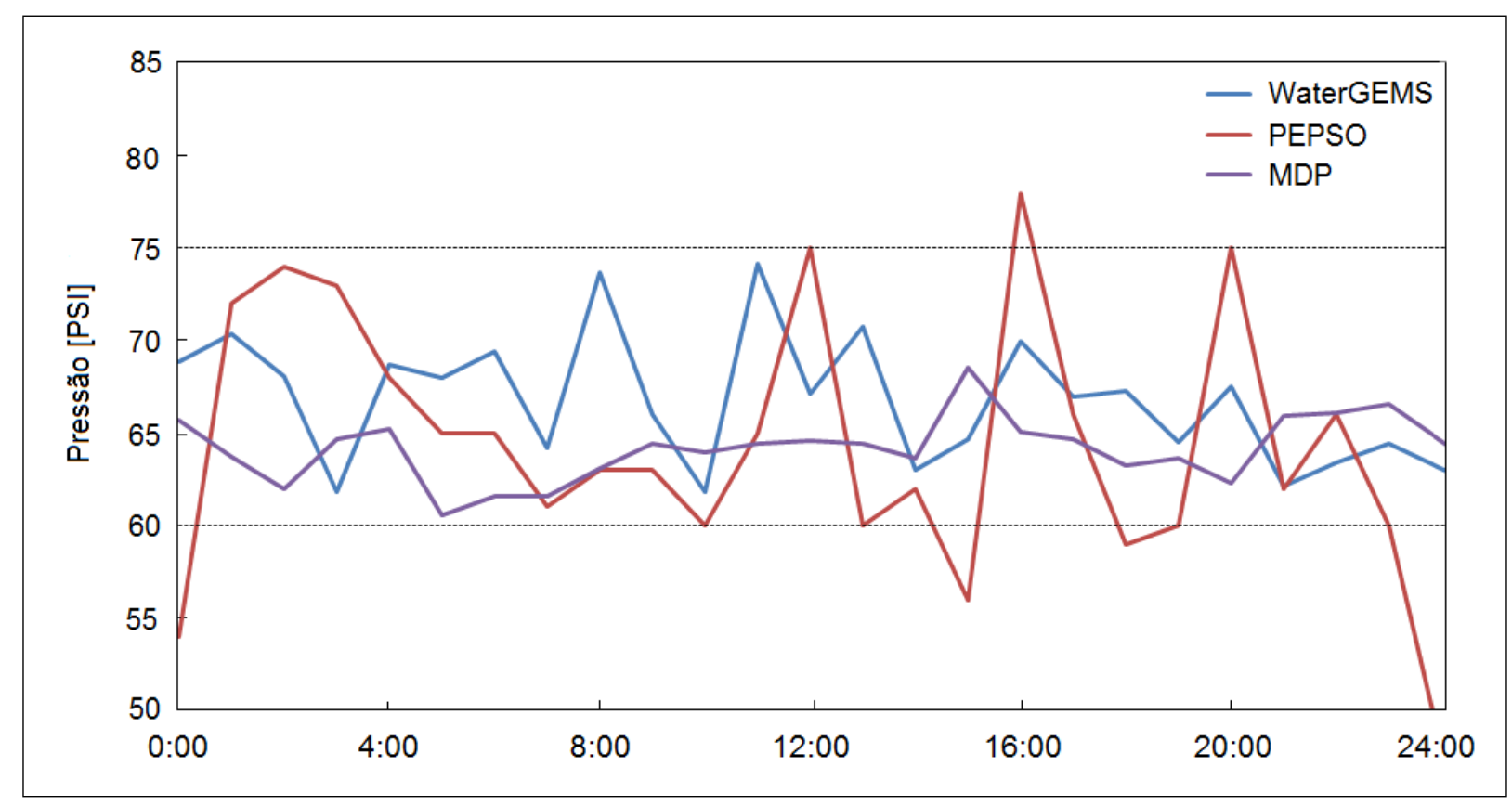

Figura 6.17: Pressão no nó $J_{6}$, onde $60 \leq P\left(J_{6}\right) \leq 75$.

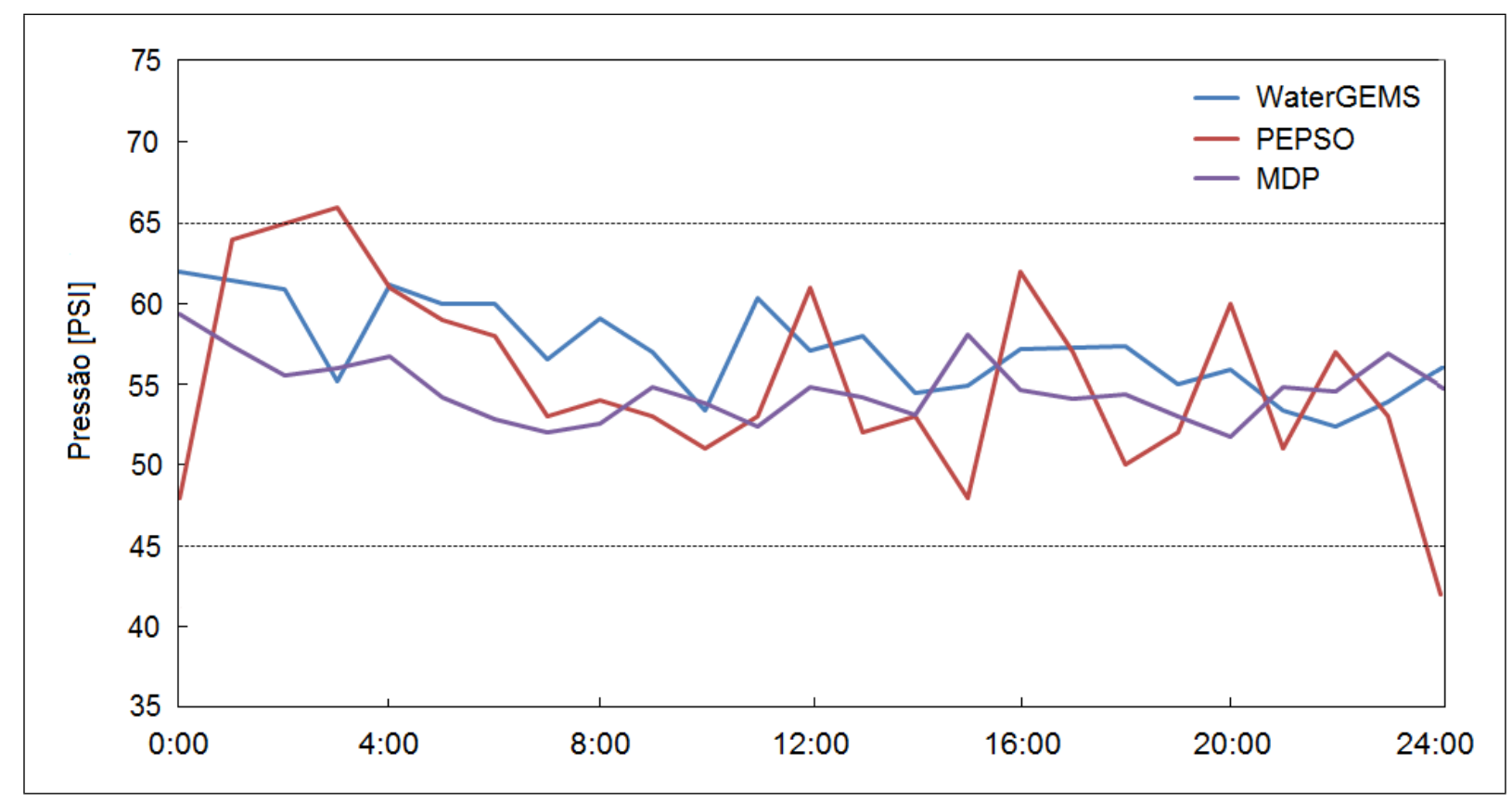

Figura 6.18: Pressão no nó $J_{27}$, onde $45 \leq P\left(J_{27}\right) \leq 65$. 


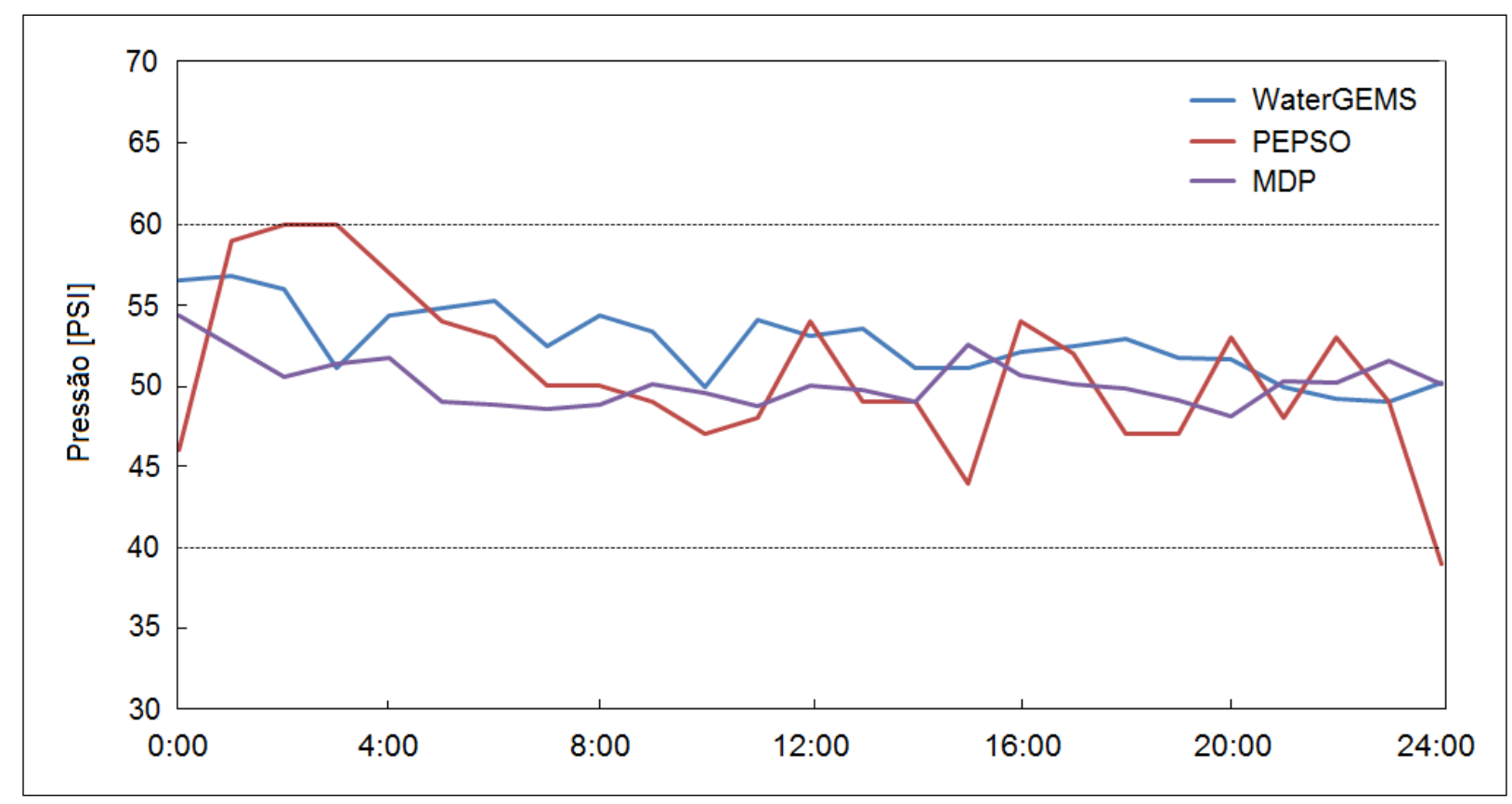

Figura 6.19: Pressão no nó $J_{131}$, onde $40 \leq P\left(J_{131}\right) \leq 60$.

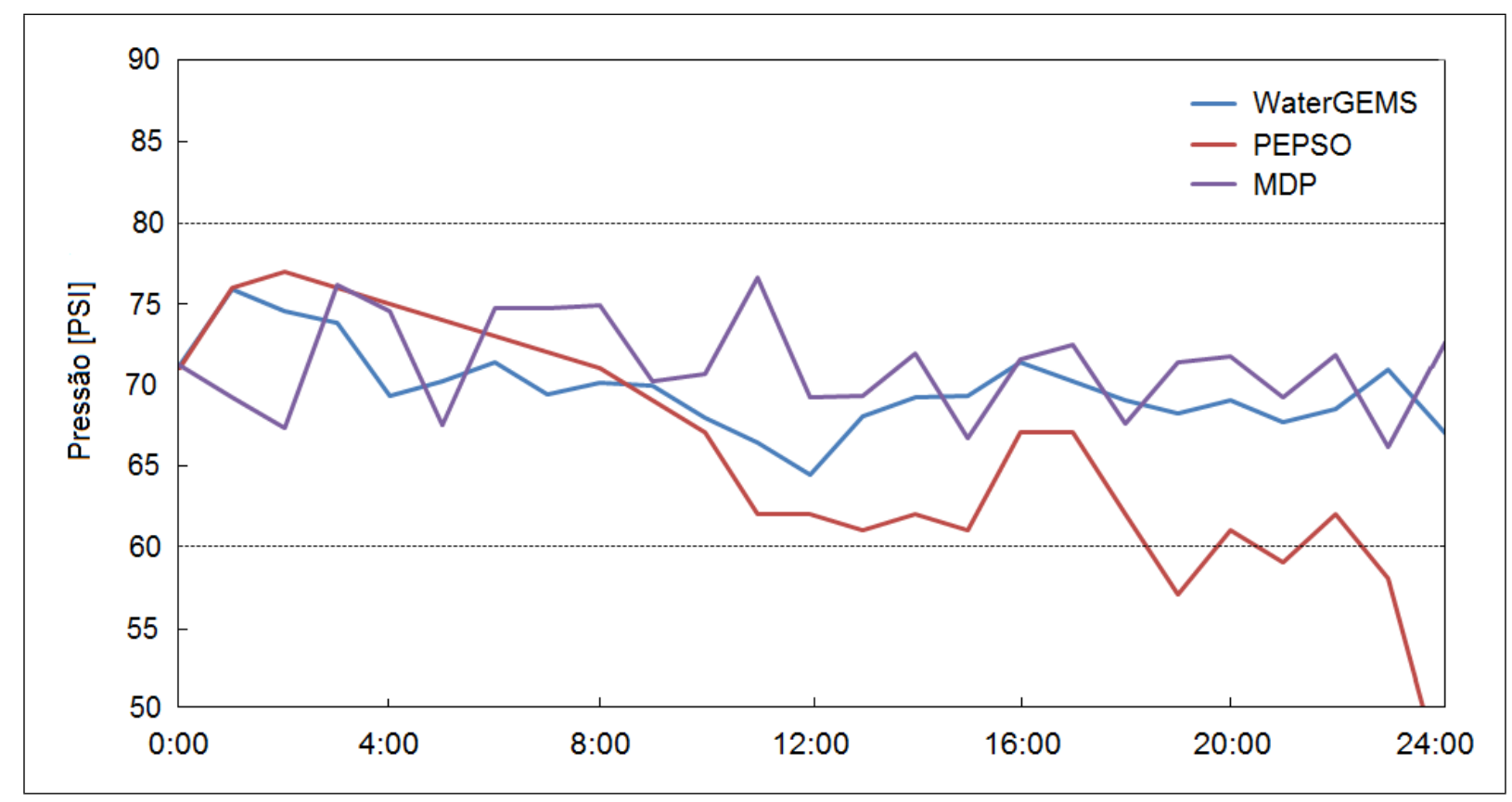

Figura 6.20: Pressão no nó $J_{514}$, onde $60 \leq P\left(J_{514}\right) \leq 80$. 


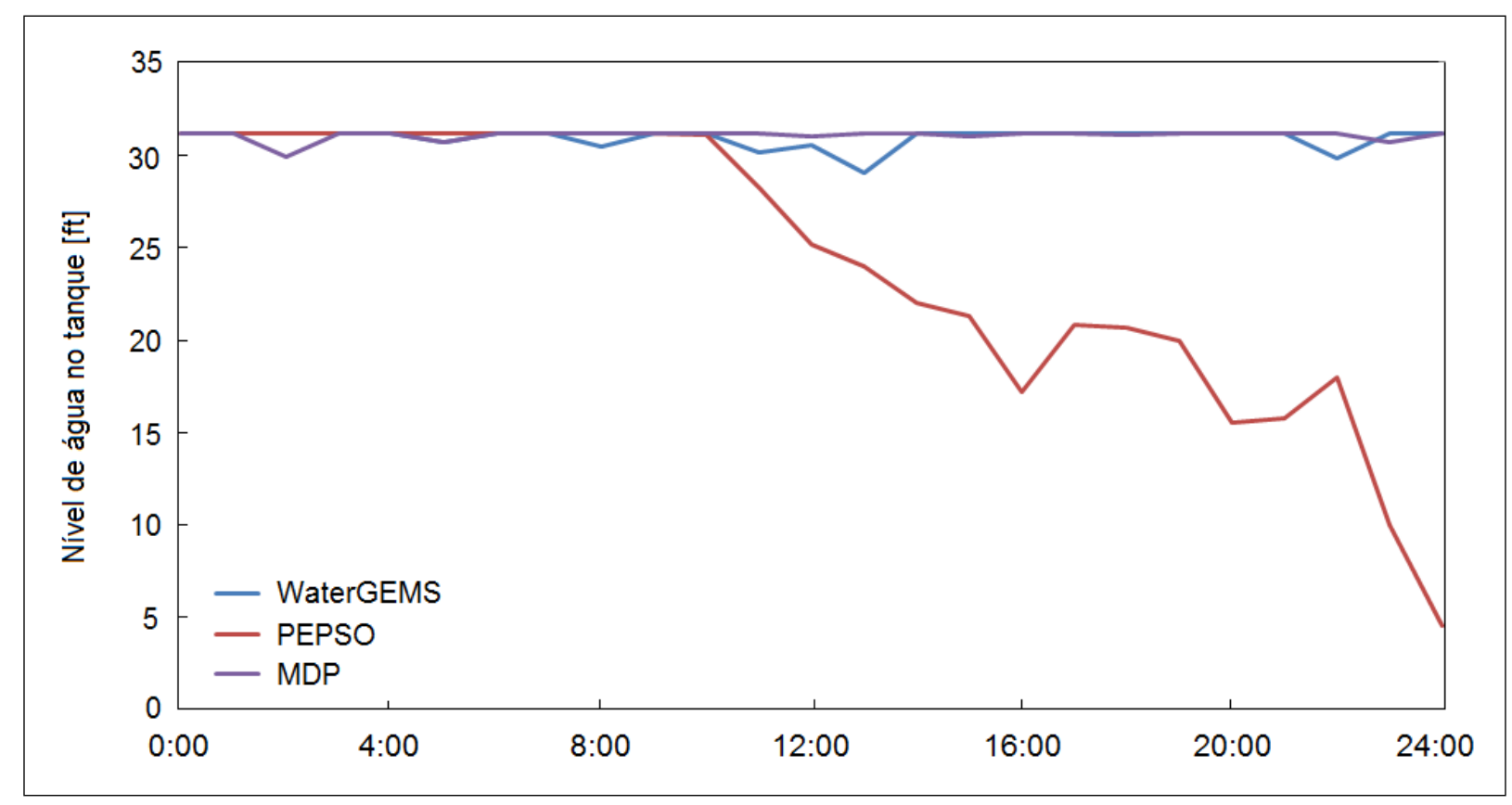

Figura 6.21: Nível de água do tanque de armazenamento $T_{2}$.

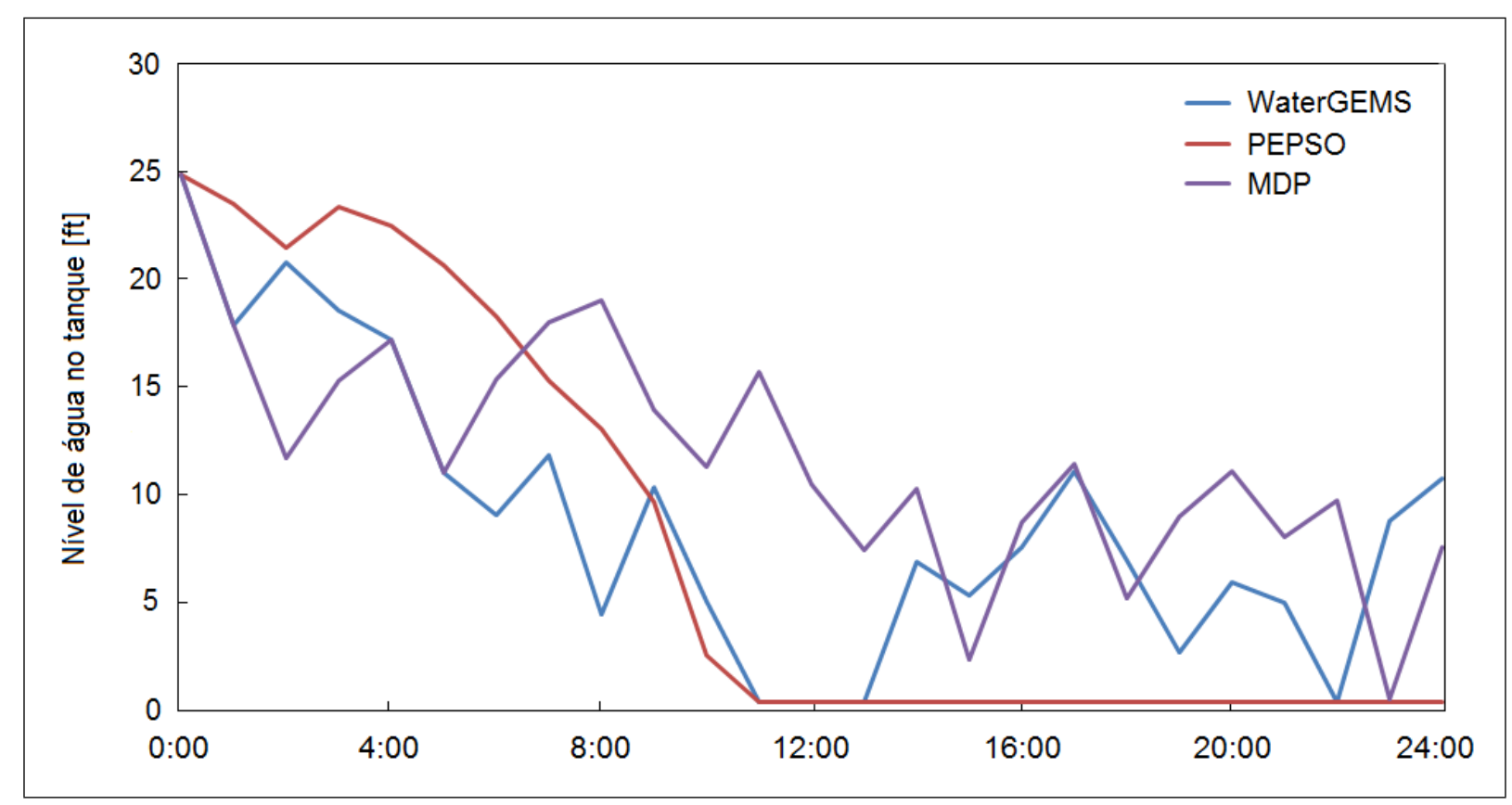

Figura 6.22: Nível de água do tanque de armazenamento $T_{3}$. 


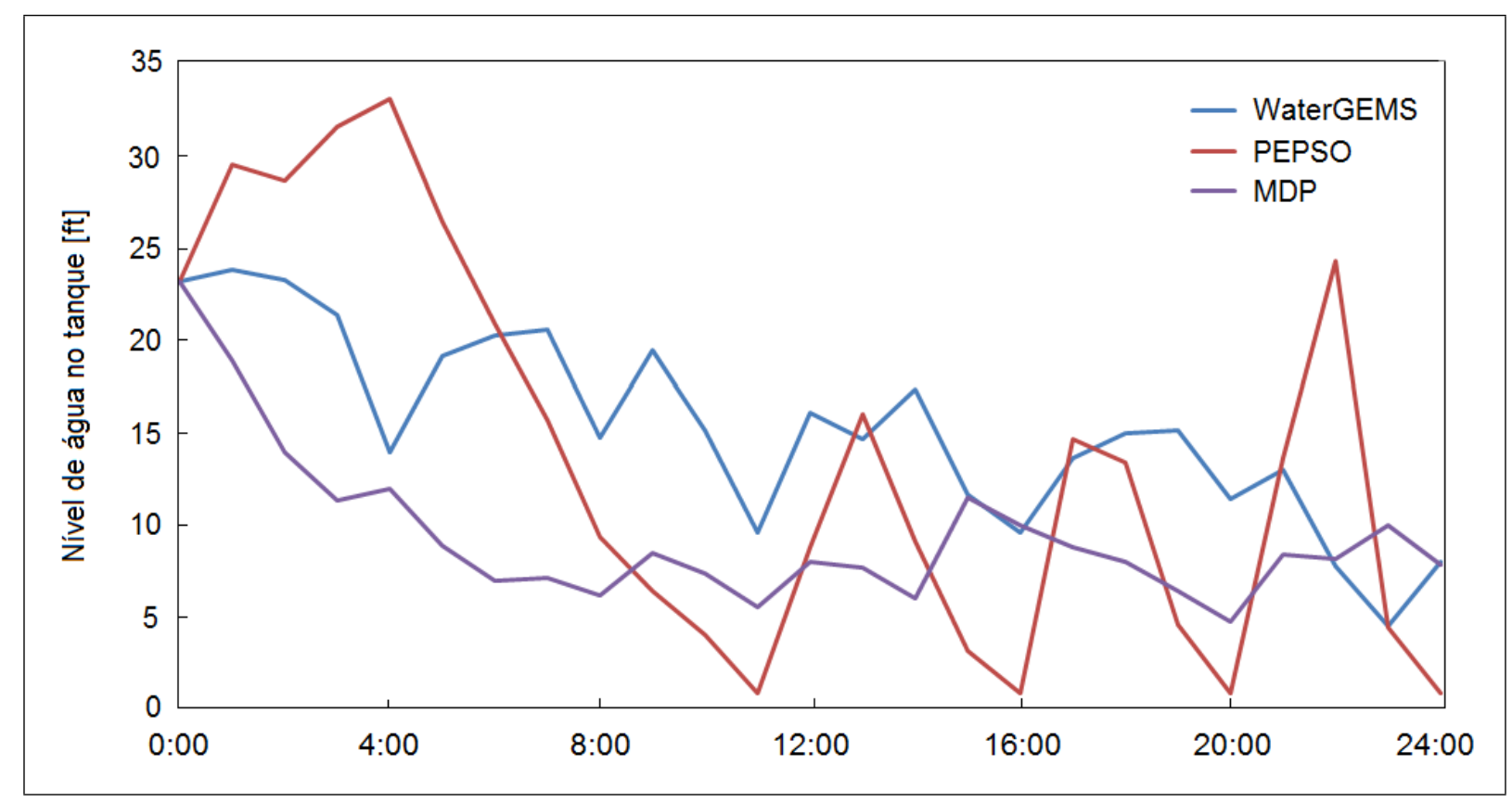

Figura 6.23: Nível de água do tanque de armazenamento $T_{5}$.

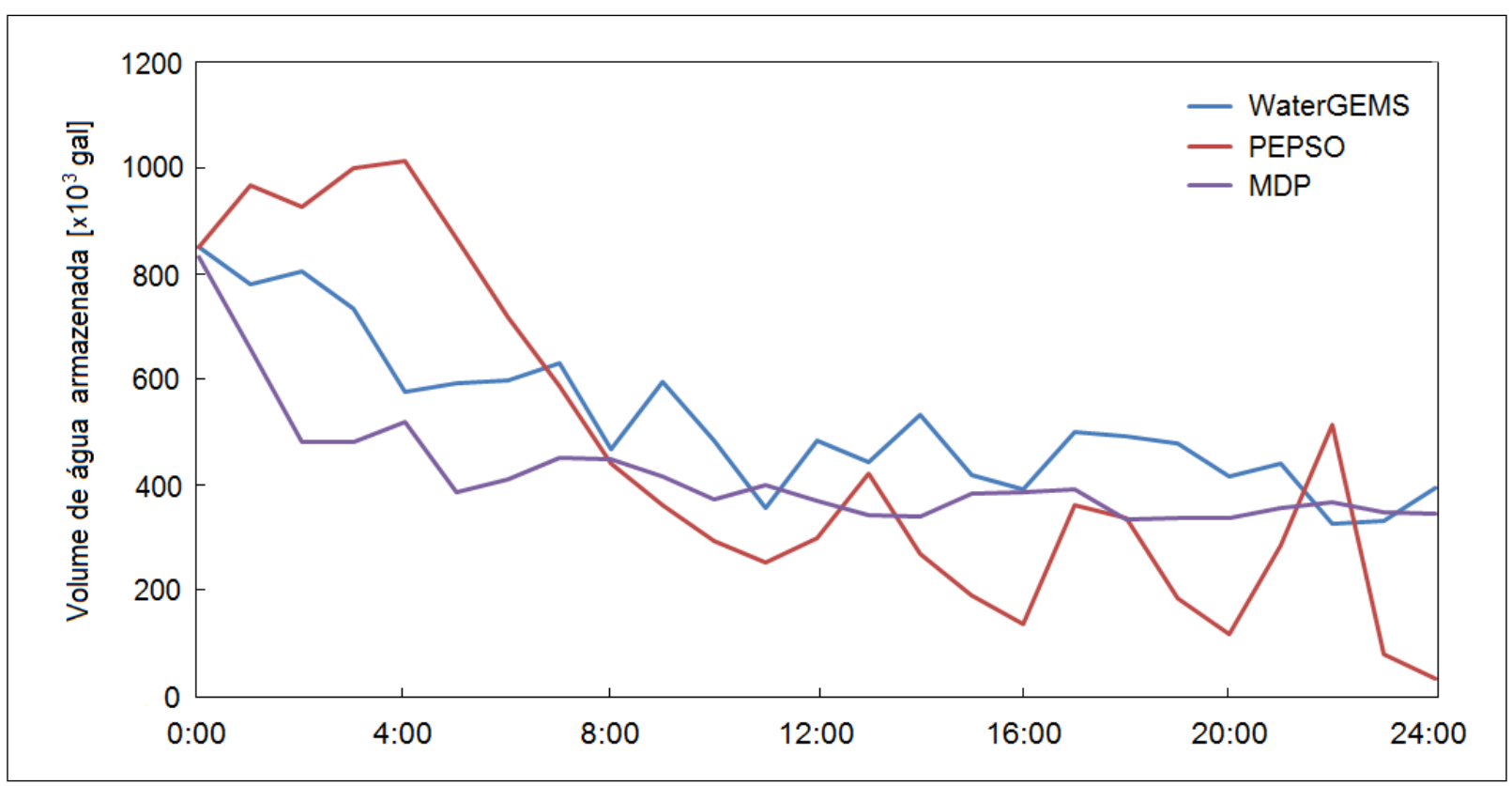

Figura 6.24: Volume de água armazenado conjuntamente pelos tanques $T_{2}, T_{3}$ e $T_{5}$. 
Tabela 6.9: Acionamento das bombas realizado pelo WaterGEMS.

\begin{tabular}{|c|c|c|c|c|c|c|c|c|c|c|c|c|c|}
\hline Tempo & $E_{2}$ & $E_{3}$ & $E_{4}$ & $E_{5}$ & $E_{6}$ & $E_{7}$ & $W_{8}$ & $W_{9}$ & $W_{10}$ & $W_{11}$ & $W_{12}$ & $P M P_{9}$ & $P M P_{544}$ \\
\hline 00:00 & & 1 & & & & & & & & & 1 & & \\
\hline 01:00 & & 1 & & 1 & & & & & & & 1 & 0,95 & \\
\hline 02:00 & & 1 & & & & & & & & & 1 & & 0,65 \\
\hline 03:00 & & & & & & & & & & & 1 & 0,7 & \\
\hline 04:00 & & & & & 1 & & & & & & & & \\
\hline 05:00 & & & & & 1 & & & & & & & 0,65 & \\
\hline 06:00 & & & & & & & 1 & & & & & & 0,90 \\
\hline 07:00 & & 1 & & 1 & & & & & & & & 0,65 & \\
\hline 08:00 & & & & & 1 & & 1 & & & & & 1,00 & 0,85 \\
\hline 09:00 & 1 & & & & & & & & & 1 & 1 & 0,65 & 0,70 \\
\hline $10: 00$ & 1 & 1 & & & & & & & & & 1 & & 0,80 \\
\hline 11:00 & & & & & 1 & & 1 & & & & & 0,75 & 0,70 \\
\hline $12: 00$ & & 1 & & & 1 & & & & & & & 0,75 & 0,65 \\
\hline $13: 00$ & 1 & 1 & & & 1 & & & & & & 1 & 0,85 & 0,85 \\
\hline $14: 00$ & & & & & & & & & & 1 & 1 & 0,70 & 0,80 \\
\hline $15: 00$ & & 1 & & 1 & & 1 & & & & & & 0,75 & 0,85 \\
\hline $16: 00$ & 1 & 1 & & & & & & 1 & & & & 0,85 & 0,85 \\
\hline $17: 00$ & & 1 & & & 1 & & & & & & & 0,65 & 0,65 \\
\hline $18: 00$ & & & 1 & & 1 & & & & & & & 0,65 & 0,75 \\
\hline 19:00 & & & & & & & & 1 & & & & 1,00 & \\
\hline 20:00 & & & & 1 & & & & & 1 & & & 0,95 & \\
\hline 21:00 & & & & 1 & & & & & & 1 & & 0,80 & \\
\hline $22: 00$ & & & & & 1 & 1 & & & & & & 0,95 & 0,90 \\
\hline 23:00 & & & & & 1 & 1 & & & & & & 0,95 & \\
\hline
\end{tabular}


Tabela 6.10: Acionamento das bombas realizado pelo PEPSO.

\begin{tabular}{|c|c|c|c|c|c|c|c|c|c|c|c|c|c|}
\hline Tempo & $E_{2}$ & $E_{3}$ & $E_{4}$ & $E_{5}$ & $E_{6}$ & $E_{7}$ & $W_{8}$ & $W_{9}$ & $W_{10}$ & $W_{11}$ & $W_{12}$ & $P M P_{9}$ & $P M P_{544}$ \\
\hline 00:00 & & & & & & 1 & 1 & & & & & 0,65 & \\
\hline 01:00 & & & & & 1 & & & & & & & 0,65 & \\
\hline 02:00 & & & & & & 1 & & & & 1 & 1 & & 0,85 \\
\hline 03:00 & & 1 & 1 & 1 & & & & & & & & 0,65 & \\
\hline 04:00 & & & & & & 1 & & & & & & & 0,65 \\
\hline 05:00 & & & 1 & & & & & & & & & & 0,65 \\
\hline 06:00 & 1 & & 1 & & & & & & & & & & 0,65 \\
\hline 07:00 & & 1 & & 1 & & & & & & & & 0,85 & \\
\hline 08:00 & & 1 & 1 & & & & & & & & 1 & & 0,80 \\
\hline 09:00 & 1 & & 1 & & & & & & & 1 & & & 0,80 \\
\hline $10: 00$ & & & & 1 & & & & & & 1 & & & 0,80 \\
\hline 11:00 & & & & 1 & & & & 1 & & & & & 0,80 \\
\hline $12: 00$ & & 1 & & 1 & & & & & 1 & & 1 & & 0,80 \\
\hline $13: 00$ & & 1 & & & & 1 & & & & & & & 0,80 \\
\hline $14: 00$ & & & 1 & & & & & & & 1 & & 0,85 & \\
\hline $15: 00$ & & & & 1 & & 1 & & & & & & & 0,85 \\
\hline $16: 00$ & & & & 1 & & & & 1 & 1 & & & 0,75 & 0,85 \\
\hline $17: 00$ & & & & & 1 & & & & & & 1 & & 0,85 \\
\hline 18:00 & 1 & & & & & & & & & 1 & & & 0,85 \\
\hline 19:00 & 1 & & & & & 1 & & & & & 1 & 0,65 & \\
\hline 20:00 & & & & 1 & & 1 & & 1 & & 1 & & 0,65 & 0,70 \\
\hline $21: 00$ & & & & 1 & 1 & & 1 & 1 & & & 1 & 0,65 & 0,70 \\
\hline $22: 00$ & & & & & & & & & & & & & 0,70 \\
\hline 23:00 & 1 & & 1 & & & & & & & & & 0,65 & \\
\hline
\end{tabular}


Tabela 6.11: Acionamento das bombas realizado pelo MDP.

\begin{tabular}{|c|c|c|c|c|c|c|c|c|c|c|c|c|c|}
\hline Tempo & $E_{2}$ & $E_{3}$ & $E_{4}$ & $E_{5}$ & $E_{6}$ & $E_{7}$ & $W_{8}$ & $W_{9}$ & $W_{10}$ & $W_{11}$ & $W_{12}$ & $P M P_{9}$ & $P M P_{544}$ \\
\hline 00:00 & & & & & & 1 & & & & & & & \\
\hline 01:00 & & & & & & 1 & & & & & & & \\
\hline 02:00 & & & & & 1 & & & & & & & 0,85 & 0,85 \\
\hline 03:00 & & & & & 1 & & & & & & & & 0,85 \\
\hline 04:00 & & & & & & 1 & & & & & & & \\
\hline 05:00 & & & & & 1 & & & & & & & 0,85 & 0,85 \\
\hline 06:00 & 1 & & & & 1 & & & & & & & 0,85 & 0,85 \\
\hline 07:00 & & & & & 1 & 1 & & & & & & 0,85 & 0,85 \\
\hline 08:00 & & & & & 1 & 1 & & & & & & & 0,70 \\
\hline 09:00 & & & & & 1 & 1 & & & & & & & 0,85 \\
\hline $10: 00$ & 1 & & & & 1 & 1 & & & & & & 1,00 & 1,00 \\
\hline $11: 00$ & & & & & 1 & 1 & & & & & & & 0,70 \\
\hline $12: 00$ & & & & & 1 & 1 & & & & & & & 0,85 \\
\hline $13: 00$ & & & & & 1 & 1 & & & & & & 0,85 & 0,85 \\
\hline $14: 00$ & 1 & & & & 1 & 1 & & & & & & & 0,70 \\
\hline $15: 00$ & & & & & 1 & 1 & & & & & & 0,85 & 0,85 \\
\hline $16: 00$ & & & & & 1 & 1 & & & & & & 0,85 & 0,85 \\
\hline $17: 00$ & 1 & & & & 1 & & & & & & & & 0,70 \\
\hline 18:00 & & & & & 1 & 1 & & & & & & 0,85 & 0,85 \\
\hline 19:00 & & & & & 1 & 1 & & & & & & 0,85 & 0,85 \\
\hline 20:00 & 1 & & & & 1 & 1 & & & & & & & 0,85 \\
\hline $21: 00$ & 1 & & & & 1 & 1 & & & & & & 0,85 & 0,85 \\
\hline $22: 00$ & & & & & 1 & & & & & & 1 & & 0,70 \\
\hline 23:00 & 1 & & & & 1 & & & & & & & & 1,00 \\
\hline
\end{tabular}




\subsubsection{Análise dos Resultados}

A partir dos resultados dos experimentos comparativos apresentados na seção anterior é possível verificar que a técnica de modelagem por MDP, descrita por esta tese, foi a técnica que obteve o menor consumo energético no período de experimento, além de cumprir com todas as restrições de pressão impostas nos 4 nós monitorados da rede de distribuição da cidade de Monroe - MI.

O consumo da técnica de modelagem por MDP é cerca de $1 \%$ menor que da técnica PEPSO e 6,4\% menor que a do programa WaterGEMS, porém, a primeira técnica possui muitas restrições de pressão violadas e níveis dos tanques de armazenamento em muitos momentos em condições mínimas, fazendo com que a comparação não tenha sentido prático dado a grande possibilidade de interrupção do fornecimento de água na rede de distribuição do algoritmo PEPSO.

Sobre o acionamento das bombas, ambas as técnicas baseadas em algoritmos genéticos distribuem o acionamento nas diversas bombas do sistema de distribuição. Este fato remete a própria concepção do algoritmo, que realiza múltiplas mutações e recombinações nos acionamentos para tentar minimizar a função objetivo e sem observar as consequências do consumo de energia das ações futuras. Já a técnica de modelagem por MDP concentra o acionamento nas bombas com maior eficiência, tanto isoladamente, como combinadas, resultando em menor consumo, menor número de re-acionamentos (liga e desliga) e sem violação nas restrições do problema. Adicionalmente, a concentração das ações nas bombas $E_{6}$ e $E_{7}$ apresenta um cenário onde provavelmente houve um equívoco no projeto de dimensionamento das outras bombas, que na maioria do tempo não são utilizadas.

Apesar de não ser um parâmetro comparativo do experimento, a demanda de energia é o fator mais relevante na composição do custo da energia elétrica. Este parâmetro também mostra a superioridade da modelagem por MDP em relação às técnicas baseadas em algoritmos genéticos, sendo cerca de $18 \%$ menor que a do programa WaterGEMS e de $40 \%$ menor que da técnica PEPSO.

Sobre as pressões monitoradas nos nós $J_{6}, J_{27}, J_{131}$ e $J_{514}$, tanto a técnica de modelagem por MDP como o programa WaterGEMS não tiverem nenhuma restrição violada. Em contrapartida, o algoritmo PEPSO teve restrições superiores e inferiores violadas. As restrições inferiores são limites mínimos para o abastecimento de água em determinadas localidades, principalmente àquelas com cotas mais elevadas. Já as restrições superiores são relacionadas aos limites de segurança para evitar ruptura nas tubulações. Assim, o algoritmo PEPSO, no caso de implementação num sistema real, pode ocasionar instabili- 
dade no sistema de distribuição.

Com relação ao nível de água nos tanques de armazenamento, no caso de $T_{2}$ tanto a técnica de modelagem por MDP como o programa WaterGEMS tentam deixar o tanque com nível máximo, visando manter a região em seu entorno pressurizada e abastecida dado o seu distanciamento da ETA e das estações de bombeamento. No caso de $T_{3}$, dado o grande consumo de água em seu entorno e cota elevada fazem com que o nível oscile próximo do valor mínimo para ambas as técnicas. Finalmente, no caso de $T_{5}$ tanto para a técnica de modelagem por MDP como para o programa WaterGEMS o nível tende a uma estabilidade em torno de $10 \mathrm{ft}$; já o algoritmo PEPSO possui dificuldade em manter estabilizado o nível do tanque.

Outro fator indireto para avaliar o consumo energético é a quantidade de água armazenada nos tanques, dado que consome-se energia para enviá-la da estação de bombeamento ao tanque, e além disso, para elevar a sua cota quando o tanque é enchido. Assim, apesar da técnica PEPSO possuir consumo energético próximo ao da técnica de modelagem por MDP, a quantidade de água armazenada é cerca de 10 vezes menor.

Finalmente, o último parâmetro avaliado é o tempo de processamento. Neste quesito o algoritmo PEPSO possui os melhores resultados. Com relação à técnica de modelagem por MDP, um dos seus pontos fracos é a explosão combinacional, tanto de estados como de ações. Para que a técnica possua tempos de execução factíveis, a discretização dos estados não pode ser muito fina e o número de ações, o mais reduzido possível. Assim, neste problema o número de possíveis ações foi reduzido em $85 \%$. Isto é possível devido a existência de bombas com características equivalentes, como $E_{3} \equiv E_{4} \equiv E_{5}, W_{8} \equiv W_{9} \equiv$ $W_{10}$ e $P M P_{9} \equiv P M P_{544}$. Assim, pode-se optar, durante a execução da política, pelo escalonamento do acionamento das bombas equivalentes com o objetivo de redução na quantidade de tempo de acionamento de uma determinada bomba.

\subsection{Experimentos com Sistema Real}

Os experimentos desta seção apresentam o comparativo entre o controlador de uma cidade de pequeno porte e o mesmo sistema de distribuição simulado, porém utilizando a técnica de modelagem por MDP. O controlador utilizado no sistema real é baseado em nível, onde o acionamento das bombas (ligar/desligar) é função de valores pré-definidos do nível de um tanque de armazenamento. Já a abordagem proposta, além do nível do tanque, também utiliza o horário do dia para o acionamento das bombas. 
Os experimentos realizados visam identificar os potenciais ganhos no caso de implementação do sistema de controle apresentado nesta tese, onde são propostas duas abordagens para acionamento das bombas.

\subsubsection{Objetivo}

O objetivo deste experimento é identificar os potenciais de redução dos gastos com energia elétrica durante o período de um ciclo tarifário no caso de implementação do sistema de controle apresentado nesta tese no sistema real. São apresentadas duas abordagens para o acionamento das bombas: a primeira utilizando bombas com acionamento direto, onde não é necessário nenhum investimento em equipamentos; e a segunda, utilizando acionamento por inversores de frequência, onde é necessária a compra dos mesmos.

\subsubsection{Detalhamento do Experimento}

Os experimentos com dados reais foram realizados em um dos ramais do sistema de distribuição de água de uma cidade da região americana conhecida como Front Range e que abastece cerca de 10000 habitantes atendidos. As informações utilizadas neste experimento foram fornecidas pela Divisão de Utilidades da cidade e foram compiladas a partir de dados de projeto, testes de medição em campo e simulações hidráulicas.

A rede de distribuição de água do sistema real é apresentada na Figura 6.25. Este sistema de distribuição de água é composto por dois reservatórios de água tratada (pontos na cor azul claro), duas bombas (pontos na cor vermelha), um tanque de armazenamento (pontos na cor cinza), cerca de $31500 \mathrm{ft}$ de tubulações com diâmetros variando entre 20 e 60 polegadas (linhas na cor azul escuro) e 34 nós de consumo (pontos na cor verde).

Os reservatórios de água tratada $R_{7000}$ e $R_{7008}$ provêm água tratada da Estação de Tratamento de Água para distribuição aos usuários do ramal. Como este reservatório está vinculado à estação de tratamento, $\operatorname{a~} \operatorname{cota}^{9}$ da lâmina de água possui variação cíclica durante o dia, conforme apresenta a Figura 6.26.

Já as bombas $U_{5007}$ e $U_{5009}$ são idênticas, ligadas em paralelo, com acionamento direto e possuem curva de desempenho descrita pela Figura 6.27, onde a linha sólida mais grossa descreve a variação da pressão manométrica em função da vazão, as linhas sólidas mais estreitas descrevem as curvas isométricas do rendimento e as linhas tracejadas descrevem o NPSH mínimo requerido pelas bombas (não utilizados neste experimento).

\footnotetext{
${ }^{9}$ Cota em ralação ao nível do mar.
} 


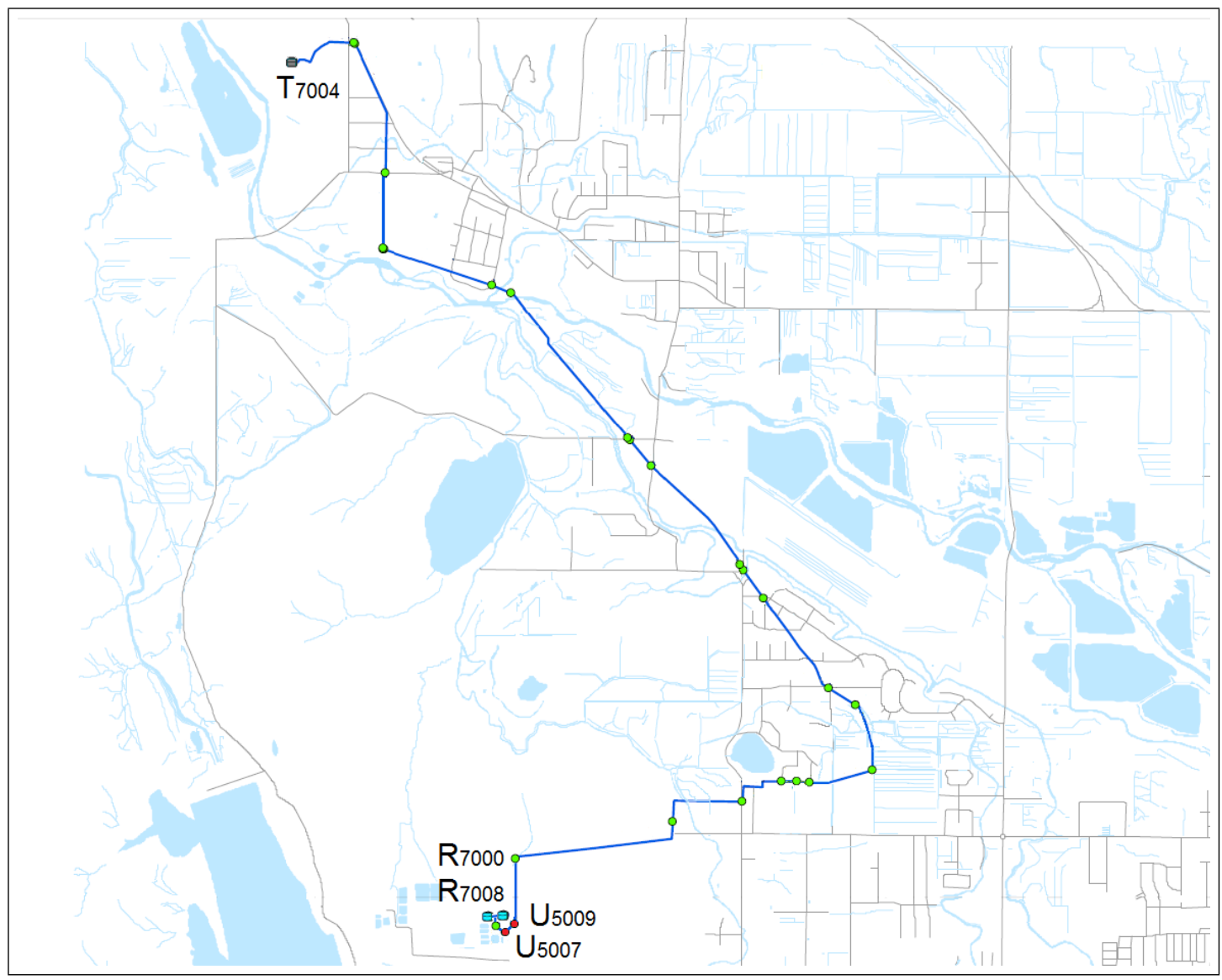

Figura 6.25: Rede de distribuição de água do sistema real.

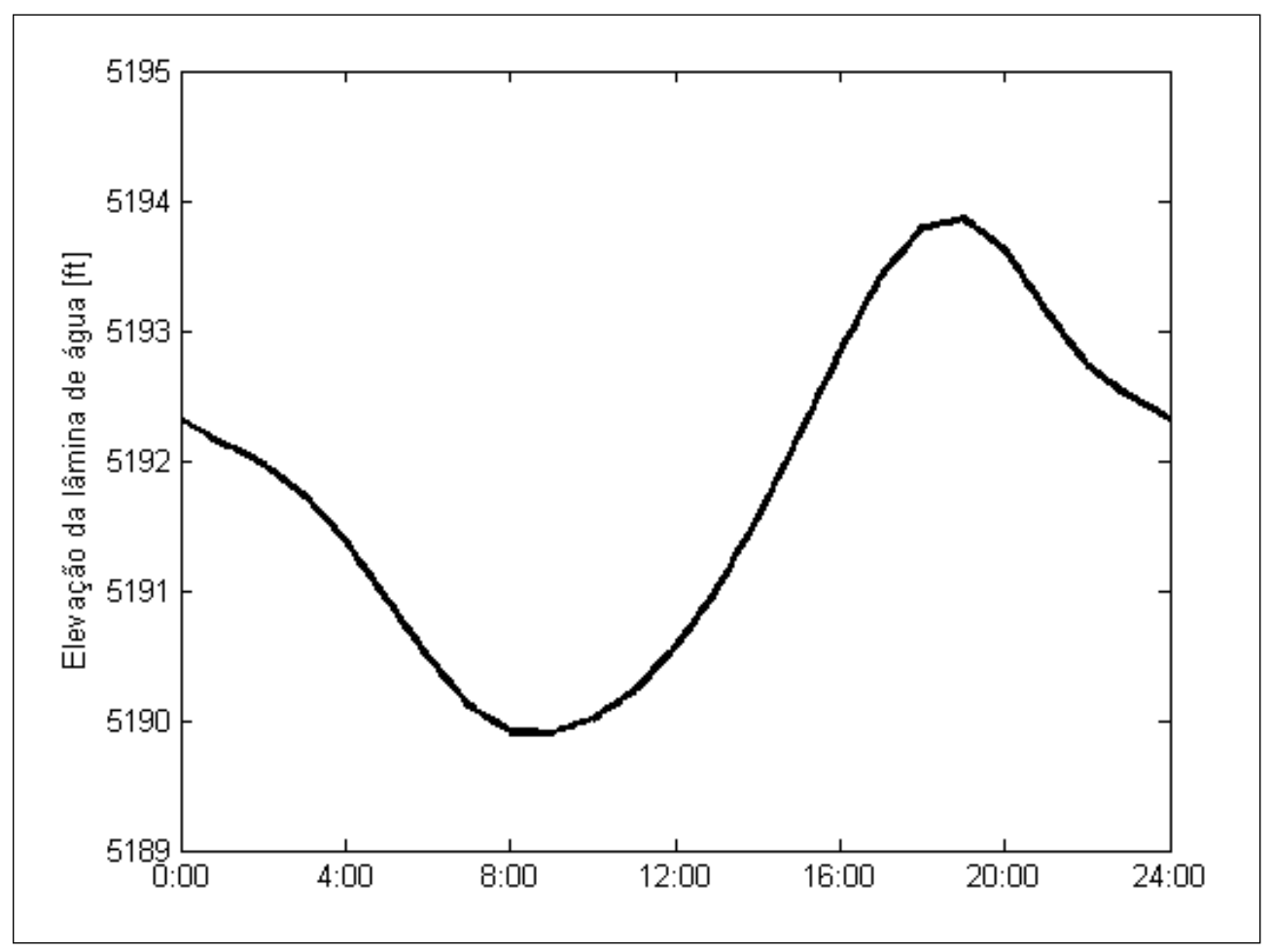

Figura 6.26: Variação da cota da lâmina de água dos reservatórios $R_{7000}$ e $R_{7008}$. 


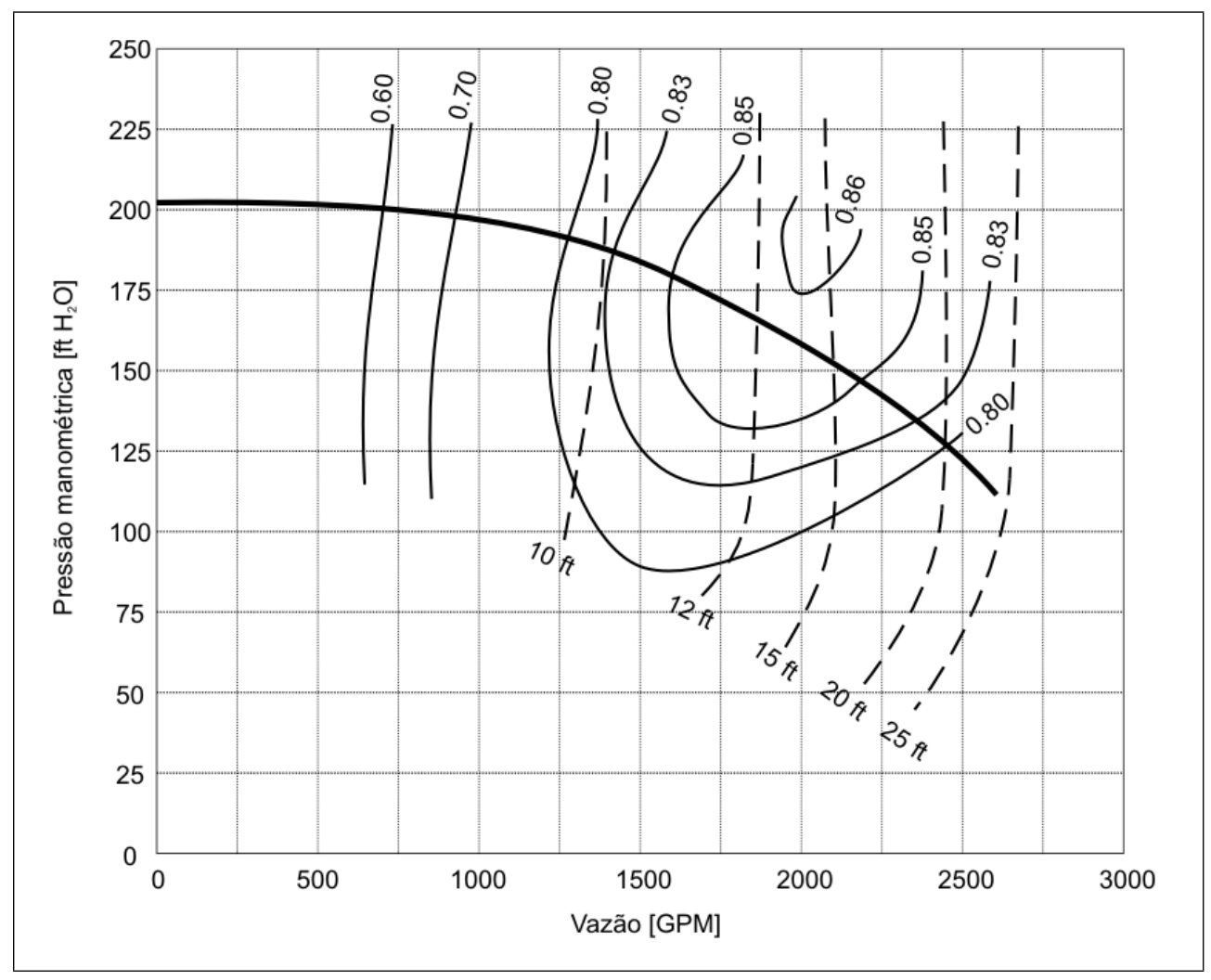

Figura 6.27: Curva de desempenho e rendimento das bombas $U_{5007}$ e $U_{5009}$.

O tanque de armazenamento $T_{7004}$ está situado num ponto elevado em relação ao restante do sistema, com cota de $5291 \mathrm{ft}$. Já com relação as suas características construtivas, este é cilíndrico, com área de $8332 \mathrm{ft}^{210}$, com nível variando entre $15 \mathrm{ft}$ e $24 \mathrm{ft}$ e cuja capacidade máxima de armazenamento é de aproximadamente $1,5 \cdot 10^{6} \mathrm{gal}$. Devido aos constantes incêndios florestais que atingem a região, foi estabelecido o nível de $15 \mathrm{ft}$ como limite mínimo de operação deste tanque de armazenamento.

O consumo de água deste ramal foi obtido a partir de dados históricos do mês de junho de 2012, mês com maior consumo de água e crítico para a companhia de saneamento local, descrito pela Figura 6.28. Nesta figura a linha sólida representa a demanda de água, as barras verticais, o desvio padrão da demanda durante o mês e a linha tracejada representa a demanda média de água, neste caso de 939, 9 GP $M^{11}$.

Já as informações relativas às tubulações e aos nós do ramal são descritas nas Tabelas C.1 e C.2 do Anexo C.

Finalmente, para minimização dos gastos com energia elétrica, uma das informações mais importantes está relacionada ao custos de sua utilização, podendo ser fixos, como

\footnotetext{
${ }^{10}$ Conversão: $1 \mathrm{ft}^{2}=0,0929 \mathrm{~m}^{2}$

${ }^{11}$ Conversão: $1 G P M=0,227 \mathrm{~m}^{3} / \mathrm{h}$
} 


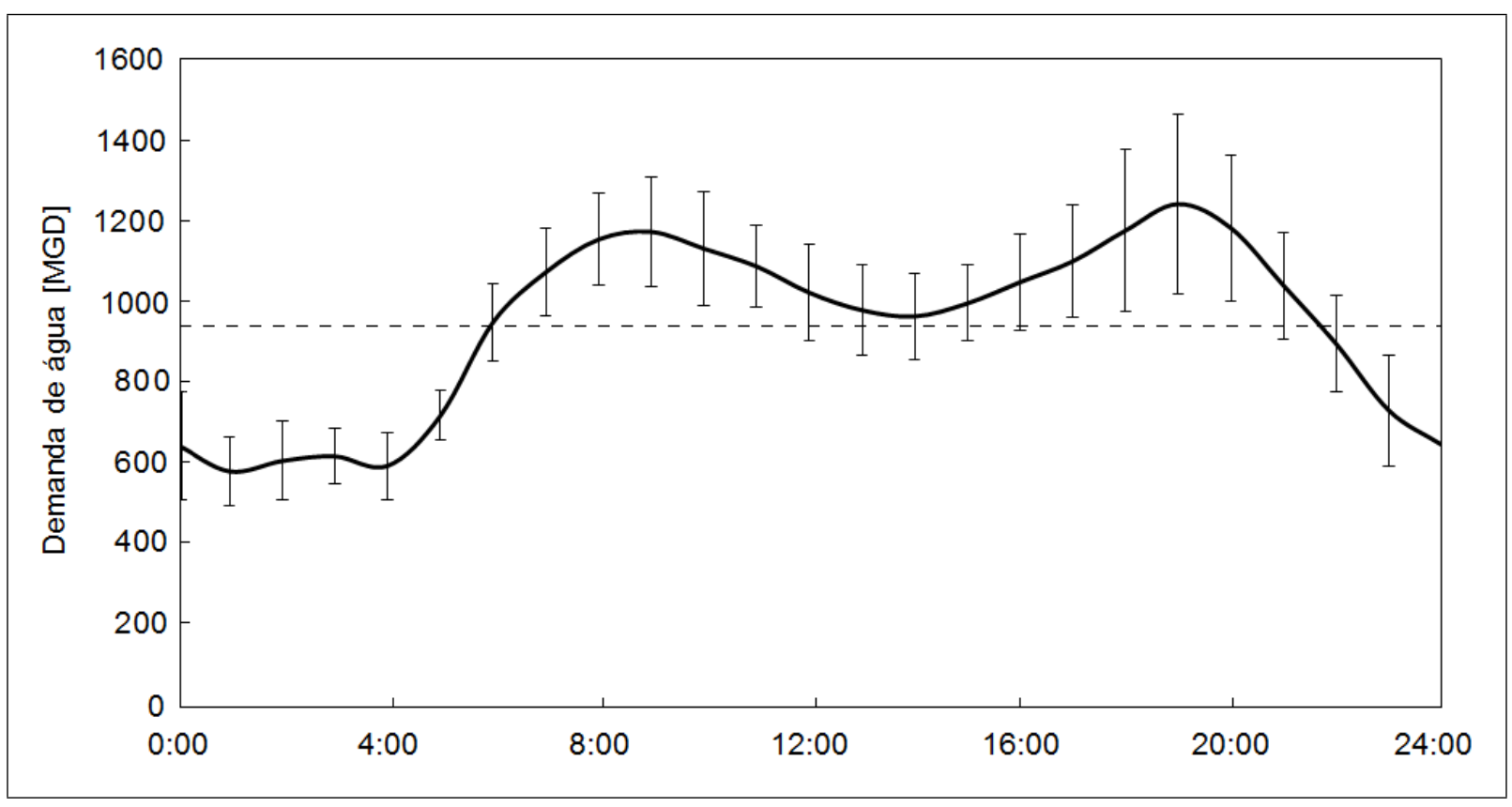

Figura 6.28: Demanda de água do sistema real, referente ao mês de junho de 2012.

taxa de serviço, e variáveis, que são função da demanda e energia utilizadas durante o mês. Este trabalho limita-se apenas a analisar os custos variáveis uma vez que são aqueles em que é possível incorrer reduções. Neste cenário, a concessionária de energia elétrica que atende à cidade pratica os seguintes valores para consumidores industriais trifásicos:

- Demanda (máxima potência utilizada no mês): $U \$ 18,8916 / k W$;

- Energia no horário de ponta (das 09:00 às 20:59): $U \$ 0,03749 / k W h$; e

- Energia no horário fora-de-ponta (das 21:00 às 08:59): $U \$ 0,02831 / k W h$.

\subsubsection{Controlador Atual}

O controlador atualmente utilizado neste sistema de distribuição está baseado na seguinte estratégia: uma das duas bomba é ligada quando o nível do tanque de armazenamento for inferior a $15 \mathrm{ft}$ e permanece ligada até o momento em que o nível for superior a $20 \mathrm{ft}$; depois, esta bomba é desligada até que o nível do tanque se reduza naturalmente por meio do consumo de água até valores inferiores a $15 \mathrm{ft}$, momento em que a outra bomba é ligada. Este processo é repetido de forma que o nível do tanque de armazenamento oscile apenas $5 \mathrm{ft}$, entre $15 \mathrm{ft}$ e $20 \mathrm{ft}$, e com alternância no acionamento das bombas. 


\subsubsection{Modelo MDP}

O problema de minimização de gastos com energia elétrica da rede de distribuição de água do sistema real é modelado por MDP, como os experimentos anteriores, e descrito pela tupla $\langle\mathcal{S}, \mathcal{A}, \mathcal{D}, \mathcal{T}, \mathcal{R}\rangle$.

A representação fatorada do conjunto de estados $\mathcal{S}$ é descrita pelo nível de água no único tanque de armazenamento do sistema, $H\left(T_{7004}\right)$. Como esta variável é descrita no espaço contínuo, a mesma é discretizada em 30 níveis no intervalo útil do tanque, neste caso no intervalo $[15,24]$, o que resulta em:

$$
S=H\left(T_{7004}\right)=\{15.15,15.45,15.75, \ldots, 23.25,23.55,23.85\}
$$

O conjunto $\mathcal{A}$ é descrito pelas ações que podem ser executadas pelas 2 bombas deste sistema de distribuição, resultando em:

$$
\mathcal{A}=\left(K\left(U_{5007}\right), K\left(U_{5009}\right)\right)
$$

onde $K\left(U_{5007}\right)$ e $K\left(U_{50097}\right)$ representam a condição de operação das bombas $U_{5007}$ e $U_{5009}$, respectivamente

No caso de utilização da instalação atual, onde o acionamento das bombas é feito de forma direta, as possíveis ações são: $K_{\text {dir }}\left(U_{5007}\right)=K_{\text {dir }}\left(U_{5009}\right)=\{0,1\}$, onde 0 representa a bomba desligada e 1 representa a bomba ligada. Desta forma, o conjunto de ações no caso de acionamento das bombas de forma direta é:

$$
\mathcal{A}_{\text {dir }}=\{(0,0),(1,0),(1,1)\}
$$

Como as bombas $U_{5007}$ e $U_{5009}$ são idênticas, o conjunto de ações pode ser reduzido a apenas 3 ações.

Como também se pretende avaliar a inclusão de inversores de frequência para o acionamento das bombas, a condição de operação das bombas $U_{5007}$ e $U_{5009}$ pode ser descrita por meio do conjunto discretizado, com incremento percentual unitário, abaixo:

$$
K_{V F D}\left(U_{5007}\right)=K_{V F D}\left(U_{5009}\right)=\{0.00,0.75,0.76,0.77, \ldots, 0.98,0.99,1.00\}
$$

onde $75 \%$ é o limite mínimo operacional do inversor de frequência para as bombas $U_{5007}$ e $U_{5009}$ na condição de instalação.

Desta forma, o conjunto de ações quando o acionamento for realizado por meio de 
inversores de frequência consiste no produto cartesiano dos conjuntos discretizados da condição de operação:

$$
\mathcal{A}_{V F D}=K_{V F D}\left(U_{5007}\right) \times K_{V F D}\left(U_{5009}\right)
$$

O conjunto de épocas de decisão, como nos experimentos anteriores, foi definido no intervalo de tempo de 24 horas, iniciando às 0:00 e finalizando às 24:00. Apesar do problema de minimização de gastos com energia elétrica ser definido no período de 30 dias, correspondente a um ciclo tarifário, a demanda de água e a cota da lâmina de água dos reservatórios $R_{7000}$ e $R_{7008}$ possuem variação temporal cíclica, com repetição a cada 24 horas. Assim, a política resultante é a mesma para cada um dos 30 dias do período de modelagem o problema.

Como o tempo é um intervalo contínuo, o mesmo é discretizado uniformemente pelo passo de tempo $\Delta t=0: 15$, ou seja, a cada 15 minutos, resultando no seguinte conjunto de épocas de decisão:

$$
\begin{aligned}
\mathcal{D} & =\left\{T_{\min }, T_{\min }+\Delta t, \ldots, T_{\max }\right\} \\
& =\{0: 00,0: 15,0: 30, \ldots, 23: 30,23: 45,24: 00\}
\end{aligned}
$$

onde $T_{\min }$ é o instante de tempo inicial e $T_{\max }$ é o horizonte de tempo do problema

Como no experimento anterior, onde há a utilização de simulador hidráulico, a transição de estado é realizada pelo software EPANET e novamente o valor do próximo estado é descrito pela seguinte função:

$$
\sigma^{\prime}=f_{T}(\sigma, \alpha, d)
$$

onde $f_{T}$ é a função que calcula o próximo estado $\sigma^{\prime}$ por meio do software de simulação hidráulica, $\sigma$ é o estado atual, $\alpha$ é a ação executada no estado e $d$ é a época de decisão.

Neste experimento a incerteza associada à função de transição de estado utiliza o modelo completo descrito no Capítulo 4, onde as fontes de incerteza são: do modelo hidráulico, inerente à reprodução de um sistema real por meio de uma modelo computacional; da previsão da demanda, devido ao desconhecimento do valor futuro da demanda de água; do truncamento, fruto do truncamento do algoritmo iterativo de cálculo do software de simulação hidráulica; e da discretização, devido às variáveis de estado serem transformadas do espaço contínuo para o espaço discreto. Desta forma, a incerteza da função de transição de estado é:

$$
u\left(f_{T}\right)=\sqrt{\left(\frac{\partial f_{T}}{\partial \mathcal{M}} \cdot u(\mathcal{M})\right)^{2}+\left(\frac{\partial f_{T}}{\partial D} \cdot u(D)\right)^{2}+\left(\frac{\partial f_{T}}{\partial T} \cdot u(T)\right)^{2}+\left(\frac{\partial f_{T}}{\partial \mathcal{X}} \cdot u(\mathcal{X})\right)^{2}},
$$


onde $u(\mathcal{M}), u(D), u(T)$ e $u(\mathcal{X})$ são as incertezas padrão do modelo hidráulico, da previsão da demanda, do truncamento e da discretização, respectivamente; já $\frac{\partial f_{T}}{\partial \mathcal{M}}, \frac{\partial f_{T}}{\partial D}, \frac{\partial f_{T}}{\partial T}$ e $\frac{\partial f_{T}}{\partial \mathcal{X}}$ são os coeficientes de sensibilidade do modelo hidráulico, da previsão da demanda, do truncamento e da discretização das variáveis de estado, respectivamente.

A incerteza do modelo hidráulico é baseada em testes de medição em campo de forma a verificar a exatidão do modelo hidráulico em relação ao sistema real. No caso da rede de distribuição do sistema real, o modelo apresenta incerteza expandida de $5 \%$, conforme informações da Divisão de Utilidades da cidade. Assim, a incerteza padrão do modelo hidráulico é:

$$
u(\mathcal{M})=\frac{U(\mathcal{M})}{k}=\frac{0,05}{2}=2,5 \cdot 10^{-2},
$$

onde $k=2$ é o fator de abrangência supondo uma distribuição normal com nível de confiança de $95,45 \%$.

Já a incerteza da curva da demanda é obtida a partir do desvio padrão, conforme descrito pelas barras verticais da Figura 6.28, dividido pela raiz do número de observações, neste caso 30 dias, resultando em:

$$
u(D)=\frac{\sigma(D)}{\sqrt{N_{D}}},
$$

onde $\sigma(D)$ é o desvio padrão da demanda no período compreendido por $N_{D}$ dias.

A incerteza padrão do truncamento é o próprio erro de truncamento definido no software de simulação hidráulica EPANET, neste experimento igual a 0,001. Assim, a sua incerteza é: $u(T)=1 \cdot 10^{-3}$.

Com relação à incerteza da discretização, ela é o coeficiente de discretização divido por raiz de 12, uma vez que esta fonte de incerteza possui distribuição de probabilidade uniforme. Neste experimente o coeficiente de discretização é calculado como:

$$
\Delta H=\frac{H_{\max }-H_{\min }}{N}=\frac{24-15}{30}=0,3 .
$$

Assim, a incerteza padrão da discretização é igual a:

$$
u(\mathcal{X})=\frac{\Delta H}{\sqrt{12}}=\frac{0,3}{\sqrt{12}}=8,66 \cdot 10^{-2} .
$$

Os coeficientes de sensibilidade do modelo hidráulico, da demanda, do truncamento e da discretização são calculados conforme descrito pelo Capítulo 4. O primeiro deles é considerado unitário e os demais calculados como derivadas parciais numéricas em torno da sua respectiva fonte de incerteza. 
Finalmente, a função de recompensas $\mathcal{R}$ é definida como o custo da energia elétrica durante um ciclo tarifário e definida por:

$$
\mathcal{R}=-30 \cdot\left(\sum_{t=09: 00}^{20: 59} P w(t) \cdot \Delta T \cdot P_{O P}+\sum_{t=21: 00}^{08: 59} P w(t) \cdot \Delta T \cdot P_{F P}\right)-P w(t) \cdot P_{D M}
$$

onde $P w(t)$ é a potência elétrica no instate $t$, em $k W, P_{O P}$ é o preço da energia no período de ponta, em $U \$ / k W h, P_{F P}$ é o preço da energia no período fora-de-ponta, em $U \$ / k W h$, e $P_{D M}$ é o preço demanda elétrica, em $U \$ / k W$.

\subsubsection{Resultados}

Esta seção apresenta os resultados dos experimentos para identificar os potenciais de redução dos gastos com energia elétrica durante o período de um ciclo tarifário no caso de implementação de um dos dois sistema de controle propostos da rede de distribuição do sistema real.

A partir dos dados históricos do mês de junho de 2012 é possível determinar que a rede de distribuição do sistema real teve gastos de $U \$ 2089,83$ com energia elétrica. Este valor é a composição dos gastos com energia nos períodos de ponta e fora-de-ponta, além dos gastos com a demanda, conforme apresenta a Tabela 6.12. Estes dados serão utilizados como referência para determinar o potencial de reduções que pode ser alcançado nas análises comparativas.

Tabela 6.12: Gastos com energia elétrica do mês de junho de 2012 da rede de distribuição do sistema real.

\begin{tabular}{r|cc}
\hline Gastos com energia elétrica & Valor & Custo \\
\hline Energia no horário fora-de-ponta & $9289,04 k W h$ & $U \$ 262,97$ \\
Energia no horário de ponta & $10674,40 \mathrm{kWh}$ & $U \$ 400,18$ \\
Demanda & $75,52 \mathrm{~kW}$ & $U \$ 1426,68$ \\
\hline Total no período de tarifação & $19963,44 k W h$ & $U \$ 2089,83$ \\
\hline
\end{tabular}

Com relação ao sistema de controle com modelagem por MDP, foi calculada a política para as duas abordagens de acionamento das bombas: acionamento direto e acionamento por inversor de frequência. A Figura 6.29 apresenta a política de controle utilizando bombas com acionamento direto e a Figura 6.30, a política utilizando bombas com acionamento por inversores de frequência.

Em ambas as figuras o eixo das ordenadas representa o nível de água no tanque de armazenamento $T_{7004}$ e o eixo das abscissas, as épocas de decisão para um período de 
24 horas. Na Figura 6.29 a cor branca representa as duas bombas desligadas e a cor preta, apenas uma bomba acionada. Já na Figura 6.30 a cor branca também representa as duas bombas desligadas e os tons de cinza representam os diferentes percentuais de acionamento de apenas uma das bombas, cuja variação está entre $78 \%$ (tom mais claro de cinza) e $87 \%$ (tom mais escuro de cinza).

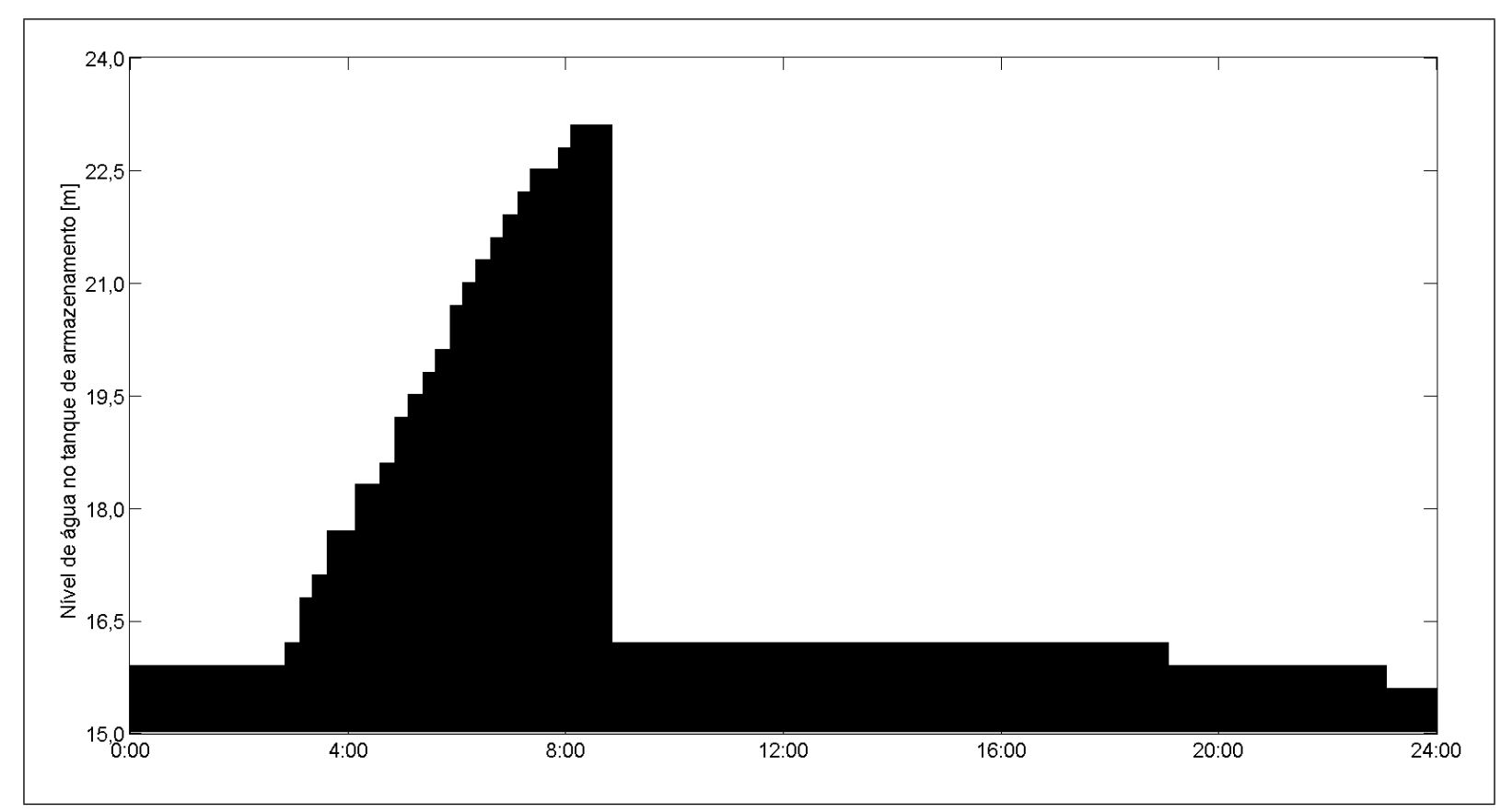

Figura 6.29: Política do sistema de controle com modelagem por MDP quando as bombas são acionadas diretamete.

A partir dessas políticas e utilizando os mesmos valores dos dados históricos da demanda de água no período de 30 dias do mês de junho de 2012, foi possível estimar os gastos com energia da rede de distribuição de água do sistema real utilizando os dois controladores propostos. Desta forma, os três controladores utilizaram os mesmos valores de demanda, o que faz com que a análise comparativa seja balizada. Além disso, para simular a incerteza do modelo hidráulico, foi incluído ruído branco à variável de estado $H\left(T_{7004}\right)$, cujo desvio padrão foi igual a $u(\mathcal{M})=2,5 \%$.

Assim, as Tabelas 6.13 e 6.14 apresentam a composição dos gastos com energia elétrica quando aplicadas as políticas de controle do modelo MDP com acionamento direto das bombas e com acionamento das bombas por inversor de frequência, respectivamente. 


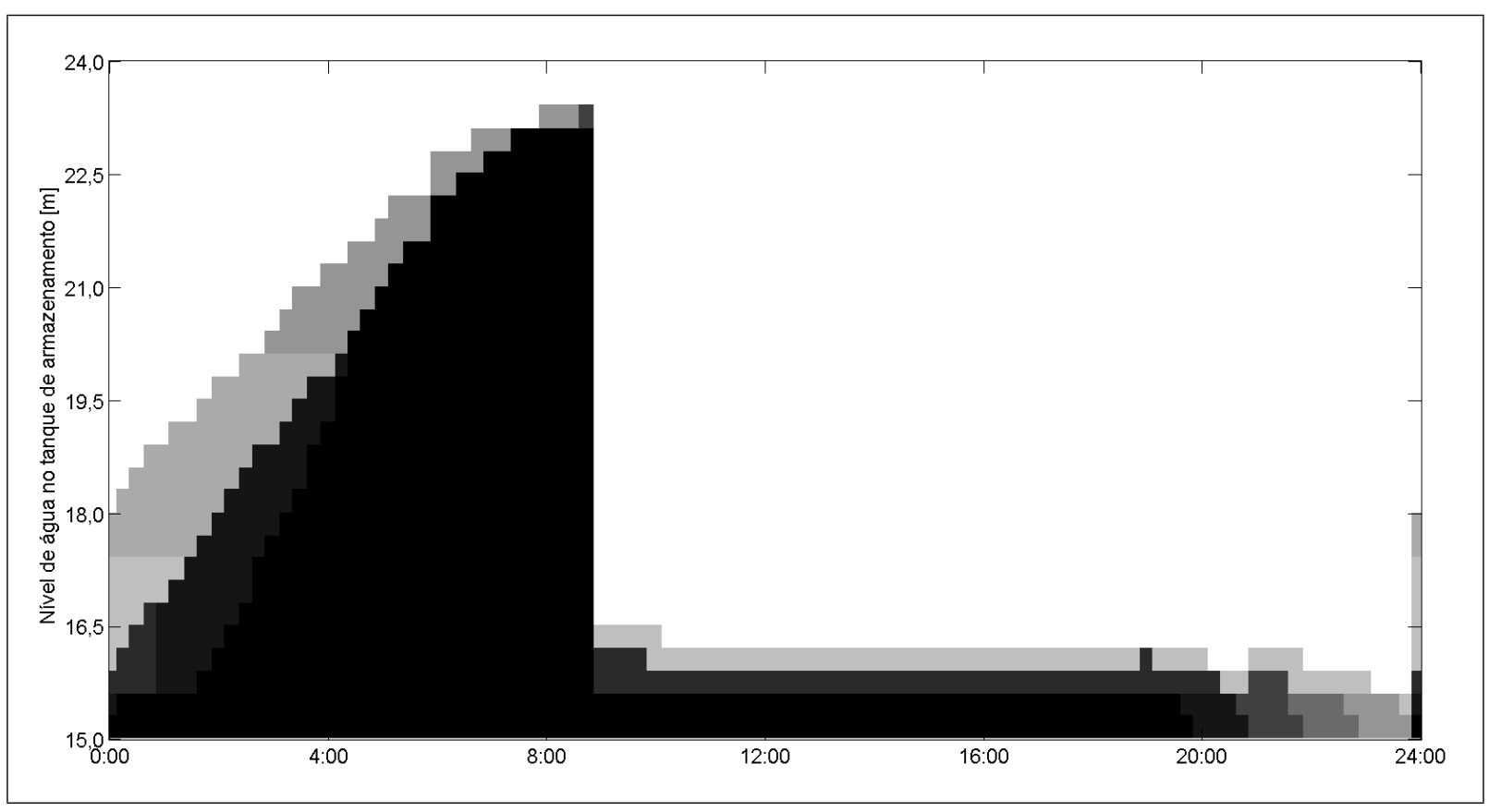

Figura 6.30: Política do sistema de controle com modelagem por MDP quando as bombas são acionadas por inversores de frequência.

Tabela 6.13: Gastos com energia elétrica da rede de distribuição do sistema real utilizando controlador MDP com acionamento direto das bombas.

\begin{tabular}{r|cc}
\hline Gastos com energia elétrica & Valor & Custo \\
\hline Energia no horário fora-de-ponta & $15797,50 \mathrm{kWh}$ & $U \$ 447,23$ \\
Energia no horário de ponta & $4094,11 \mathrm{kWh}$ & $U \$ 153,49$ \\
Demanda & $75,29 \mathrm{~kW}$ & $U \$ 1422,39$ \\
\hline Total no período de tarifação & $19891,61 \mathrm{kWh}$ & $U \$ 2023,11$ \\
\hline
\end{tabular}

Tabela 6.14: Gastos com energia elétrica da rede de distribuição do sistema real utilizando controlador MDP com acionamento das bombas por inversor de frequência.

\begin{tabular}{r|cc}
\hline Gastos com energia elétrica & Valor & Custo \\
\hline Energia no horário fora-de-ponta & $13997,52 \mathrm{kWh}$ & $U \$ 396,27$ \\
Energia no horário de ponta & $3168,03 \mathrm{kWh}$ & $U \$ 118,77$ \\
Demanda & $46,37 \mathrm{~kW}$ & $U \$ 876,04$ \\
\hline Total no período de tarifação & $17165,55 \mathrm{kWh}$ & $U \$ 1391,08$ \\
\hline
\end{tabular}

\subsubsection{Análise dos Resultados}

Uma particularidade do sistema real é o superdimensionamento de sua estação de bombeamento. Na Figura 6.27 é possível verificar que a vazão fornecida por uma bomba pode ser o dobro da demanda média de água. Já quando se utilizam duas bombas, este 
valor se aproxima a 4 vezes. Além disso, devido à grande capacidade de bombeamento instalada é possível reduzir o nível mínimo de água no tanque de água, que hoje é $15 \mathrm{ft}$, produzindo-se dois ganhos: redução do consumo energético, devido à redução da pressão manométrica de bombeamento, e diminuição da idade da água, um dos principais fatores que influenciam em sua qualidade.

Por meio da análise das políticas dos controladores com modelagem por MDP, apresentadas nas Figuras 6.29 e 6.30, é possível verificar que em ambos os casos as políticas encontradas acionam apenas uma bomba em cada estado. Este fato está relacionado à demanda, que, caso haja o acionamento de uma bomba adicional, fará com que o custo da demanda dobre, tornando a solução desvantajosa economicamente.

A partir dos resultados dos gastos com energia elétrica da rede de distribuição do sistema real apresentados pelas Tabelas $6.12,6.13$ e 6.14 é possível realizar a análise comparativa de cada um dos gastos individuais para determinar os potenciais de redução, conforme mostra a Tabela 6.15. Esta tabela apresenta as diferenças absolutas e percentuais dos dois controladores propostos, tomando como base os gastos do sistema real no mês de junho de 2012.

Tabela 6.15: Potencial de redução dos gastos com energia elétrica da rede de distribuição do sistema real utilizando controlador MDP com acionamento direto das bombas (Direto) e por inversor de frequência (VFD).

\begin{tabular}{r|cc|cc}
\hline \multirow{2}{*}{ Gastos com energia elétrica } & \multicolumn{2}{|c|}{ Diferença absoluta } & \multicolumn{2}{c}{ Diferença percentual } \\
& Direto & VFD & Direto & VFD \\
\hline Energia no horário fora-de-ponta & $+U \$ 184,26$ & $+U \$ 133,30$ & $+70,1 \%$ & $+50,7 \%$ \\
Energia no horário de ponta & $-U \$ 246,69$ & $-U \$ 281,41$ & $-61,6 \%$ & $-70,3 \%$ \\
Demanda & $-U \$ 4,29$ & $-U \$ 550,64$ & $-0,3 \%$ & $-38,6 \%$ \\
\hline Total no período de tarifação & $-U \$ 66,73$ & $-U \$ 698,75$ & $-3,2 \%$ & $-33,4 \%$ \\
\hline
\end{tabular}

Nesta tabela é possível observar que o controlador MDP com acionamento direto das bombas possui redução dos gastos totais com energia elétrica muito pequena com relação ao controlador atual, somente de $3,2 \%$. Este fato está relacionado a não ser possível reduzir os gastos com a demanda, parte mais significativa dos gastos com energia elétrica, devido ao acionamento da bomba ser o mesmo nos controlares atual e proposto (acionamento direto das bombas), além dos aspectos relacionados ao nível mínimo do tanque e do superdimensionamento da bombas. Independente disso, é possível observar que houve uma migração dos gastos energéticos do período de ponta para o período forade-ponta, migração esta que representou quase a totalidade da redução alcançada. 
Já no caso do controlador MDP com acionamento das bombas por inversor de frequência é possível obter reduções expressivas dos gastos totais com energia elétrica, de cerca de um terço. Essa redução está concentrada na demanda uma vez que, segundo a Lei de Afinidades, a potência elétrica é proporcional ao cubo da velocidade de rotação. Assim, reduções de $15 \%$ na velocidade de rotação da bomba representam redução de mais de $38 \%$ na potência utilizada. Além disso, reduções na demanda permitem reduções de perdas elétricas por efeito Joule nos condutores elétricos (valores não contabilizados neste trabalho). Finalmente, neste controlador também houve migração do consumo energético do período de ponta para o período fora-de-ponta e que representou reduções absolutas até maiores do que as do controlador MDP com acionamento direto das bombas, fato relacionado à operação com nível de água mais baixo no tanque de armazenamento $T_{7004}$.

Desta forma, concluí-se que se a Divisão de Utilidade da cidade fizer investimentos para a compra de um inversor de frequência, da ordem de $U \$ 3500,00$, o retorno será inferior a 6 meses $^{12}$, o que, em termos financeiros, é muito atraente.

\footnotetext{
${ }^{12}$ Análise feita utilizado-se o método de payback simples.
} 


\section{Conclusão}

Esta tese apresentou um sistema de controle para redução de gastos com energia elétrica em sistemas de distribuição de água utilizando modelagem por Processos Decisórios de Markov, nos quais a função de transição de estado é probabilística devido a incertezas decorrentes do modelo hidráulico, da curva de demanda, do truncamento do algoritmo de cálculo e da discretização das variáveis de estado.

Assim, finalizando os assuntos abordados por esta tese, este capítulo apresenta as considerações finais a respeito dos resultados dos experimentos realizados, identificando os pontos fortes e as fraquezas do sistema de controle proposto, ressaltando as contribuições alcançadas. Além disso, são apresentadas sugestões de trabalhos futuros a partir da vivência conseguida durante a execução deste trabalho.

\subsection{Discussão sobre os Resultados dos Experimentos}

Conforme foi apresentado no experimento com sistema de distribuição simplificado e modelo hidráulico explícito, a inclusão de função de transição de estado probabilística, calculada a partir de incertezas da curva de demanda e da discretização da variável de estado, tornou o controlador mais robusto. Esta condição faz com que ele seja apto a atuar em sistemas reais, nos quais as variáveis possuem variabilidade e são dinâmicas. Técnicas de otimização que não levam em conta as incertezas inerentes ao processo estão desprezando uma informação importante para a robustez do sistema de controle e consequentemente, estão fadadas ao fracasso.

Já o experimento comparativo mostrou que a técnica de otimização mais utilizada nos problemas de redução de gastos com energia elétrica em sistema de distribuição de água, os algoritmos genéticos, apresentam fragilidades quando a função objetivo leva em conta restrições impostas pelo problema, mesmo em problemas que não sofrem com a variabilidade e o dinamismo que são encontrados em sistemas reais. Além disso, as técnicas meta heurísticas, devido a sua concepção, estão condenadas a encontrarem mínimos locais 
ao invés de mínimos globais.

No experimento com um sistema real, a política foi determinada a partir de dados do valor médio da demanda em um mês com consumo de água elevado. Entretanto, o controlador utilizou esta política com dados reais da demanda neste mês, ou seja, com variabilidade em torno do valor médio da demanda. Assim, este experimento demonstrou a aplicabilidade do controlador proposto, identificando potenciais de reduções em torno de um terço, quando utilizado acionamento das bombas por meio de inversores de frequência.

A maior fragilidade da modelagem de problemas por MDP e solucionados por programação dinâmica está ligada à maldição da dimensionalidade, nos quais o tempo de processamento das soluções cresce exponencialmente com o número de estados e de ações. Este problema foi contornado parcialmente nesta tese devido a inclusão da incerteza na discretização das variáveis de estado, porém, no caso de problemas com poucos estados é muito difícil representar fielmente o comportamento do sistema a ser modelado. Além disso, técnicas de programação paralela também ajudaram a reduzir parcialmente o tempo de processamento. Ainda sim, problemas com muitas variáveis de estados e discretizadas finamente tornam o tempo de processamento proibitivo.

Finalmente, a modelagem do problema por MDP permite a representação das ações de forma implícita, condicionada às variáveis de estado, que são aquelas que se deseja controlar. Desta forma, a política de controle mapeia o conjunto de estados no conjunto de ações, fazendo com que as respostas sejam mais robustas. No caso da representação das ações de forma explícita, principalmente relacionando ações com instantes de tempo como na grande maioria das técnicas disponíveis na literatura, tem-se o problema de que quaisquer pequenas variações do modelo do sistema resultem em soluções não-ótimas, ou até mesmo, que alguma restrição do problema seja infringida.

\subsection{Contribuições}

Esta tese apresenta três contribuições para o estado da arte nas áreas de controle e otimização.

A primeira e principal delas diz respeito à proposta de um novo sistema de controle, modelado por Processos Decisórios de Markov e aplicado a sistemas de distribuição de água, com foco na redução de gastos com energia elétrica. Com este novo sistema é possível realizar o controle autônomo do acionamento de bombas e válvulas em sistemas de distribuição de água, respeitando-se as restrições operacionais e características do 
problema, e com a premissa de redução das despesas com energia elétrica.

A segunda contribuição diz respeito à incerteza associada à função de transição de estados dos Processos Decisórios de Markov. Esta tese apresenta uma função de transição probabilística, calculada a partir de incertezas decorrentes do modelo hidráulico, da curva de demanda, do truncamento do algoritmo de cálculo e da discretização das variáveis de estado.

Finalmente, a última contribuição desta tese é a disponibilização dos dados para a realização de experimentos comparativos futuros com outros sistemas de controle. Durante a pesquisa bibliográfica observou-se que as técnicas presentes na literatura não descreviam detalhadamente os experimentos realizados, fazendo com que estes não fossem reprodutíveis e comprometendo a análise com outras técnicas.

Como resultado destas contribuições, as seguintes publicações foram geradas:

- Paulo Thiago Fracasso, Frank Barnes, Anna Helena Reali Costa. Energy Cost Optimization in Water Distribution Systems using Markov Decision Processes. $4^{\text {th }}$ International Green Computing Conference, Arlington, USA, 2013.

- Paulo Thiago Fracasso, Frank Barnes, Anna Helena Reali Costa. Optimized Control for Water Utilities. $12^{\text {th }}$ International Conference on Computing and Control for the Water Industry, Perugia, Italy, 2013.

- Fatemeh Alighalehbabakhani, Carol Jean Miller, Seyed Mohsen Sadatiyan Abkenar, Paulo Thiago Fracasso e Shawn McElmmury. Comparative Evaluation of 3 Distinct Water/Energy Optimization Tools Applied to Real System (Monroe, MI). Journal of Sustainable Computing, Informatics and Systems, 2014.

- Paulo Thiago Fracasso, Anna Helena Reali Costa. Water Distribution Systems Modeled as a Markov Decision Processes to Reduce Energy Expenses. Journal of Water Resources Management (em elaboração).

\subsection{Trabalhos Futuros}

Nesta seção são apresentadas algumas sugestões de trabalho futuros para problemas de redução de gastos com energia elétrica em sistemas de distribuição de água.

A redução de gastos com energia elétrica não se resume apenas aos sistemas de controle. Grande parte das empresas de saneamento, que são massivas consumidoras de 
energia, não estão atentas ao arcabouço regulatório relacionado a este tema. Alterações na classe de tarifação resultam em ganhos expressivos sem que haja necessidade de investimento ou conhecimento do sistema de distribuição, apenas do histórico do consumo de energia elétrica. Assim, trabalhos nesta área seriam muito benéficos às empresas.

Com relação aos sistemas de distribuição de água, observa-se que anteriormente à alteração das políticas de controle, questões primordiais devem ser atacadas, como universalização do abastecimento, diminuição dos índices elevados de perda e otimização do circuito hidráulico do sistema de distribuição. Uma possível contribuição seria a inclusão de formas de modelagem das perdas de água na rede de distribuição, cujo objetivo, além da redução com os gastos com energia elétrica, seria a redução das perdas de água na distribuição.

Finalmente com relação à modelagem do problema utilizando Processos Decisórios de Markov, verifica-se a possibilidade de sua utilização, principalmente no que tange às funções de transição de estado probabilísticas, em problemas de otimização diversos, como: redução de tempo ou percurso de entrega em sistema de logística; aumento da robustez em sistema de distribuição de energia elétrica com a presença de fontes de geração intermitente, como eólica ou solar; e até mesmo no controle de tráfego aéreo, visando a diminuição do tempo de espera nas operações de pouso. Além disso, a política fornecida pelo MDP poderia sofrer um ajuste fino utilizando técnicas de aprendizado por reforço, como por exemplo Q-learning ou SARSA, visando compensar as imprecisões do modelo. 


\section{Referências}

AGÊNCIA NACIONAL DE ENERGIA ELÉTRICA - ANEEL. Tarifas de Fornecimento de Energia Elétrica: Cadernos temáticos aneel - 4. Brasília, DF, 2005.

ASSOCIAÇÃO BRASILEIRA DAS EMPRESAS DE SERVIÇOS DE CONSERVAÇÃO DE ENERGIA - ABESCO. Análise dos Resultados da Pesquisa das Empresas de Serviços de Eficiência Energética no Brasil. São Paulo, SP, 2005.

BELlMAN, R. E. Dynamic Programming. Princeton, USA: Princeton University Press, 1957.

BENE, J. G.; SELEK, I.; HÖS, C. Neutral search technique for short-term pump schedule optimization. Journal of Water Resources Planning and Management, v. 136 n. 1, p. 133-137, 2010.

BENTLEY SYSTEMS. WaterGEMS V8i - User's guide. Exton, USA, 2009.

BERTSEKAS, D. P. Dynamic Programming and Optimal Control. 4th. ed. Nashua, USA: Athena Scientific, 2007.

BRAZIUNAS, D. POMDP solution methods: a survey. Toronto, Canada, 2003.

CARRAGHER, B. J.; STEWART, R. A.; BEAL, C. D. Quantifying the influence of residential water appliance efficiency on average day diurnal demand patterns at an end use level: A precursor to optimised water service infrastructure planning. Journal of Resources, Conservation and Recycling, v. 62, p. 81-90, 2012.

COSTA, L. H. M.; CASTRO, M. A. H. de; RAMOS, H. Utilização de um algoritmo genético híbrido para operação ótima de sistemas de abastecimento de água. Jornal de Engenharia Sanitária e Ambiental, v. 15 - n. 2, p. 187-196, 2010.

COX, M. G.; HARRIS, P. M. Best Practice Guide - Uncertainty Evaluation. Teddington, United Kingdom, 2006.

DIECK, R. H. Measurement Uncertainty: Methods and Applications. 2nd. ed. Durham, NC, USA: ISA - Instrument Society of America, 1997.

DÖTSCH, F.; DENZINGER, J.; KASINGER, H.; BAUER, B. Decentralized real-time control of water distribution networks using self-organizing multi-agent systems. In: Proceedings of the 4 th IEEE International Conference on Self-Adaptive and Self-Organizing Systems. Budapest, Hungary: IEEE, 2010. p. 223-232.

EMPRESA DE PESQUISA ENERGÉTICA - EPE. Plano Nacional de Energia - 2030. Rio de Janeiro, RJ, 2006. 
EMPRESA DE PESQUISA ENERGÉTICA - EPE. Balanço Energético Nacional 2011 Ano base 2010: Resultados preliminares. Rio de Janeiro, RJ, 2011.

EMPRESA DE PESQUISA ENERGÉTICA - EPE. Balanço Energético Nacional 2013 Ano base 2012. Rio de Janeiro, RJ, 2013.

ENERGY AND WATER DEPARTMENT - EWD. The Challenge of Reducing Non-Revenue Water in Developing Countries: How the private sector can help: A look at performance-based service contracting. Washington, USA, 2006.

EPP, B.; FOWLER, A. G. Efficient code for steady-state flows in networks. Journal of the Hydraulics Division, v. 96 - n. 1, p. 43-56, 1970.

FANG, H. en; GAO, J.; YUAN, Y. Optimal scheduling of multi-tank multi-source system using genetic algorithm. In: Proceedings of the 2nd International Workshop on Intelligent Systems and Applications. Wuhan, China: ISA, 2010. p. 1-6.

FENG, Z.; HANSEN, E. A. Symbolic heuristic search for factored markov decision processes. In: Proceedings of the Eighteenth National Conference on Artificial Intelligence. Edmonton, Canada: AAAI Press, 2002. p. 455-460.

FIRMinO, M. B. M.; AlBUQUerque, A. A.; CURI, W. F.; SIlvA, N. C. Método de eficiência energética no bombeamento de água via programação linear e inteira. In: Anais do VI Seminário Iberoamericano sobre Sistemas de Abastecimento Urbano de Água. João Pessoa, Brasil: SEREA, 2006. p. 1-11.

GARCIA, C. Modelagem e Simulação de Processos Industriais e de Sistemas Eletromecânicos. São Paulo, Brasil: EdUSP, 2005.

GILPIN, A. Environmental Impact Assessment (EIA): Cutting Edge for the Twenty-first Century. Cambridge, United Kingdom: Cambridge University Press, 1995.

GOLDMAN, F. E.; SAKARYA, A. B. A.; ORMSBEE, L. E.; UBER, J. G.; MAYS, L. W. Water Distribution Systems Handbook. New York, USA: McGraw-Hill, 1999.

HAESTAD, M.; WALSKI, T. M.; CHASE, D. V.; SAVIC, D. A.; GRAYMAN, W.; BECKWITH, S.; KOELLE, E. Advanced Water Distribution Modeling and Management. Waterbury, USA: Haestad Press, 2003.

HAIMES, Y. Y. Hierarchical Analyses of Water Resources Systems: Modeling and Optimization of Large-Scale Systems. New York, USA: McGraw-Hill, 1977.

HOWARD, R. A. Dynamic Programming and Markov Processes. Cambridge, USA: MIT Press, 1960.

HYDRAULIC RESEARCH. Tables for the Hydraulic Design of Pipes and Sewers. Wallingford, England, 1983.

IDELCHIK, I. E. Handbook of Hydraulic Resistance. New York, USA: Begell House, Inc., 2005 .

INTERNATIONAL ENERGY AGENCY - IEA. Key World Energy Statistics. Paris, France, 2013. 
INTERNATIONAL ORGANIZATION FOR STANDARDIZATION - ISO. Guide 99 International vocabulary of metrology: Basic and general concepts and associated terms (VIM). Geneve, Switzerland, 2007.

INTERNATIONAL ORGANIZATION FOR STANDARDIZATION - ISO. Guide 98-3

- Uncertainty of measurement - Part 3: Guide to the expression of uncertainty in measurement. Geneve, Switzerland, 2008.

INTERNATIONAL WATER ASSOCIATION - IWA. Losses from Water Supply Systems: Standard terminology and recommended performance measures. London, UK, 2000.

KING, R. S. The post-fukushima world. IEEE Spectrum, v. 48:11, p. 44-45, 2011.

LEIBY, V. M.; BURKE, M. E. Energy Efficiency Best Practices for North American Drinking Water Utilities. Denver, CO, USA, 2011.

LÓPEZ-IBÁÑEZ, M. Operational Optimisation of Water Distribution Networks. Tese (Doutorado) - Edinburgh Napier University, 2009.

LÓPEZ-IBÁÑEZ, M.; PRASAD, T. D.; PAECHTER, B. Multi-objective optimisation of the pump scheduling problem using spea2. In: Proceedings of the 2005 IEEE Congress on Evolutionary Computation. Edinburgh, Scotland: IEEE, 2005. v. 1, p. 435-442.

LÓPEZ-IBÁÑNZ, M.; PRASAD, T. D.; PAECHTER, B. Ant colony optimization for optimal control of pumps in water distribution networks. Journal of the Water Resources Planning and Management, v. 134 - n. 4, p. 337-346, 2008.

MATURANA, F.; KOTINA, R.; STARON, R.; TICHÝ, P.; VRBA, P. Agent-based water-waste water control system architecture. In: Proceedings of the 2006 International Conference Applied Computing. San Sebastian, Spain: IADIS, 2006. v. 1, p. 661-666.

MAUSAM; KOLOBOV, A. Planning with Markov Decision Processes: An AI Perspective. San Rafael, CA, USA: Morgan \& Claypool Publishers, 2012.

MINISTÉRIO DE MINAS E ENERGIA - MME. Plano Nacional de Eficiência Energética: Premissas e diretrizes básicas na elaboração do plano. Brasília, DF, 2010.

MUNOS, R.; MOORE, A. Barycentric interpolators for continuous space and time reinforcement learning. In: Proceedings of Neural Information Processing Systems. Denver, CO, USA: MIT Press, 1998. p. 1024-1030.

MURPHY, R. R. Introduction to AI Robotics. 1st. ed. Cambridge, USA: MIT Press, 2000 .

OGATA, K. Modern Control Engineering. 4th. ed. New Jersey, USA: Prentice Hall, 2002.

PASHA, M. F. K.; LANSEY, K. Optimal pump scheduling by linear programming. In: Proceedings of the World Environmental and Water Resources Congress 2009: Great Rivers. Kansas City, USA: ASCE, 2009. p. 395-404.

PROGRAMA NACIONAL DE CONSERVAÇÃO DE ENERGIA ELÉTRICA PROCEL. Eficiência Energética em Sistemas de Bombeamento: Manual prático. Rio de Janeiro, RJ, 2005. 
PROGRAMA NACIONAL DE CONSERVAÇÃO DE ENERGIA ELÉTRICA PROCEL. Conservação de Energia: Eficiência energética de equipamentos e instalações. Itajubá, MG, 2006.

PUTERMAN, M. L. Markov Decision Processes - Discrete Stochastic Dynamic Programming. 1st. ed. New York, NY, USA: John Wiley \& Sons, 1994.

QUEENSLAND ENVIRONMENTAL PROTECTION AGENCY AND WIDE BAY WATER. Managing and Reducing Losses from Water Distribution Systems: Manual 7: Managing apparent loss. Queensland, Australia, 2002.

RENEWABLE ENERGY POLICY NETWORK FOR THE 21ST CENTURY - REN21. Renewables 2011: Global status report. Paris, France, 2011.

SANNER, S.; DELGADO, K. V.; ; BARROS, L. N. de. Symbolic dynamic programming for discrete and continuous state mdps. In: Proceedings of the Twenty-seventh Conference on Uncertainty in Artificial Intelligence. Chengdu, China: AAAI Press, 2011. p. 643-652.

SAVIC, D. A.; BICIK, J.; MORLEY, M. S. A dss generator for multiobjective optimisation of spreadsheet-based models. Journal of the Environmental Modeling and Software, v. 26, p. 551-561, 2011.

SECRETARIA DE ENERGIA ELÉTRICA - SEE. Boletim de Monitoramento do Sistema Elétrico Brasileiro: Janeiro/2013. Brasília, DF, 2013.

SECRETARIA NACIONAL DE SANEAMENTO AMBIENTAL - SNSA. Sistema Nacional de Informações sobre Saneamento - SNIS: Diagnóstico dos serviços de água e esgoto - 2007. Brasília, DF, 2009.

SHIHU, S.; DONG, Z.; SUIQING, L.; MING, Z.; YIXING, Y.; HONGBIN, Z. Power saving in water supply system with pump operation optimization. In: Proceedings of the 2010 Asia-Pacific Power and Energy Engineering Conference. Chengdu, China: IEEE, 2010. p. 1-6.

SIROVÝ, M.; PEROUTKA, Z.; MOLNÁR, J.; MICHALÍK, J.; BYRTUS, M.; WIKSTROEM, P. Sophisticated software for design and optimization of vsds for high-power pumps: Variable speed drive with frequency converter. In: Proceedings of the 14 th International Power Electronics and Motion Control Conference. Ohrid, Macedonia: IEEE, 2010. p. 70-77.

SKWORCOW, P.; ABDELMEGUID, H.; UlAnICKI, B.; BOUNDS, P. Optimal pump scheduling with pressure control aspects: Case studies. In: Proceedings of the 10th International Conference on Computing and Control in the Water Industry. Sheffield, England: ICE, 2009. p. 113-119.

SUTTON, R. S.; BARTO, A. G. Reinforcement Learning: An introduction - Adaptive Computation and Machine Learning. Cambridge, USA: MIT Press, 1998.

TAKAHASHI, S.; SALDARRIAGA, J. G.; VEGA, M. C.; HERNÁNDEZ, F. Water distribution system model calibration under uncertainty environments. Journal of Water Science 8 Technology: Water Supply, v. 10.1, p. 31-38, 2010. 
ULANICKI, B.; KAHLER, J.; SEE, H. Dynamic optimization approach for solving an optimal scheduling problem in water distribution systems. Journal of the Water Resources Planning and Management, v. 133 - n. 1, p. 23-32, 2007.

UNITED NATIONS DEVELOPMENT PROGRAMME - UNDP. World Energy Assessment: Overview - 2004 update. New York, USA, 2004.

UNITED STATES ENVIRONMENTAL PROTECTION AGENCY - EPA. EPANET 2.0 - User Manual. Cincinnati, USA, 2000.

WANG, J.; BRDYS, M. A. Optimal operation of water distribution systems under full range of operating scenarios. In: Proceedings of the 6th International Control Conference. Glasgow, Scotland: UKACC, 2006. p. 1-6.

WANG, J.-Y.; CHANG, T.-P.; CHEN, J.-S. An enhanced genetic algorithm for bi-objective pump scheduling in water supply. Journal of the Expert Systems with Applications, v. 36, p. 10249-10258, 2009.

WELCH, B. L. The generalization of "student's"problem when several different population variances are involved. Biometrika, v. 34, p. 28-35, 1947.

WHITE, D. J. Markov Decision Processes. Chichester, England: John Wiley \& Sons, 1993.

WIERING, M.; OTTERLO, M. van. Reinforcement Learning - State-of-the-Art. 1st. ed. Berlin, Germany: Springer-Verlag, 2012.

YANG, Z.; BøRSTING, H. Optimal scheduling and control of a multi-pump boosting system. In: Proceedings of the 2010 IEEE International Conference on Control Applications. Yokohama, Japan: IEEE, 2010. p. 2071-2076.

ZHUAN, X.; ZHANG, L.; GUO, J. Optimal operation scheduling of a pump station. In: Proceedings of the 2011 Chinese Control and Decision Conference. Mianyang, China: IEEE, 2011. p. 3797-3802. 


\section{Apêndice A - Avaliação da Incerteza}

Este apêndice apresenta a técnica de combinação de variâncias das fontes de erro, recomendada e normalizada pela ISO (International Organization for Standardization), para o cálculo da incerteza associada à função de transição de estados na modelagem por MDP do problema de minimização de gastos com energia elétrica em sistemas de distribuição de água.

\section{A.1 Introdução}

Quando se expressa o valor do resultado de uma medição ou se estima o valor de uma grandeza física é necessário apresentar alguma indicação quantitativa da qualidade deste resultado, de forma que se possa avaliar sua confiabilidade. Sem essa indicação, resultados de medição ou estimativa de valores não podem ser comparados, seja entre eles mesmos ou com valores de referência fornecidos por conhecimento prévio, especificações ou normas.

Neste contexto a incerteza busca a avaliação adequada de um mensurando, uma vez que caracteriza a dispersão dos valores atribuídos a ele e reflete o conhecimento, ou a falta de conhecimento, do valor verdadeiro (COX; HARRIS, 2006).

Além disso, sempre que uma variável é medida ou calculada, diferentes componentes produzem um desvio na obtenção do seu valor, ou simplesmente, associam um erro à medição. Assim, o termo erro é formalmente definido como a diferença entre o valor do mensurando e seu correspondente valor verdadeiro (DIECK, 1997).

Embora amplamente reconhecido que, quando todos os componentes de erro conhecidos ou presumidos tenham sido avaliados e as correções adequadas tenham sido aplicadas, ainda permanece uma incerteza sobre quão correto é o resultado declarado, isto é, uma dúvida acerca de quão corretamente o resultado da medição representa o valor da grandeza que está sendo medida ou estimada.

Os erros podem ser classificados em três tipos: espúrios, aleatórios ou sistemáticos. 
Os erros espúrios são enganos evidentes que invalidam o resultado de uma medição, tais como erros de transcrição de dados, configuração incorreta de unidades ou falhas de comunicação. Já os erros aleatórios são aqueles que não são possíveis de se evitar e ocasionados principalmente devido ao número de medições não ser suficientemente representativo, como por exemplo o lançamento de um dado apenas poucas vezes para determinação das probabilidades de obtenção de um dos seus valores de face. Finalmente os erros sistemáticos são fruto de inexatidões inerentes ao instrumento ou equipamento utilizado para medição, da metodologia de cálculo utilizada e das condições em que foram realizadas as medições, como por exemplo medição de temperatura com um termômetro descalibrado.

Assim, a incerteza é uma estimativa dos limites (definidos como uma probabilidade da abrangência ou nível da confiança) que o erro pode alcançar quando é realizada uma medição ou cálculo. Formalmente, é definida pelo Guide to the Expression of Uncertainty in Measurement (ISO, 2008) como sendo o parâmetro associado ao resultado de uma medição, que caracteriza a dispersão dos valores que podem ser fundamentalmente atribuídos à medição.

\section{A.2 Incerteza-padrão}

Em grande parte dos problemas que se deseja determinar o valor de um mensurando $Y$, o mesmo não é obtido de forma direta, e sim, a partir de $N$ outras grandezas de influência $X_{1}, X_{2}, \ldots, X_{N}$, o que pode ser descrito por meio de uma relação funcional:

$$
Y=f\left(X_{1}, X_{2}, \ldots, X_{N}\right)
$$

onde o conjunto das grandezas de entrada $X_{1}, X_{2}, \ldots, X_{N}$ pode ser categorizado como:

•variáveis cujos valores e incertezas podem ser diretamente determinados na medição, por meio de uma única observação, de observações repetidas, ou de julgamento baseado na experiência; ou

• grandezas cujos valores e incertezas são incorporados à medição a partir de fontes externas, tais como grandezas associadas com padrões de medição calibrados, materiais de referência e dados de referência obtidos de manuais técnicos.

Uma estimativa do mensurando $Y$, designada por $y$, é obtida a partir da Equação A.1 utilizando estimativas de entrada $x_{1}, x_{2}, \ldots, x_{N}$ para os valores das $N$ grandezas de influência $X_{1}, X_{2}, \ldots, X_{N}$. Assim, a estimativa do mensurando $y$, que é o resultado de 
uma medição, é dada pela média aritmética de $N_{Y}$ medições independentes de $Y$ :

$$
y=\bar{Y}=f\left(x_{1}, x_{2}, \ldots, x_{N}\right)
$$

Sendo assim, a incerteza-padrão associada à variável de entrada $x_{i}$, designada por $u\left(x_{i}\right)$, nada mais é do que a incerteza, expressa como um desvio padrão, associado com a estimativa desta entrada (ISO, 2007).

Cada estimativa de entrada $x_{i}$ e sua incerteza-padrão associada $u\left(x_{i}\right)$ são obtidas de uma distribuição de valores possíveis da grandeza de entrada $X_{i}$. Essa distribuição de probabilidade pode ser baseada na frequência, isto é, em uma série de observações de $X_{i}$, também conhecida como avaliação do Tipo A, ou por meio de uma distribuição definida a priori, também conhecida como avaliação do Tipo B. Deve-se reconhecer que em ambos os casos as distribuições são modelos utilizados para representar o estágio de nosso conhecimento. A seguir as avaliações do Tipo A e do Tipo B são descritas em detalhes.

\section{A.2.1 Avaliação do Tipo A}

As avaliações do tipo A são as que possuem incertezas baseadas em métodos estatísticos de uma série de medições, como por exemplo, a dispersão das leituras de um instrumento.

Assim, a melhor estimativa do valor esperado de uma variável $X_{A}$, no qual foram realizadas $N_{X}$ observações independentes sob a mesma condição, é a média aritmética destas observações, resultando em:

$$
\overline{x_{A}}=\frac{1}{N_{X}} \sum_{k=1}^{N_{X}} x_{k},
$$

onde $x_{k}$ é uma observação qualquer da variável $X_{A}$.

As observações individuais $x_{k}$ diferem entre si devido a variações aleatórias na grandeza de influência. Portanto, a variância experimental das observações, que estima a variância da distribuição de probabilidade de $X_{A}$, é calculada como um desvio-padrão da amostra:

$$
s^{2}\left(x_{A}\right)=\frac{1}{N_{X}-1} \sum_{k=1}^{N_{X}}\left(x_{k}-\overline{x_{A}}\right)^{2},
$$

onde $s^{2}\left(x_{A}\right)$ caracteriza a dispersão das observações $x_{k}$ em torno do valor $\overline{x_{A}}$.

Devido a impossibilidade de observações infinitas da variável $X_{A}$ para se obter o 
valor da variância da população, a sua melhor estimativa é obtida por meio da variância experimental da média, calculada como:

$$
s^{2}\left(\overline{x_{A}}\right)=\frac{s^{2}\left(x_{A}\right)}{N_{X}} .
$$

Assim, para uma grandeza de entrada $X_{A}$, estimada por meio de $N_{X}$ observações independentes sob as mesmas condições, a incerteza-padrão $u\left(x_{A}\right)$ de sua estimativa será o próprio desvio-padrão da média:

$$
u^{2}\left(x_{A}\right)=s^{2}\left(\overline{x_{A}}\right) \Rightarrow u\left(x_{A}\right)=s\left(\overline{x_{A}}\right)
$$

\section{A.2.2 Avaliação do Tipo B}

As avaliações do Tipo B, diferentemente das avaliações do Tipo A, são aquelas cuja avaliação não realiza análise estatística de uma séries de observações, e sim, é realizada por meio do julgamento científico baseando em todas as informações disponíveis sobre a possível variabilidade da variável $X_{B}$. O conjunto de informações pode incluir:

•dados de medições prévias;

•experiência ou conhecimento do comportamento das propriedades de materiais e instrumentos relevantes;

-especificações do fabricante;

•dados fornecidos em certificados de calibração ou outros documentos; e

•incertezas atribuídas a dados de referência extraídos de manuais.

Nas fontes de incertezas do Tipo B, o valor da incerteza obedece regras referentes ao tipo de distribuição a que estão associadas. Por exemplo, as fonte de incerteza do Tipo B que possuem distribuição normal (principalmente aquelas oriundas de certificados de calibração) a incerteza-padrão $u\left(x_{B}\right)$ é calculada pela seguinte equação:

$$
u\left(x_{B}\right)=\frac{U\left(x_{B}\right)}{k},
$$

onde $U\left(x_{B}\right)$ é a incerteza expandida da variável $X_{B}$ e $k$ é o fator de abrangência que está associado ao nível de confiança e ao número de graus de liberdade da distribuição.

Outros tipos mais comuns de distribuição que são fontes de incerteza do Tipo B (ISO, 2008) são descritas no quadro na Figura A.1, onde $\overline{x_{B}}$ é o valor médio da distribuição. 


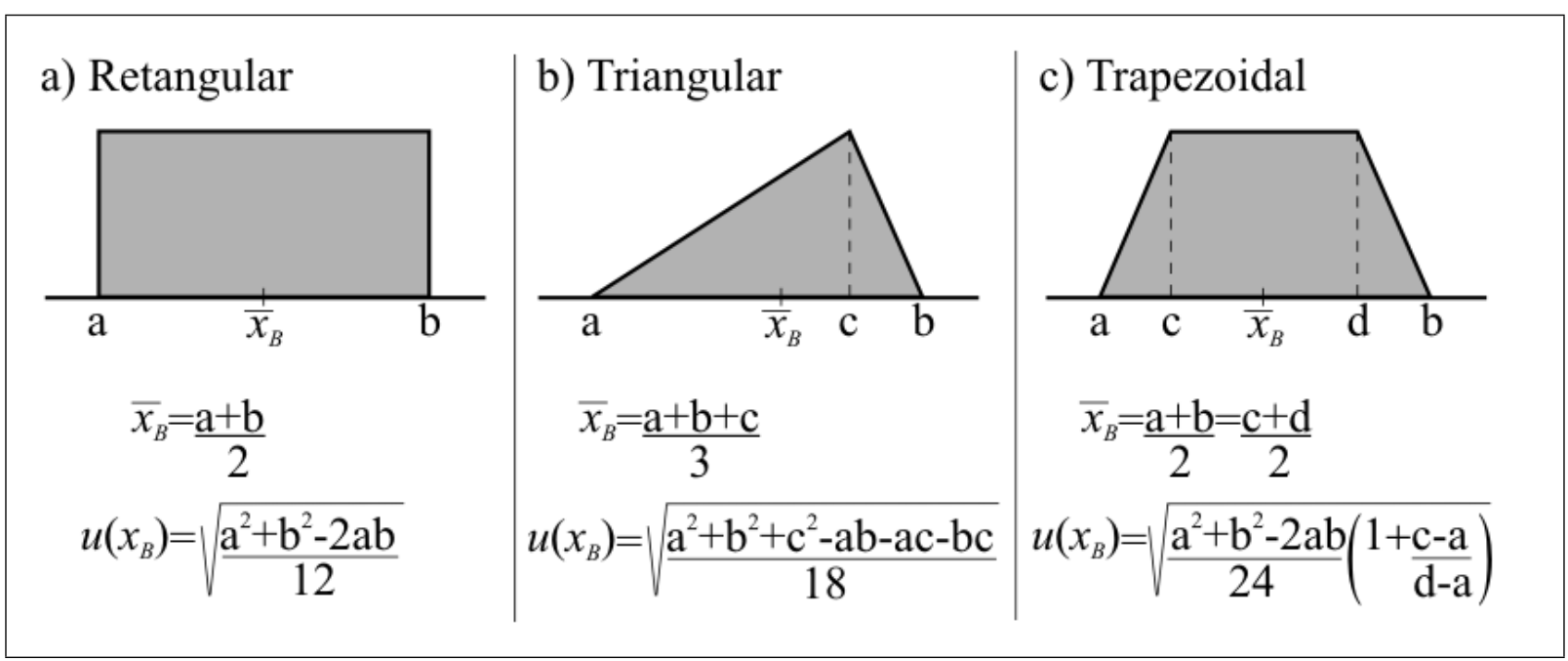

Figura A.1: Distribuições de probabilidade fontes de incerteza do tipo B.

Dentro das distribuições de probabilidade descritas na Figura A.1, a distribuição retangular é indicada quando há igual probabilidade de um evento ocorrer dentro do intervalo compreendido entre os valores $a$ e $b$. Em muitos casos, é mais realista esperar que valores próximos aos limites sejam menos prováveis do que os que estejam perto do ponto médio. Portanto, é razoável substituir a distribuição retangular por distribuições triangulares ou trapezoidais.

\section{A.3 Combinando as fontes de incerteza}

A partir das incertezas-padrão das $N$ grandezas de influência do mensurando $Y$, podendo ser tanto do Tipo A como do Tipo B, os seus valores são combinadas para se obter a incerteza-padrão de $Y$, também conhecida como incerteza-padrão combinada $u_{C}(y)$.

Esta técnica é baseada na combinação das variâncias das grandezas de influência e descrita detalhadamente a seguir.

\section{A.3.1 Coeficiente de sensibilidade}

Os coeficientes de sensibilidade, vistos como os fatores de conversão de unidades, ponderam o valor da incerteza-padrão de uma determinada grandeza de influência para a mesma unidade da incerteza do mensurando.

Este ponderador é obtido por meio da derivada parcial do mensurando $Y$, descrito por meio da Equação A.1, em função de uma determinada variável de influência $X_{i}$ e 
calculado nos valores esperados de todas as variáveis de influência, resultando em:

$$
c_{i}=\left.\frac{\partial f}{\partial x_{i}}\right|_{X_{1}=\overline{x_{1}}, \ldots, X_{N}=\overline{x_{N}}},
$$

onde $c_{i}$ é o coeficiente de sensibilidade da variável $X_{i}$ e $X_{1}=\overline{x_{1}}, \ldots, X_{N}=\overline{x_{N}}$ são os valores esperados das $N$ variáveis de influência do mensurando.

\section{A.3.2 Incerteza-padrão combinada}

A partir dos valores das incertezas-padrão e dos seus respectivos coeficientes de sensibilidade é possível calcular a incerteza-padrão combinada do mensurando, que pode ser a partir de duas formas: com variáveis de influência independentes, ou com variáveis de influência correlacionadas. No primeiro caso a incerteza-padrão combinada será:

$$
u_{C}^{2}(y)=\sum_{i=1}^{N} c_{i}^{2} \cdot u^{2}\left(x_{i}\right)
$$

Já no caso de variáveis de influência correlacionadas tem-se:

$$
u_{C}^{2}(y)=\sum_{i=1}^{N} c_{i}^{2} \cdot u^{2}\left(x_{i}\right)+\left.2 \sum_{i=1}^{N-1} \sum_{j=i+1}^{N} c_{i} \cdot c_{j} \cdot u\left(x_{i}, x_{j}\right)\right|_{X_{1}=\overline{x_{1}}, \ldots, X_{N}=\overline{x_{N}}},
$$

onde $u\left(x_{i}, x_{j}\right)$ é a covariância estimada associada entre as variáveis $X_{i}$ e $X_{j}$.

O grau de correlação entre $X_{i}$ e $X_{j}$ pode ser caracterizado pelo coeficiente de correlação, descrito por:

$$
r\left(x_{i}, x_{j}\right)=\frac{u\left(x_{i}, x_{j}\right)}{u\left(x_{i}\right) \cdot u\left(x_{j}\right)},
$$

onde $-1 \leq r\left(x_{i}, x_{j}\right) \leq+1$. Desta forma, a Equação A.10 pode ser re-escrita como:

$$
u_{C}^{2}(y)=\sum_{i=1}^{N} c_{i}^{2} \cdot u^{2}\left(x_{i}\right)+\left.2 \sum_{i=1}^{N-1} \sum_{j=i+1}^{N} c_{i} \cdot c_{j} \cdot u\left(x_{i}\right) \cdot u\left(x_{j}\right) \cdot r\left(x_{i}, x_{j}\right)\right|_{X_{1}=\overline{x_{1}}, \ldots, X_{N}=\overline{x_{N}}} .
$$

\section{A.4 Abrangência da estimativa de incerteza}

Segundo o Guide to the Expression of Uncertainty in Measurement (ISO, 2008), a equação da incerteza-padrão combinada associada ao mensurando $Y$ segue uma distribuição do tipo t-Student. Neste tipo de distribuição quanto maior for o número de graus de liberdade, mais próxima a distribuição estará de uma distribuição Normal.

A seguir é descrito como é calculado o número efetivo de graus de liberdade do men- 
surando e sua relação com o fator de abrangência e intervalo de confiança.

\section{A.4.1 Graus de liberdade efetivos}

O número de graus de liberdade associado a uma grandeza de influência é determinado pelo tipo de avaliação. Avaliações do Tipo A possuem número de graus de liberdade definido por:

$$
\nu\left(x_{A}\right)=N_{X}-1
$$

onde $N_{X}$ é o número de medições realizadas da variável $X_{A}$.

Já no caso de avaliações do Tipo B o número de graus de liberdade é definido como uma grandeza subjetiva cujo valor é obtido por julgamento científico baseado no conjunto de informações disponíveis. A equação a seguir é utilizada como uma aproximação para definir o número de graus de liberdade de uma avaliação do Tipo B:

$$
\nu\left(x_{B}\right) \simeq \frac{1}{2}\left(1-\frac{\Delta u\left(x_{i}\right)}{u\left(x_{i}\right)}\right)^{-2},
$$

onde $\frac{\Delta u\left(x_{i}\right)}{u\left(x_{i}\right)}$ é a confiabilidade da avaliação da incerteza-padrão $u\left(x_{i}\right)$. Por exemplo, julgouse que a avaliação de $u\left(x_{i}\right)$ é confiável em cerca de $65 \%$ dos casos. Isso pode ser tomado como significando que a incerteza relativa $\frac{\Delta u\left(x_{i}\right)}{u\left(x_{i}\right)}=0,65 \mathrm{e}$, assim, $\nu \simeq 4$. Se no entanto, o valor de $u\left(x_{i}\right)$ for julgado confiável em $100 \%$ dos casos, tem-se que $\nu=\infty$.

Desta forma, o número de graus efetivos do mensurando $Y$ é obtido por meio da equação de Welch-Satterthwaite (WELCH, 1947):

$$
\nu(y)=\frac{u_{C}^{4}(y)}{\sum_{i=1}^{N} \frac{u^{4}\left(x_{i}\right)}{\nu\left(x_{i}\right)}} .
$$

\section{A.4.2 Fator de abrangência}

Segundo a ISO (2007), o fator de abrangência, designado como $k$, é o fator numérico utilizado como um multiplicador da incerteza-padrão combinada de modo a obter-se a incerteza expandida. Ele é determinado a partir do número de graus de liberdade efetivos $\nu$ e de um intervalo de confiança $p$, resultando em:

$$
k=t_{p}(\nu),
$$


onde $t_{p}(\nu)$ é o valor da distribuição t-Student com número de graus de liberdade igual a $\nu$ e intervalo de confiança igual a $p$, conforme apresenta a Tabela A.1.

Tabela A.1: Valor da distribuição t-Student com número de graus de liberdade igual a $\nu$ e intervalo de confiança igual a $p$.

\begin{tabular}{c|cccccc}
\hline Graus de & \multicolumn{6}{|c}{ Nível de confiança $\boldsymbol{p}$} \\
liberdade $\boldsymbol{\nu}$ & $\mathbf{6 8 , 2 7 \%}$ & $\mathbf{9 0 \%}$ & $\mathbf{9 5 \%}$ & $\mathbf{9 5 , 4 5 \%}$ & $\mathbf{9 9 \%}$ & $\mathbf{9 9 , 7 3 \%}$ \\
\hline 1 & 1,84 & 6,31 & 12,71 & 13,97 & 63,66 & 235,8 \\
2 & 1,32 & 2,92 & 4,30 & 4,53 & 9,92 & 19,21 \\
3 & 1,20 & 2,35 & 3,18 & 3,31 & 5,84 & 9,22 \\
4 & 1,14 & 2,13 & 2,78 & 2,87 & 4,60 & 6,62 \\
5 & 1,11 & 2,02 & 2,57 & 2,65 & 4,03 & 5,51 \\
10 & 1,05 & 1,81 & 2,23 & 2,28 & 3,17 & 3,96 \\
15 & 1,03 & 1,75 & 2,13 & 2,18 & 2,95 & 3,59 \\
20 & 1,03 & 1,72 & 2,09 & 2,13 & 2,85 & 3,42 \\
25 & 1,02 & 1,71 & 2,06 & 2,11 & 2,79 & 3,33 \\
30 & 1,02 & 1,70 & 2,04 & 2,09 & 2,75 & 3,27 \\
35 & 1,01 & 1,69 & 2,03 & 2,07 & 2,72 & 3,23 \\
40 & 1,01 & 1,68 & 2,02 & 2,06 & 2,70 & 3,20 \\
45 & 1,01 & 1,68 & 2,01 & 2,06 & 2,69 & 3,18 \\
50 & 1,01 & 1,68 & 2,01 & 2,05 & 2,68 & 3,16 \\
100 & 1,005 & 1,660 & 1,984 & 2,025 & 2,626 & 3,077 \\
$\infty$ & 1,000 & 1,645 & 1,960 & 2,000 & 2,576 & 3,000 \\
\hline
\end{tabular}

\section{A.4.3 Incerteza expandida}

Finalmente a incerteza expandida é definida como sendo a quantidade que define um intervalo em torno do resultado de uma medição com o qual se espera abranger uma fração, determinada pelo fator de abrangência, da distribuição dos valores que podem ser razoavelmente atribuídos ao mensurando.

Assim, a incerteza expandida do mensurando $Y$, designado como $U(y)$, será o valor da incerteza-padrão combinada $u_{C}(y)$ multiplicado pelo fator de abrangência $k$, resultando na seguinte equação:

$$
U(y)=u_{C}(y) \cdot k
$$

O resultado de uma medição é então convenientemente expresso como $Y=y \pm U(y)$, que é interpretado como a melhor estimativa do mensurando $Y$ é o valor $y$, e que $y-U(y)$ a $y+U(y)$ é o intervalo com o qual se espera abranger uma extensa fração da distribuição de valores que podem ser razoavelmente atribuídos a $Y$, com nível de confiança igual a $p$.

Assim, na modelagem por MDP do problema de redução de gastos com energia elétrica 
em sistemas de distribuição de água são utilizados para calcular a incerteza associada à função de transição de estados, que cujas as fontes são oriundas do modelo hidráulico da rede de distribuição de água, da previsão da demanda, do truncamento do algoritmo de cálculo e da discretização das variáveis de estado. 


\section{Apêndice B - Resultados dos Experimentos Comparativos}

Tabela B.1: Valores das pressões no nó $J_{6}$, onde $60 \leq P\left(J_{6}\right) \leq 75$ (Unidade: $P S I$ ).

\begin{tabular}{c|ccc}
\hline Tempo & WaterGEMS & PEPSO & MDP \\
\hline 00:00 & 68,9 & $\mathbf{5 4 , 0}$ & 65,7 \\
01:00 & 70,4 & 72,0 & 63,8 \\
02:00 & 68,1 & 74,0 & 61,9 \\
03:00 & 61,8 & 73,0 & 64,7 \\
04:00 & 68,7 & 68,0 & 65,2 \\
05:00 & 68,0 & 65,0 & 60,6 \\
06:00 & 69,4 & 65,0 & 61,6 \\
07:00 & 64,2 & 61,0 & 61,6 \\
08:00 & 73,7 & 63,0 & 63,1 \\
09:00 & 66,0 & 63,0 & 64,4 \\
10:00 & 61,8 & 60,0 & 64,0 \\
11:00 & 74,2 & 65,0 & 64,4 \\
12:00 & 67,1 & 75,0 & 64,6 \\
13:00 & 70,8 & 60,0 & 64,4 \\
14:00 & 63,0 & 62,0 & 63,7 \\
15:00 & 64,7 & $\mathbf{5 6 , 0}$ & 68,6 \\
16:00 & 70,0 & $\mathbf{7 8 , 0}$ & 65,1 \\
17:00 & 67,0 & 66,0 & 64,6 \\
18:00 & 67,3 & $\mathbf{5 9 , 0}$ & 63,3 \\
19:00 & 64,5 & 60,0 & 63,6 \\
20:00 & 67,5 & 75,0 & 62,3 \\
21:00 & 62,1 & 62,0 & 65,9 \\
$22: 00$ & 63,4 & 66,0 & 66,1 \\
23:00 & 64,4 & 60,0 & 66,6 \\
24:00 & 63,1 & $\mathbf{4 8 , 0}$ & 64,6 \\
\hline & & & \\
\hline
\end{tabular}


Tabela B.2: Valores das pressões no nó $J_{27}$, onde $45 \leq P\left(J_{27}\right) \leq 65$ (Unidade: $P S I$ ).

\begin{tabular}{c|ccc}
\hline Tempo & WaterGEMS & PEPSO & MDP \\
\hline 00:00 & 62,0 & 48,0 & 59,4 \\
01:00 & 61,4 & 64,0 & 57,4 \\
02:00 & 60,9 & 65,0 & 55,6 \\
03:00 & 55,2 & $\mathbf{6 6 , 0}$ & 56,0 \\
04:00 & 61,2 & 61,0 & 56,8 \\
05:00 & 60,0 & 59,0 & 54,2 \\
06:00 & 60,0 & 58,0 & 52,9 \\
07:00 & 56,6 & 53,0 & 52,0 \\
08:00 & 59,1 & 54,0 & 52,6 \\
09:00 & 57,0 & 53,0 & 54,8 \\
10:00 & 53,4 & 51,0 & 53,9 \\
11:00 & 60,4 & 53,0 & 52,4 \\
12:00 & 57,1 & 61,0 & 54,8 \\
13:00 & 58,0 & 52,0 & 54,2 \\
14:00 & 54,5 & 53,0 & 53,1 \\
15:00 & 54,9 & 48,0 & 58,1 \\
16:00 & 57,2 & 62,0 & 54,6 \\
17:00 & 57,3 & 57,0 & 54,1 \\
18:00 & 57,4 & 50,0 & 54,4 \\
19:00 & 55,0 & 52,0 & 53,1 \\
20:00 & 55,9 & 60,0 & 51,7 \\
21:00 & 53,4 & 51,0 & 54,8 \\
22:00 & 52,4 & 57,0 & 54,6 \\
23:00 & 53,9 & 53,0 & 56,9 \\
24:00 & 56,0 & $\mathbf{4 2 , 0}$ & 54,9 \\
\hline & & & \\
\hline
\end{tabular}


Tabela B.3: Valores das pressões no nó $J_{131}$, onde $40 \leq P\left(J_{131}\right) \leq 60$ (Unidade: $P S I$ ).

\begin{tabular}{c|ccc}
\hline Tempo & WaterGEMS & PEPSO & MDP \\
\hline 00:00 & 56,5 & 46,0 & 54,4 \\
01:00 & 56,8 & 59,0 & 52,4 \\
02:00 & 56,0 & 60,0 & 50,6 \\
$03: 00$ & 51,1 & 60,0 & 51,3 \\
04:00 & 54,4 & 57,0 & 51,7 \\
05:00 & 54,8 & 54,0 & 49,0 \\
06:00 & 55,3 & 53,0 & 48,9 \\
07:00 & 52,5 & 50,0 & 48,6 \\
08:00 & 54,4 & 50,0 & 48,8 \\
09:00 & 53,4 & 49,0 & 50,1 \\
10:00 & 49,9 & 47,0 & 49,6 \\
11:00 & 54,1 & 48,0 & 48,8 \\
12:00 & 53,1 & 54,0 & 50,0 \\
13:00 & 53,5 & 49,0 & 49,8 \\
14:00 & 51,1 & 49,0 & 49,0 \\
15:00 & 51,1 & 44,0 & 52,5 \\
16:00 & 52,1 & 54,0 & 50,6 \\
17:00 & 52,5 & 52,0 & 50,1 \\
18:00 & 52,9 & 47,0 & 49,8 \\
19:00 & 51,7 & 47,0 & 49,1 \\
20:00 & 51,6 & 53,0 & 48,1 \\
21:00 & 49,9 & 48,0 & 50,3 \\
22:00 & 49,2 & 53,0 & 50,2 \\
23:00 & 49,0 & 49,0 & 51,5 \\
24:00 & 50,2 & $\mathbf{3 9 , 0}$ & 50,1 \\
\hline & & & \\
\hline
\end{tabular}


Tabela B.4: Valores das pressões no nó $J_{514}$, onde $60 \leq P\left(J_{514}\right) \leq 80$ (Unidade: $P S I$ ).

\begin{tabular}{c|ccc}
\hline Tempo & WaterGEMS & PEPSO & MDP \\
\hline 00:00 & 71,2 & 71,0 & 71,2 \\
01:00 & 75,9 & 76,0 & 69,2 \\
02:00 & 74,5 & 77,0 & 67,3 \\
$03: 00$ & 73,8 & 76,0 & 76,1 \\
04:00 & 69,3 & 75,0 & 74,5 \\
05:00 & 70,2 & 74,0 & 67,5 \\
06:00 & 71,4 & 73,0 & 74,7 \\
$07: 00$ & 69,4 & 72,0 & 74,7 \\
$08: 00$ & 70,1 & 71,0 & 74,9 \\
$09: 00$ & 69,9 & 69,0 & 70,1 \\
10:00 & 67,9 & 67,0 & 70,6 \\
11:00 & 66,4 & 62,0 & 76,6 \\
12:00 & 64,4 & 62,0 & 69,2 \\
13:00 & 68,0 & 61,0 & 69,3 \\
14:00 & 69,2 & 62,0 & 71,9 \\
15:00 & 69,3 & 61,0 & 66,7 \\
16:00 & 71,4 & 67,0 & 71,5 \\
17:00 & 70,2 & 67,0 & 72,5 \\
18:00 & 69,0 & 62,0 & 67,5 \\
19:00 & 68,2 & $\mathbf{5 7 , 0}$ & 71,3 \\
$20: 00$ & 69,0 & 61,0 & 71,7 \\
$21: 00$ & 67,7 & $\mathbf{5 9 , 0}$ & 69,2 \\
$22: 00$ & 68,5 & 62,0 & 71,8 \\
$23: 00$ & 70,9 & $\mathbf{5 8 , 0}$ & 66,1 \\
$24: 00$ & 67,3 & $\mathbf{4 6 , 0}$ & 72,2 \\
\hline & & & \\
\hline
\end{tabular}


Tabela B.5: Valores do nível do tanque de armazenamento $T_{2}$, onde $0,5 \leq H\left(T_{2}\right) \leq 31,25$ (Unidade: $f t$ )

\begin{tabular}{c|ccc}
\hline Tempo & WaterGEMS & PEPSO & MDP \\
\hline 00:00 & 31,25 & 31,25 & 31,25 \\
01:00 & 31,25 & 31,25 & 31,25 \\
02:00 & 31,25 & 31,25 & 29,98 \\
03:00 & 31,25 & 31,25 & 31,25 \\
04:00 & 31,25 & 31,25 & 31,25 \\
05:00 & 30,78 & 31,25 & 30,78 \\
06:00 & 31,25 & 31,25 & 31,25 \\
07:00 & 31,25 & 31,25 & 31,25 \\
08:00 & 30,57 & 31,25 & 31,25 \\
09:00 & 31,25 & 31,25 & 31,25 \\
10:00 & 31,25 & 31,21 & 31,25 \\
11:00 & 30,24 & 28,33 & 31,25 \\
12:00 & 30,64 & 25,31 & 31,11 \\
13:00 & 29,18 & 24,07 & 31,25 \\
14:00 & 31,25 & 22,08 & 31,25 \\
15:00 & 31,25 & 21,37 & 31,16 \\
16:00 & 31,25 & 17,29 & 31,25 \\
17:00 & 31,25 & 20,91 & 31,25 \\
18:00 & 31,25 & 20,75 & 31,17 \\
19:00 & 31,25 & 20,02 & 31,25 \\
20:00 & 31,25 & 15,64 & 31,25 \\
21:00 & 31,25 & 15,88 & 31,25 \\
22:00 & 29,97 & 18,05 & 31,25 \\
23:00 & 31,25 & 10,09 & 30,80 \\
24:00 & 31,25 & 4,65 & 31,25 \\
\hline & & & \\
& 395 & \\
\hline
\end{tabular}


Tabela B.6: Valores do nível do tanque de armazenamento $T_{3}$, onde $0,5 \leq H\left(T_{3}\right) \leq 28,0$ (Unidade: $f t$ ).

\begin{tabular}{|c|c|c|c|}
\hline Tempo & WaterGEMS & PEPSO & MDP \\
\hline 00:00 & 25,00 & 25,00 & 25,00 \\
\hline 01:00 & 18,02 & 23,62 & 18,02 \\
\hline 02:00 & 20,90 & 21,59 & 11,84 \\
\hline 03:00 & 18,71 & 23,51 & 15,45 \\
\hline 04:00 & 17,30 & 22,60 & 17,30 \\
\hline 05:00 & 11,17 & 20,75 & 11,17 \\
\hline 06:00 & 9,21 & 18,40 & 15,46 \\
\hline 07:00 & 11,94 & 15,43 & 18,16 \\
\hline 08:00 & 4,54 & 13,21 & 19,18 \\
\hline 09:00 & 10,49 & 9,80 & 14,04 \\
\hline 10:00 & 5,21 & 2,70 & 11,39 \\
\hline 11:00 & 0,50 & 0,50 & 15,81 \\
\hline $12: 00$ & 0,50 & 0,50 & 10,61 \\
\hline $13: 00$ & 0,50 & 0,50 & 7,52 \\
\hline $14: 00$ & 6,99 & 0,50 & 10,39 \\
\hline $15: 00$ & 5,44 & 0,50 & 2,44 \\
\hline $16: 00$ & 7,67 & 0,50 & 8,82 \\
\hline $17: 00$ & 11,23 & 0,50 & 11,58 \\
\hline 18:00 & 7,10 & 0,50 & 5,29 \\
\hline 19:00 & 2,78 & 0,50 & 9,11 \\
\hline 20:00 & 6,08 & 0,50 & 11,22 \\
\hline 21:00 & 5,09 & 0,50 & 8,14 \\
\hline $22: 00$ & 0,50 & 0,50 & 9,83 \\
\hline 23:00 & 8,88 & 0,50 & 0,65 \\
\hline 24:00 & 10,85 & 0,50 & 7,66 \\
\hline
\end{tabular}


Tabela B.7: Valores do nível do tanque de armazenamento $T_{5}$, onde $1,0 \leq H\left(T_{5}\right) \leq 33,25$ (Unidade: $f t$ ).

\begin{tabular}{|c|c|c|c|}
\hline Tempo & WaterGEMS & PEPSO & MDP \\
\hline 00:00 & 23,33 & 23,33 & 23,33 \\
\hline 01:00 & 23,95 & 29,63 & 19,04 \\
\hline 02:00 & 23,41 & 28,72 & 14,01 \\
\hline 03:00 & 21,48 & 31,67 & 11,41 \\
\hline 04:00 & 14,02 & 33,16 & 12,06 \\
\hline 05:00 & 19,25 & 26,57 & 8,95 \\
\hline 06:00 & 20,37 & 21,02 & 7,07 \\
\hline 07:00 & 20,65 & 15,78 & 7,26 \\
\hline 08:00 & 14,83 & 9,47 & 6,29 \\
\hline 09:00 & 19,54 & 6,54 & 8,58 \\
\hline $10: 00$ & 15,23 & 4,11 & 7,48 \\
\hline $11: 00$ & 9,71 & 1,00 & 5,68 \\
\hline $12: 00$ & 16,16 & 8,90 & 8,10 \\
\hline $13: 00$ & 14,71 & 16,12 & 7,75 \\
\hline $14: 00$ & 17,44 & 9,22 & 6,12 \\
\hline $15: 00$ & 11,72 & 3,25 & 11,55 \\
\hline $16: 00$ & 9,72 & 1,00 & 10,10 \\
\hline $17: 00$ & 13,71 & 14,76 & 8,86 \\
\hline $18: 00$ & 15,08 & 13,52 & 8,13 \\
\hline 19:00 & 15,26 & 4,66 & 6,51 \\
\hline 20:00 & 11,50 & 1,00 & 4,82 \\
\hline 21:00 & 13,07 & 13,75 & 8,46 \\
\hline $22: 00$ & 7,84 & 24,37 & 8,23 \\
\hline 23:00 & 4,63 & 4,50 & 10,09 \\
\hline $24: 00$ & 8,08 & 1,00 & 7,92 \\
\hline
\end{tabular}


Tabela B.8: Volume de água armazenado conjuntamente pelos tanques $T_{2}, T_{3}$ e $T_{5}$ (Unidade: $\times 10^{3} \mathrm{gal}$ ).

\begin{tabular}{|c|c|c|c|}
\hline Tempo & WaterGEMS & PEPSO & MDP \\
\hline 00:00 & 847,8 & 847,8 & 828,7 \\
\hline 01:00 & 777,0 & 964,0 & 655,2 \\
\hline 02:00 & 801,2 & 922,8 & 478,0 \\
\hline 03:00 & 729,6 & 997,1 & 479,5 \\
\hline 04:00 & 573,3 & 1011,2 & 515,8 \\
\hline 05:00 & 590,9 & 865,1 & 382,4 \\
\hline 06:00 & 595,9 & 715,9 & 407,9 \\
\hline 07:00 & 627,3 & 583,8 & 448,0 \\
\hline 08:00 & 464,6 & 438,1 & 446,2 \\
\hline 09:00 & 591,3 & 358,3 & 412,6 \\
\hline $10: 00$ & 482,3 & 292,5 & 369,2 \\
\hline $11: 00$ & 352,4 & 249,8 & 396,2 \\
\hline $12: 00$ & 480,5 & 295,9 & 367,6 \\
\hline $13: 00$ & 439,5 & 417,5 & 340,3 \\
\hline $14: 00$ & 530,5 & 266,3 & 338,4 \\
\hline $15: 00$ & 415,1 & 187,2 & 382,0 \\
\hline $16: 00$ & 388,2 & 132,8 & 384,3 \\
\hline $17: 00$ & 497,0 & 358,4 & 388,7 \\
\hline $18: 00$ & 488,9 & 333,7 & 332,3 \\
\hline 19:00 & 474,9 & 181,9 & 333,6 \\
\hline 20:00 & 414,6 & 115,1 & 333,9 \\
\hline 21:00 & 438,8 & 283,2 & 352,7 \\
\hline $22: 00$ & 323,8 & 511,3 & 363,7 \\
\hline $23: 00$ & 329,5 & 77,9 & 344,8 \\
\hline $24: 00$ & 390,6 & 30,2 & 343,4 \\
\hline
\end{tabular}




\section{Apêndice C - Informações dos Experimentos com Sistema Real}

Tabela C.1: Dados das tubulações da rede de distribuição do sistema real.

\begin{tabular}{|c|c|c|c|c|c|}
\hline Identificação & Nó inicial & Nó final & $\begin{array}{c}\text { Comprimento } \\
{[f t]}\end{array}$ & $\begin{array}{l}\text { Diâmetro } \\
\qquad[i n]\end{array}$ & $\begin{array}{l}\text { Rugosidade } \\
{\left[\times 10^{-3} \mathrm{ft}\right]}\end{array}$ \\
\hline 11 & 550 & 5000 & 1348,12 & 42 & 131 \\
\hline 2018 & 1276 & 1492 & 1587,10 & 60 & 137 \\
\hline 10002 & 7004 & 2 & 1470,08 & 20 & 135 \\
\hline 15815 & 2 & 6 & 33,73 & 20 & 140 \\
\hline 15829 & 368 & 350 & 1804,78 & 24 & 140 \\
\hline 15845 & 1209 & 1344 & 932,97 & 42 & 135 \\
\hline 15941 & 17100 & 1596 & 2351,36 & 24 & 140 \\
\hline 15942 & 1593 & 1604 & 51,32 & 24 & 140 \\
\hline 15944 & 1344 & 1476 & 975,39 & 42 & 135 \\
\hline 159410 & 1714 & 17100 & 263,88 & 24 & 140 \\
\hline 160730 & 17814 & 17816 & 26,23 & 24 & 140 \\
\hline 160734 & 17816 & 1265 & 571,59 & 24 & 140 \\
\hline 161534 & 1265 & 18610 & 2890,36 & 16 & 124 \\
\hline 161536 & 18610 & 19686 & 212,74 & 16 & 124 \\
\hline 161538 & 19792 & 18614 & 3621,48 & 60 & 140 \\
\hline 161542 & 18618 & 18616 & 11,05 & 12 & 100 \\
\hline 161544 & 18614 & 18620 & 25,74 & 12 & 100 \\
\hline 161546 & 18622 & 18618 & 8,43 & 12 & 100 \\
\hline 161548 & 18620 & 18624 & 8,14 & 12 & 100 \\
\hline 213212 & 1476 & 1493 & 248,80 & 42 & 135 \\
\hline 213214 & 19316 & 17814 & 362,96 & 24 & 140 \\
\hline 213756 & 19678 & 368 & 3545,14 & 24 & 126 \\
\hline 213764 & 19682 & 621 & 76,84 & 24 & 140 \\
\hline 213772 & 19684 & 19316 & 531,98 & 24 & 140 \\
\hline 213776 & 19686 & 1204 & 417,33 & 16 & 124 \\
\hline 213938 & 2639 & 19790 & 131,94 & 12 & 137 \\
\hline
\end{tabular}


Tabela C.1: Dados dos nós da rede de distribuição do sistema real.

\begin{tabular}{|c|c|c|c|c|c|}
\hline Identificação & Nó inicial & Nó final & $\begin{array}{c}\text { Comprimento } \\
{[f t]}\end{array}$ & $\begin{array}{l}\text { Diâmetro } \\
\quad[i n]\end{array}$ & $\begin{array}{l}\text { Rugosidade } \\
{\left[\times 10^{-3} \mathrm{ft}\right]}\end{array}$ \\
\hline 213942 & 19862 & 19792 & 5743,88 & 60 & 140 \\
\hline 213944 & 18616 & 19798 & 858,82 & 20 & 139 \\
\hline 213946 & 19802 & 19790 & 15,88 & 20 & 140 \\
\hline 213948 & 19798 & 19800 & 29,40 & 20 & 140 \\
\hline 213952 & 19800 & 19802 & 2666,18 & 20 & 140 \\
\hline 213966 & 19814 & 1276 & 10507,42 & 60 & 137 \\
\hline 213968 & 19816 & 19814 & 53,34 & 24 & 135 \\
\hline 213972 & 19820 & 19682 & 613,65 & 24 & 140 \\
\hline 214044 & 1492 & 19862 & 551,86 & 60 & 130 \\
\hline 214226 & 19974 & 115 & 143,50 & 27 & 140 \\
\hline 214234 & 6 & 19978 & 2736,51 & 20 & 139 \\
\hline 214248 & 19986 & 92 & 77,41 & 27 & 140 \\
\hline 214252 & 19978 & 19998 & 1543,15 & 20 & 139 \\
\hline 214254 & 19990 & 64 & 2280,02 & 27 & 140 \\
\hline 214262 & 19998 & 46 & 11,56 & 20 & 139 \\
\hline 214372 & 7000 & 546 & 122,90 & 54 & 130 \\
\hline 214374 & 7008 & 547 & 358,69 & 60 & 130 \\
\hline 224700 & 5000 & 891 & 5906,02 & 42 & 131 \\
\hline 224820 & 552 & 19814 & 212,84 & 60 & 137 \\
\hline 224840 & 891 & 1209 & 2423,37 & 42 & 131 \\
\hline 300003 & 46 & 19990 & 28,76 & 27 & 140 \\
\hline 300011 & 64 & 67 & 409,15 & 27 & 140 \\
\hline 300058 & 67 & 19986 & 3762,06 & 27 & 140 \\
\hline 300070 & 92 & 94 & 667,92 & 27 & 140 \\
\hline 300083 & 94 & 19974 & 2686,36 & 27 & 140 \\
\hline 300101 & 150 & 115 & 680,89 & 27 & 140 \\
\hline 300120 & 247 & 150 & 2244,10 & 27 & 127 \\
\hline 300125 & 270 & 247 & 627,94 & 27 & 140 \\
\hline 300144 & 322 & 270 & 1395,58 & 27 & 140 \\
\hline 300146 & 557 & 560 & 24,46 & 60 & 140 \\
\hline 300148 & 556 & 554 & 27,73 & 60 & 140 \\
\hline 300149 & 565 & 558 & 22,01 & 60 & 140 \\
\hline 300150 & 350 & 328 & 1169,10 & 24 & 126 \\
\hline 300154 & 330 & 322 & 1295,91 & 24 & 140 \\
\hline 300155 & 558 & 556 & 25,57 & 60 & 140 \\
\hline 300163 & 328 & 329 & 313,03 & 24 & 126 \\
\hline 300164 & 329 & 330 & 253,02 & 24 & 126 \\
\hline 300174 & 572 & 19820 & 10,53 & 24 & 140 \\
\hline \multicolumn{6}{|c|}{ Continua ... } \\
\hline
\end{tabular}


Tabela C.1: Dados dos nós da rede de distribuição do sistema real.

\begin{tabular}{|c|c|c|c|c|c|}
\hline Identificação & Nó inicial & Nó final & $\begin{array}{c}\text { Comprimento } \\
{[f t]}\end{array}$ & $\begin{array}{c}\text { Diâmetro } \\
\quad[i n]\end{array}$ & $\begin{array}{c}\text { Rugosidade } \\
{\left[\times 10^{-3} \mathrm{ft}\right]}\end{array}$ \\
\hline 300198 & 1069 & 19684 & 100,90 & 24 & 140 \\
\hline 300200 & 621 & 1069 & 4386,20 & 24 & 140 \\
\hline 300240 & 1714 & 1265 & 2910,15 & 24 & 140 \\
\hline 300250 & 7006 & 1714 & 907,89 & 24 & 140 \\
\hline 300251 & 1596 & 1592 & 149,14 & 24 & 140 \\
\hline 300252 & 1592 & 1587 & 525,70 & 24 & 126 \\
\hline 300253 & 1587 & 1594 & 49,16 & 24 & 126 \\
\hline 300266 & 17110 & 1594 & 2640,92 & 24 & 126 \\
\hline 300267 & 1604 & 1767 & 658,74 & 12 & 123 \\
\hline 300268 & 1767 & 1817 & 273,01 & 12 & 123 \\
\hline 300278 & 1817 & 1863 & 292,00 & 12 & 123 \\
\hline 300288 & 1863 & 1964 & 538,46 & 12 & 123 \\
\hline 300292 & 1964 & 1994 & 156,54 & 12 & 123 \\
\hline 300296 & 1994 & 2098 & 524,00 & 12 & 123 \\
\hline 300308 & 2098 & 2235 & 812,65 & 12 & 123 \\
\hline 300309 & 2602 & 2235 & 2229,36 & 20 & 137 \\
\hline 300500 & 19790 & 2602 & 107,12 & 20 & 140 \\
\hline 300505 & 2729 & 2639 & 533,00 & 12 & 137 \\
\hline 300530 & 2787 & 2729 & 295,19 & 12 & 137 \\
\hline 300532 & 2874 & 2787 & 499,76 & 12 & 137 \\
\hline 300534 & 2926 & 2874 & 403,80 & 12 & 137 \\
\hline 300536 & 2941 & 2926 & 142,21 & 12 & 137 \\
\hline 300537 & 2981 & 2941 & 223,89 & 12 & 137 \\
\hline 300543 & 3066 & 2981 & 361,77 & 12 & 137 \\
\hline 300545 & 19798 & 3066 & 68,43 & 20 & 139 \\
\hline 301741 & 552 & 571 & 117,46 & 30 & 140 \\
\hline 301742 & 571 & 569 & 28,72 & 60 & 140 \\
\hline 301743 & 569 & 565 & 29,49 & 60 & 140 \\
\hline 301752 & 570 & 572 & 33,04 & 60 & 140 \\
\hline 301753 & 568 & 570 & 25,91 & 60 & 140 \\
\hline 301765 & 1594 & 1593 & 13,29 & 24 & 126 \\
\hline 301825 & 547 & 550 & 46,97 & 42 & 140 \\
\hline 301855 & 546 & 547 & 37,55 & 48 & 140 \\
\hline 301865 & 547 & 552 & 126,28 & 60 & 140 \\
\hline 301975 & 560 & 19678 & 1391,65 & 24 & 126 \\
\hline 3002660 & 2235 & 17110 & 675,03 & 24 & 126 \\
\hline
\end{tabular}


Tabela C.2: Dados dos nós da rede de distribuição do sistema real.

\begin{tabular}{|c|c|c|}
\hline Identificação & $\begin{array}{c}\text { Elevação } \\
{[f t]}\end{array}$ & $\begin{array}{c}\text { Demanda base } \\
{[G P M]}\end{array}$ \\
\hline 2 & 5126,36 & 0,0 \\
\hline 6 & 5126,36 & 0,0 \\
\hline 46 & 5083,00 & 0,2 \\
\hline 64 & 5069,93 & 1,3 \\
\hline 67 & 5066,44 & 0,0 \\
\hline 92 & 5049,00 & 11,5 \\
\hline 94 & 5045,11 & 55,3 \\
\hline 115 & 5054,37 & 794,0 \\
\hline 150 & 5075,00 & 4,2 \\
\hline 247 & 5075,74 & 2,1 \\
\hline 270 & 5074,76 & 48,7 \\
\hline 322 & 5077,00 & 0,0 \\
\hline 328 & 5094,86 & 7,7 \\
\hline 329 & 5091,89 & 1,8 \\
\hline 330 & 5088,96 & 2,0 \\
\hline 350 & 5103,00 & 10,9 \\
\hline 368 & 5121,00 & 0,0 \\
\hline 546 & 5175,90 & 0,0 \\
\hline 547 & 5175,83 & 0,0 \\
\hline 552 & 5168,85 & 0,0 \\
\hline 554 & 5165,53 & 0,0 \\
\hline 556 & 5166,24 & 0,0 \\
\hline 557 & 5165,47 & 0,0 \\
\hline 558 & 5166,90 & 0,0 \\
\hline 560 & 5165,87 & 0,0 \\
\hline 565 & 5167,11 & 0,0 \\
\hline 569 & 5167,82 & 0,0 \\
\hline 571 & 5168,94 & 0,0 \\
\hline 19678 & 5158,00 & 0,1 \\
\hline 19974 & 5052,30 & 0,1 \\
\hline 19978 & 5094,00 & 0,0 \\
\hline 19986 & 5056,00 & 0,0 \\
\hline 19990 & 5090,00 & 0,0 \\
\hline 19998 & 5090,00 & 0,0 \\
\hline
\end{tabular}

